\title{
Experimental studies on innate immune regulatory proteins during non-infectious tissue damage : a focus on Mammose-binding lectin as an innate regulator of immunity
}

Citation for published version (APA):

Matthijsen, R. A. (2010). Experimental studies on innate immune regulatory proteins during non-infectious tissue damage : a focus on Mammose-binding lectin as an innate regulator of immunity. [Doctoral Thesis, Maastricht University]. Maastricht University. https://doi.org/10.26481/dis.20101112rm

Document status and date:

Published: 01/01/2010

DOI:

10.26481/dis.20101112rm

Document Version:

Publisher's PDF, also known as Version of record

Please check the document version of this publication:

- A submitted manuscript is the version of the article upon submission and before peer-review. There can be important differences between the submitted version and the official published version of record. People interested in the research are advised to contact the author for the final version of the publication, or visit the DOI to the publisher's website.

- The final author version and the galley proof are versions of the publication after peer review.

- The final published version features the final layout of the paper including the volume, issue and page numbers.

Link to publication

\footnotetext{
General rights rights.

- You may freely distribute the URL identifying the publication in the public portal. please follow below link for the End User Agreement:

www.umlib.nl/taverne-license

Take down policy

If you believe that this document breaches copyright please contact us at:

repository@maastrichtuniversity.nl

providing details and we will investigate your claim.
}

Copyright and moral rights for the publications made accessible in the public portal are retained by the authors and/or other copyright owners and it is a condition of accessing publications that users recognise and abide by the legal requirements associated with these

- Users may download and print one copy of any publication from the public portal for the purpose of private study or research.

- You may not further distribute the material or use it for any profit-making activity or commercial gain

If the publication is distributed under the terms of Article 25fa of the Dutch Copyright Act, indicated by the "Taverne" license above, 


\section{Experimental studies on innate immune regulatory proteins during non-infectious tissue damage}

A focus on Mannose-Binding Lectin as an innate regulator of immunity

Robert Alexander Matthijsen 


\title{
Experimental studies on innate immune regulatory proteins during non-infectious tissue damage A focus on Mannose-Binding Lectin as an innate regulator of immunity
}

\author{
Proefschrift \\ ter verkrijging van de graad van doctor \\ aan de Universiteit van Maastricht \\ op gezag van de Rector Magnificus, \\ Prof. Mr. G.P.M.F. Mols, \\ volgens het besluit van het College van Decanen, \\ in het openbaar te verdedigen \\ op vrijdag 12 november 2010 om 12.00 uur
}

door

Robert Alexander Matthijsen 


\section{Promotor}

Prof. dr. W.A. Buurman

\section{Beoordelingscommissie:}

Prof. dr. M.J. Daemen (voorzitter)

Prof. dr. H. ten Cate

Prof. dr. L. Hofstra

Prof. dr. J.C. Jensenius University of Aarhus, Aarhus, Denmark

Prof. dr. C. Weber RWTH Aachen University, Aachen, Germany Maastricht University Medical Center, MUMC

\section{Layout and Design:}

Eric Lemmens

www.dlgraphics.nl

\section{Drukkerij:}

Schrijen-Lippertz

ISBN/EAN: 978-90-8590-045-0 


\section{TABLE OF CONTENTS}

1. Innate immunity activation during pathology associated tissue damage 7

1.1 General introduction 8

1.2 The immune system and its response to acute tissue damage Innate 8

1.3 immune activation during chronic tissue damage 22

1.4 Aims to be studied $\quad 24$

2. Innate immune regulatory proteins in renal ischemia reperfusion $\quad 35$ injury

2.1 Introduction 36

2.2 Myeloperoxidase is critically involved in the induction of organ 38 damage after renal ischemia reperfusion. American Journal of Pathology. 2007, 171: 1743-1752.

2.3 Inhibition of complement factor C5 protects against renal ischemia- 58 reperfusion injury: inhibition of late apoptosis and inflammation. Transplantation. 2003, 75: 375-382.

2.4 Lysophosphatidic acid prevents renal ischemia-reperfusion injury by inhibition of apoptosis and complement activation. American Journal of Pathology. 2003, 163: 47-56.

2.5 Autologous Transplantation of Ischemically Injured Kidneys in Pigs. 98 Published, - Journal of Surgical Research. 2010

2.6 Influence of the Donor MBL Genotype on Outcome of Non-Heart- 114 Beating Donor Kidney Transplantation. Submitted.

3. Principles of innate immune activation following human intestinal ischemia reperfusion

3.1 Introduction

3.2 A new model to study intestinal ischemia-reperfusion damage in man. 138 Published, - Journal of Surgical Research. 2010

3.3 Rapid reversal of human intestinal ischemia-reperfusion induced 149 damage by shedding of injured enterocytes and reepithelialisation. PLoS One. 2008, 3: e3428.

3.4 Enterocyte shedding and epithelial lining repair following ischemia of the 169 human small intestine attenuate inflammation. PLoS One. 2009, 4: e7045. 
3.5 Mannose-binding lectin null alleles are associated with preserved 190 epithelial cell integrity following intestinal ischemia reperfusion in man.

Molecular Immunology. 2009, 46: 2244-2248.

4. Innate immune regulation of chronic vascular tissue damage

4.1 Introduction

4.2 Macrophage-specific expression of mannose-binding lectin controls 205 atherosclerosis in low-density lipoprotein receptor-deficient mice. Circulation. 2009, 119: 2188-2195.

5. Discussion and Summary

6. Nederlandse Samenvatting

7. Dankwoord

8. Curriculum vitae

9. Scientific output 
Chapter 1

Innate immunity activation during

pathology associated tissue damage 


\section{Chapter 1}

\subsection{INTRODUCTION}

An inflammatory reaction is a complex set of interactions that are triggered by traumatic, infectious, post-ischemic, toxic or autoimmune injury. The process normally leads to wound healing or recovery from infection. Inflammation can be triggered in reaction to self and non-self danger signals. Non-self danger signals arise from pathogens like bacteria or viruses, whereas self danger signals are generated by tumorous, infected, damaged or dying host cells. This ability to specifically target threatening agents and processes attributes to the well functioning of an organism and maintain its critical homeostasis. In order to mount an immune response, an elaborate system of proteins and cells recognize danger and trigger a multi layered attack with some functional 'redundancy' among its different contributors. This immune response is aimed at effectively clearing possible self or non-self threats. The immune system consists of two main parts, denominated as the innate and the adaptive immune system. The two immune systems, along with several soluble and cellular innate immune contributors, will be highlighted in Chapter 1.2. The effect of innate immune activation on the development of acute tissue damage following periods of organ ischemia and reperfusion will also be discussed in Chapter 1.2. The role of innate immune contributors, especially Mannose-Binding Lectin, in chronic tissue damage will be introduced in Chapter 1.3. The aims of this thesis are formulated in section 1.4.

\subsection{The IMMUNe SYSTEM AND ITS RESPONSE tO ACUTE tisSUe DAMAGE}

In order to fully comprehend the capabilities of our immune system that have evolved over hundreds of millions of years, it is necessary to understand some of its functional principles. The most basic requirement of our immune system is the ability to distinguish legitimate cells, tissues and organs from invading and potentially harmful pathogens (non-self) as well as altered, damaged or dead endogenous cells (altered self). To both altered self and non-self danger signals, our immune system has developed a successful and characteristically redundant defence mechanism. The multi-layered aspect of our immune system is of critical importance to ensure an effective attack. The broad arsenal of cells, peptides, proteins, immunoglobulins, enzymes, barriers and many more different immune mechanisms minimize the chance of evasion by invading pathogens. The defence 
system is traditionally divided into adaptive and innate components, each with a different role as well as timely function within a carefully orchestrated reaction aimed at abrogation of pathogen invasion, elimination of altered self or wound healing.

\section{The adaptive immune system}

The adaptive immune system is responsible for elimination of pathogens in the late phase of infection and for the generation of immunological memory. ${ }^{1}$ It is controlled principally by professional antigen presenting cells (APC) such as dendritic cells. APCs, derived from hemopoietic bone marrow progenitor cells, present immunogenic antigens to B- and T-lymphocytes thereby activating them and inducing their response type differentiation, e.g. Th1 or Th2. The different Th1 or Th2 adaptive immune responses are characterized by a different subset of cytokines, inducing a balanced immune response aimed at non-self or self danger signals triggering the immune system. Every individual B- and T-lymphocyte expresses a structurally unique antigen receptor. The ability to develop an extremely broad and randomly generated, initial repertoire of lymphocyte receptors (approximately $10^{14}$ and $10^{18}$ in every individual) increases the possibility that invading non-self danger signals are recognized and bound. Such randomly occurring antigen-receptor binding triggers activation and proliferation of a specific lymphocyte, initiating clonal selection and improvement of its receptor specificity by multiple gene rearrangements. This process of recognition, clonal selection and proliferation ensures the development and production of specific antibodies (improved and soluble copies of the original lymphocyte surface receptor), specific T-cells, immunological memory and results in efficient elimination of pathogens. It takes a few days for an efficient number of clones to proliferate. This would leave more than enough time for a wide spread infection to develop, considering a pathogen duplication time of, in some instances, as little as twenty minutes. In this way the damage to the host would be substantial, if not lethal. However, in order to solve such problems a phylogenetically much older line of defence has coevolved: our innate immune system.

\section{The innate immune system}

The innate immune system constitutes the first line of defence against non-self as well as altered self danger signals. It plays a crucial role in the first recognition and 


\section{Chapter 1}

elimination of pathogens and triggers a pro-inflammatory reaction against danger signals. Many cell types contribute to the innate immune system. Ranging from epithelial cells of skin and mucosae to liver cells producing complement factors and phagocytic cells expressing antimicrobial peptides, complement receptors, toll like receptors (TLR) and multiple other mostly cellular bound or soluble pattern recognition molecules (PRMs). These receptor molecules of our innate immune system differ from those characteristic to the adaptive immune system. Most strikingly, they are germ line encoded molecules. This means that they are, together with their specificity, passed on between generations. This, in contrast to the previously discussed adaptive receptors on B- and T-lymphocytes, that can not be passed on to next generations and are generated by somatic rearrangements. All the different innate PRMs share, however, some tremendously important features i) they are expressed by a wide variety of tissues, increasing the possibility of a danger signal being detected ii) they recognize and bind a diversity of conserved microbial and altered self structures. ${ }^{2}$ These highly conserved antigenic structures share multiple biochemical features, which are called pathogen-associated molecular patterns, or PAMPs. However, multicellular organisms do not only need to detect invading pathogens, but similarly have to be able to distinguish between healthy, damaged or dead cells. ${ }^{3}$ Evidence is accumulating that cell damage, cell death or an aberrant cell function are recognized at a cellular level by our immune system in much the same way as exogenous danger signals or PAMPs. Recognition occurs similarly via a PRM-mediated detection of specific, highly conserved molecules released by dead, damaged or altered cells, which are collectively determined as self danger signals. ${ }^{1,3-6}$ This hypothesis was already proposed in 2004 by Seong and Matzinger who stated that PAMPs and self danger signals might not be mutually exclusive. Therefore one universal name was introduced: damage associated molecular patterns (DAMP) with innate and adaptive immune activating properties. ${ }^{6}$ DAMPs, such as lipopolysaccharides (LPS) for GRAM negative bacteria, repetitive carbohydrate structures on bacterial surfaces, viral RNA, ßdefensin, heat-shock proteins, flagellin from flagellated bacteria, mitochondrial peptides and DNA or hydrophobic structures of bio-molecules are not found to circulate freely in well functioning multi cellular organisms and therefore considered characteristic to invading bacteria, invading pathogens as well as malfunctioning and damaged host cells or altered self in general.,5,

One could state that the innate immune response has an hour-glass shape. ${ }^{8}$ 
Bacteria and endogenous cells are extremely complex, consisting of thousands of proteins, large quantities of nucleic acids and many more types of organic molecules. However, the host is oblivious to most of these structures and initiates an innate immune reaction only to a handful of DAMPs by an even smaller number of PRMs. ${ }^{1}$ Only a limited number of adaptor proteins are involved in the primary signalling of the DAMPs. In case of downstream TLR signalling, only five adaptor proteins have been identified so far; MyD88, MAL, TRIF, TRAM and SARM. These adaptor proteins, activated by DAMP-TLR coupling lead to activation of transcription factors such as nuclear factor- $\kappa \mathrm{B}(\mathrm{NF}-\kappa \mathrm{B})$ and members of the interferon (IFN)-regulatory factor (IRF) family. ${ }^{8,9}$ Together, these transcription factors induce the multitude of transcriptional changes that arise from immune-cellular activation, forming the lower and wider part of the hour-glass (Figure 1). The immediate activation of cells and proteins, induced by PRM-DAMP binding,

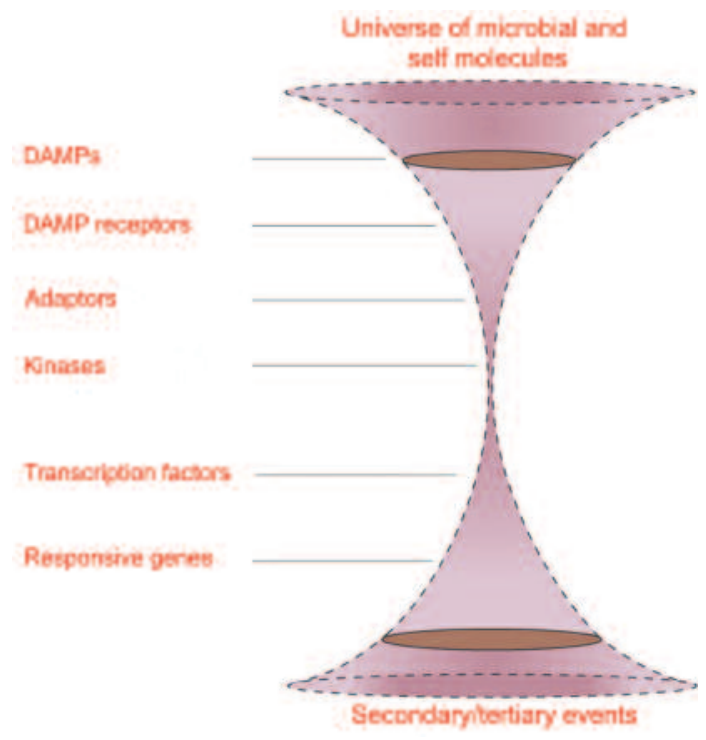

Figure 1. The hourglass shape of the innate immune system. The range of different non-self and altered self dangers is enormous. Although activation of the innate immune system ultimately involves the combined result of many hundreds of genes, intra-cellular innate immune signalling upon activation of host cells in response to different DAMPs involves only a limited number of intra-cellular effector molecules (adaptors, kinases and transcription factors). Innate immune activation traverses a channel of low complexity. ${ }^{8}$ Free from Beutler B. et al. Nature 2004. 


\section{Chapter 1}

ensures a quick response of the innate immune system. As a result of this quality, the innate immune system has the ability to signal early pathogen invasion or self danger. ${ }^{1}$

\section{Ischemia reperfusion induced tissue damage and its effect on innate immune activation.}

Ischemia reperfusion is an important event in numerous clinical conditions such as myocardial, renal, intestinal or cerebral infarction. Moreover, it is inextricably associated with organ transplantation, trauma and large vascular surgical procedures. Ischemia is characterized by an important interruption of the blood flow to a tissue or organ, depriving the affected organ of oxygen, nutrients as well as allowing for energy (adenosinetriphosphate - ATP) depletion and waste product build-up. The most logical therapy of this acute form of tissue damage would be restoration of blood flow to the impaired organ or tissue, called reperfusion. Reperfusion of ischemic tissue, however vital to some parts of the affected tissue, creates a paradoxical effect by exacerbating tissue damage, particularly after longer periods of ischemia. This negative effect of reperfusion is the result of an inflammatory reaction induced by the restoration of blood flow and is called ischemia-reperfusion (I/R) injury. ${ }^{10}$ As a result, reperfusion may cause irreversible damage to cells that actually were viable prior to reperfusion. The additional or secondary cellular damage induced by reperfusion may limit the beneficial effect of reperfusion under critical conditions such as large operative procedures, total organ ischemia or trauma.

A large body of literature shows the activation and contribution of the innate immune system in secondary ischemia reperfusion injury. Expression of self danger signals, that are exposed solely as a result of primary ischemic cellular injury, may function as DAMP and are recognized by PRMs such as TLR or macrophageinducible C-type lectin (MINCLE). ${ }^{6,11}$ Different immunostimulatory DAMPs have been studied and identified over the past years, such as heat-shock proteins, surfactant protein, B-defensin, nuclear proteins such as SAP130 and certain phospholipids normally confined to the inner cell membrane leaflet., ${ }^{111-14}$

The in vivo role of innate immune components in secondary IR damage has predominantly been derived from experimental studies which block or knock-out specific innate immune proteins during IR. From this we have come to understand the importance of cytokines, endothelial activation proteins, polymorphonuclear neutrophils (PMN), the complement system, macrophages, and TLRs. ${ }^{15-22}$ If primary 
IR induced cell damage (eg apoptosis and necrosis) is attenuated and a subsequent inflammatory response is diminished, secondary IR induced injury is reduced, preserving organ integrity and function. ${ }^{23}$ Fully understanding these complex inflammatory mechanisms which contribute substantially to secondary IR induced organ damage might prove essential to clinical practice. If, by any means, we would be able to control an IR induced immune response, it would undoubtedly improve transplantation outcome and protect patients following major trauma or vascular surgery.

Some innate immune components which contribute to self danger signalling are highlighted. This overview is by no means complete, but rather aims to illustrate the diversity of different immune contributors and ensures the reader's understanding and possible appreciation of the subsequent study outline as well as the performed experiments comprising this thesis.

\section{Endothelial cells}

Since endothelial cells are located on the interface between circulating blood and the surrounding tissue and cover a total surface area of about $4000-7000 \mathrm{~m}^{2}$ in adult humans, endothelial cells are among the first cells to come into contact with invading pathogens or DAMPs entering the bloodstream. ${ }^{24}$ To this end endothelial cells have been equipped with a multitude of PRMs. Endothelial cells have been shown to express multiple TLRs: receptors specifically recognising and binding self and non-self danger signals like LPS, flagellin, single or double-stranded RNA or viral and bacterial CpG DNA. ${ }^{2}$ In case of PRM-DAMP interaction, endothelial cells are activated inducing a multitude of pro-inflammatory reactions. Among other things, the critical inter-cellular tight junctions between adjacent endothelial cells are lost, creating inter-cellular passage possibilities that allow free passage of plasma proteins to adjacent tissue. Some of these plasma proteins act again as PRM, such as complement proteins, further stimulating a developing innate immune reaction. Endothelial adhesion surface molecules, such as intercellular adhesion molecule 1 (ICAM-1), vascular cell adhesion molecule 1 (VCAM-1) and E-selectin, are involved in adhering, rolling, sequestration and activation of polymorphonuclear cells (PMN) into neighbouring affected tissue. It is important to notice that PMN and their reactive constituents contribute to early innate immune responses as discussed in Chapters 1.2.7 and 1.2.8. Endothelial cells are among 


\section{Chapter 1}

the first cells to respond to prolonged periods of organ ischemia and subsequent reperfusion. Inhibition of endothelial adhesion molecules during IR, diminishes subsequent inflammation and reduces IR induced tissue injury. ${ }^{20-22}$

\section{The Complement System}

The complement system is considered to be an important regulator of innate immune activity. It comprises at least 35 proteins, inhibitors and complement protein receptors. Individual complement components are predominantly located in the plasma or membrane bound as inactive pro-enzymes. These pro-enzymes are, according to the present knowledge, activated by three activation pathways, the classical, alternative and lectin pathway, in turn activated by characteristically different complement activating pattern recognition molecules (CAPRM) C1q, C3 and MBL or ficolins, respectively (Figure 2).

Aimed at microbial detection and DAMP recognition, complement has three predominant physiologic activities comprising of opsonisation of microbials, attraction and activation of leucocytes to sites of complement activity and lysis of invading pathogens or pathogen containing cells. ${ }^{25}$ Moreover, complement forms a cross-talk between the innate immune system and the adaptive immune response.

The classical pathway is activated by the binding of $\mathrm{C} 1 \mathrm{q}$ to antigen-antibody complexes, pentraxins and some DAMPs on microbial surfaces. C1 $\mathrm{q}$ binding to antigen-antibody complexes implies that complement activity mediated by the classical route of complement activation is dependent on discriminatory processes of the adaptive immune system. Together with the enzymatically active components $\mathrm{C} 1 \mathrm{r}$ and $\mathrm{C} 1 \mathrm{~s}, \mathrm{C} 1 \mathrm{q}$ forms the $\mathrm{C} 1$ complex. This complex can then activate subsequent downstream complement proteins $\mathrm{C} 4$ and $\mathrm{C} 2$, creating a functional C3 activating convertase (C4bC2a) activating C3. The relevance of antibody mediated complement activation, as an early level cross-talk between innate and adaptive immune components, is highlighted in various studies using both complement or $\mathrm{RAG}^{-1-}$ knockout animals in experimental studies on acute and chronic inflammation. ${ }^{6-28}$

The alternative pathway of complement activation primarily uses reverse pathogen recognition. ${ }^{29}$ It is known to be constantly activated by spontaneous low grade plasma hydrolysis, called 'tick-over'. This activity results in activated C3 proteins that can covalently bind any cell surface in its direct vicinity, using properdin as a stabilizing protein. However, host cells have been equipped with efficient inhibitors, such as factor- $\mathrm{H}$ and decay accelerating factor (DAF), to tackle 
this constant threat of innate immune activation. Invading pathogens lack such specific complement regulators, inducing spontaneous and unrestrained complement activity on its cellular surface.

Alternative pathway activity is additionally considered a complement activity amplification route to other complement activating pathways. Once C3b has been stably bound to the cellular surface along with its much needed co-factor Factor B

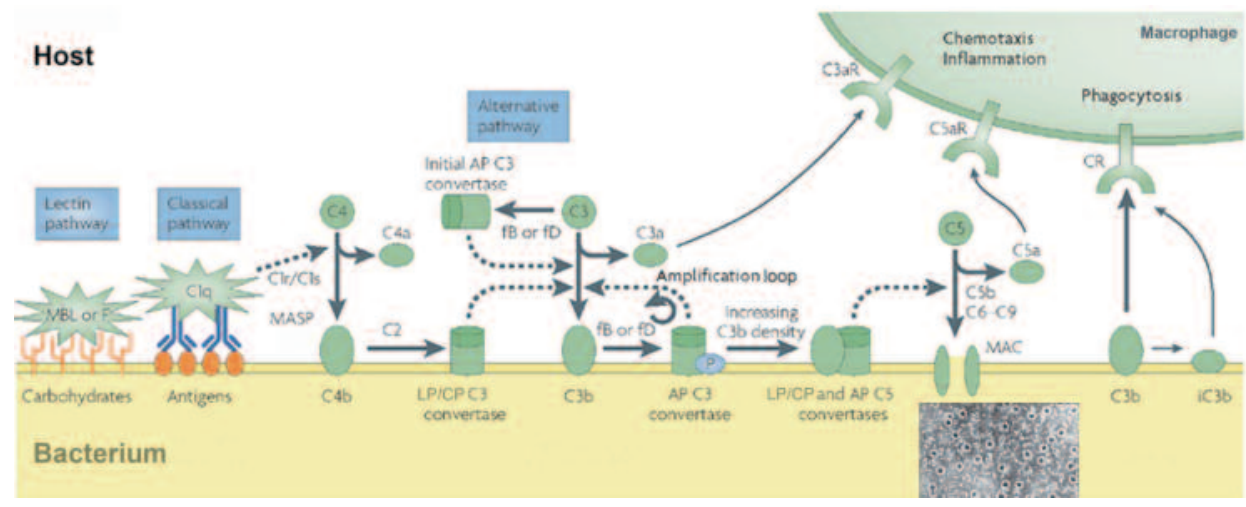

Figure 2. Schematic overview of the complement system. Complement is activated by three distinct pathways; the classical (CP), lectin (LP) and alternative pathway (AP). Microbial (example) or altered self DAMPs are bound by complement initiating proteins, C1q (CP), MBL/ficolins (LP) and C3 (AP). Upon binding and in association with pathway specific co-factors, bound C1q, MBL/ficolins or C3 generate new proteases, capable of binding and activating subsequent complement proteins. The different CP, LP and AP of early complement activation converge at the level of $\mathrm{C} 3$, by generating one universal $\mathrm{C} 5$-convertase. The $\mathrm{C} 5$ convertase initiates the common pathway, leading to formation of the Membrane Attack Complex (MAC), a ring -like perforating structure in the cell membrane of invading pathogens or altered self cells. The MAC (dark holes in the black and white picture insert) allows for free and lethal fluid transfer between the inner and outer environment of the invading pathogen or altered self.

As a result of complement activation, small activating split products ( $\mathrm{C} 3 \mathrm{a}$ and $\mathrm{C} 5 \mathrm{a}$ ) are formed, called anaphylatoxins. Anaphylatoxins attract specific receptor carrying inflammatory cells like leucocytes and macrophages to the afflicted area.

$\mathrm{C} 3 \mathrm{~b}$ as well as its inactive iC3b counterpart act as opsonins. Opsonins facilitate the rapid uptake of destroyed pathogens or altered self by recruited leucocytes or macrophages. Free from Lambris J. et al. Nature Review Microbiology 2008. 


\section{Chapter 1}

and properdin (Figure 2, indicated by P), a new and stable C3 activating convertase is generated (C3bBb). This $\mathrm{C} 3$ convertase in itself is a potent activating enzyme of the alternative pathway, acting as an amplification loop, rapidly increasing alternative and overall complement activity.

The lectin pathway of complement activation is triggered by MannoseBinding Lectin (MBL) or ficolins ( $\mathrm{L}-, \mathrm{H}$ - and $\mathrm{M}$-ficolin being the known ficolins). Both MBL and ficolins are considered PRMs with particular affinity to various specific sugars, such as mannose, $\mathrm{N}$-acetyl-glycosamine, fucose and glucose, present on microbial cellular membranes. ${ }^{30} \mathrm{As}$ is the case with $\mathrm{C} 1 \mathrm{q}$, bound $\mathrm{MBL}$ or ficolins can only activate complement in association with specific serine proteases. For the lectin pathway these complement activating enzymes are called MBLassociated serine proteases or MASPs. Three MASPs (MASP-1, -2 \& -3) along with CAPRM-associated molecules, MAp19 and MAp44, have been identified so far. Complement activating properties have hitherto only been demonstrated for MASP-1 and -2, although modulation of the activity of the lectin pathway through the competitive inhibition of MASP-2 by Map44 has been observed. ${ }^{31,99} \mathrm{MBL}$ forms higher order oligomers in plasma to ensure effective binding to carbohydrate structures. ${ }^{30}$ Similar to the classical pathway, the lectin pathway MBL-MASP complex creates a C3 convertase by $\mathrm{C} 4$ and $\mathrm{C} 2$ activation (C4bC2a).

From this it can be concluded that all complement activating pathways converge at the level of C3, activating multiple C3 molecules through its internal amplification route, generating the next complement activating enzyme, a C5 convertase. This C5 convertase is the first step in initiating the activation of the common complement pathway, leading to membrane attack complex (MAC) formation. This MAC has a major part in complement function and immunity, by inducing the build up of a perforating ring-like structure in the cell membrane of invading pathogens, pathogen containing cells or altered self, inducing cell lysis. It can do so by the subsequent activation and recruitment of complement proteins $\mathrm{C} 5, \mathrm{C} 6$, C7, C8 and multiple C9 molecules. Once active, the C9 molecules build a lipophylic ring structure, firmly anchored in the cell membrane, perforating it and inducing inevitable cell death by free transfer of intra- and extra-cellular fluids. Again, well functioning host cells are equipped with complement regulatory proteins to hinder complement auto-destruction. CD-59 is the membrane bound glycoprotein that regulates MAC formation and prevents autologous complement induced cell lysis. ${ }^{32}$ Moreover, we have come to understand a great deal about 
different complement activating by-products, such as C3a and C5a, which target PMN towards sites of complement activity by chemotaxis. Termed anaphylatoxins, these proteins have a tremendous responsibility in generating early proinflammatory stimuli and recruiting sufficient numbers of innate immune cells to sites of inflammation.

\section{Mannose-Binding Lectin}

Experimental models on ischemia reperfusion (IR) induced tissue injury have, amongst other things, been developed to study DAMP associated innate immune activation. These studies demonstrated that MBL and its lectin complement activating pathway are critical to innate immune activation in response to excessive IR-injury. ${ }^{33-36} \mathrm{MBL}$, an innate PRM with complement activating properties, is a multimeric C-type lectin and belongs to the family of collectins. The other proteins of this family being amongst others the well known surfactant proteins A and -D. MBL consists of multiple identical $32 \mathrm{kDa}$ polypeptide chains, all comprising four distinctly different regions essential to $\mathrm{MBL}$ function. Each chain has a C-terminal, calcium dependent, carbohydrate recognition domain (CRD), a neck region, a collagenous region and a cysteine $\mathrm{N}$-terminal end. ${ }^{30}$ Its CRD binds DAMP, like cytokeratin-1, immunoglobulin- $A$ and $-M$ isoforms, mannose, $\mathrm{N}$-acetyl-d-glucosamine, $\mathrm{N}$-acetyl-monosamine, fucose and glucose. ${ }^{37,38}$ $M B L$ can act as a powerful opsonin and initiate complement activation via the lectin pathway in association with MASPs. ${ }^{39,40}$ Synthesis of MBL is mainly attributed to the liver as well as the small intestine and results in two MBL-forms, namely plasma and intracellular MBL. ${ }^{41-43}$ In addition, local MBL production by myeloid cells has been demonstrated. ${ }^{42,} 44$

Commonly occurring mutations in the first exon or promoter region of the mb/2 gene on chromosome 10q21.1 have been reported, which disrupt the functional $\mathrm{MBL}$ protein or modulate the actual amount of functional $\mathrm{MBL}$ produced. ${ }^{45}$ These genetic variations are clustered in a region of strong linkage disequilibrium with the promoter region and result in a relative or complete deficiency in functional MBL. They result from three frequently occurring first exon mutations (at codons 52, 54 and 57) and polymorphisms in the promoter region (at position $-550(\mathrm{H} / \mathrm{L})$ and $-221(\mathrm{X} / \mathrm{Y}))$ of the structural gene $(\mathrm{mb} / 2) .{ }^{46}$ Homozygous or heterozygous carriers of variant $\mathrm{mb} / 2$ alleles express different levels of a disrupted MBL protein without apparent complement activating properties. The knowledge 


\section{Chapter 1}

that the variation in plasma $\mathrm{MBL}$ levels in man is regionally distributed around the world, with approximately $5-10 \%$ lacking functional $\mathrm{MBL}$, has led to many studies investigating MBL as a modifier of disease. ${ }^{46,47}$ Some investigators argue that the spatial distribution of deficiency $\mathrm{mb} / 2$ haplotypes around the globe merely reflects the demographic history of human migrations and the effects of genetic drift. ${ }^{45}$ This hypothesis is predominantly based on the fact that the frequently occurring $\mathrm{mb} / 2$ gene haplotypes are most diverse in the African population, followed by Eurasian, Pacific and Native American populations, very much consistent with the out-ofAfrica model and the appearance of modern humans in these regions. ${ }^{45,} 48$ However, over time mb/2 variant genotypes have been considered both advantageous as well as disadvantageous to human development or the onset of human disease, and as a result studied as such. On the one hand, variant $m b / 2$ alleles are suggested to be protective against the development of IR induced renal, cardiac or intestinal, ${ }^{34-36}$ failure and leprosy. ${ }^{49}$ On the other hand, variant $\mathrm{mb} / 2$ alleles have been linked to an increased susceptibility to infectious diseases and risk of developing atherosclerosis or thrombosis. ${ }^{50-54}$ The involvement of $\mathrm{MBL}$ in the development of secondary IR induced organ damage has received increasing attention over the past years. It appears that MBL has a prominent role in the induction of inflammation during reperfusion of the ischemic tissue. Colocalisation of MBL with downstream complement components on ischemic cellular cultures and in reperfused organs indicates the ability of MBL to activate complement during reperfusion, contributing to innate immune activity. $33,34,36,55$ The exact ligands to which $M B L$ binds in response to ischemia reperfusion injury remain to be elucidated. However, it has been suggested that MBL can bind certain polymeric forms of IgA, slgM complexes or endothelial cytokeratin-I in reperfused ischemic tissues, activating the lectin mediated complement activation pathway. ${ }^{28,}$ 56, 57 Functional MBL also has opsonizing capabilities, targeting harmful self danger signals, resulting in an efficient phagocytic uptake by PMN or macrophages. ${ }^{58-60}$ Deficits in this specific MBL ability, induced by MBL gene polymorphisms, have been associated to the development of auto-immune disease in humans. ${ }^{61,}{ }^{62}$ The functions of MBL illustrate the wide range in effects associated with such immune regulatory effector proteins in response to DAMPs, observed in experimental as well as population based studies. 


\section{Polymorphonuclear leucocytes}

Polymorphonuclear leucocytes (PMN) or neutrophils are one of the body's main cellular components for the destruction of invading pathogens. ${ }^{63}$ These myeloid and short lived cells (lifespan up to 5 days) are among the first cells to arrive in large numbers at sites of inflammation. The principal contribution of PMN to the inflammatory process will be microbicidal or altered self clearance and the enabling of wound healing. ${ }^{63}$ In order to effectively perform these tasks PMN have a range of different enzymes and bactericidal peptides (lactoferrin, calprotectin, myeloperoxidase (MPO), bactericidal/permeability-increasing protein (BPI), defensins and cathepsin) used predominantly for pathogen destruction. These products are stored within PMN and used in the breakdown of phagocytized microbes. At the site of inflammation PMN locally control their own accumulation, promote their own rapid cell death and attract as well as activate macrophages (discussed below) in order to stop additional damage and initiate repair. To this end PMN release stored and readily produced cytokines and chemokines, which are small immune regulatory proteins. ${ }^{63}$ In addition to the arsenal of enzymes and cytokines aimed at pathogen destruction and inflammation, PMN undergo an oxidative burst subsequent to activation. This is a rapid reduction of oxygen, induced by an enzyme called NADPH oxidase, which results in the production of reactive oxygen species. These reactive oxygen species in turn aid PMN in their bactericidal function. However, compelling evidence demonstrates that release of reactive enzymes and oxidative burst end products by PMN into the surrounding tissue, causes additional tissue damage which may not be in balance with the anti microbial attack. ${ }^{64}$ During the development of tissue damage as a result of prolonged periods of organ ischemia and reperfusion, activated neutrophils in a similar way cause additional tissue damage as experiments with neutrophil inhibition have shown. ${ }^{65-68}$

\section{Myeloperoxidase}

Myeloperoxidase (MPO) is a $140 \mathrm{kD}$ heme protein that is predominantly stored in the azurophilic granules of PMN and to a lesser extent in the lysosomes of monocytes. ${ }^{69}$ It is one of the most abundant enzymes present in PMN and macrophages, approximately $5 \%$ and $1 \%$ of total cell protein content respectively. ${ }^{70}$ MPO is released upon neutrophil activation. The capacity of MPO to catalyze the formation of hypochlorite $(\mathrm{HOCl})$ from hydrogen peroxide $\left(\mathrm{H}_{2} \mathrm{O}_{2}\right)$ and chloride 


\section{Chapter 1}

ions makes it a powerful tool in the bactericidal armament of both macrophages and PMN. There are clinical studies indicating a potentially harmful effect of MPO in immune-mediated inflammatory syndromes, such as multiple sclerosis, ${ }^{71}$ acute coronary syndrome, ${ }^{72}$ and renal disease..$^{70}$ In addition, it has been suggested that MPO and MPO-derived oxidants are involved in the pathogenesis of atherosclerosis, ${ }^{73-75}$ organ damage following myocardial ischemia/reperfusion and infarction $^{76}$ as well as complement activation in vitro. ${ }^{77}$ Furthermore, MPO contributes to the dysfunction of the local vasculature during acute inflammation by modifying local NO production and availability, possibly contributing to IR induced tissue damage by impeding beneficial effects of $\mathrm{NO}$ on local vasculature. ${ }^{78,79} \mathrm{To}$ what extent and by what means MPO is involved in renal ischemia reperfusion injury remains to be elucidated and will be focus of attention in Chapter 2 .

\section{Macrophages}

As cells derived from myeloid tissue, circulating monocytes scavenge the body for danger signals, recognizing and binding invading pathogens or DAMPs by a vast repertoire of membrane bound PRMs. Part of their tools in order to effectively recognize and scavenge multiple danger signals are TLRs, CD14 (a TLR coreceptor) and MAC-1 (specifically recognizing activated complement protein C3b). ${ }^{80}$ Drawn towards sites of inflammation by locally produced inflammatory substances like cytokines, chemokines and anaphylatoxins, monocytes are sensitive to chemotaxis. Their main purpose at sites of inflammation is immune response coordination and phagocytosis. Phagocytosis means the uptake of PRM bound danger signals, pathogens or dead cells and apoptotic bodies at the site of inflammation. ${ }^{81}$ Once particles have been phagocytosed by macrophages, peptides of pathogens are presented to T-cells and B-cells of the adaptive immune system, triggering and coordinating an adaptive immune response early during innate immune activation. Important to realize is the fact that macrophages have a longer lifespan than PMN, varying from a few months to years in the case of specialized liver macrophages, called Kupfer cells. This implies a controlling role for macrophages not only during acute episodes of inflammation, but similarly during chronic inflammatory responses, as will be highlighted in Chapter 4. The cooperation between macrophages and adaptive immune cells is another example of cross-talk between the innate and adaptive immune system, as was described above, to occur during complement activation (Chapter 1.2.5). 


\section{Intestinal and renal epithelial cells}

Along with the skin, the epithelial surfaces of most eukaryotic (multi-cellular) organisms are the cellular barriers between the host and the hostile outside world. ${ }^{82}$ They are considered an important part of our innate immune system and are present in a multitude of organs including lungs, kidneys and intestine (Figure 3).

The primary function of the intestine is the absorption of dietary nutrients. To this end, the intestinal epithelium has to be permeable for nutrients and macromolecules important for growth and development. ${ }^{83,84}$ At the same time, the intestinal epithelium forms the barrier between the internal environment of the host and the potentially hostile exterior of the intestinal lumen. Resident commensal microbiota constantly challenge the single cell epithelial lining. The epithelial lining, together with the lamina propria, forms the mucosa of the intestine. The

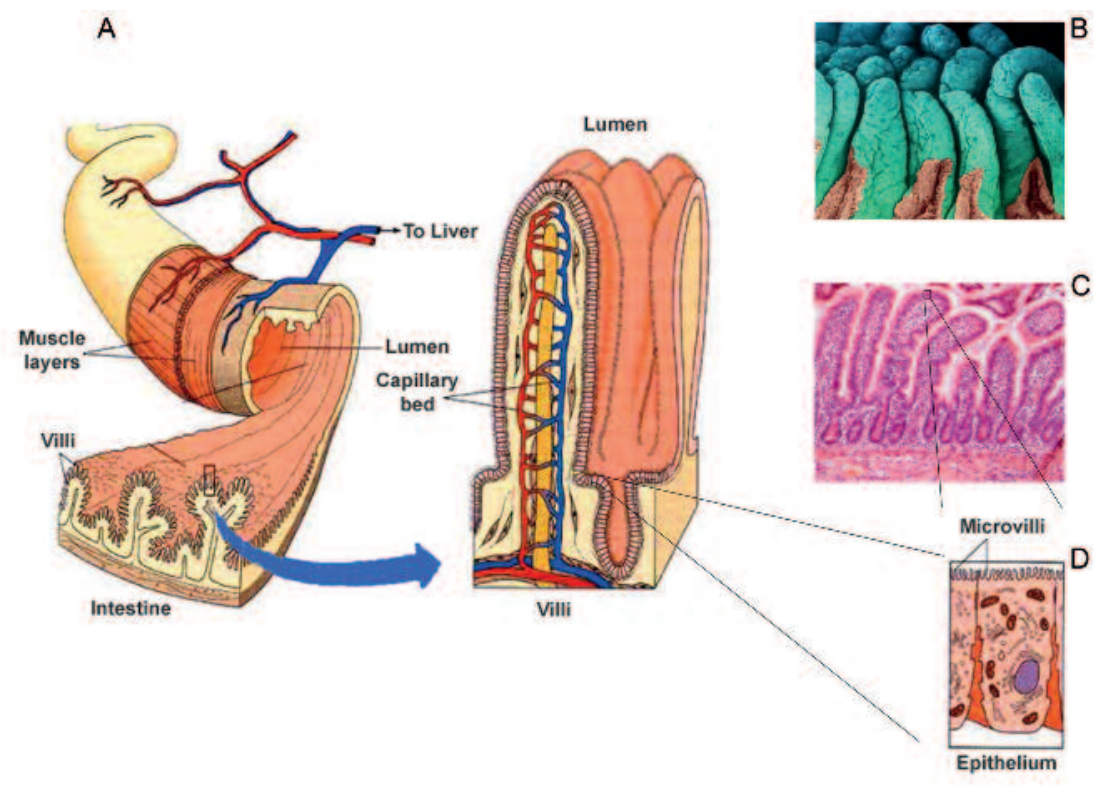

Figure 3. Layout of the small intestine. Aimed at generating a large absorbent surface, the small intestine has many folds (A), villi (B and C) and microvilli (on individual epithelial cells (D)) protruding into the intestinal luminal space. Confluent covering by intestinal epithelial cells generates an important gut barrier between the host internal milieu and potentially threatening luminal environment of the intestine.Free from Encycolpedia of Science. 


\section{Chapter 1}

epithelial stem cells, give rise to four major epithelial cells which together form the passive line of defence or intestinal epithelial barrier: 1) the enterocytes, which make up $>80 \%$ of all small intestinal epithelial cells and absorb nutrients, 2) the goblet cells, which produce various mucins and microbial peptides, protecting the epithelial lining 3) the entero-endocrine cells, which produce and excrete hormones and 4) the Paneth cells, which secrete antimicrobial peptides like lysozyme and express PRMs such as TLRs (TLR4/MD2 and TLR9) and NOD-like receptors (NLRs). ${ }^{85},{ }^{86} \mathrm{NLRs}$ which are also expressed by other intestinal epithelial cells, specifically recognize muramyl dipeptide (MDP), a peptidoglycan associated to most gram positive as well as gram negative bacteria. Together these secreting cells provide an active barrier to potentially harmful luminal antigens, toxins and microbiota. ${ }^{83,84}$

In the kidney, an epithelial barrier, containing again both passive and active barrier elements, serves similar purposes as observed in the intestine. The renal epithelial lining actively re-absorbs soluble ions like sodium and bicarbonate from pre-formed urine or secretes potassium and hydrogen ions, tightly regulating the host internal milieu and $\mathrm{pH}$. It serves as a passive barrier to the hostile exterior by a tightly joint cellular layer of epithelial cells. Moreover, the renal epithelium also has the ability to protect the internal environment from DAMPs by a range of different PRMs. PRMs effectively expressed by renal epithelial cells are TLR and complement proteins. ${ }^{86,87}$

Chapter 2 and 3 focus on the active barrier response in animal and human experimental models of IR induced damage of the epithelial barrier. Some innate contributors have been discussed in the above section, demonstrating their rapid activation during early inflammation. Additionally, their interplay in order to orchestrate an efficient innate immune response to pathogen invasion as well as tissue damage has been identified. From this it is important to understand that most of these different innate and adaptive immune mechanisms occur largely simultaneously, resulting in a multi layered way of defence against invading pathogens and non-self danger signals.

\subsection{INNATE IMMUNE ACtivation DURING CHRONIC tiSSUE DAMAGE}

Previously, the effect of acutely induced IR tissue and organ damage on innate immune elements has been discussed. In particular, the roles of MBL and MPO 
have been highlighted. The connection between MBL and the development of IR induced tissue damage has become apparent.

However, the role of $\mathrm{MBL}$ in chronic disease progression and the development of tissue damage remain to be elucidated. Most chronic pathologies are associated with some degree of progressive tissue damage, although often not as violent as acute IR induced tissue damage. Cancer, arthritis or chronic arterial occlusive disease (atherosclerosis), are all associated with a slow process of ongoing tissue damage. We are only beginning to understand that tissue damage which accompanies most chronic diseases is similarly controlled by innate

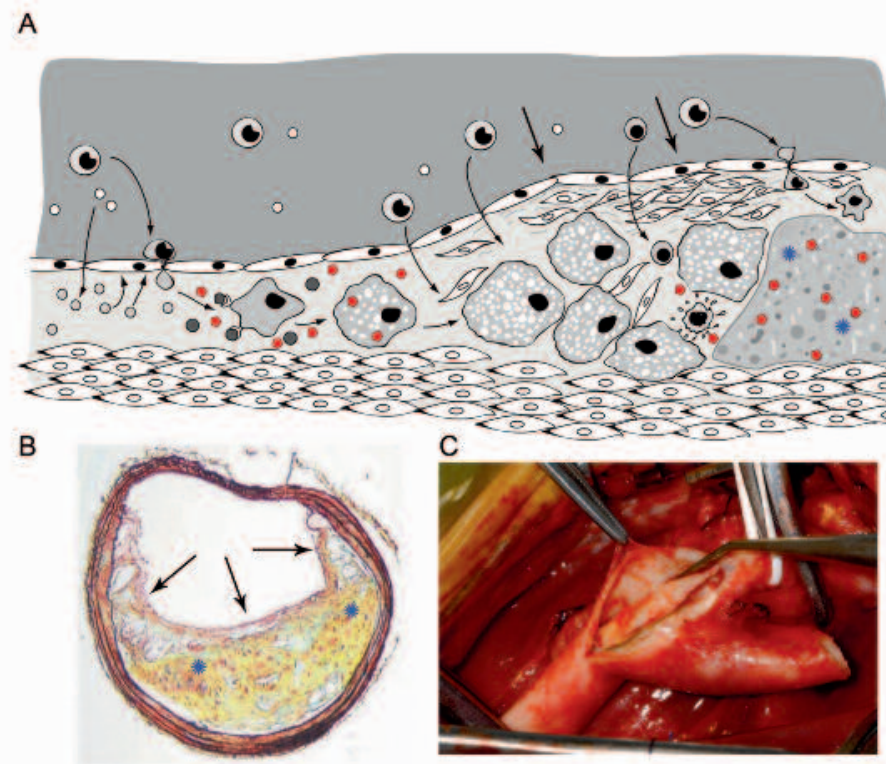

Figure 4. Atherosclerosis. A) Schematic view of atherosclerosis development in which lipids, macrophages and cellular debris accumulate in the arterial intima. The atherosclerotic build-up (blue asterisk) is covered by endothelial cells as well as a fibrous cap (arrow). MBL (indicated in red) might well have an opsonizing role during early atherosclerosis development, facilitating phagocytic clearance, thereby reducing inflammation which is known to influence atherosclerosis progression. B) A microscopic transsection of an atherosclerotic lesion, filling the arterial lumen. Lipid accumulation (blue asterisk) and fibrous cap formation (arrows) are indicated. C) In vivo demonstration of an atherosclerotic lesion, dissected from a carotid artery during surgery. Notice the thick atherosclerotic build-up which is dissected from the arterial wall of the opened artery. 


\section{Chapter 1}

immune activity, such as acute tissue damage during organ IR.

As a model of chronic and ongoing tissue damage, relevant to modern, western society and every day clinical practice, we studied the role of $\mathrm{MBL}$ in experimental atherosclerosis. Atherosclerosis is considered to be a progressive disease characterized by an accumulation of lipids, myeloid cells and fibrous elements in the vascular intima (Figure 4). ${ }^{88,89}$

A large body of research has demonstrated that atherosclerosis development is largely dependent on innate immune contributors like endothelial cell activation, expression of adhesion molecules (VCAM-1, I-CAM), leukocytes, macrophages and complement activation. ${ }^{88,89} \mathrm{All}$ are individually linked to progressive tissue damage following acute organ injury.

First reports on a role of $\mathrm{MBL}$ in atherosclerosis date back to as early as 1998. ${ }^{51}$ This first population-based report suggested that $\mathrm{mb} / 2$ gene polymorphisms influence atherosclerosis by an increased susceptibility of the vascular wall to infection by $C$. Pneumoniae. The association between atherogenesis and MBL has only partially been corroborated since, with an evident lack in experimental data. Concerning the role of $\mathrm{MBL}$ as a modifier of atherosclerosis development an intricate role for MBL in atherosclerosis is suggested, but one could say that to this day 'confusion prevails'.

The role of other complement components in atherosclerosis development is less ambiguous. In the absence of $\mathrm{C} 6$, experimental atherosclerosis in rabbits was reduced following a period of high fat feeding. ${ }^{93}$ In contrast, atherosclerosis studies in $\mathrm{C}^{-\%}$ - and $\mathrm{C}^{-} \%$-deficient mice seem to contradict the findings in $\mathrm{C}^{-/}$deficient rabbits, with an increase in atherosclerosis development in response to high fat feeding in both $\mathrm{C}^{-/}$and $\mathrm{C}^{-/-}$deficient mice. ${ }^{94,95}$ Since complement components like MAC or CD59 have pro- and anti-atherogenic effects respectively, one wonders whether these conflicting findings in experimental atherosclerosis for individual common complement components like C3 and especially C5 are brought about by model specific differences. ${ }^{96-98}$ The expression and the role of MBL during atherosclerosis development is investigated in Chapter 4.

\subsection{Aims to be STUdied}

As illustrated by the above outline the contribution of innate immune regulatory components to acute and chronic tissue damage is complex. Many different cells, 
proteins and mechanisms make up the innate immune system and have so far been involved in the development of both acute and chronic tissue damage in animals and humans. Full understanding of the components that make up the immune response to acute and chronic tissue damage will allow for a major contribution to the treatment of many present-day pathologies. Therefore, the following aims will be studied in this thesis:

Aim 1: Study of major innate immune components in experimental renal IR in order to develop strategies that preserve renal function during Non-Heart Beating kidney transplantation (Chapter 2).

Aim 2: Study the sequelae of intestinal ischemia-reperfusion in man and elucidate the role of regulatory innate immune processes in subsequent passive and active barrier failure (Chapter 3).

Aim 3: Study the functional contribution of $\mathrm{MBL}$, as a regulatory innate immune protein during chronic tissue damage, in atherosclerosis development in mice and man (Chapter 4).

\section{REFERENCES}

1. Medzhitov R, Janeway C, Jr.: Innate immunity, N Engl J Med 2000, 343:338-344

2. Opitz B, Hippenstiel S, Eitel J, Suttorp N: Extra- and intracellular innate immune recognition in endothelial cells, Thromb Haemost 2007, 98:319-326

3. Bianchi ME: DAMPs, PAMPs and alarmins: all we need to know about danger, J Leukoc Biol 2007, 81:1-5

4. Lotze MT, Zeh HJ, Rubartelli A, Sparvero LJ, Amoscato AA, Washburn NR, Devera ME, Liang X, Tor M, Billiar T: The grateful dead: damage-associated molecular pattern molecules and reduction/oxidation regulate immunity, Immunol Rev 2007, 220:60-81

5. Mogensen TH: Pathogen recognition and inflammatory signaling in innate immune defenses, Clin Microbiol Rev 2009, 22:240-273, Table of Contents

6. Seong SY, Matzinger P: Hydrophobicity: an ancient damage-associated molecular pattern that initiates innate immune responses, Nat Rev Immunol 2004, 4:469-478 


\section{Chapter 1}

7. Zhang Q, Raoof M, Chen Y, Sumi Y, Sursal T, Junger W, Brohi K, Itagaki K, Hauser CJ: Circulating mitochondrial DAMPs cause inflammatory responses to injury, Nature 2010, 464:104-107

8. Beutler B: Inferences, questions and possibilities in Toll-like receptor signalling, Nature 2004, 430:257-263

9. O'Neill LA, Bowie AG: The family of five: TIR-domain-containing adaptors in Toll-like receptor signalling, Nat Rev Immunol 2007, 7:353-364

10. Kumar; V, Abbas; AK, Fausto N: Robbins \& Cotran Pathologic Basis of Disease. Edited by Saunders, 2004, 1552 p

11. Yamasaki S, Ishikawa E, Sakuma M, Hara H, Ogata K, Saito T: Mincle is an ITAM-coupled activating receptor that senses damaged cells, Nat Immunol 2008, 9:1179-1188

12. Asea A, Rehli M, Kabingu E, Boch JA, Bare O, Auron PE, Stevenson MA, Calderwood SK: Novel signal transduction pathway utilized by extracellular HSP70: role of toll-like receptor (TLR) 2 and TLR4, J Biol Chem 2002, 277:15028-15034

13. Biragyn A, Ruffini PA, Leifer CA, Klyushnenkova E, Shakhov A, Chertov O, Shirakawa AK, Farber JM, Segal DM, Oppenheim JJ, Kwak LW: Toll-like receptor 4-dependent activation of dendritic cells by beta-defensin 2, Science 2002, 298:1025-1029

14. Martin SJ, Reutelingsperger CP, McGahon AJ, Rader JA, van Schie RC, LaFace DM, Green DR: Early redistribution of plasma membrane phosphatidylserine is a general feature of apoptosis regardless of the initiating stimulus: inhibition by overexpression of $\mathrm{Bcl}-2$ and Abl, J Exp Med 1995, 182:1545-1556

15. Colletti LM, Remick DG, Burtch GD, Kunkel SL, Strieter RM, Campbell DA, Jr.: Role of tumor necrosis factor-alpha in the pathophysiologic alterations after hepatic ischemia/reperfusion injury in the rat, J Clin Invest 1990, 85:1936-1943

16. Oyama J, Blais C, Jr., Liu X, Pu M, Kobzik L, Kelly RA, Bourcier T: Reduced myocardial ischemia-reperfusion injury in toll-like receptor 4-deficient mice, Circulation 2004, 109:784-789

17. Thornton MA, Winn R, Alpers CE, Zager RA: An evaluation of the neutrophil as a mediator of in vivo renal ischemic-reperfusion injury, Am J Pathol 1989, 135:509-515

18. Vakeva AP, Agah A, Rollins SA, Matis LA, Li L, Stahl GL: Myocardial infarction and apoptosis after myocardial ischemia and reperfusion: role of the terminal complement components and inhibition by anti-C5 therapy, Circulation 1998, 97:2259-2267

19. Furuichi K, Wada T, Iwata Y, Kitagawa K, Kobayashi K, Hashimoto H, Ishiwata Y, Asano M, Wang H, Matsushima K, Takeya M, Kuziel WA, Mukaida N, Yokoyama H: CCR2 signaling contributes to ischemia-reperfusion injury in kidney, J Am Soc Nephrol 2003, 14:2503-2515 
20. Zhao ZQ, Lefer DJ, Sato H, Hart KK, Jefforda PR, Vinten-Johansen J: Monoclonal antibody to ICAM-1 preserves postischemic blood flow and reduces infarct size after ischemiareperfusion in rabbit, J Leukoc Biol 1997, 62:292-300

21. Kelly KJ, Williams WW, Jr., Colvin RB, Bonventre JV: Antibody to intercellular adhesion molecule 1 protects the kidney against ischemic injury, Proc Natl Acad Sci U S A 1994, 91:812-816

22. Kelly KJ, Williams WW, Jr., Colvin RB, Meehan SM, Springer TA, Gutierrez-Ramos JC, Bonventre JV: Intercellular adhesion molecule-1-deficient mice are protected against ischemic renal injury, J Clin Invest 1996, 97:1056-1063

23. Daemen MA, van 't Veer C, Denecker G, Heemskerk VH, Wolfs TG, Clauss M, Vandenabeele P, Buurman WA: Inhibition of apoptosis induced by ischemia-reperfusion prevents inflammation, J Clin Invest 1999, 104:541-549

24. Danese S, Dejana E, Fiocchi C: Immune regulation by microvascular endothelial cells: directing innate and adaptive immunity, coagulation, and inflammation, J Immunol 2007, 178:6017-6022

25. Walport MJ: Complement. First of two parts, N Engl J Med 2001, 344:1058-1066

26. Sato T, van Dixhoorn MG, Heemskerk E, van Es LA, Daha MR: C1q, a subunit of the first component of complement, enhances antibody-mediated apoptosis of cultured rat glomerular mesangial cells, Clin Exp Immunol 1997, 109:510-517

27. Stokol T, O'Donnell P, Xiao L, Knight S, Stavrakis G, Botto M, von Andrian UH, Mayadas TN: C1q Governs Deposition of Circulating Immune Complexes and Leukocyte Fc\{gamma\} Receptors Mediate Subsequent Neutrophil Recruitment, J Exp Med 2004, 200:835-846

28. McMullen ME, Hart ML, Walsh MC, Buras J, Takahashi K, Stahl GL: Mannose-binding lectin binds IgM to activate the lectin complement pathway in vitro and in vivo, Immunobiology 2006, 211:759-766

29. Pangburn MK, Ferreira VP, Cortes C: Discrimination between host and pathogens by the complement system, Vaccine 2008, 26 Suppl 8:115-21

30. Dommett RM, Klein N, Turner MW: Mannose-binding lectin in innate immunity: past, present and future, Tissue Antigens 2006, 68:193-209

31. Thiel S: Complement activating soluble pattern recognition molecules with collagen-like regions, mannan-binding lectin, ficolins and associated proteins, Mol Immunol 2007, 44:3875-3888

32. Huang Y, Qiao F, Abagyan R, Hazard S, Tomlinson S: Defining the CD59-C9 binding interaction, J Biol Chem 2006, 281:27398-27404 


\section{Chapter 1}

33. de Vries B, Walter SJ, Peutz-Kootstra CJ, Wolfs TG, van Heurn LW, Buurman WA: The mannose-binding lectin-pathway is involved in complement activation in the course of renal ischemia-reperfusion injury, Am J Pathol 2004, 165:1677-1688

34. Walsh MC, Bourcier T, Takahashi K, Shi L, Busche MN, Rother RP, Solomon SD, Ezekowitz RA, Stahl GL: Mannose-binding lectin is a regulator of inflammation that accompanies myocardial ischemia and reperfusion injury, J Immunol 2005, 175:541-546

35. Moller-Kristensen M, Wang W, Ruseva M, Thiel S, Nielsen S, Takahashi K, Shi L, Ezekowitz A, Jensenius JC, Gadjeva M: Mannan-binding lectin recognizes structures on ischaemic reperfused mouse kidneys and is implicated in tissue injury, Scand J Immunol 2005, 61:426-434

36. Hart ML, Ceonzo KA, Shaffer LA, Takahashi K, Rother RP, Reenstra WR, Buras JA, Stahl GL: Gastrointestinal ischemia-reperfusion injury is lectin complement pathway dependent without involving C1q, J Immunol 2005, 174:6373-6380

37. Turner MW: Mannose-binding lectin (MBL) in health and disease, Immunobiology 1998, 199:327-339

38. Ip WK, Takahashi K, Ezekowitz RA, Stuart LM: Mannose-binding lectin and innate immunity, Immunol Rev 2009, 230:9-21

39. Kuhlman M, Joiner K, Ezekowitz RA: The human mannose-binding protein functions as an opsonin, J Exp Med 1989, 169:1733-1745

40. Ikeda K, Sannoh T, Kawasaki N, Kawasaki T, Yamashina I: Serum lectin with known structure activates complement through the classical pathway, J Biol Chem 1987, 262:7451-7454

41. Uemura K, Saka M, Nakagawa T, Kawasaki N, Thiel S, Jensenius JC, Kawasaki T: L-MBP is expressed in epithelial cells of mouse small intestine, J Immunol 2002, 169:6945-6950

42. Seyfarth J, Garred P, Madsen HO: Extra-hepatic transcription of the human mannosebinding lectin gene ( $\mathrm{mbl}$ ) and the MBL-associated serine protease 1-3 genes, Mol Immunol 2006, 43:962-971

43. Nonaka M, Ma BY, Ohtani M, Yamamoto A, Murata M, Totani K, Ito Y, Miwa K, Nogami W, Kawasaki N, Kawasaki T: Subcellular localization and physiological significance of intracellular mannan-binding protein, J Biol Chem 2007, 282:17908-17920

44. Mullighan CG, Heatley S, Doherty K, Szabo F, Grigg A, Hughes TP, Schwarer AP, Szer J, Tait BD, Bik To L, Bardy PG: Mannose-binding lectin gene polymorphisms are associated with major infection following allogeneic hemopoietic stem cell transplantation, Blood 2002, 99:3524-3529

45. Verdu P, Barreiro LB, Patin E, Gessain A, Cassar O, Kidd JR, Kidd KK, Behar DM, Froment A, Heyer E, Sica L, Casanova JL, Abel L, Quintana-Murci L: Evolutionary insights into the high worldwide prevalence of MBL2 deficiency alleles, Hum Mol Genet 2006, 15:2650-2658 
46. Turner MW, Hamvas RM: Mannose-binding lectin: structure, function, genetics and disease associations, Rev Immunogenet 2000, 2:305-322

47. Hansson GK: Epidemiology complements immunology in the heart, Arterioscler Thromb Vasc Biol 2006, 26:2178-2180

48. Cavalli-Sforza LL, Feldman MW: The application of molecular genetic approaches to the study of human evolution, Nat Genet 2003, 33 Suppl:266-275

49. Dornelles LN, Pereira-Ferrari L, Messias-Reason I: Mannan-binding lectin plasma levels in leprosy: deficiency confers protection against the lepromatous but not the tuberculoid forms, Clin Exp Immunol 2006, 145:463-468

50. Super M, Thiel S, Lu J, Levinsky RJ, Turner MW: Association of low levels of mannanbinding protein with a common defect of opsonisation, Lancet 1989, 2:1236-1239

51. Madsen HO, Videm V, Svejgaard A, Svennevig JL, Garred P: Association of mannosebinding-lectin deficiency with severe atherosclerosis, Lancet 1998, 352:959-960

52. Ohlenschlaeger T, Garred P, Madsen HO, Jacobsen S: Mannose-binding lectin variant alleles and the risk of arterial thrombosis in systemic lupus erythematosus, $\mathrm{N}$ Engl J Med 2004, 351:260-267

53. Summerfield JA, Ryder S, Sumiya M, Thursz M, Gorchein A, Monteil MA, Turner MW: Mannose binding protein gene mutations associated with unusual and severe infections in adults, Lancet 1995, 345:886-889

54. Hegele RA, Ban MR, Anderson CM, Spence JD: Infection-susceptibility alleles of mannosebinding lectin are associated with increased carotid plaque area, J Investig Med 2000, 48:198-202

55. Collard CD, Vakeva A, Morrissey MA, Agah A, Rollins SA, Reenstra WR, Buras JA, Meri S, Stahl GL: Complement activation after oxidative stress: role of the lectin complement pathway, Am J Pathol 2000, 156:1549-1556

56. Roos A, Bouwman LH, van Gijlswijk-Janssen DJ, Faber-Krol MC, Stahl GL, Daha MR: Human IgA activates the complement system via the mannan-binding lectin pathway, J Immunol 2001, 167:2861-2868

57. Collard CD, Montalto MC, Reenstra WR, Buras JA, Stahl GL: Endothelial oxidative stress activates the lectin complement pathway: role of cytokeratin 1, Am J Pathol 2001, 159:1045-1054

58. Nauta AJ, Daha MR, Kooten C, Roos A: Recognition and clearance of apoptotic cells: a role for complement and pentraxins, Trends Immunol 2003, 24:148-154

59. Hart SP, Smith JR, Dransfield I: Phagocytosis of opsonized apoptotic cells: roles for 'oldfashioned' receptors for antibody and complement, Clin Exp Immunol 2004, 135:181-185 


\section{Chapter 1}

60. Nauta AJ, Castellano G, Xu W, Woltman AM, Borrias MC, Daha MR, van Kooten C, Roos A: Opsonization with $\mathrm{C} 1 \mathrm{q}$ and mannose-binding lectin targets apoptotic cells to dendritic cells, J Immunol 2004, 173:3044-3050

61. Ip WK, Chan SY, Lau CS, Lau YL: Association of systemic lupus erythematosus with promoter polymorphisms of the mannose-binding lectin gene, Arthritis Rheum 1998, 41:1663-1668

62. Garred P, Madsen HO, Halberg P, Petersen J, Kronborg G, Svejgaard A, Andersen V, Jacobsen S: Mannose-binding lectin polymorphisms and susceptibility to infection in systemic lupus erythematosus, Arthritis Rheum 1999, 42:2145-2152

63. Nathan C: Neutrophils and immunity: challenges and opportunities, Nat Rev Immunol 2006, 6:173-182

64. Nathan CF: Neutrophil activation on biological surfaces. Massive secretion of hydrogen peroxide in response to products of macrophages and lymphocytes, J Clin Invest 1987, 80:1550-1560

65. Linas SL, Shanley PF, Whittenburg D, Berger E, Repine JE: Neutrophils accentuate ischemiareperfusion injury in isolated perfused rat kidneys, Am J Physiol 1988, 255:F728-735

66. Rabb H, O'Meara YM, Maderna P, Coleman P, Brady HR: Leukocytes, cell adhesion molecules and ischemic acute renal failure, Kidney Int 1997, 51:1463-1468

67. Jordan JE, Zhao ZQ, Vinten-Johansen J: The role of neutrophils in myocardial ischemiareperfusion injury, Cardiovasc Res 1999, 43:860-878

68. Jaeschke H, Farhood A, Smith CW: Neutrophils contribute to ischemia/reperfusion injury in rat liver in vivo, Faseb J 1990, 4:3355-3359

69. Klebanoff SJ: Myeloperoxidase: friend and foe, J Leukoc Biol 2005, 77:598-625

70. Malle E, Buch T, Grone HJ: Myeloperoxidase in kidney disease, Kidney Int 2003, 64:19561967

71. Nagra RM, Becher B, Tourtellotte WW, Antel JP, Gold D, Paladino T, Smith RA, Nelson JR, Reynolds WF: Immunohistochemical and genetic evidence of myeloperoxidase involvement in multiple sclerosis, J Neuroimmunol 1997, 78:97-107

72. Baldus S, Heeschen C, Meinertz T, Zeiher AM, Eiserich JP, Munzel T, Simoons ML, Hamm CW: Myeloperoxidase serum levels predict risk in patients with acute coronary syndromes, Circulation 2003, 108:1440-1445

73. Hazell LJ, Arnold L, Flowers D, Waeg G, Malle E, Stocker R: Presence of hypochloritemodified proteins in human atherosclerotic lesions, J Clin Invest 1996, 97:1535-1544

74. Podrez EA, Schmitt D, Hoff HF, Hazen SL: Myeloperoxidase-generated reactive nitrogen species convert LDL into an atherogenic form in vitro, J Clin Invest 1999, 103:1547-1560 
75. Bergt C, Pennathur S, Fu X, Byun J, O'Brien K, McDonald TO, Singh P, Anantharamaiah GM, Chait A, Brunzell J, Geary RL, Oram JF, Heinecke JW: The myeloperoxidase product hypochlorous acid oxidizes HDL in the human artery wall and impairs ABCA1-dependent cholesterol transport, Proc Natl Acad Sci U S A 2004, 101:13032-13037

76. Vasilyev N, Williams T, Brennan ML, Unzek S, Zhou X, Heinecke JW, Spitz DR, Topol EJ, Hazen SL, Penn MS: Myeloperoxidase-generated oxidants modulate left ventricular remodeling but not infarct size after myocardial infarction, Circulation 2005, 112:2812-2820

77. Vogt W: Complement activation by myeloperoxidase products released from stimulated human polymorphonuclear leukocytes, Immunobiology 1996, 195:334-346

78. Eiserich JP, Baldus S, Brennan ML, Ma W, Zhang C, Tousson A, Castro L, Lusis AJ, Nauseef WM, White CR, Freeman BA: Myeloperoxidase, a leukocyte-derived vascular NO oxidase, Science 2002, 296:2391-2394

79. Baldus S, Heitzer T, Eiserich JP, Lau D, Mollnau H, Ortak M, Petri S, Goldmann B, Duchstein HJ, Berger J, Helmchen U, Freeman BA, Meinertz T, Munzel T: Myeloperoxidase enhances nitric oxide catabolism during myocardial ischemia and reperfusion, Free Radic Biol Med 2004, 37:902-911

80. Khazen W, M'Bika J P, Tomkiewicz C, Benelli C, Chany C, Achour A, Forest C: Expression of macrophage-selective markers in human and rodent adipocytes, FEBS Lett 2005, 579:5631-5634

81. Serhan CN, Savill J: Resolution of inflammation: the beginning programs the end, Nat Immunol 2005, 6:1191-1197

82. Medzhitov R: Recognition of microorganisms and activation of the immune response, Nature 2007, 449:819-826

83. Sansonetti PJ: War and peace at mucosal surfaces, Nat Rev Immunol 2004, 4:953-964

84. Nagler-Anderson C: Man the barrier! Strategic defences in the intestinal mucosa, Nat Rev Immunol 2001, 1:59-67

85. Lala S, Ogura Y, Osborne C, Hor SY, Bromfield A, Davies S, Ogunbiyi O, Nunez G, Keshav S: Crohn's disease and the NOD2 gene: a role for paneth cells, Gastroenterology 2003, 125:47-57

86. Wolfs TG, Derikx JP, Hodin CM, Vanderlocht J, Driessen A, de Bruine AP, Bevins CL, Lasitschka F, Gassler N, van Gemert WG, Buurman WA: Localization of the lipopolysaccharide recognition complex in the human healthy and inflamed premature and adult gut, Inflamm Bowel Dis 16:68-75

87. Wolfs TG, Buurman WA, van Schadewijk A, de Vries B, Daemen MA, Hiemstra PS, van 't Veer C: In vivo expression of Toll-like receptor 2 and 4 by renal epithelial cells: IFN-gamma and TNF-alpha mediated up-regulation during inflammation, J Immunol 2002, 168:1286-1293 


\section{Chapter 1}

88. Libby P: Inflammation in atherosclerosis, Nature 2002, 420:868-874

89. Hansson GK: Inflammation, atherosclerosis, and coronary artery disease, N Engl J Med 2005, 352:1685-1695

90. Rugonfalvi-Kiss S, Endresz V, Madsen HO, Burian K, Duba J, Prohaszka Z, Karadi I, Romics L, Gonczol E, Fust G, Garred P: Association of Chlamydia pneumoniae with coronary artery disease and its progression is dependent on the modifying effect of mannose-binding lectin, Circulation 2002, 106:1071-1076

91. Keller TT, van Leuven SI, Meuwese MC, Wareham NJ, Luben R, Stroes ES, Hack CE, Levi M, Khaw KT, Boekholdt SM: Serum levels of mannose-binding lectin and the risk of future coronary artery disease in apparently healthy men and women, Arterioscler Thromb Vasc Biol 2006, 26:2345-2350

92. Best LG, Davidson M, North KE, MacCluer JW, Zhang Y, Lee ET, Howard BV, DeCroo S, Ferrell RE: Prospective analysis of mannose-binding lectin genotypes and coronary artery disease in American Indians: the Strong Heart Study, Circulation 2004, 109:471-475

93. Schmiedt W, Kinscherf R, Deigner HP, Kamencic H, Nauen O, Kilo J, Oelert H, Metz J, Bhakdi S: Complement C6 deficiency protects against diet-induced atherosclerosis in rabbits, Arterioscler Thromb Vasc Biol 1998, 18:1790-1795

94. Patel S, Thelander EM, Hernandez M, Montenegro J, Hassing H, Burton C, Mundt S, Hermanowski-Vosatka A, Wright SD, Chao YS, Detmers PA: ApoE(-/-) mice develop atherosclerosis in the absence of complement component C5, Biochem Biophys Res Commun 2001, 286:164-170

95. Persson L, Boren J, Robertson AK, Wallenius V, Hansson GK, Pekna M: Lack of complement factor C3, but not factor B, increases hyperlipidemia and atherosclerosis in apolipoprotein E-/low-density lipoprotein receptor-/- mice, Arterioscler Thromb Vasc Biol 2004, 24:1062-1067

96. Wu G, Hu W, Shahsafaei A, Song W, Dobarro M, Sukhova GK, Bronson RR, Shi GP, Rother RP, Halperin JA, Qin X: Complement regulator CD59 protects against atherosclerosis by restricting the formation of complement membrane attack complex, Circ Res 2009, 104:550-558

97. Niculescu F, Niculescu T, Rus H: C5b-9 terminal complement complex assembly on apoptotic cells in human arterial wall with atherosclerosis, Exp Mol Pathol 2004, 76:17-23

98. Niculescu F, Rus H: Complement activation and atherosclerosis, Mol Immunol 1999, 36:949-955

99. Degn SE, Hansen AG, Steffensen R, Jacobsen Ch, Jensenius JC, Thiel S: Map44, a human protein associated with pattern recognition molecules of the complement system and regulating the lectin pathway of complement activation, J Immunol 2009, 183:7371-7378 


\section{ChAPTER 2 \\ Innate immune regulatory proteins in renal ischemia reperfusion damage}




\section{Chapter 2}

\subsection{INTRODUCTION}

Renal insufficiency as a consequence of ischemia followed by reperfusion is of particular relevance during kidney transplantation, trauma, sepsis and major surgical procedures. Many studies show that an inflammatory response induced by ischemia followed by reperfusion is largely responsible for functional organ failure and tissue damage. Several inflammatory mediators critical in renal IR damage development have been identified over time.

In order to answer the first aim of this thesis, Chapters 2.2 and 2.3 discuss the role of myeloperoxidase (MPO) and the common complement component $\mathrm{C} 5$ in the development of experimental renal ischemia reperfusion injury.

As highlighted in the introduction (Chapter 1.2.8), MPO is a major constituent of PMN and monocytes with considerable immune-activating properties. For MPO pro-apoptotic, complement activating, reactive species (ROS) generating and neutrophil activating properties have been described. The relevance of these immunogenic properties of MPO in the development of IR induced renal damage was the focus of our studies (Chapter 2.2).

Complement component $\mathrm{C} 5$ is the first component of the common complement pathway, leading to the generation of the membrane attack complex (MAC). It is an inactive pro-enzyme, which is cleaved upon activation by a C5 convertase, generating two active $\mathrm{C} 5$ split products $\mathrm{C} 5 \mathrm{a}$ and $\mathrm{C} 5 \mathrm{~b}$, the latter being the first MAC building block. C5a is a small soluble immune peptide with chemotactic properties, called an anaphylatoxin. The role of C5 and C5 cleavage in response to renal IR was studied in Chapter 2.3.

Preservation of renal functional capabilities following organ IR is of critical benefit in many situations. The possibility to control the progression of secondary and inflammation mediated organ damage will undoubtedly enhance the pool of renal transplant organs, enhance post transplant organ function or improve major surgical outcome. In order to preserve renal function following IR the effects of Lysophosphatidic Acid (LPA), a potentially protective phospholipid, on experimental murine renal IR will be investigated (Chapter 2.4). LPA is a phospholipid with a pleiotropic range of functions on cell proliferation and apoptosis inhibition. Its in vivo role during renal IR will be studied. LPA was tested using a murine model of renal IR that was developed at the laboratories of the department of surgery around 1999 and has been well established since. ${ }^{1-4}$ 
Translation of experimental data to the setting of human transplantation medicine remains a challenge and is of eminent importance. This translation requires the development of clinically relevant large animal models. In Chapter 2.5 the development of an autologous pig kidney transplant model is described. This model bridges the gap between small animal experimental IR models and the clinical setting of human renal organ transplantation from organ donors after cardiac death (non-heart beating donors or NHB-donors).

Ultimately, Chapter 2.6 describes the effects of $\mathrm{mb} / 2$ gene variants of human non-heart beating renal transplantation. As described, MBL is a potent immune regulatory PRM with complement activating properties of which both function and plasma levels are tightly regulated by frequently occurring $\mathrm{mb} / 2$ haplotypes. The effect of different donor and recipient $\mathrm{mb} / 2$ haplotypes on post operative primary non-function and 5-year graft-survival will be discussed.

\section{References}

1. Daemen MA, van de Ven MW, Heineman E, Buurman WA: Involvement of endogenous interleukin-10 and tumor necrosis factor-alpha in renal ischemia-reperfusion injury, Transplantation 1999, 67:792-800

2. Daemen MA, van 't Veer C, Denecker G, Heemskerk VH, Wolfs TG, Clauss M, Vandenabeele P, Buurman WA: Inhibition of apoptosis induced by ischemia-reperfusion prevents inflammation, J Clin Invest 1999, 104:541-549

3. Daemen MA, Heemskerk VH, van't Veer C, Denecker G, Wolfs TG, Vandenabeele P, Buurman WA: Functional protection by acute phase proteins alpha(1)-acid glycoprotein and alpha(1)-antitrypsin against ischemia/reperfusion injury by preventing apoptosis and inflammation, Circulation 2000, 102:1420-1426

4. de Vries B, Walter SJ, Peutz-Kootstra CJ, Wolfs TG, van Heurn LW, Buurman WA: The mannose-binding lectin-pathway is involved in complement activation in the course of renal ischemia-reperfusion injury, Am J Pathol 2004, 165:1677-1688 


\section{Chapter 2.2}

\section{Myeloperoxidase Is Critically Involved in the Induction of Organ Damage after Renal Ischemia Reperfusion}

Robert A. Matthijsen, Dennis Huugen, Nicole T. Hoebers, Bart de Vries, Carine J. Peutz-Kootstra, Yasuaki Aratani, Mohamed R. Daha, Jan Willem Cohen Tervaert, Wim A. Buurman, and Peter Heeringa. 


\section{Abstract}

In this study the role of MPO in a murine $(\mathrm{C} 57 \mathrm{BL} / 6)$ model of ischemia and reperfusion $(\mathrm{I} / \mathrm{R})$ induced renal failure is investigated. The renal function following I/R was analyzed in MPO deficient $\left(\mathrm{Mpo}^{-/}\right)$mice and compared to wildtype (WT) controls. A significant reduction in renal function loss (blood urea nitrogen, BUN) was observed following 24 hours of reperfusion of ischemically damaged kidneys in $\mathrm{Mpo}^{-/}$mice compared to I/R WT controls $\left(\mathrm{I} / \mathrm{R} \mathrm{Mpo}^{-/}=31.3 \pm 1.7 \mathrm{mMol} / \mathrm{l} \mathrm{vs}\right.$. I/R WT $=42.8 \pm 2.1 \mathrm{mMol} / \mathrm{l}$. SHAM = $7.0 \pm 0.5 \mathrm{mMol} / \mathrm{l} . \mathrm{P}=0.003)$. The early reperfusion phase ( 2 hours of reperfusion) was characterized by substantial increase of apoptosis and early complement activation, surprisingly similar in $\mathrm{Mpo}^{-/}$and WT mice. Improved renal function in $\mathrm{Mpo}^{-/}$mice following extended reperfusion was accompanied by a reduced neutrophil influx $(P=0.017)$ compared to WT controls. Activation and deposition of complement was not significantly reduced in $\mathrm{Mpo}^{-1}$ compared to WT controls after $24 \mathrm{~h}$ of reperfusion, indicating no specific in vivo role for MPO in activating complement following renal I/R.

Taken together, these results demonstrated an important contribution of MPO in the induction of organ damage after renal I/R by influencing critical factors like neutrophil extravasation, but not complement activation.

\section{INTRODUCTION}

In clinical medicine, complications arising from organ ischemia and reperfusion $(\mathrm{I} / \mathrm{R})$ are common phenomena, complicating the treatment of severely injured or ill patients and influencing the outcome of various clinical conditions. Over the past decades studies into the pathophysiology of $\mathrm{I} / \mathrm{R}$ induced organ damage have identified several critical factors - cellular injury, endothelial dysfunction, microcirculatory collapse, neutrophil activation and extravasation and complement activation, all contributing to the development of organ dysfunction. Our limited understanding of exact pathophysiological mechanisms has so far impaired the development of new and effective therapies.

Cellular injury, induced by ischemia and aggravated upon reperfusion, forms a potent trigger for activation of an extensive inflammatory response, illustrated by the production of various cytokines such as tumor necrosis factor- $\alpha$ (TNF- $\alpha$ ), interferon$\gamma\left(\right.$ IFN- $\gamma$ ) and the interleukins 6, 10, 12 and 18, ${ }^{1,2}$ the activation and sequestration of polymorphonuclear neutrophils (PMNs) in the affected area, ${ }^{3}$ as well as the 


\section{Chapter 2}

expression and deposition of various components of the innate immune response, such as complement factors. ${ }^{4-6}$ Under healthy conditions, cells and proteins of the innate immune system protect the organism by orchestrating a well-mounted attack on invading micro-organisms, but when faced with extensive I/R injury, sufficient means of control seem absent. Already during the eighties a detrimental role for PMN was shown during hypoperfusion and ischemia followed by reperfusion., 8 These early studies proposed a role for activated neutrophils in the frequently observed no-reflow phenomenon ${ }^{9}$ and the generation of harmful reactive oxygen species (ROS) following reperfusion of ischemically damaged tissue. ${ }^{10}$

Myeloperoxidase (MPO) is a $140 \mathrm{kD}$ heme protein that is predominantly stored in the lysosomes of monocytes and in the azurophilic granules of PMN. ${ }^{11}$ It is one of the most abundant enzymes released upon neutrophil activation. The capacity of MPO to catalyze the formation of hypochlorite $(\mathrm{HOCl})$ from hydrogen peroxide $\left(\mathrm{H}_{2} \mathrm{O}_{2}\right)$ and chloride ions makes it a powerful tool in the bactericidal armament of these cells. However, there are clinical studies indicating a potentially harmful effect of MPO in immune-mediated inflammatory syndromes, such as multiple sclerosis, ${ }^{12}$ acute coronary syndrome, ${ }^{13,14}$ and renal disease. ${ }^{15}$ In addition, a considerable line of research indicates that MPO and MPO-derived oxidants are involved in the pathogenesis of atherosclerosis, ${ }^{16-18}$ organ damage following myocardial $\mathrm{I} / \mathrm{R}$ and infarction ${ }^{19}$ as well as complement activation in vitro. ${ }^{20}$ Furthermore, MPO contributes to the dysfunction of the local vasculature during acute inflammation by modifying local $\mathrm{NO}$ production and availability. ${ }^{21}$

In order to study the in vivo contribution of MPO in the development of I/Rinduced injury, the role of MPO in a mouse model of renal $\mathrm{I} / \mathrm{R}$ injury was investigated. Disease severity was compared between MPO-deficient $\left(\mathrm{Mpo}^{-/}\right)$and wildtype (WT) mice with respect to renal function, complement activation, neutrophil activation and extravasation, renal morphology and apoptosis. Our results show that MPO plays a detrimental role in the pathogenic mechanisms involved in this model and is in part responsible for the development of renal damage resulting from $\mathrm{I} / \mathrm{R}$ without influencing complement activation in vivo. 


\section{Materials And Methods}

\section{Mice}

$\mathrm{Mpo}^{-/}$mice, backcrossed to a C57BL/6 background six times, were genotyped using PCR-amplified DNA from tail clippings. ${ }^{22}$ Wildtype male C57BL/6 control mice (11 weeks of age) were obtained from Charles River Breeding Laboratories (Heidelberg, Germany). Mice were kept according to University of Maastricht animal facility regulations, and all experiments were approved by the local animal ethical committee.

\section{Experimental procedure}

Experiments were carried out as previously described, with minor modifications. ${ }^{6}$ At the start of the experiments, mice ( $n=6$ in each group) were anesthetized with sodium pentobarbital (100 mg/kg i.p.). Body temperature was maintained at $37^{\circ} \mathrm{C}$ by a heating pad until animals recovered from anesthesia. Under aseptic conditions a 1.0-cm long midline abdominal incision was made and ischemia was induced by applying a nontraumatic vascular clamp to the left renal pedicle for 40 minutes. Subsequently, the wound was covered with cotton soaked in sterile phosphate-buffered saline (PBS). After removal of the clamp, the left kidney was inspected for restoration of blood flow and the contralateral kidney was removed and stored for analysis. The wound was closed in two layers and in mice that were to be sacrificed after 24 hours, $0.25 \%$ bupivacaine was applied topically to the wound for postoperative pain management. The animals were killed 2 or 24 hours after reperfusion. At the time of sacrifice, plasma was collected and the left kidney was harvested for morphological, immunohistochemical and immunofluorescent analysis. Macroscopic evaluation of the ischemic kidneys during the procedure resulted in the exclusion of one mouse, since its kidney appeared to have been insufficiently ischemic during the experiment. One WT frozen tissue sample to be used for preparation of frozen sections was lost during work-up.

\section{Plasma Measurements of Blood Urea Nitrogen (BUN) and MPO}

In mice sacrificed after 24 hours, BUN levels in the plasma were determined by an enzymatic degradation assay on a Synchron LX20 PRO chemical analyzer (Beckman Coulter Inc., Fullerton, CA). Plasma MPO levels were determined by inhouse catching ELISA as described previously. ${ }^{23}$ Briefly, microtiter plates were coated $(1 \mathrm{~g} / \mathrm{ml})$ with FC fragment-specific goat anti-mouse IgG (Jackson 


\section{Chapter 2}

ImmunoResearch, West Grove, PA), incubated for 48 hours at $4^{\circ} \mathrm{C}$, and blocked with $1 \%$ bovine serum albumin in PBS. Plates were then incubated with an antimurine MPO-specific monoclonal antibody (mAb) (clone 8F4. Hbt, Uden, the Netherlands), followed by incubation with appropriately diluted plasma samples. Next, the plates were incubated with polyclonal rabbit anti-human MPO (DakoCytomation, Glostrup, Denmark) and alkaline phosphatase-labeled polyclonal goat anti-rabbit $\lg G$ as primary and secondary detection antibody, respectively. 4-Nitrophenyl phosphate (pNPP) was used as substrate, and results were analyzed spectrophotometrically at $405 \mathrm{~nm}$. Concentrations were calculated from a standard curve of purified murine MPO (range, 2.5-100 ng/ml).

\section{Immunofluorescence and Immunohistochemistry}

Kidneys were snap-frozen in OCT compound. Five- $\mathrm{m}$ sections were cut with a cryostat, dried and stored at $-70^{\circ} \mathrm{C}$. The slides were fixed in $-20^{\circ} \mathrm{C}$ cold acetone and stained for neutrophil influx using a rat anti-mouse neutrophil antibody (clone NIMPR14, Hbt)..$^{24}$ After incubation of the primary antibody, endogenous peroxidase activity was blocked using $0.05 \% \mathrm{H}_{2} \mathrm{O}_{2}$ in PBS, and rabbit anti-rat $\lg \mathrm{G}$ and goat anti-rabbit IgG-PO (both DakoCytomation) were then used as secondary and tertiary antibodies, respectively. Antibody binding was visualized using 3-amino-9ethylcarbazole (AEC) with $\mathrm{H}_{2} \mathrm{O}_{2}$ as substrate. Sections were counterstained with haematoxylin, and juxtamedullary neutrophil influx was quantified by counting the average number of NIMP-R14-positive cells in 10 high-power fields of four tissue sections per kidney in WT and $\mathrm{MpO}^{-}$-mice ( $\mathrm{n}=5$ per group), at $24 \mathrm{~h}$ after reperfusion.

To determine co-localization of PMNs with renal MPO deposits, renal crosssections were double-stained with a biotinylated mouse $\mathrm{mAb}$ specific for murine MPO (clone 8F4, Hbt) ${ }^{23}$ and rat anti-mouse neutrophil mAb NIMP-R14 (Hbt), using ALEXA 488-labeled streptavidin and ALEXA 568-labeled goat anti rat IgG (both Invitrogen Molecular Probes, Leiden, the Netherlands) respectively, as conjugates. Murine complement factors MBL-A, MBL-C, C3, C6 and C9 were determined by using rat monoclonal (MBL-A, clone 8G6; MBL-C, clone 14D12; iC3b, clone 2/11; $\mathrm{Hbt}$ ) or rabbit polyclonal anti mouse C6 (kindly provided by Dr. A. Tenner. University of California, Irvine, CA) and rabbit anti mouse C9 (in-house made by M.R.D.) primary antibodies. Specific binding was detected by using peroxidase-conjugated secondary antibodies to rat and rabbit IgG respectively (Jackson ImmunoResearch). Staining was visualized by 3-amino-9-ethylcarbazole (AEC) followed by 
haematoxylin. No significant staining was detected in slides incubated with control rat IgG (for NIMP-R14, MBL-A, MBL-C and C3), mouse IgG (for MPO) and rabbit IgG (for C6 and C9). After immunohistochemical staining of kidneys ( $\mathrm{n}=5$ per group) renal deposition of complement factors was scored arbitrarily as negative (-), slightly positive $(+)$, moderately positive $(++)$ and intensively positive $(+++)$.

\section{Western Blot}

Western blot analyses of C6 deposition in sham-treated or reperfused ischemic knockout (KO) and WT kidneys was performed as described before, with minor modifications. ${ }^{25}$ Renal tissue samples from WT and KO I/R or sham-treated animals were homogenized in lysis buffer $(200 \mathrm{mmol} / \mathrm{L} \mathrm{NaCl}, 10 \mathrm{mM}$ Tris base, $5 \mathrm{mmol} / \mathrm{L}$ ethylenediaminetetraacetic acid EDTA), 10\% Glycerin, $1 \mathrm{mmol} / \mathrm{L}$ phenylmethyl sulfonyl fluoride (PMSF), $0.1 \mathrm{U} / \mathrm{ml}$ Aprotinin and $1 \mu \mathrm{g} / \mathrm{ml}$ Leupeptin). Tissue homogenates were centrifuged at $300 \mathrm{rpm}$ for 10 minutes, after which the collected supernatants were centrifuged again at 10,000 rpm for 3 minutes. The protein concentration of the different lysates was determined using Bradford analyses. Aliquots containing equal amounts

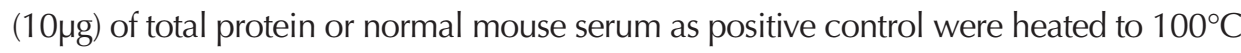
for 5 minutes in sodium dodecyl sulphate-sample buffer containing 5\% ßmercaptoethanol (Sigma, Chicago, IL), transferred to a $8 \%$ sodium dodecyl sulphate (SDS)-polyacrylamide gel and blotted on an Immobilon-P polyvinylidene fluoride (PVDF) membrane (Millipore, Bedford, MA). After blotting of the proteins, the blocking and antibody incubation steps were performed in phosphate-buffered saline containing $5 \%$ bovine serum albumin and $0.1 \%$ Tween-20 (Sigma). C6 was detected by incubating PVDF membranes overnight at $4{ }^{\circ} \mathrm{C}$ in buffer containing properly diluted rabbit anti mouse C6 (Hbt). Binding of the primary antibody was detected with a peroxidase conjugated secondary antibody to rabbit IgG (Jackson). After washing positive bands were visualized using chemiluminescence (Supersignal, Pierce, Rockford, IL).

\section{Apoptosis Assay}

The presence of internucleosomal DNA cleavage in kidneys was established with a commercial ligase-mediated (LM)-polymerase chain reaction (PCR) assay kit (Apoalert, Clontech, Palo Alto, CA) enabling semiquantitative measurement of the extent of apoptosis. ${ }^{26}$ 


\section{Chapter 2}

\section{Renal Morphology}

Paraffin-embedded sections from the 24 hours reperfusion group were prepared and stained using Periodic Acid-Schiff (PAS) staining. Morphological changes resulting from ischemia/reperfusion injury were graded using the scoring system described by Leemans et al. ${ }^{27}$ Tubules, cast deposition, brush border loss and necrosis were identified in at least 10 randomly chosen $\times 200$ fields in the cortico-medullary region of 3 sections per kidney. Total scores were calculated for each kidney.

\section{Statistical analysis}

Data are expressed as means ( \pm SEM) and were analyzed by unpaired two-tailed Student $T$-test, using Graphpad Prism 4.01 for Windows (Graphpad Software, San Diego CA). P-value $\leq 0.05$ was considered statistically significant.

\section{Results}

\section{Renal histology}

To directly assess tissue damage, induced by 40 minutes of ischemia followed by 24 hours of reperfusion, paraffin sections were stained using PAS staining (Figure 1). Moderate to severe damage involving $\sim 25 \%$ of the cortex was similarly observed in both $\mathrm{Mpo}^{-\%}$ and WT kidneys (Table 1), using the histopathological scoring system developed by Leemans and colleagues to assess the renal damage. ${ }^{27} \mathrm{No}$ damage was seen in sham-treated animals.

Figure 1. Similar renal morphology of ischemically damaged and sham-treated kidneys, following 24 hours of reperfusion. Microphotographs showing PAS staining of kidney sections of sham-treated (A) as well

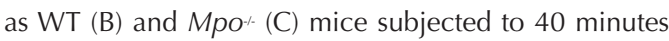
of ischemia followed by 24 hours of reperfusion. Shown are representative microphotographs of all groups. Original magnification x 100 .

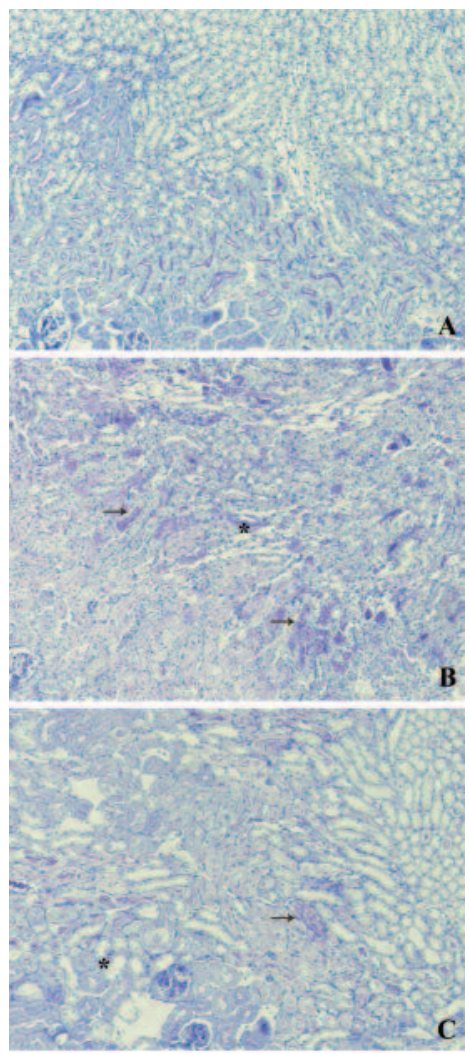


Table 1. Immunohistochemical and Histological Analysis of Renal Complement Deposition and Damage

\begin{tabular}{|c|c|c|c|c|c|c|c|c|c|c|c|}
\hline \multirow{3}{*}{$\begin{array}{l}\text { Ischemia } \\
\text { (minutes) }\end{array}$} & \multirow{3}{*}{$\begin{array}{l}\text { Repefusion } \\
\text { (hours) }\end{array}$} & \multicolumn{4}{|c|}{ Lectin pathway } & \multirow{2}{*}{\multicolumn{2}{|c|}{$\begin{array}{l}\text { Alternative pathway } \\
\text { C3 }\end{array}$}} & \multirow{2}{*}{\multicolumn{2}{|c|}{$\begin{array}{c}\text { Common pathway } \\
\text { C6/C9 }\end{array}$}} & \multirow{2}{*}{\multicolumn{2}{|c|}{$\begin{array}{l}\text { Histology } \\
\text { PAS }\end{array}$}} \\
\hline & & \multicolumn{2}{|c|}{ MBL-A } & \multicolumn{2}{|c|}{ MBL-C } & & & & & & \\
\hline & & WT & $\mathrm{Mpo}^{-/}$ & WT & $\mathrm{Mpo}^{-\%}$ & WT & $\mathrm{Mpo}^{-/}$ & WT & $\mathrm{Mpo}^{-/-}$ & WT & $\mathrm{Mpo}^{-/-}$ \\
\hline- & - & - & - & - & - & - & - & - & - & 0 & 0 \\
\hline 40 & 2 & - & - & + & + & + & + & - & - & - & - \\
\hline 40 & 24 & ++ & ++ & ++ & ++ & + & + & ++ & ++ & 29.2 & 27.4 \\
\hline
\end{tabular}

${ }^{*}$ Average score from 10 randomly chosen $x 200$ fields. I/R WT $=29.2 \pm 2.5$ versus I/R Mpo- $/-=27.4 \pm 3.3 P=0.68$

\section{MPO deficiency reduces renal dysfunction}

Renal dysfunction was reflected by an increase in BUN levels after 24 hours of reperfusion (Figure 2). Forty minutes of unilateral ischemia followed by 24 hours of reperfusion caused an elevation of BUN levels in $\mathrm{Mpo}^{-/}$and WT mice. However, $\mathrm{Mpo}$ - mice displayed a markedly less pronounced increase in renal failure compared to WT mice $\left(\mathrm{I} / \mathrm{R} \mathrm{Mpo}^{-/}=31.3 \pm 1.7 \mathrm{mmol} / \mathrm{L}\right.$ versus $\mathrm{I} / \mathrm{R}$ WT $=42.8 \pm 2.1 \mathrm{mmol} / \mathrm{L} . \mathrm{P}=$ 0.003 . SHAM $=7.0 \pm 0.5 \mathrm{mmol} / \mathrm{L}$ ). These findings illustrate a contribution of MPO to the development of organ failure of reperfused ischemic kidneys.

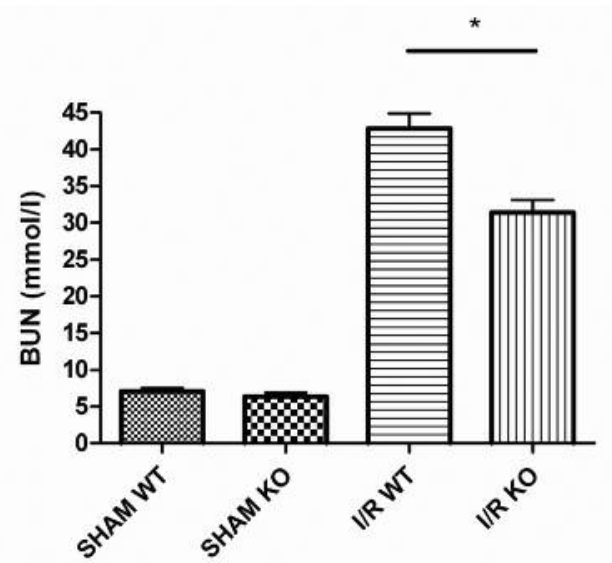

Figure 2. MPO deficiency significantly reduces renal function loss after renal I/R. Renal function following 24 hours of reperfusion as reflected by BUN concentration. Statistical significance of renal function in $\mathrm{MpO}^{\star}$ mice as compared to WT animals was denoted at $\mathrm{P}<0.003\left(^{*}\right)$. 


\section{MPO deficiency fails to abrogate apoptosis and mannose-binding lectin deposition during early reperfusion}

Previously, it was demonstrated that apoptosis plays an important role in the development of organ damage induced by the reperfusion of ischemic kidneys. ${ }^{28}$ Because some studies show that MPO induces apoptosis by directly mediating caspase activation, the hypothesis that MPO deficiency preserves renal function by inhibition of apoptosis was tested. Apoptosis after 2 hours of reperfusion, analyzed

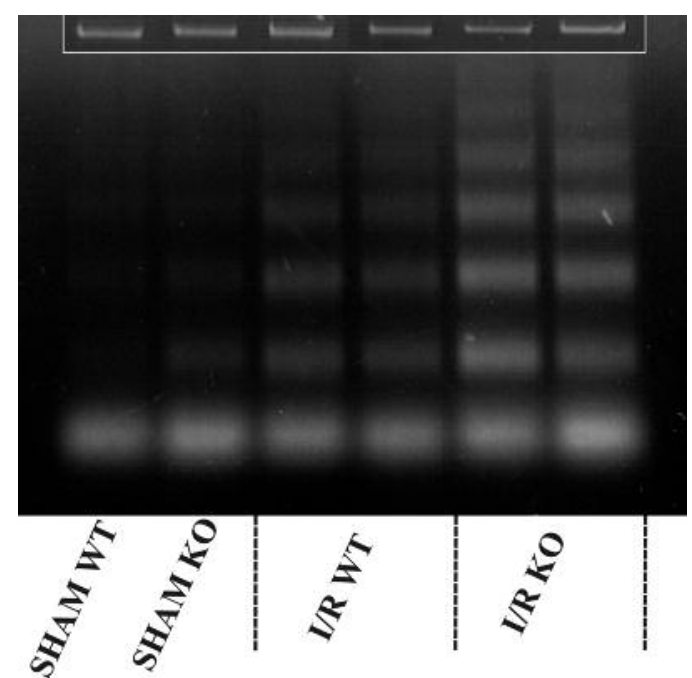

Figure 3. MPO deficiency does not affect I/R-induced early apoptosis. Shown are two sham-treated animals as well as two representatives of each experimental group. Loading controls are given in the insert.

by typical DNA cleavage, is depicted in Figure 3. Clearly shown is the by $\mathrm{l} / \mathrm{R}$-induced increase in apoptosis, when comparing experimental and sham-treated animals. $\mathrm{MpO}^{-/}$and WT animals showed a similar increase in apoptosis. The slightly larger amount of apoptosis that was observed in $\mathrm{Mpo}^{-/}$as compared to WT mice after 2 hours of reperfusion, was similarly observed in sham treated $\mathrm{Mpo}^{-/}$and WT mice. This indicates that the rise in apoptosis in $\mathrm{Mpo}^{-/}$and WT experimental animals was in fact similar and certainly not reduced in $\mathrm{Mpo}^{-/}$animals.

It has been shown that bound complement components are critical in the induction and propagation of $\mathrm{I} / \mathrm{R}$-induced organ damage following initial cellular damage and apoptosis. ${ }^{29,30}$ Predominantly the murine $\mathrm{MBL}$ variant $\mathrm{C}$ is one of the first 
Figure 4. Two hours of reperfusion of ischemically damaged kidneys results in early MBL-C deposition, similar in $\mathrm{Mpo}^{\circ}$ and WT mice. MBL-C binding in WT sham-treated (not shown) and KO sham-treated (A) animals was only observed in glomeruli. MBL-C deposition was evident in peritubular capillaries, the interstitium and along the epithelial brush border of damaged tubules in both WT (B) and $\mathrm{Mpo}^{*}$ (C) mice subjected to renal I/R. Shown are representative microphotographs of all groups. Original magnification x200 (x600 for the insert in A).

inflammatory factors observed to bind during early reperfusion. ${ }^{31}$ Therefore, an immunohistochemical staining was performed on early 2-hour reperfusion samples, to study the deposition of activated MBL-C. No differences were detected in the amount of MBL-C present in the cortico-medullary region on peritubular capillaries and in the interstitium of reperfused ischemic kidneys from either $\mathrm{MPO}^{-/}$or WT mice (Figure 4), suggesting similar levels of complement activation as a result of comparable ischemia induced cellular damage and apoptosis in $\mathrm{Mpo}^{-/}$and WT animals.

\section{PMN influx and MPO release}

Next the influx and activation of inflammatory mediators present during the subsequent progression phase of reperfusion was investigated. Neutrophils, invading the damaged tissue, contribute to the local inflammatory response in part by releasing their lysosomal constituents, including MPO. MPO released by the activated PMN has been shown to be important in the activation and adhesion of other neutrophils. ${ }^{32,33}$ WT mice had high levels of circulating MPO (Figure 5), indicating I/R mediated neutrophil activation. This idea was strengthened by the lack of MPO in sham-treated animals. 


\section{Chapter 2}

Figure 5. MPO plasma levels, representing total neutrophil activation, are increased 24 hours after reperfusion of ischemically damaged WT kidneys. No $\mathrm{MPO}$ was detected in $\mathrm{Mpo}^{\star}$ mice. Statistical significance of WT MPO levels as compared to sham treated animals was denoted at $\mathrm{P}<0.0001$.
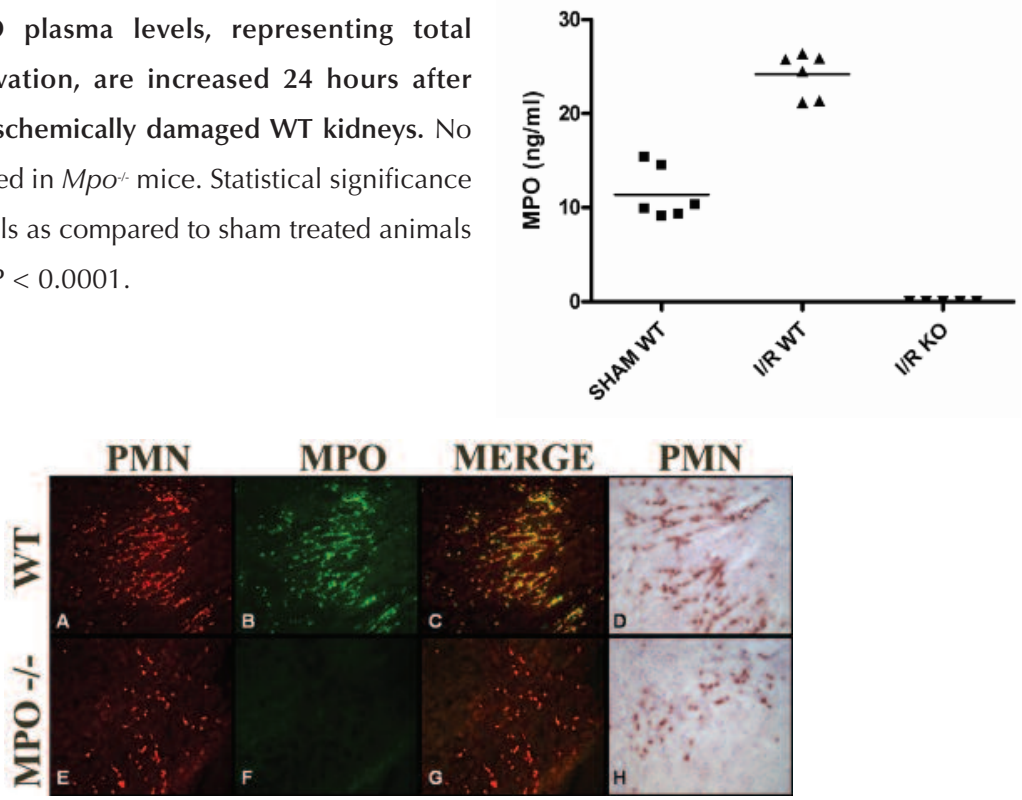

Figure 6. Immunofluorescent staining showing PMN sequestration (red, ALEXA 568) and MPO presence (green, ALEXA 488) in kidneys of WT (A-C) and $\mathrm{Mpo}^{-/}(\mathrm{E}-\mathrm{G})$ mice subjected to I/R. Overlapping PMN and MPO data depict the fact that MPO is predominantly located around NIMPR14 positive PMNs. D (WT) and $\mathrm{H}\left(\mathrm{MpO}^{-1}\right)$ show PMN infiltration in relation to structural changes. Shown are representative microphotographs of all groups. Original magnification x200.

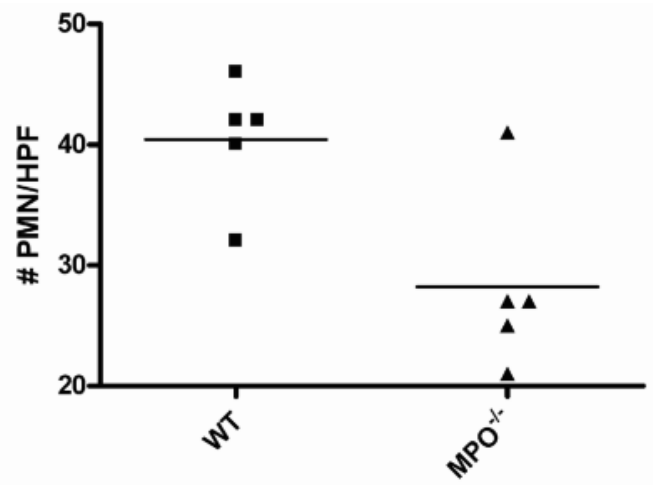

Figure 7. MPO deficiency reduces neutrophil infiltration after renal $I / R$. Statistical significance as compared to WT animals was denoted at $\mathrm{P}=0.017$. 
Immunohistology revealed high levels of MPO in the kidney, mostly comprised to NIMP-R14-positive PMNs and their direct surroundings (Figure 6A-C). As expected $\mathrm{MPO}$ was absent in samples from $\mathrm{Mpo}^{-/-}$mice (Figure 5 and $6 \mathrm{~F}$ ). To quantify the neutrophil infiltration, we counted cells positive for NIMP-R14, a neutrophil marker not influenced by the lack of MPO. Analysis revealed a significant reduction of $\mathrm{I} / \mathrm{R}$ induced $\mathrm{PMN}$ infiltration of the $\mathrm{Mpo}^{-/}$kidneys in comparison to the WT $\left(\mathrm{I} / \mathrm{R} \mathrm{Mpo}^{-/}=28.2 \pm 3.3 \mathrm{PMN} /\right.$ high-power fields versus I/R WT $=40.4 \pm 2.3$ $\mathrm{PMN} /$ high-power fields. $\mathrm{P}=0.017$ ), indicating an important in vivo role for MPO in the extravasation of neutrophils following I/R (Figure 7).

\section{Complement Activation}

Studies of the complement system during renal ischemia and reperfusion revealed the lectin and alternative as well as the subsequent common complement pathway as key effectors in the induction of I/R induced organ failure. ${ }^{4,31} \mathrm{MPO}$ has been described as an activator of complement. ${ }^{20}$ In vitro experiments revealed complement component C5 activating properties for various proteolytic enzymes that were released upon PMN stimulation. Similarly, purified MPO was shown to activate $\mathrm{C} 5$ by hypochlorite formation in vitro. From this we hypothesized that MPO might regulate complement activation and influence renal function in an in vivo renal I/R model.

Figure 8. MBL-C and C3 (inserts) deposition in WT and $\mathrm{Mpo}^{-/-}$mice following 24 hours of reperfusion. MBL-C and C3 deposition was not different in WT (B) or $\mathrm{Mpo}^{-1}$ (C) mice. Virtually no MBL-C or C3 staining was detected in sham treated WT (not shown) and $\mathrm{Mpo}^{-1}$ mice (A). Corresponding data were obtained for MBL-A deposition (data not shown). Shown are representative microphotographs of all groups. Original magnification x200 (x200 for the inserts in A, B and C).
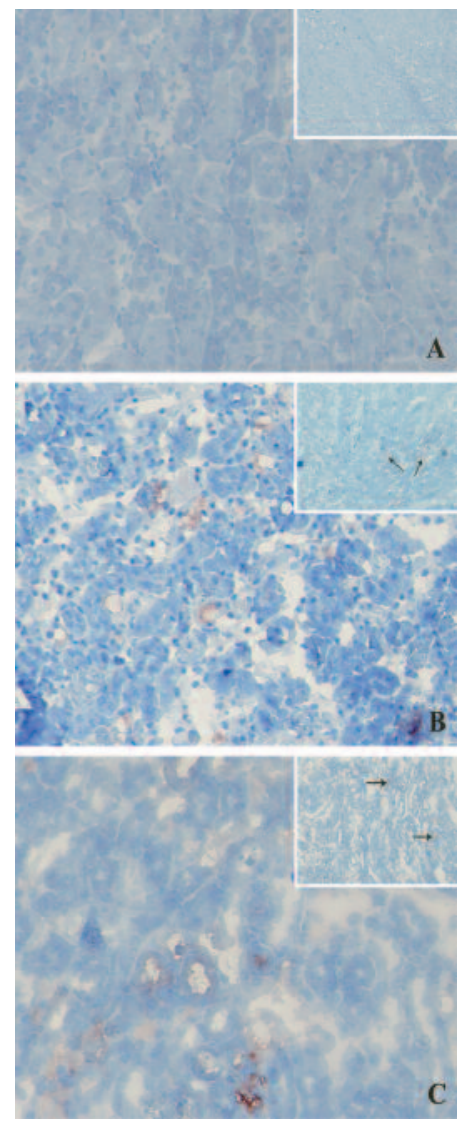


\section{Chapter 2}

Activation of the complement system was assessed after prolonged 24 hours of reperfusion (Table 1). Immunohistochemistry revealed similar activation of early and late common pathway complement proteins in $\mathrm{Mpo}^{-/}$and WT mice. The deposition of early complement factors MBL-A, MBL-C and C3 increased in both $\mathrm{Mpo}^{-/}$and WT mice after 24 hours of reperfusion when compared to the 2 hour reperfusion samples. MBL-C and C3 deposition was abundantly present in peritubular capillaries and interstitium as well as on the epithelial lining of damaged tubules after I/R.

Surprisingly, no differences in the quantity of complement proteins MBL-A, MBL-C, and C3 were detected between $\mathrm{Mpo}^{-/}$and WT groups subjected to I/R (Figure 8). Since C5 convertase like properties have been described for MPO in vitro, the in vivo deposition of common pathway complement components was analyzed. Similar to the results observed for early complement proteins, the deposition of common pathway proteins C6 (Figure 9), analyzed by

Figure 9. Common pathway activation as determined by immunohistochemical and western blot analyses of C6 deposition in WT and $\mathrm{Mpo}^{-/}$mice following 24 hours of reperfusion. $\mathrm{C} 6$ deposition in $\mathrm{MpO}^{-}$mice (C) was similar as compared to WT (B) controls. No C6 staining was detected between WT-sham (not shown) and $\mathrm{Mpo}^{\circ}$ sham treated mice (A). Shown are representative microphotographs of all groups. Western blot results for C6 (SHAM in A; WT in B; KO in C) under reducing conditions are shown in the inserts. Original magnification x200.

immunohistochemical staining and Western blot, and C9 (Figure 10) were not substantially reduced in MPO deficient mice after $24 \mathrm{~h}$ of reperfusion, suggesting no considerable role for MPO in the activation of common pathway complement components in vivo in response to kidney I/R. C6 and C9 depositions were similarly observed in WT and $\mathrm{Mpo}^{-/}$mice on

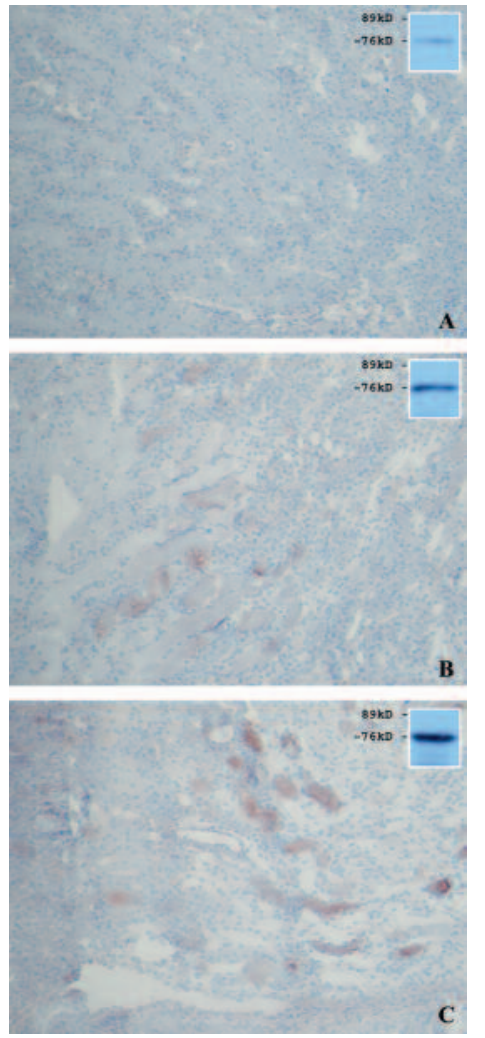


the epithelial lining of damaged tubules as well as on tubular cast formations observed after 24 hours of reperfusion.

Figure 10. Similar common pathway activation between $\mathrm{Mpo}^{-/}$(C) and WT (B) mice following 24 hours of reperfusion was confirmed by $\mathrm{C} 9$ immunostaining.

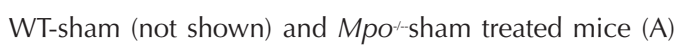
did not demonstrate any C9 staining. Original magnification $x 100$ (x200 for the inserts in B and C).

\section{Discussion}

The results provide evidence that a lack of MPO reduces renal function loss following ischemia and reperfusion. By showing that MPO-deficient mice are partially protected from I/R-induced renal failure, the results demonstrate that this enzyme plays an important role in the pathogenesis of $\mathrm{I} / \mathrm{R}$ induced renal damage. MPO

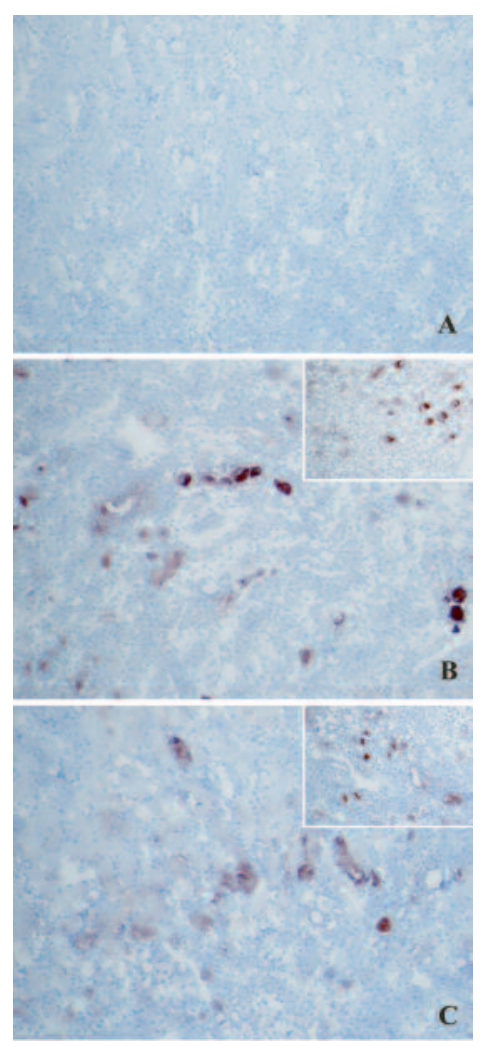
deficiency reduced PMN infiltration but failed to abrogate complement activation in reperfused murine kidneys.

MPO is a neutrophil-derived enzyme with the capacity to catalyze the formation of the pro-inflammatory oxidant $\mathrm{HOCl}$ and chlorinating species out of $\mathrm{H}_{2} \mathrm{O}_{2}$ and chlorideions. ${ }^{11}$ Apart from MPO's contribution to innate immunity, there is in vitro evidence that MPO plays a role in apoptosis. Neutrophil derived proteinase 3 and MPO mediate proapoptotic caspase-3 activation or induce direct HL-60 leukemia cell and endothelial cell apoptosis in vitro. ${ }^{34-36}$ Throughout the years, a massive body of literature has emerged describing the activation of apoptotic pathways in renal I/R. ${ }^{37,38}$ Furthermore, inhibition of apoptosis through administration of the anti-apoptotic agents like IGF-1 or ZVAD-fmk (a broad caspase inhibitor) has been shown to preserve renal function after $\mathrm{I} / \mathrm{R} .{ }^{28}$ The hypothesis is tested that, in our model, a decrease in MPO-mediated apoptosis is one of the mechanisms through which $\mathrm{Mpo}^{-/}$mice are protected from injury caused by renal I/R. Analyzing the overall levels of apoptosis, by 


\section{Chapter 2}

detecting specific DNA fragmentation, it is shown that renal ischemia followed by 2 hours of reperfusion induces a marked increase in the level of apoptosis in both $\mathrm{KO}$ and WT animals. Moreover, the observed increase in apoptosis in $\mathrm{Mpo}^{-/}$mice is similar to the rise of apoptosis in WT animals during this early phase of reperfusion. Similarly, studies by Vasilyev and colleagues could not show a significant contribution for MPO or its derived oxidants in the induction of apoptosis and necrosis in vivo. ${ }^{19} \mathrm{MPO}$ rather adversely influenced organ function by the production of cytotoxic aldehydes ${ }^{19}$ or the oxidative inactivation of plasminogen activator inhibitor 1 (PAI-1). ${ }^{39}$ The present data indeed suggest that MPO has no significant in vivo role in the induction of renal cell death throughout the first moments of $I / R$, but rather has a profound effect on organ function during late reperfusion, known as progression phase.

PMN influence I/R induced tissue damage in a multitude of organs by capillary plugging, ${ }^{9}$ induction of tubular leakage, ${ }^{40}$ release of oxygen-free radicals ${ }^{41}$ and lysosomal enzyme activity. ${ }^{42-45}$ MPO specifically mediates neutrophil activation by binding to CD11b/CD18 (MAC1) integrins, ${ }^{32}$ as well as PMN adhesion via the $\alpha_{m} \beta_{2}$ integrin, ${ }^{33}$ thereby facilitating PMN extravasation. Inhibiting PMN extravasation, abrogates renal I/R injury. ${ }^{14,46}$ The reduced levels of BUN, observed in this model in $\mathrm{MpO}^{-/}$mice, are accompanied by a decrease in PMN influx during late (24 hours) reperfusion. Our data are in line with the effect of MPO on PMN and indicate that the absence of MPO prevents PMN activation and adhesion, thereby effectively reducing the amount of neutrophils invading the damaged tissue and preserving organ function.

A major role in the induction and continuation of local inflammation is played by the complement system. Complement proteins contribute to the development of I/R-induced organ injury. $6,31,47$ Predominantly the activation of the lectin ${ }^{30,31}$ and alternative pathway ${ }^{48}$ as well as the formation of the membrane attack complex (MAC) $)^{49}, 50$ and small cationic proteins (C3a, C4a and C5a), known as anaphylatoxins, have been shown to be involved in I/R-induced tissue injury. ${ }^{6,26}$ The deposition of early complement activating proteins following 2 or 24 hours of reperfusion was similar between $\mathrm{Mpo}^{-/}$and WT treated mice. Neutrophils produce several proteins, like properdin and MPO, which have been shown to activate the complement cascade. Myeloperoxidase is reported to directly activate C5, generating a functional common pathway convertase capable of activating C6. ${ }^{20}$ We hypothesized that with the absence of MPO adequate means to locally activate common complement components in reperfused kidneys would be reduced. To elucidate common complement pathway activation we analyzed C6 and C9 
deposition in reperfused kidneys of $\mathrm{Mpo}^{-/}$and WT controls after 24 hours of reperfusion. Similar to the activation of $\mathrm{MBL}$ and $\mathrm{C} 3$ no reduction in common complement pathway activity was shown in $\mathrm{Mpo}^{-/}$mice. Our data suggest that complement activation initiated by the local presence of MPO, is not of particular importance during renal I/R and consequently has no significant contribution to I/R induced renal function loss. It has been described that several important proteins of the common complement cascade like $\mathrm{C} 6$ and $\mathrm{C} 7,51$ are directly produced by PMN and released upon their activation. This would mean that PMN provide the necessary elements, i.e. C6 and C7, to boost common pathway activation at sites of ongoing inflammation. This could imply a limited presence of these important common pathway components in case of a reduced PMN influx, as was observed in the reperfused kidneys of $\mathrm{Mpo}^{-/}$mice. However, our data do not support that this quality attributed to the PMN has a detrimental role in our renal I/R model.

In conclusion, a reduced function loss in $\mathrm{Mpo}^{-/}$mice as compared to WT controls was observed in a well established model of renal I/R. Apoptosis and activation of the early complement lectin and alternative pathway proteins, $\mathrm{MBL}$ A, MBL-C and C3, occurred similarly in $\mathrm{Mpo}^{-/}$and WT mice during the first hours of reperfusion. After 24 hours of reperfusion, $\mathrm{Mpo}^{-/}$mice exhibited preservation of renal function along with a strongly reduced number of neutrophils, present in the damaged renal tissue. The absence of MPO and the decrease in the number of neutrophils however, did not correlate with a diminished activation of the common complement pathway in $\mathrm{Mpo}^{-/}$mice. This observation might well illustrate that the contribution of MPO to renal organ damage after $I / R$ is more determined by its influence on neutrophil extravasation and tissue infiltration than by its ability to mediate local complement activation in vivo. The results clarify important mechanisms by which polymorphonuclear neutrophils and their derived activation products mediate I/R induced renal injury on a local level.

\section{ACKNOWLEDGMENTS}

We thank Jelly Nelissen and Isabelle Daisormont for their excellent technical assistance. 


\section{Chapter 2}

\section{ReFERENCES}

1. Daemen MA, van de Ven MW, Heineman E, Buurman WA: Involvement of endogenous interleukin-10 and tumor necrosis factor-alpha in renal ischemia-reperfusion injury, Transplantation 1999, 67:792-800

2. Daemen MA, van't Veer C, Wolfs TG, Buurman WA: Ischemia/reperfusion-induced IFNgamma up-regulation: involvement of IL-12 and IL-18, J Immunol 1999, 162:5506-5510

3. Thakur ML, Gottschalk A, Zaret BL: Imaging experimental myocardial infarction with indium-111-labeled autologous leukocytes: effects of infarct age and residual regional myocardial blood flow, Circulation 1979, 60:297-305

4. Zhou W, Farrar CA, Abe K, Pratt JR, Marsh JE, Wang Y, Stahl GL, Sacks SH: Predominant role for C5b-9 in renal ischemia/reperfusion injury, J Clin Invest 2000, 105:1363-1371

5. Vakeva AP, Agah A, Rollins SA, Matis LA, Li L, Stahl GL: Myocardial infarction and apoptosis after myocardial ischemia and reperfusion: role of the terminal complement components and inhibition by anti-C5 therapy, Circulation 1998, 97:2259-2267

6. De Vries B, Matthijsen RA, Wolfs TG, Van Bijnen AA, Heeringa P, Buurman WA: Inhibition of complement factor $\mathrm{C} 5$ protects against renal ischemia-reperfusion injury: inhibition of late apoptosis and inflammation, Transplantation 2003, 75:375-382

7. Hernandez LA, Grisham MB, Twohig B, Arfors KE, Harlan JM, Granger DN: Role of neutrophils in ischemia-reperfusion-induced microvascular injury, Am J Physiol 1987, 253:H699-703

8. Romson JL, Hook BG, Kunkel SL, Abrams GD, Schork MA, Lucchesi BR: Reduction of the extent of ischemic myocardial injury by neutrophil depletion in the dog, Circulation 1983, 67:1016-1023

9. Schmid-Schonbein GW: Capillary plugging by granulocytes and the no-reflow phenomenon in the microcirculation, Fed Proc 1987, 46:2397-2401

10. Kilgore KS, Lucchesi BR: Reperfusion injury after myocardial infarction: the role of free radicals and the inflammatory response, Clin Biochem 1993, 26:359-370

11. Klebanoff SJ: Myeloperoxidase: friend and foe, J Leukoc Biol 2005, 77:598-625

12. Nagra RM, Becher B, Tourtellotte WW, Antel JP, Gold D, Paladino T, Smith RA, Nelson JR, Reynolds WF: Immunohistochemical and genetic evidence of myeloperoxidase involvement in multiple sclerosis, J Neuroimmunol 1997, 78:97-107

13. Baldus S, Heeschen C, Meinertz T, Zeiher AM, Eiserich JP, Munzel T, Simoons ML, Hamm $\mathrm{CW}$ : Myeloperoxidase serum levels predict risk in patients with acute coronary syndromes, Circulation 2003, 108:1440-1445 
14. Miura M, Fu X, Zhang QW, Remick DG, Fairchild RL: Neutralization of Gro alpha and macrophage inflammatory protein-2 attenuates renal ischemia/reperfusion injury, Am J Pathol 2001, 159:2137-2145

15. Malle E, Buch T, Grone HJ: Myeloperoxidase in kidney disease, Kidney Int 2003, 64:19561967

16. Hazell LJ, Arnold L, Flowers D, Waeg G, Malle E, Stocker R: Presence of hypochloritemodified proteins in human atherosclerotic lesions, J Clin Invest 1996, 97:1535-1544

17. Podrez EA, Schmitt D, Hoff HF, Hazen SL: Myeloperoxidase-generated reactive nitrogen species convert LDL into an atherogenic form in vitro, J Clin Invest 1999, 103:1547-1560

18. Bergt C, Pennathur S, Fu X, Byun J, O'Brien K, McDonald TO, Singh P, Anantharamaiah GM, Chait A, Brunzell J, Geary RL, Oram JF, Heinecke JW: The myeloperoxidase product hypochlorous acid oxidizes HDL in the human artery wall and impairs ABCA1-dependent cholesterol transport, Proc Natl Acad Sci U S A 2004, 101:13032-13037

19. Vasilyev N, Williams T, Brennan ML, Unzek S, Zhou X, Heinecke JW, Spitz DR, Topol EJ, Hazen SL, Penn MS: Myeloperoxidase-generated oxidants modulate left ventricular remodeling but not infarct size after myocardial infarction, Circulation 2005, 112:2812-2820

20. Vogt W: Complement activation by myeloperoxidase products released from stimulated human polymorphonuclear leukocytes, Immunobiology 1996, 195:334-346

21. Eiserich JP, Baldus S, Brennan ML, Ma W, Zhang C, Tousson A, Castro L, Lusis AJ, Nauseef WM, White CR, Freeman BA: Myeloperoxidase, a leukocyte-derived vascular NO oxidase, Science 2002, 296:2391-2394

22. Aratani Y, Koyama H, Nyui S, Suzuki K, Kura F, Maeda N: Severe impairment in early host defense against Candida albicans in mice deficient in myeloperoxidase, Infect Immun 1999, 67:1828-1836

23. Huugen D, Xiao H, van Esch A, Falk RJ, Peutz-Kootstra CJ, Buurman WA, Tervaert JW, Jennette JC, Heeringa P: Aggravation of anti-myeloperoxidase antibody-induced glomerulonephritis by bacterial lipopolysaccharide: role of tumor necrosis factor-alpha, Am J Pathol 2005, 167:47-58

24. Lopez AF, Strath M, Sanderson CJ: Differentiation antigens on mouse eosinophils and neutrophils identified by monoclonal antibodies, Br J Haematol 1984, 57:489-494

25. Wolfs TG, de Vries B, Walter SJ, Peutz-Kootstra CJ, van Heurn LW, Oosterhof GO, Buurman WA: Apoptotic cell death is initiated during normothermic ischemia in human kidneys, Am J Transplant 2005, 5:68-75 


\section{Chapter 2}

26. de Vries B, Kohl J, Leclercq WK, Wolfs TG, van Bijnen AA, Heeringa P, Buurman WA: Complement factor $\mathrm{C} 5$ a mediates renal ischemia-reperfusion injury independent from neutrophils, J Immunol 2003, 170:3883-3889

27. Leemans JC, Stokman G, Claessen N, Rouschop KM, Teske GJ, Kirschning CJ, Akira S, van der Poll T, Weening JJ, Florquin S: Renal-associated TLR2 mediates ischemia/reperfusion injury in the kidney, J Clin Invest 2005, 115:2894-2903

28. Daemen MA, van 't Veer C, Denecker G, Heemskerk VH, Wolfs TG, Clauss M, Vandenabeele $\mathrm{P}$, Buurman WA: Inhibition of apoptosis induced by ischemia-reperfusion prevents inflammation, J Clin Invest 1999, 104:541-549

29. Walsh MC, Bourcier T, Takahashi K, Shi L, Busche MN, Rother RP, Solomon SD, Ezekowitz RA, Stahl GL: Mannose-binding lectin is a regulator of inflammation that accompanies myocardial ischemia and reperfusion injury, J Immunol 2005, 175:541-546

30. Moller-Kristensen M, Wang W, Ruseva M, Thiel S, Nielsen S, Takahashi K, Shi L, Ezekowitz A, Jensenius JC, Gadjeva M: Mannan-binding lectin recognizes structures on ischaemic reperfused mouse kidneys and is implicated in tissue injury, Scand J Immunol 2005, 61:426-434

31. de Vries B, Walter SJ, Peutz-Kootstra CJ, Wolfs TG, van Heurn LW, Buurman WA: The mannose-binding lectin-pathway is involved in complement activation in the course of renal ischemia-reperfusion injury, Am J Pathol 2004, 165:1677-1688

32. Lau D, Mollnau H, Eiserich JP, Freeman BA, Daiber A, Gehling UM, Brummer J, Rudolph V, Munzel T, Heitzer T, Meinertz T, Baldus S: Myeloperoxidase mediates neutrophil activation by association with CD11b/CD18 integrins, Proc Natl Acad Sci U S A 2005, 102:431-436

33. Johansson MW, Patarroyo M, Oberg F, Siegbahn A, Nilsson K: Myeloperoxidase mediates cell adhesion via the alpha M beta 2 integrin (Mac-1, CD11b/CD18), J Cell Sci 1997, 110 ( Pt 9):1133-1139

34. Wagner BA, Buettner GR, Oberley LW, Darby CJ, Burns CP: Myeloperoxidase is involved in H2O2-induced apoptosis of HL-60 human leukemia cells, J Biol Chem 2000, 275:22461-22469

35. Tsurubuchi T, Aratani Y, Maeda N, Koyama H: Retardation of early-onset PMA-induced apoptosis in mouse neutrophils deficient in myeloperoxidase, J Leukoc Biol 2001, 70:52-58

36. Myzak MC, Carr AC: Myeloperoxidase-dependent caspase-3 activation and apoptosis in HL-60 cells: protection by the antioxidants ascorbate and (dihydro)lipoic acid, Redox Rep 2002, 7:47-53

37. Kaushal GP, Basnakian AG, Shah SV: Apoptotic pathways in ischemic acute renal failure, Kidney Int 2004, 66:500-506

38. Dagher PC: Apoptosis in ischemic renal injury: roles of GTP depletion and p53, Kidney Int 2004, 66:506-509 
39. Askari AT, Brennan ML, Zhou X, Drinko J, Morehead A, Thomas JD, Topol EJ, Hazen SL, Penn MS: Myeloperoxidase and plasminogen activator inhibitor 1 play a central role in ventricular remodeling after myocardial infarction, J Exp Med 2003, 197:615-624

40. Hellberg PO, Kallskog TO: Neutrophil-mediated post-ischemic tubular leakage in the rat kidney, Kidney Int 1989, 36:555-561

41. Linas SL, Shanley PF, Whittenburg D, Berger E, Repine JE: Neutrophils accentuate ischemiareperfusion injury in isolated perfused rat kidneys, Am J Physiol 1988, 255:F728-735

42. Rabb H, O'Meara YM, Maderna P, Coleman P, Brady HR: Leukocytes, cell adhesion molecules and ischemic acute renal failure, Kidney Int 1997, 51:1463-1468

43. Jordan JE, Zhao ZQ, Vinten-Johansen J: The role of neutrophils in myocardial ischemiareperfusion injury, Cardiovasc Res 1999, 43:860-878

44. Jaeschke H, Farhood A, Smith CW: Neutrophils contribute to ischemia/reperfusion injury in rat liver in vivo, Faseb J 1990, 4:3355-3359

45. Klausner JM, Paterson IS, Goldman G, Kobzik L, Rodzen C, Lawrence R, Valeri CR, Shepro D, Hechtman HB: Postischemic renal injury is mediated by neutrophils and leukotrienes, Am J Physiol 1989, 256:F794-802

46. Kelly KJ, Williams WW, Jr., Colvin RB, Meehan SM, Springer TA, Gutierrez-Ramos JC, Bonventre JV: Intercellular adhesion molecule-1-deficient mice are protected against ischemic renal injury, J Clin Invest 1996, 97:1056-1063

47. Weisman HF, Bartow T, Leppo MK, Marsh HC, Jr., Carson GR, Concino MF, Boyle MP, Roux $\mathrm{KH}$, Weisfeldt ML, Fearon DT: Soluble human complement receptor type 1: in vivo inhibitor of complement suppressing post-ischemic myocardial inflammation and necrosis, Science 1990, 249:146-151

48. Lin T, Zhou W, Farrar CA, Hargreaves RE, Sheerin NS, Sacks SH: Deficiency of C4 from donor or recipient mouse fails to prevent renal allograft rejection, Am J Pathol 2006, 168:1241-1248

49. Kilgore KS, Ward PA, Warren JS: Neutrophil adhesion to human endothelial cells is induced by the membrane attack complex: the roles of P-selectin and platelet activating factor, Inflammation 1998, 22:583-598

50. Kilgore KS, Flory CM, Miller BF, Evans VM, Warren JS: The membrane attack complex of complement induces interleukin-8 and monocyte chemoattractant protein-1 secretion from human umbilical vein endothelial cells, Am J Pathol 1996, 149:953-961

51. Hogasen AK, Wurzner R, Abrahamsen TG, Dierich MP: Human polymorphonuclear leukocytes store large amounts of terminal complement components C7 and C6, which may be released on stimulation, J Immunol 1995, 154:4734-4740 


\section{Chapter 2.3}

\section{Inhibition of complement factor C5 protects against renal ischemia- reperfusion injury: inhibition of late apoptosis and inflammation.}

Bart de Vries, Robert A. Matthijsen, Tim G.A.M. Wolfs, Annemarie A.J.H.M. van Bijnen, Peter Heeringa, and Wim A. Buurman.

Transplantation. 2003,15:375-382. 


\section{Abstract}

Background. Complement has been implicated in the pathophysiology of renal ischemia-reperfusion (I/R) injury. However, the mechanism underlying complement-mediated renal I/R injury is thus far unknown. To investigate the involvement of complement in $\mathrm{I} / \mathrm{R}$ injury, we studied the activation and deposition of complement in a murine model of renal $\mathrm{I} / \mathrm{R}$ injury. Furthermore, we examined the effect of inhibition of complement-factor $\mathrm{C} 5$ on renal $\mathrm{I} / \mathrm{R}$ injury.

Methods. Mice were subjected to 45 minutes of unilateral ischemia and subsequent contralateral nephrectomy and reperfusion for 2, 12, or 24 hours. Mice were control treated or treated with BB5.1, a monoclonal antibody that prevents cleavage of complement factor $\mathrm{C} 5$, thereby preventing $\mathrm{C} 5 \mathrm{a}$ generation and formation of the membrane attack complex (MAC).

Results. Renal I/R induced extensive deposition of C3 early after reperfusion, whereas C6 and C9 deposition (MAC formation) occurred relatively late. I/Rinduced complement deposition was mainly localized to tubular epithelium. Treatment with BB5.1 totally prevented MAC formation but also reduced C3 deposition. Inhibition of $\mathrm{C} 5$ strongly inhibited late inflammation, as measured by neutrophil influx and induction of the murine CXC chemokines macrophage inflammatory protein-2, KC, and lipopolysacharide-induced CXC chemokine. AntiC5 treatment furthermore abrogated late I/R-induced apoptosis, whereas early apoptosis was not affected. Moreover, BB5.1 treatment significantly protected against I/R-induced renal dysfunction.

Conclusions. Renal I/R is followed by activation of the complement system and intrarenal deposition of C3 and MAC. Complement activation plays a crucial role in the regulation of inflammation and late apoptosis. Complement inhibition, by preventing $\mathrm{C} 5$ activation, abrogates late apoptosis and inflammation, being strongly protective against renal function loss. 


\section{Chapter 2}

\section{INTRODUCTION}

Apoptosis plays a crucial role in the pathophysiology of ischemia-reperfusion (I/R) injury. ${ }^{1-5}$ Recently, we showed that apoptosis is functionally involved in the induction of inflammation after renal ischemia. ${ }^{1}$ This inflammatory response is known to be responsible for tissue damage upon reperfusion. ${ }^{6,7}$ The $\mathrm{l} / \mathrm{R}$-induced inflammatory response is characterized by the influx of neutrophils, ${ }^{6,8}$ a process that is mediated by, among others, interleukin 1, tumor necrosis factor aplha (TNF$\alpha$ ), and especially the CXC chemokines $\mathrm{KC}$, macrophage inflammatory protein (MIP)-2, and lipopolysacharide-induced CXC chemokine (LIX). ${ }^{7,9-11}$ The complement system is also activated in several models of $\mathrm{I} / \mathrm{R}$ injury. ${ }^{12-16}$ Activation of the complement system results in the release of the anaphylatoxins C3a and C5a and the formation of the membrane attack complex (MAC). Both C3a and C5a mediate activation of neutrophils. C5a might be involved in the influx of neutrophils upon $\mathrm{I} / \mathrm{R}$ because of its direct chemotactic effect and its ability to induce chemokines. ${ }^{17,18}$ The MAC also mediates neutrophil influx, induces synthesis of proinflammatory cytokines, and directly causes cell injury, apoptosis, and necrosis. ${ }^{19-22}$ Complete deficiencies of complement factors C3, C5, and C6 have been shown to be protective against renal $\mathrm{I} / \mathrm{R}$ injury, the latter implying that in particular the MAC is involved. ${ }^{12}$ In models of experimental glomerulonephritis, the MAC has been implicated in the induction of apoptosis. ${ }^{23-25}$ Because apoptosis is essentially involved in renal $I / R$ injury, we investigated the activation of complement and subsequently whether complement activation is involved in the induction of apoptosis and inflammation in a murine model of renal $\mathrm{I} / \mathrm{R}$ injury. Here, we show that renal $I / R$ induces complement activation and intrarenal deposition of MAC. When C5 activation is prevented, subsequent apoptosis and inflammation, measured by neutrophil influx and chemokine induction, are strongly inhibited. This leads a significant reduction in renal function loss.

\section{MATERIALS AND MEthods}

\section{Antibodies and reagents}

For in vivo studies, anti-murine C5 hybridoma BB5.1 was used (kindly provided by Dr. B. Stockinger, National Institute for Medical Research, London, UK). This is a murine antibody specific for the mouse $\mathrm{C} 5$ protein, raised by immunization of $\mathrm{C} 5$ - 
deficient mice, ${ }^{26}$ which has been shown to block $\mathrm{C} 5 \mathrm{a}$ and MAC generation in vivo. ${ }^{27}$ Murine monoclonal antibody (mAb) ENA-1 (anti-human E-selectin) was used as control antibody. Both murine antibodies have the 1 isotype. Rabbit antimouse C6 was kindly provided by Dr. N.R. Cooper (Scripps Research Institute, La Jolla, CA) and rabbit anti-rat C9 by Dr. B.P. Morgan (University of Wales College of Medicine, Cardiff, UK); goat anti-mouse C3 was purchased from Cappel (ICN Biomedicals, Aurora, OH). NIMP-R14 (rat anti-mouse neutrophil mAb) was kindly provided by Dr. M. Strath (National Institute for Medical Research, London, UK). Secondary antibodies, peroxidase-conjugated donkey anti-goat, goat anti-rabbit, and goat anti-rat IgG, were purchased from Jackson ImmunoResearch (West Grove, PA). All other reagents were purchased from Sigma (St. Louis, MO).

\section{Experimental protocol}

Male Swiss mice weighing 20 to 25 g were obtained from Charles River Breeding Laboratories (Heidelberg, Germany). Animals were housed individually in standard laboratory cages and were allowed free access to food and water throughout the experiments. The studies were performed under a protocol approved by the Institutional Animal Care Committee of the University of Maastricht. At the start of the experiments, mice were anesthetized with sodium pentobarbital $(100 \mathrm{mg} / \mathrm{kg}$ intraperitoneally [IP]). Body temperature was maintained at $39^{\circ} \mathrm{C}$ by a heating pad until animals recovered from anesthesia. Under aseptic conditions, a $1.0-\mathrm{cm}$ long midline abdominal incision was made and ischemia was induced by applying a nontraumatic vascular clamp to the left renal pedicle for 45 minutes. Subsequently, the wound was covered with cotton soaked in sterile phosphate-buffered saline (PBS). After removal of the clamp, the left kidney was inspected for restoration of blood flow and the contralateral kidney was removed. The wound was closed in two layers, and $0.25 \%$ bupivacaine was applied topically for postoperative pain management. The animals were killed at the indicated time points after reperfusion. At the time of death, blood was collected and the left kidney was harvested for analysis.

Mice were subjected to ischemia and treated with anti-C5 mAb BB5.1, control mAb ENA-1, or PBS. Pharmacologic interventions were performed during ischemia, 15 minutes before removal of the clamps, to be effective immediately upon reperfusion. Mice ( $\mathrm{n}=6$ per group) received $1 \mathrm{mg}$ of BB5.1 or ENA-1 dissolved in $1 \mathrm{~mL}$ of PBS, or $1 \mathrm{~mL}$ of PBS IP. The treatment dose used has been 


\section{Chapter 2}

shown to have complement-inhibiting capacities in vivo. ${ }^{27}$ Mice treated with the isotype-matched control antibody (ENA-1) showed no significant differences when compared with the PBS-treated control group with regard to renal function, neutrophil influx, and apoptosis, indicating that aspecific murine $\lg G$ does not affect evaluated parameters.

\section{$\mathrm{CH} 50$}

$\mathrm{CH} 50$ was measured as described previously. ${ }^{28}$ In brief, serum samples were titrated in veronal buffered saline containing $\mathrm{MgCl} 2$ and $\mathrm{CaCl} 2$ in 96-well plates. Antibody-sensitized rabbit erythrocytes were added, and plates were incubated for 1 hour at $30^{\circ} \mathrm{C}$. After centrifugation, supernatants were read at $405 \mathrm{~nm}$. CH50 was calculated using water and veronal buffer controls as described. ${ }^{28}$

\section{Renal histology}

Cryostat sections $(5 \mathrm{~m}$ ) of frozen tissue were fixed with acetone and stained for complement factors, $\mathrm{C} 3, \mathrm{C} 6$ and $\mathrm{C} 9$, the latter using rabbit anti-rat $\mathrm{C} 9$, which cross-reacts with murine $\mathrm{C} 9$, followed by appropriate secondary antibodies. Staining was visualized by 3-amino-9-ethylcarbazole followed by haematoxylin counterstain. No significant staining was detected in slides incubated with control antibodies, normal goat serum for $\mathrm{C} 3$ or rabbit serum for $\mathrm{C} 6$ and $\mathrm{C} 9$, instead of the specific antisera, indicating the absence of significant background staining. Staining for neutrophils was performed with mAb NIMP-R14. Neutrophils were counted by examining 20 fields of vision per kidney section $(3-4$ sections per kidney) at x200 magnification in a blinded fashion.

\section{Apoptosis assays}

The presence of internucleosomal DNA cleavage in kidneys was investigated with a commercial ligase-mediated (LM)-polymerase chain reaction (PCR) assay kit (Apoalert, Clontech, Palo Alto, CA) enabling semiquantitative measurement of the extent of apoptosis. In brief, DNA was isolated from tissue samples using a commercially available DNA purification kit (Promega, Madison, WI). DNA purity and concentration were determined by electrophoresis through a $0.8 \%$ agarose gel containing ethidium bromide followed by visualization under ultraviolet illumination and by measuring absorbance at 260/280 nm. Dephosphorylated adaptors were ligated to 5'-phosphorylated blunt ends with T4 DNA ligase (during 
16 hours at $16^{\circ} \mathrm{C}$ ) and served as primers in an LM-PCR. Amplified DNA was subjected to gel electrophoresis on a $1.2 \%$ agarose gel containing ethidium bromide.

\section{Measurement of renal TNF- $\alpha$, MIP-2, KC, and LIX mRNA levels by reverse transcriptase (RT)-PCR}

For RT-PCR, total RNA was extracted from kidneys using the SV Total RNA isolation system (Promega) and treated with RQ1 RNase-Free DNase (Promega). Total RNA was reverse transcribed using oligo (dT) primer and Moloney murine leukemia virus reverse transcriptase. cDNA samples were standardized based on the content of $\beta$-actin cDNA as housekeeping gene. B-actin cDNA was evaluated by performance of a $\beta$-actin PCR on multiple dilutions of each cDNA sample.

The amount of amplified product was estimated by densitometry of ethidium bromide-stained $1.2 \%$ agarose gels using a CCD camera and Imagemaster VDS software (Pharmacia, Uppsala, Sweden). Primers used for the amplification of murine $\beta$-actin were as follows: 5'-TAA AAC GCA GCT CAG TAA CAG TCG G-3' (sense primer) and 5'-TGC AAT CCT GTG GCA TCC ATG AAA C-3' (antisense primer). To determine renal TNF- $\alpha$, MIP-2, KC, and LIX mRNA expression, PCR reactions with specific primers were performed using appropriate dilutions of the cDNA. The sequences of these specific primers were as follows: TNF- $\alpha$ : 5 '-GGC AGG TCT ACT TTG GAG TCA TTG C-3' (sense) and 5'-ACA TTC GAG GCT CCA GTG AAT TCG G-3' (antisense); MIP-2: 5'-TGC CGG CTC CTC AGT GCT G-3' (sense) and 5'-AAA CTT TTT GAC CGC CCT TGA-3' (antisense); KC: 5'-CGC TCG CTT CTC TGT GCA-3' (sense) and 5'-ATT TTC TGA ACC AAG GGA GCT-3' (antisense); and LIX: 5'-TTC CTC AGT CAT AGC CGC AAC-3' (sense) and 5'-TCC GCT TAG CTT TCT TTT TGT C-3' (antisense). For each primer couple the following PCR conditions were used: TNF- $\alpha$ : $95^{\circ} \mathrm{C}$ for $30 \mathrm{sec}, 63^{\circ} \mathrm{C}$ for $30 \mathrm{sec}, 72^{\circ} \mathrm{C}$ for 30 sec during 38 cycles; MIP-2: $95^{\circ} \mathrm{C}$ for $30 \mathrm{sec}, 55^{\circ} \mathrm{C}$ for sec, $72^{\circ} \mathrm{C}$ for sec during 34 cycles; $\mathrm{KC}: 95^{\circ} \mathrm{C}$ for $30 \mathrm{sec}, 55^{\circ} \mathrm{C}$ for $30 \mathrm{sec}, 72^{\circ} \mathrm{C}$ for $30 \mathrm{sec}$ during $35 \mathrm{cycles}$; and LIX: $95^{\circ} \mathrm{C}$ for $30 \mathrm{sec}, 56^{\circ} \mathrm{C}$ for $30 \mathrm{sec}, 72^{\circ} \mathrm{C}$ for $30 \mathrm{sec}$ during 37 cycles. PCR reactions were performed in a total volume of 25 I in PCR buffer (Perkin Elmer, Boston MA), in the presence of $0.2 \mathrm{mM}$ dNTP (Pharmacia), 1.0 $\mathrm{M}$ of each primer, $0.3 \mathrm{mM} \mathrm{MgCl}$, and $0.5 \mathrm{U}$ of Taq polymerase (Perkin Elmer). After separation on $1.2 \%$ agarose gel, the amplified product was visualized using a CCD camera and Imagemaster VDS software (Pharmacia). 


\section{Chapter 2}

\section{Renal function}

Blood urea nitrogen (BUN) and serum creatinine were measured in serum obtained at the time of death using a Urea 25 Kit (ABX Diagnostics, Eindhoven, Holland) and CREA MPR3 Kit (Boehringer Mannheim, Mannheim, Germany) in a Cobas Fara autoanalyzer (Roche, Basle, Switzerland).

\section{Statistical analysis}

Data are expressed as medians with interquartile ranges. Statistical analysis was performed by the Mann-Whitney $U$ test. $P$ less than 0.05 denoted statistical significance.

\section{RESULTS}

\section{Complement activation and deposition after renal $\mathrm{I} / \mathrm{R}$}

First, we investigated whether renal $\mathrm{I} / \mathrm{R}$ leads to consumption of complement by measurement of $\mathrm{CH} 50$. The data (Table 1 ) show that total complement activity is significantly reduced at 2 hours and 12 hours of reperfusion upon renal ischemia and gradually recovered during the reperfusion period.

This led us to investigate whether renal $\mathrm{I} / \mathrm{R}$ leads to intrarenal deposition of complement factors. Deposition of C3, C6, and C9 was examined at different time points after renal I/R by immunohistochemistry. Healthy control kidneys showed faint staining for all studied complement factors along the basement membranes of tubular epithelial cells and glomeruli (Figs. 1A, 2A, and 3A). The same pattern of

Table 1. Renal I/R injury induces consumption of complement reflected by loss of $\mathrm{CH} 50^{\alpha}$

\begin{tabular}{lcccc} 
& Healthy & \multicolumn{3}{c}{ I/R } \\
\cline { 3 - 5 } & & $2 \mathrm{hr}$ & $12 \mathrm{hr}$ & $24 \mathrm{hr}$ \\
\hline CH50 (U/mL) & 209 & $81.5^{\mathrm{b}}$ & $136^{\mathrm{b}}$ & 151 \\
& $(203.8-210.5)$ & $(77.5-85.5)$ & $(121.8-146.5)$ & $(127.3-270)$ \\
\hline
\end{tabular}

$\alpha$ Sera of healthy control mice $(n=6)$ and mice subjected to renal ischemia followed by 2,12 , or $24 \mathrm{hr}$ of reperfusion ( $n=5-6$ each) were studied. Data shown are median $\mathrm{CH} 50$ with interquartile ranges between parentheses.

b $P<0.05$ versus healthy controls. 
staining was observed in ischemic kidneys without reperfusion (data not shown). After reperfusion, intense staining for C3 was observed at 2 hours and remained present during 24 hours of reperfusion (Fig. 1C and E). Intense C3 staining was localized to cellular debris and injured tubular epithelial cells. Intrarenal depositions of C6 were seen at 12 hours after reperfusion and increased over time. The deposition of C6 was primarily localized to tubular casts and injured tubular epithelium (Fig. 2C). Deposition of C9, like C6 indicative for MAC formation, was first observed after 18 hours of reperfusion and was distributed similar to C6

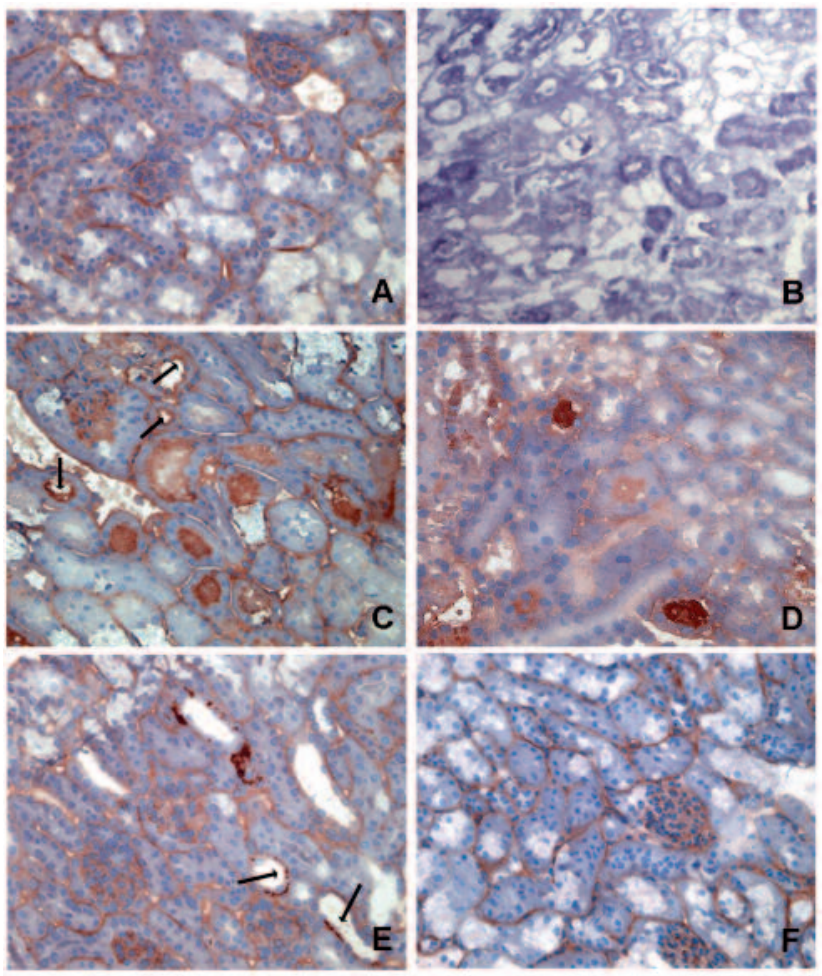

Figure 1. Treatment with BB5.1 strongly reduces C3 deposition induced by renal I/R. Healthy animals (A) showed linear staining for $\mathrm{C} 3$ at the basement membranes of tubular epithelium. After I/R, an intense staining for $\mathrm{C} 3$ localized to injured tubular epithelium (arrows) and tubular debris as shown at 2 and 24 hours of reperfusion (C and E, respectively). Anti-C5 treatment did not reduce early C3 deposition at 2 hours of reperfusion, whereas the deposition of C3 at 24 hours of reperfusion was substantially reduced (D and F). Non-specific antibody staining was negligible (B). 


\section{Chapter 2}

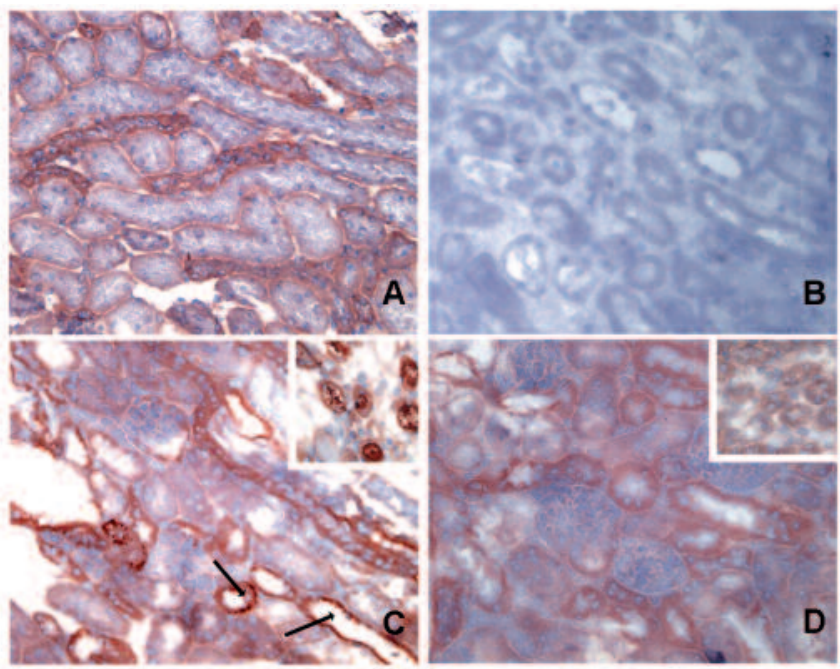

Figure 2. Ischemia followed by reperfusion leads to strong intrarenal deposition of $\mathrm{C} 6$, which is totally abrogated by BB5.1 treatment. Healthy (A) and control antibody-treated animals (data not shown) showed a linear staining for $\mathrm{C} 6$ at the basal aspect of tubular epithelium. $\mathrm{l} / \mathrm{R}$ induced intense additional staining of C6, which was localized to damaged tubular epithelium and tubular casts at 24 hours of reperfusion, as shown in cortex $(\mathrm{C})$ and medulla (C, right upper corner). Anti-C5 treatment totally prevented $\mathrm{l} / \mathrm{R}$-induced deposition of $\mathrm{C} 6$ as shown at 24 hours of reperfusion in cortex (D) and medulla ( $\mathrm{D}$, right upper corner). (B) Control antibody staining.

deposition, although more intense in tubular casts. More clear-cut deposits of C9 were detected at 24 hours of reperfusion (Fig. 3C). Control antiserum staining using kidney sections at 24 hours of reperfusion showed that non-specific antibody binding was very low for the antisera used in this study (Fig. 1B, 2B, and 3B, respectively).

\section{Inhibition of $\mathrm{C} 5$ activation prevents $\mathrm{I} / \mathrm{R}$-induced complement deposition and MAC formation}

Kidneys from BB5.1-treated animals showed complete abrogation of I/R-induced C6 and C9 deposition (Fig. 2D and 3D, respectively). The above reported faint staining seen in healthy kidneys at the tubular and glomerular epithelial was not affected. Inhibition of C5 did not reduce C3 deposition at 2 hours of reperfusion (Fig. 1D). Interestingly, at 12 and 24 hours of reperfusion, C3 deposition was substantially reduced in BB5.1-treated animals, when compared with nontreated 

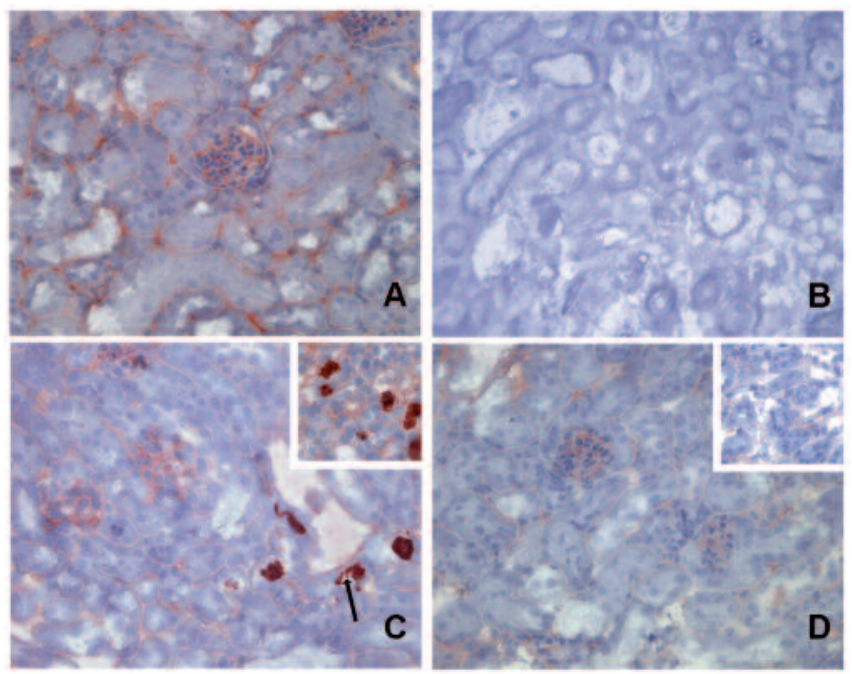

Figure 3. Renal I/R induces intense staining for $C 9$, indicating MAC formation, which is totally prevented by BB5.1 treatment. Positive staining for C9 was observed in healthy animals (A) localized to the basement membranes of the tubular epithelium and glomeruli. After ischemia, strong tubular depositions of C9 are seen at 24 hours of reperfusion, as shown in cortex (C) and medulla (C right upper corner). Although control antibody treatment did not effect C3 deposition (data not shown), BB5.1 treatment totally prevented the deposition of $C 9$ induced by $\mathrm{L} / \mathrm{R}$, as shown here at 24 hours of reperfusion: cortex (D) and medulla (D, right upper corner). Control antibody staining was negligible (B).

and control-treated animals (Fig. 1F). Taken together, inhibition of C 5 by BB5.1 did not prevent early $\mathrm{C} 3$ deposition but did reduce late $\mathrm{C} 3$ deposition and totally prevented the I/R-induced deposition of C6 and C9 and thus MAC formation.

\section{Inhibition of C5 prevents I/R-induced inflammatory response}

The renal influx of neutrophils, an important feature of $\mathrm{I} / \mathrm{R}$-induced inflammation, was assessed by immunohistochemistry. Renal $\mathrm{I} / \mathrm{R}$ induced a strong influx of neutrophils at 24 hours of reperfusion (Fig. 4B). Treatment with anti-C5 did clearly reduce the influx of neutrophils at 24 hours (Fig. 4C). To quantify the neutrophil infiltration, we counted NIMP-R14-positive cells in tissue sections $(\mathrm{n}=3-4$ per kidney) of kidneys in the control and experimental groups at 12 and 24 hours of reperfusion ( $n=4$ per group). Renal $I / R$ induced a gradual increase in neutrophil influx that was maximal at 24 hours of reperfusion (Fig. 4D). Anti-C5 treatment slightly, but significantly, reduced neutrophil influx at 12 hours and totally 


\section{Chapter 2}

abrogated further neutrophil influx at 24 hours of reperfusion (Fig. 4D). No differences in neutrophil influx were observed between control antibody and PBStreated animals $(\mathrm{P}>0.5)$.

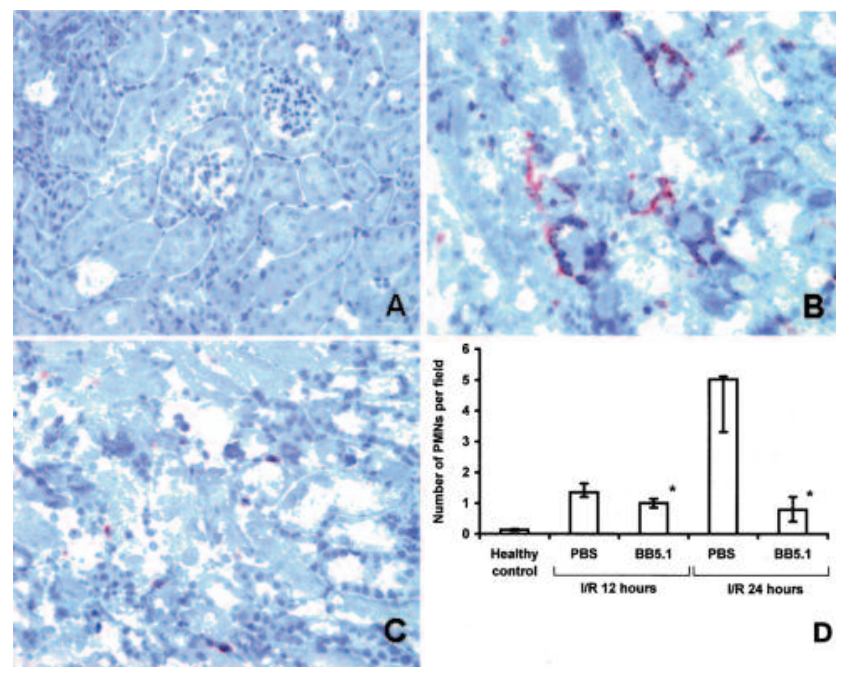

Figure 4. Renal I/R induces neutrophil influx, which is significantly reduced by inhibition of C5. Neutrophils were scarcely present in kidneys obtained from healthy or sham-operated mice (A). Ischemia followed by 24 hours of reperfusion led to a strong influx of neutrophils, mainly localized to the cortico-medullary region (B). Treatment with BB5.1 strongly reduced the influx of neutrophils at 24 hours of reperfusion (C). Neutrophils were counted (3-4 sections per kidney, 4 kidneys per group) and data are expressed as the median of number of neutrophils per field of vision with interquartile ranges (D). Statistical significance as compared with PBS-treated animals at the same time point was denoted at $\mathrm{P}<0.05\left(^{*}\right)$. Control antibody treatment did not effect neutrophil influx as compared with PBS-treated animals $(P>0.5)$. PMN, polymorphonuclear neutrophils.

Next, we investigated whether complement activation is responsible for the generation of proinflammatory cytokines involved in recruitment of inflammatory cells. We determined renal mRNA levels of TNF- $\alpha$ and of the mouse CXC chemokines KC, MIP-2, and LIX. Here, we show that the induction of MIP-2, KC, and LIX is strongly inhibited after BB5.1 treatment (Fig. 5). Typically, the inhibitory effect is most pronounced at 24 hours of reperfusion, which correlates with the inhibitory effect on neutrophil influx. In contrast, BB5.1 treatment did not effect the $\mathrm{l} / \mathrm{R}$-induced renal expression of TNF- $\alpha$ (Fig. 5). 

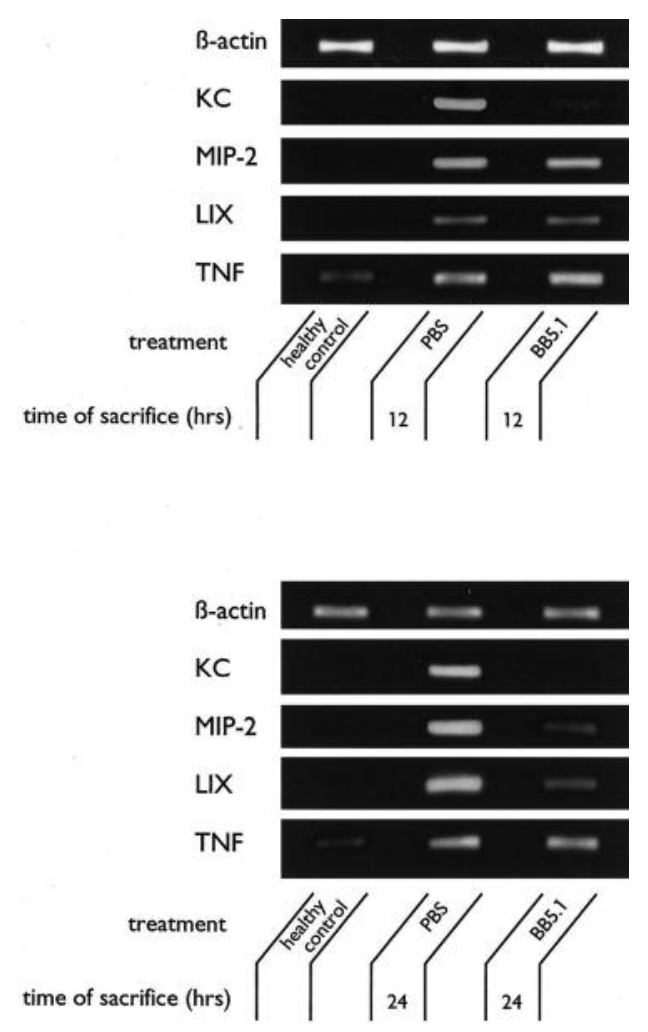

Figure 5. BB5.1 treatment inhibits I/R-induced up-regulation of KC, MIP-2, and LIX mRNA levels. Renal I/R induces a significant up-regulation of KC, MIP-2, LIX. and TNF- $\alpha$ at 12 and 24 hours (A and B, respectively). Treatment with BB5.1 strongly inhibits expression of KC at 12 hours of reperfusion, whereas at this time of reperfusion, BB5.1 had no effect on MIP-2 and LIX levels (A). At 24 hours of reperfusion, BB5.1 significantly reduced the expression of KC, MIP-2, and LIX (B). The induction of TNF- $\alpha$ was not effected by BB5.1 treatment. Shown are representative samples ( $n=3$ per group) calibrated against equal amounts of $\beta$-actin mRNA.

\section{Inhibition of C5 prevents late I/R-induced apoptosis}

Previously, we demonstrated that apoptosis plays a crucial role in renal I/R injury. Because MAC is capable of inducing apoptosis in several models of experimental nephritis, we examined whether inhibition of $\mathrm{C} 5$, which abrogates MAC formation, inhibits apoptosis. Typical DNA cleavage was detected at 2, 12, and 24 hours of reperfusion in ischemic kidneys obtained from control-treated mice. BB5.1 did not 


\section{Chapter 2}

affect apoptosis at 2 and 12 hours of reperfusion. In contrast, apoptosis was strongly inhibited at 24 hours of reperfusion compared with control-treated mice (Fig. 6). To obtain a better tissue distribution of the anti-C 5 antibody at the early phase of reperfusion, mice were pretreated with BB5.1, 2 hours before ischemia. Pretreatment also did not prevent early apoptosis (Fig. 6). Taken together, inhibition of complement factor $\mathrm{C} 5$ did not affect early apoptosis after $\mathrm{I} / \mathrm{R}$ but did prevent late apoptosis.

The inhibitory effect on late apoptosis correlated with the above-reported inhibition of MAC formation.

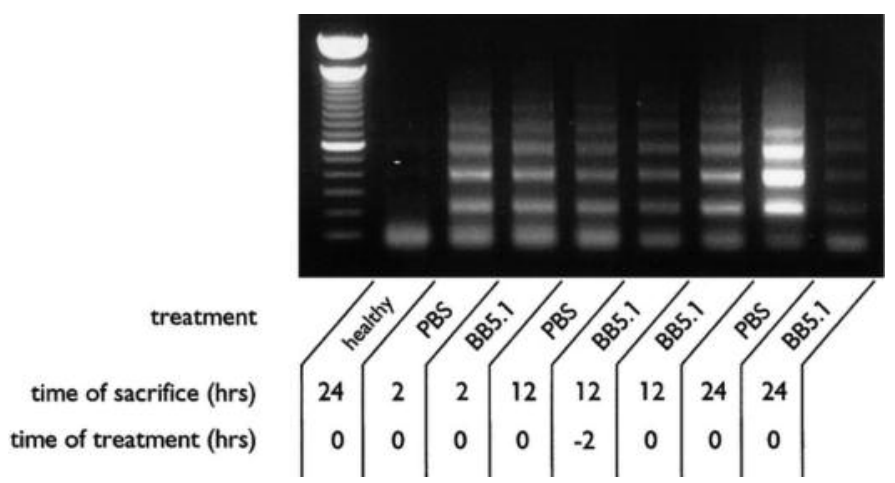

Figure 6. Anti-C5 treatment prevents late I/R-induced apoptosis. The extent of renal apoptosis was reflected by fragmented DNA amplified by LM-PCR and visualized on ethidium bromide-stained gel. In PBS-treated animals, internucleosomal DNA cleavage was evident after 2 and 12 hours and further increased after 24 hours of reperfusion. Treatment with BB5.1 or control antibody did not effect early internucleosomal DNA cleavage, whereas late apoptosis was totally prevented by BB5.1. Data shown are representative of three independent assays on different renal samples ( $\mathrm{n}=3$ per group). Lane 1, 100-base pair molecular weight marker.

\section{Inhibition of C5 prevents I/R-induced renal dysfunction}

Next, we investigated whether inhibition of $\mathrm{C} 5$, which prevents MAC formation in addition to $\mathrm{C} 5 \mathrm{a}$ generation and which abrogates late apoptosis and inflammation, is accompanied by improvement of organ function. Therefore, we determined renal function by measurement of serum creatinine and BUN 24 hours upon reperfusion. Compared with PBS or control antibody-treated animals, treatment with BB5.1 during ischemia significantly reduced creatinine and BUN content. No difference was observed between PBS and control antibody-treated animals $(\mathrm{P}=0.53$ for serum creatinine and $\mathrm{P}=0.41$ for $\mathrm{BUN})$. The control-treated group showed a 
median creatinine of $391.3 \mathrm{~mol} / \mathrm{L}$ and $\mathrm{BUN}$ of $64.5 \mathrm{mmol} / \mathrm{L}$, which were strongly reduced by BB5.1 treatment to $157.5 \mathrm{~mol} / \mathrm{L}$ and $21.9 \mathrm{mmol} / \mathrm{L}$, respectively $(\mathrm{P}<$ 0.05) (Fig. 7).
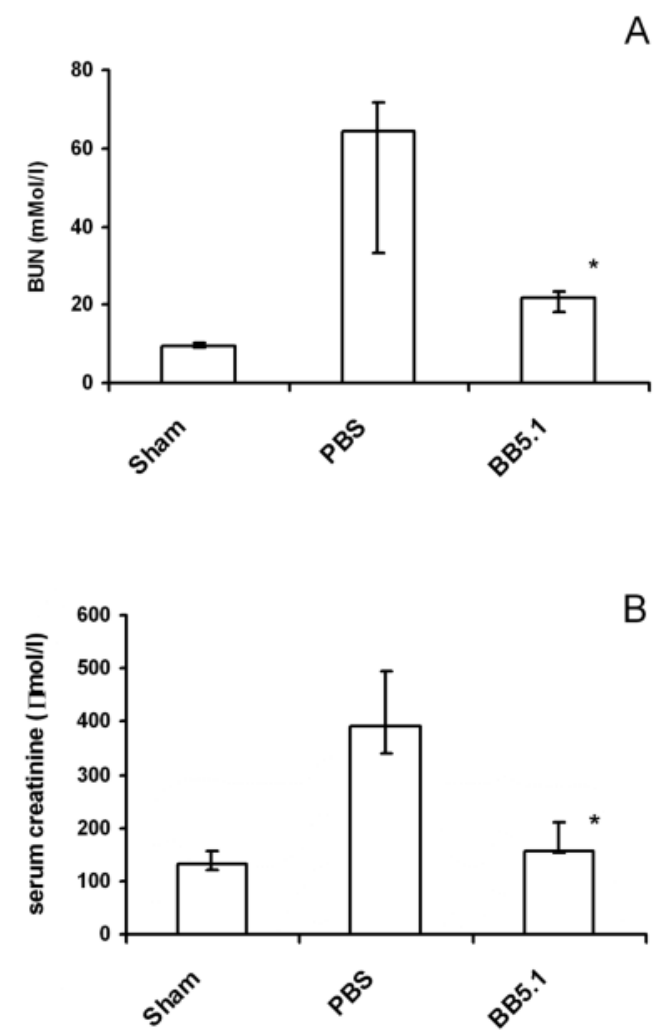

Figure 7. Renal function after 24 hours in the different experimental groups as reflected by BUN (A) and serum creatinine (B). Statistical significance as compared with control-treated animals was denoted at $P<0.05\left(^{*}\right)$. Renal function did not differ between control antibody-treated and PBS-treated animals ( $P=0.41$ for BUN and $\mathrm{P}=0.53$ for serum creatinine). The data shown are medians with interquartile ranges.

\section{Discussion}

In this study, we investigated the involvement of complement activation in renal I/R. In line with others, the presence of complement factors in healthy kidneys was localized to basement membranes of tubular and glomerular epithelium. ${ }^{29}$ In our 


\section{Chapter 2}

model, deposition of C3 occurred early after reperfusion and was localized to cellular debris and injured tubular epithelial cells. These data are supported by studies showing C3 deposition in rodent kidney after $\mathrm{I} / \mathrm{R}$ and in infarcted human kidney. ${ }^{12,15,29}$ For the first time, we show that renal I/R leads to strong deposition of $\mathrm{C} 6$ and $\mathrm{C} 9$, representing MAC formation. Interestingly, intrarenal deposition of C6 and C9 has previously been reported in old infarcted areas of human postmortem kidneys. ${ }^{29}$ Compared with cardiac and intestinal ischemia, complement deposition occurred relatively late in our murine model of renal $\mathrm{I} / \mathrm{R}$ injury. We observed no MAC formation before 12 hours of reperfusion. In contrast, in a rat model of myocardial ischemia, MAC formation was present as early as 3 hours after induction of ischemia. ${ }^{14}$ After intestinal ischemia in a rat model, MAC formation also was seen early, at 1 hour of reperfusion. ${ }^{16}$ These differences may be explained by the fact that in renal $\mathrm{I} / \mathrm{R}$ injury, the primary target for complement attack is not the endothelium, as reported for intestinal and especially cardiac ischemia, but rather the renal parenchyma. Proximal tubular epithelial cells, in particular, express relatively low amounts of complement regulatory proteins such as CD46, CD55, and CD59, making these cells potentially susceptible to complement attack. ${ }^{30}$ This fits well with our observations that formation of the MAC is mainly localized to the tubular epithelium.

The MAC has been reported to mediate neutrophil influx and to induce apoptosis and necrosis. ${ }^{19-21}$ Experiments with complement-deficient $\left(\mathrm{C}^{-/}\right)$animals indicated that the MAC is essentially involved in the development of renal disease such as I/R injury and experimental glomerulonephritis. ${ }^{12,23-25}$ Our data show that renal MAC formation can be pharmacologically prevented by inhibition of C5 activation. Administration of the anti-murine C5 mAb BB5.1 totally abrogated I/Rinduced renal deposition of C6 and C9. Inhibition of the complement system at the level of complement factor $\mathrm{C} 5$ in rat models of myocardial and intestinal I/R injury indicated that inhibition of $\mathrm{C} 5$ is protective against organ damage upon reperfusion. ${ }^{13,16}$ Interestingly, inhibition of $\mathrm{C} 5$ in our renal model of $\mathrm{I} / \mathrm{R}$ injury also prevented extensive deposition of C3. As far as we know, no direct feedback mechanism between $\mathrm{C} 5$ and $\mathrm{C} 3$ activation has been described. However, inhibition of the formation of $\mathrm{C} 5 \mathrm{a}$ and MAC could well have reduced secondary cellular damage and inflammation. This may subsequently prevent ongoing C3 deposition. The pathways that activate the complement system in the course of renal I/R injury remain to be elucidated. In myocardial $I / R$ models, recent work indicates that the mannose-binding lectin and the classical activation pathways are crucially involved 
in $\mathrm{I} / \mathrm{R}$ injury. ${ }^{31,32}$ Others showed that C4-deficient mice, in contrast to C3-deficient mice, are not protected against $I / R$ injury, indicating the involvement of the alternative pathway. ${ }^{12}$ Influx of neutrophils is an important aspect of renal $\mathrm{I} / \mathrm{R}$ injury. ${ }^{6,8,11}$ In this study, administration of the anti-C5 mAb significantly inhibited the influx of neutrophils after $\mathrm{I} / \mathrm{R}$, starting at 12 hours of reperfusion, totally abrogating the infiltration of neutrophils between 12 and 24 hours of reperfusion. These data indicate that activation of $\mathrm{C} 5$ is central to the influx of neutrophils. Activation of $\mathrm{C} 5$ results in the formation of $\mathrm{C} 5 \mathrm{a}$ and $\mathrm{C} 5 \mathrm{~b}$, the latter being the first step in MAC formation. Both $\mathrm{C} 5 \mathrm{a}$ and MAC have been reported to be involved in the induction of cytokines and chemokines, such as TNF- $\alpha, K C$, and MIP-2, which are known to be up-regulated in $\mathrm{I} / \mathrm{R}$ injury. As a potent chemotactic factor, C5a may also directly mediate neutrophil influx upon I/R injury. Recently, KC and MIP-2 have been shown to be functionally involved in $\mathrm{l} / \mathrm{R}$-induced neutrophil influx, ${ }^{11}$ whereas Chandrasekar et al. ${ }^{10}$ showed that in myocardial I/R the recruitment of neutrophils is largely dependent on LIX rather than KC and MIP-2. Here, we show for the first time that the induction of chemokines upon renal $\mathrm{I} / \mathrm{R}$ is largely dependent on complement activation, because inhibition of the complement system using anti-C5 strongly inhibits the induction of the chemokines LIX, KC, and MIP-2. Moreover, this article is the first to describe the induction of LIX after renal I/R. The contribution of these different chemokines to neutrophil influx in the course of renal $I / R$ remains to be elucidated. Interestingly, anti-C5 treatment did not effect the I/R induced upregulation of TNF- $\alpha$, in contrast to the work of Wada et al. ${ }^{16}$ who showed that inhibition of C5 significantly inhibited local TNF- $\alpha$ expression after intestinal $\mathrm{I} / \mathrm{R}$ injury. This may be explained by the fact that local TNF- $\alpha$ expression is an early feature of renal I/R injury, already occurring during ischemia and early reperfusion, probably induced by oxygen free radicals and less dependent on complement activation. ${ }^{9}$ We have previously reported that apoptosis in the later phase of reperfusion (18-24 hours) is strongly associated with inflammation and loss of renal function. ${ }^{7} \mathrm{C} 5 \mathrm{a}$ and $\mathrm{MAC}$ are potentially involved in the induction of apoptosis in the course of renal I/R. C5a is capable of inducing apoptosis in thymocytes and neuroblastoma cells. ${ }^{33,34}$ Moreover $\mathrm{C} 5 \mathrm{a}$-activated neutrophils and their products may cause epithelial apoptosis. ${ }^{35,36}$ In vitro, the MAC can also directly induce apoptosis. ${ }^{21,22}$ Indeed, recent studies in experimental glomerulonephritis have shown that the MAC is essentially involved in apoptosis of mesangial cells and glomerular endothelial cells. ${ }^{23-25}$ Our data show that inhibition of C5 totally 


\section{Chapter 2}

abrogated the occurrence of late apoptosis after renal I/R. Which mechanism underlies complement-mediated apoptosis and which cells die by apoptosis after complement attack upon renal I/R remains to be resolved. In contrast to our data, complement inhibition using the rodent C3-convertase inhibitor Crry-lg was not protective in murine renal $I / R$, which suggested that the complement system is not essentially involved in renal $I / R$ injury. ${ }^{37}$ The model used in this elegant study is characterized by a very short duration of renal ischemia (20 - 30 minutes) compared with studies of Zhou et al. ${ }^{12}$ and our study, which show the involvement of the complement system in renal $\mathrm{I} / \mathrm{R}$ injury. This could indicate that such a relatively mild ischemic insult does not lead to complement-dependent injury. ${ }^{37}$

\section{Conclusion}

Renal I/R induces complement activation and intrarenal deposition of MAC. Anti$\mathrm{C} 5$ treatment, preventing MAC formation and $\mathrm{C} 5 \mathrm{a}$ generation, abrogates late apoptosis and strongly reduces chemokine induction and neutrophil influx. These data show that complement activation is crucially involved in the regulation of both apoptosis and inflammation in the course of renal I/R injury. Moreover, complement inhibition is strongly protective against the development of renal failure upon $\mathrm{l} / \mathrm{R}$ injury.

\section{REFERENCES}

1. Daemen MA, van 't Veer C, Denecker G, et al. Inhibition of apoptosis induced by ischemiareperfusion prevents inflammation. J Clin Invest 1999; 104(5): 541.

2. Yaoita H, Ogawa K, Maehara K, et al. Attenuation of ischemia/reperfusion injury in rats by a caspase inhibitor. Circulation 1998; 97(3): 276.

3. Endres H, Namura S, Skimizu-Sasamata M, et al. Attenuation of delayed neuronal death after mild focal ischemia in mice by inhibition of the caspase family. J Cereb Blood Flow Metab 1998; 18(3): 238.

4. Ikeda H, Suzuki Y, Suzuki M, et al. Apoptosis is a major mode of cell death caused by ischaemia and ischaemia/reperfusion injury to the rat intestinal epithelium. Gut 1998; 42(4): 530.

5. Cursio R, Gugenheim J, Ricci JE, et al. A caspase inhibitor fully protects rats against lethal normothermic liver ischemia by inhibition of liver apoptosis. FASEB J 1999; 13(2): 253. 
6. Heinzelmann M, Mercer JM, Passmore JC. Neutrophils and renal failure. Am J Kidney Dis 1999; 34(2): 384.

7. Daemen MA, van de Ven MW, Heineman E, et al. Involvement of endogenous interleukin10 and tumor necrosis factor-alpha in renal ischemiareperfusion injury. Transplantation 1999; 67(6): 792.

8. De Greef KE, Ysebaert DK, Ghielli M, et al. Neutrophils and acute ischemia-reperfusion injury. J Nephrol 1998; 11(3): 110.

9. Donnahoo KK, Meng X, Ayala A, Cain MP, Harken AH, Meldrum DR. Early kidney TNFalpha expression mediates neutrophil infiltration and injury after renal ischemiareperfusion. Am J Physiol 1999; 277: R922.

10. Chandrasekar B, Smith JB, Freeman GL. Ischemia-reperfusion of rat myocardium activates nuclear factor-KappaB and induces neutrophil infiltration via lipopolysaccharide-induced CXC chemokine. Circulation 2001; 103(18): 2296.

11. Miura M, Fu X, Zhang QW, et al. Neutralization of gro-alpha and macrophage inflammatory protein-2 attenuates renal ischemia/reperfusion injury. Am J Pathol 2001; 159(6): 2137.

12. Zhou W, Farrar CA, Abe K, et al. Predominant role for C5b-9 in renal ischemia/reperfusion injury. J Clin Invest 2000; 105(10): 1363.

13. Vakeva AP, Agah A, Rollins SA, et al. Myocardial infarction and apoptosis after myocardial ischemia and reperfusion: role of the terminal complement components and inhibition by anti-C5 therapy. Circulation 1998; 97(22): 2259.

14. Vakeva A, Morgan BP, Tikkanen I, et al. Time course of complement activation and inhibitor expression after ischemic injury of rat myocardium. Am J Pathol 1994; 144(6): 1357.

15. Stein JH, Osgood RW, Barnes JL, et al. The role of complement in the pathogenesis of postischemic acute renal failure. Miner Electrolyte Metab 1985; 11(4): 256.

16. Wada K, Montalto MC, Stahl GL. Inhibition of complement C5 reduces local and remote organ injury after intestinal ischemia/reperfusion in the rat. Gastroenterology 2001; 120(1): 126.

17. Czermak BJ, Sarma V, Bless NM, et al. In vitro and in vivo dependency of chemokine generation on C5a and TNF-alpha. J Immunol 1999; 162(4): 2321.

18. Ivey $\mathrm{CL}$, Williams FM, Collins PD, et al. Neutrophil chemoattractants generated in two phases during reperfusion of ischemic myocardium in the rabbit: evidence for a role for C5a and interleukin-8. J Clin Invest 1995; 95(6): 2720.

19. David S, Biancone L, Caserta C, et al. Alternative pathway complement activation induces proinflammatory activity in human proximal tubular epithelial cells. Nephrol Dial Transplant 1997; 12(1): 51. 


\section{Chapter 2}

20. Kilgore KS, Flory CM, Miller BF, et al. The membrane attack complex of complement induces interleukin-8 and monocyte chemoattractant protein-1 secretion from human umbilical vein endothelial cells. Am J Pathol 1996; 149(3): 953.

21. Cragg MS, Howatt WJ, Bloodworth L, et al. Complement mediated cell death is associated with DNA fragmentation. Cell Death Differ 2000; 7(1): 48.

22. Nauta AJ, Daha MR, Tijsma O, et al. The membrane attack complex of complement induces caspase activation and apoptosis. Eur J Immunol 2002; 32(3): 783.

23. Hughes J, Nangaku M, Alpers CE, et al. C5b-9 membrane attack complex mediates endothelial cell apoptosis in experimental glomerulonephritis. Am J Physiol 2000; 278(5): F747.

24. Sato T, Van Dixhoorn MG, Prins FA, et al. The terminal sequence of complement plays an essential role in antibody-mediated renal cell apoptosis. J Am Soc Nephrol 1999; 10(6): 1242.

25. Shimizu A, Masuda Y, Kitamura $\mathrm{H}$, et al. Complement-mediated killing of mesangial cells in experimental glomerulonephritis: cell death by a combination of apoptosis and necrosis. Nephron 2000; 86(2): 152.

26. Frei Y, Lambris JD, Stockinger B. Generation of a monoclonal antibody to mouse C5 application in an ELISA assay for detection of anti-C5 antibodies. Mol Cell Probes 1987; 1(2): 141.

27. Wang Y, Rollins SA, Madri JA, et al. Anti-C5 monoclonal antibody therapy prevents collagen-induced arthritis and ameliorates established disease. Proc Natl Acad Sci USA 1995; 92(19): 8955.

28. Klerx JP, Beukelman CJ, Van Dijk H, et al. Microassay for colorimetric estimation of complement activity in guinea pig, human and mouse serum. J Immunol Methods 1983; 63(2): 215.

29. Vakeva A, Meri S, Lehto T, et al. Activation of the terminal complement cascade in renal infarction. Kidney Int 1995; 47(3): 918.

30. Ichida S, Yuzawa $\mathrm{Y}$, Okada $\mathrm{H}$, et al. Localization of the complement regulatory proteins in the normal human kidney. Kidney Int 1994; 46(1): 89.

31. Jordan JE, Montalto MC, Stahl GL. Inhibition of mannose-binding lectin reduces postischemic myocardial reperfusion injury. Circulation 2001; 104(12): 1413.

32. Buerke M, Schwertz H, Seitz W, et al. Novel small molecule inhibitor of c1s exerts cardioprotective effects in ischemia-reperfusion injury in rabbits. J Immunol 2001; 167(9): 5375.

33. Guo RF, Huber-Lang M, Wang $X$, et al. Protective effects of anti-C5a in sepsis-induced thymocyte apoptosis. J Clin Invest 2000; 106(10): 1271. 
34. Farkas I, Baranyi L, Liposits ZS, et al. Complement C5a anaphylatoxin fragment causes apoptosis in TGW neuroblastoma cells. Neuroscience 1998; 86(3): 903.

35. Serrao KL, Fortenberry JD, Owens ML, et al. Neutrophils induce apoptosis of lung epithelial cells via release of soluble Fas ligand. Am J Physiol 2001; 280(2): L298.

36. Yang J, Preston GA, Pendergraft WF, et al. Internalization of proteinase 3 is concomitant with endothelial cell apoptosis and internalization of myeloperoxidase with generation of intracellular oxidants. Am J Pathol 2001; 158(2): 581.

37. Park P, Haas M, Cunningham PN, et al. Inhibiting the complement system does not reduce injury in renal ischemia reperfusion. J Am Soc Nephrol 2001; 12(7): 1383. 


\section{Chapter 2.4}

\section{Lysophosphatidic acid prevents renal ischemia-reperfusion injury by inhibition of apoptosis and complement activation.}

Bart de Vries, Robert A. Matthijsen, Annemarie A.J.H.M. van Bijnen, Tim G.A.M. Wolfs, and Wim A. Buurman

American Journal of Pathology. 2003, 163: 47-56. 


\section{Abstract}

Renal ischemia-reperfusion $(\mathrm{I} / \mathrm{R})$ injury is an important cause of acute renal failure as observed after renal transplantation, major surgery, trauma, and septic as well as hemorrhagic shock. We previously showed that the inhibition of apoptosis is protective against renal $\mathrm{I} / \mathrm{R}$ injury, indicating that apoptotic cell death is an important feature of $\mathrm{I} / \mathrm{R}$ injury. Lysophosphatidic acid (LPA) is an endogenous phospholipids growth factor with anti-apoptotic properties. This tempted us to investigate the effects of exogenous LPA in a murine model of renal I/R injury. LPA administered at the time of reperfusion dose dependently inhibited renal apoptosis as evaluated by the presence of internucleosomal DNA cleavage. I/R-induced renal apoptosis was only present in tubular epithelial cells with evident disruption of brush border as assessed by immunohistochemistry for active caspase-7 and filamentous actin, respectively. LPA treatment specifically prevented tubular epithelial cell apoptosis but also reduced the I/R-induced loss of brushborder integrity. Besides, LPA showed strong anti-inflammatory effects, inhibiting the renal expression of tumor necrosis factor- $\alpha$ and abrogating the influx of neutrophils. Next, LPA dose dependently inhibited activation of the complement system. Moreover, treatment with LPA abrogated the loss of renal function in the course of renal $\mathrm{I} / \mathrm{R}$. This study is the first to show that administration of the phospholipid LPA prevents I/R injury, abrogating apoptosis and inflammation. Moreover, exogenous LPA is capable of preventing organ failure because of an ischemic insult and thus may provide new means to treat clinical conditions associated with $I / R$ injury in the kidney and potentially also in other organs.

\section{INTRODUCTION}

Post ischemic organ failure of organs such as the heart, brain, and kidneys represents a major problem in clinical medicine. Acute renal failure because of ischemia-reperfusion $(I / R)$ injury is observed after transplantation and as a major complication in cardiac and vascular surgery, septic as well as hypovolemic shock, and trauma. ${ }^{1}$ Ischemia directly induces cellular injury, which is aggravated by reperfusion. ${ }^{2}$ In the setting of I/R injury cellular damage will, if severe enough, lead to cell death that may be apoptotic as well as necrotic. ${ }^{3}$ Both apoptosis and necrosis have been implicated in the induction of inflammation in the course of 


\section{Chapter 2}

$\mathrm{I} / \mathrm{R}$, an important cause of tissue injury induced by renal I/R. ${ }^{4}$ This inflammatory response is characterized by activation of the complement system, induction of cytokines and chemokines, and subsequent influx of neutrophils. ${ }^{2,4}$ Previously, we showed that early apoptosis is essentially involved in the initiation of this inflammatory reaction and moreover that inhibition of apoptosis protects against $\mathrm{I} / \mathrm{R}$ injury. ${ }^{5,6}$ On the other hand, inflammation has been shown to be involved in the regulation of apoptotic cell-death in several models of renal inflammation.-11

Growth and survival factors, such as insulin-like growth factor-1, fibroblast growth factor, and hepatocyte growth factor have been shown to prevent apoptosis, inflammation, and to protect against renal $\mathrm{I} / \mathrm{R}$ injury. ${ }^{5,12}$ Lysophosphatidic acid (LPA) is a member of the phospholipids growth factor family, having pleiotropic effects such as enhancement of cell survival and cell proliferation. LPA is normally present in serum, binding with high affinity to albumin, in concentrations ranging between 5 to $20 \mathrm{~mol} / \mathrm{L} .{ }^{13}$ LPA signals via the G-protein-coupled receptors LPA1, LPA2, and LPA3.$^{14}$ All LPA receptors have been found to be localized among others in renal tissue. ${ }^{14,15}$ In vitro, LPA has been shown to function as a growth and survival factor for renal proximal tubular cells, inhibiting apoptosis induced by growth factor deprivation. ${ }^{16}$ The aim of this study was to characterize the in vivo effects of exogenous LPA in a renal I/R model, with special emphasis on the influence of LPA on I/R-induced apoptosis. Furthermore, we aimed to study the effects of LPA on the inflammatory response in the course of renal $I / R$, in particular the activation of the complement system, the induction of chemokines, cytokines, and the influx of neutrophils.

\section{Materials and Methods}

\section{Antibodies and reagents}

Lysophosphatidic acid (1-oleoyl-2-hydroxy-sn-glycero-3-phosphate) was purchased from Avanti Polar Lipids (Alabaster, AL), polyclonal rabbit anti-active caspase-7 antibody was from Biovision (Mountain View, CA), and Texas Redphalloidin was from Molecular Probes (Eugene, OR). Rabbit anti-mouse C6 was kindly provided by Dr. N. R. Cooper (Scripps Research Institute, La Jolla, CA), rabbit anti-rat C9 was a kind gift from Dr. B. P. Morgan (University of Wales College of Medicine, Cardiff, UK), and goat anti-mouse C3 was purchased from Cappel (ICN Biomedicals, Aurora, OH). NIMP-R14 (rat anti mouse neutrophil monoclonal 
antibody) was kindly provided by Dr. M. Strath (National Institute for Medical Research, London, UK). Secondary antibodies, peroxidase-conjugated rabbit antigoat, goat anti-rabbit, and goat anti-rat IgG as well as fluorescein isothiocyanate labelled goat anti-rabbit IgG were purchased from Jackson (West Grove, PA). All other reagents were purchased from Sigma (St. Louis, MO).

\section{Experimental protocol}

Male Swiss mice weighing 25 to $30 \mathrm{~g}$ were obtained from Charles River Breeding Laboratories (Heidelberg, Germany). Animals were housed individually in standard laboratory cages and were allowed free access to food and water. The studies were performed under a protocol approved by the Institutional Animal Care Committee of the University of Maastricht. At the start of the experiments, mice were anesthetized with sodium pentobarbital $(100 \mathrm{mg} / \mathrm{kg}$ i.p.). Body temperature was maintained at $38^{\circ} \mathrm{C}$ by a heating pad until animals recovered from anesthesia. Under aseptic conditions a $1.0-\mathrm{cm}$-long midline abdominal incision was made and ischemia was induced by applying a nontraumatic vascular clamp to the left renal pedicle for 45 minutes. After removal of the clamp the contralateral kidney was removed and the wound was closed in two layers. The animals were sacrificed 24 hours after reperfusion. At the time of sacrifice, blood was collected and the left kidney was harvested for analysis. During ischemia, just before reperfusion, mice were administered $0.01,0.1,1$, or $2 \mathrm{mg}$ of LPA (intraperitoneally) dissolved in $1.0 \mathrm{ml}$ of phosphate-buffered saline (PBS) ( $\mathrm{n}=$ 6 per group). The control group was treated with vehicle consisting of $1.0 \mathrm{ml}$ of PBS intraperitoneally $(n=6)$.

\section{Renal histology}

Cryostat sections $(5 \mathrm{~m}$ ) of frozen tissue were cut and double-stained for active caspase-7 and filamentous actin (F-actin). Briefly, slides were dried, fixed in acetone for 10 minutes, and air-dried. Slides were immersed in PBS for 5 minutes and subsequently in 5\% normal goat serum in PBS to block aspecific antibody binding. Slides were stained for 1 hour at room temperature with the anti-active caspase-7 primary antibody in PBS with $0.1 \%$ bovine serum albumin. After three washes in PBS with $0.1 \%$ Tween for 5 minutes each, slides were incubated for 30 minutes with the fluorescein isothiocyanate-labelled secondary antibody diluted in the same buffer with the addition of Texas Red-phalloidin that specifically binds to F-actin. After three 


\section{Chapter 2}

washes in PBS-Tween, the slides were mounted using glycerol-PBS with 1,4diazabicyclo (2,2,2)octane and 4,6-diamidino(2)phenylindole, and viewed with an immunofluorescence microscope. No significant staining was detected in slides incubated with control serum instead of the primary antibody indicating the absence of significant background staining. The number of caspase-7-positive tubules was quantified by counting 20 fields of vision per kidney section (three sections per kidney, four kidneys per group) at x200 magnification in a blinded manner. Cryostat sections (5 m) of frozen tissue were stained for complement factors C3, C6, and C9. Briefly, slides were dried and fixed in acetone. Slides were immersed in Tris-buffered saline (TBS) for 5 minutes, in $0.03 \% \mathrm{H} 2 \mathrm{O} 2$ in TBS for 30 minutes at room temperature to eliminate endogenous peroxidase activity, and in 5\% normal goat or rabbit serum (depending on the antibodies used) in TBS to block aspecific antibody binding. Subsequently, slides were stained for 1 hour at room temperature with primary antibodies in TBS with $0.1 \%$ bovine serum albumin. After three washes in TBS with $0.1 \%$ Tween (TTBS) for 5 minutes each, slides were incubated for 30 minutes with appropriate peroxidase-labelled secondary antibodies diluted in the same buffer. After three washes in TTBS staining was visualized by 3-amino-9-ethylcarbazole followed by haematoxylin counterstain. Finally, the slides were coverslipped and viewed with a light microscope. No significant staining was detected in slides incubated with control sera instead of the primary antibody indicating the absence of significant background staining. Staining for neutrophils was performed with monoclonal antibody NIMP-R14 as described above. Neutrophils were counted by examining 10 fields of vision per kidney section (three to four sections per kidney, four kidneys per group) at $\times 200$ magnification in a blinded manner.

\section{Apoptosis assay}

Presence of internucleosomal DNA cleavage in kidneys was investigated with a commercial ligase-mediated polymerase chain reaction (PCR) assay kit (Apoalert; Clontech, Palo Alto, CA) enabling semiquantitative measurement of the extent of apoptosis. In brief, DNA was isolated from tissue samples using a commercially available DNA purification kit (Promega, Madison, WI). DNA purity and concentration were determined by electrophoresis through a $0.8 \%$ agarose gel containing ethidium bromide followed by visualization under ultraviolet illumination as well as by measuring absorbance at $260 / 280 \mathrm{~nm}$. Dephosphorylated adaptors were ligated to 5'-phosphorylated blunt ends with T4 DNA ligase (during 16 hours at 
$16^{\circ} \mathrm{C}$ ) and served as primers in a ligase-mediated PCR. Amplified DNA was subjected to gel electrophoresis on a $1.2 \%$ agarose gel containing ethidium bromide.

\section{Measurement of renal KC, MIP-2, and tumor necrosis factor (TNF)- $\alpha$ mRNA levels by reverse transcriptase-PCR}

For reverse transcriptase-PCR total RNA was extracted from kidneys using the SV Total RNA isolation system (Promega) and treated with RQ1 RNase-Free DNase (Promega). Total RNA was reverse-transcribed using oligo (dT) primer and Moloney murine leukemia virus reverse transcriptase (Life Technologies, Paisley, UK). For semiquantitative PCR analysis cDNA samples were standardized based on the content of $\beta$-actin cDNA as housekeeping gene. ß-actin cDNA was evaluated by performance of a $\beta$-actin PCR on multiple dilutions of each cDNA sample. The amount of amplified product was estimated by densitometry of ethidiumbromide stained $1.2 \%$ agarose gels using a charge-coupled device camera and Imagemaster VDS software (Pharmacia, Uppsala, Sweden). To determine renal KC and MIP-2 mRNA expression, PCR reactions with specific primers were performed using appropriate dilutions of the cDNA. Primers used for $\beta$-actin, KC, and MIP-2 PCR have been described in detail previously. ${ }^{6}$ Real-time quantitative reverse transcriptase-PCR for TNF- $\alpha$ was performed on a TaqMan ABI 7700 sequence detection system (Applied Biosystems, Foster City, CA). ß-actin was used as reference gene. The following oligonucleotide primers and probes were used: $\beta$ actin, 5' - GAC AGG ATG CAG AAG GAG ATT ACT G-3' (sense) and 5'-CCA CCG ATC CAC ACA GAG TAC TT-3' (antisense) both at a concentration of $300 \mathrm{nmol} / \mathrm{L}$, and internal fluorescence-labelled probe (JOE) 5'-ATC AAG ATC ATT GCT CCT CCT GAG CGC-3' at a concentration of $200 \mathrm{nmol} / \mathrm{L} ; \mathrm{TNF}-\alpha, 5^{\prime}$-CAT CTT CTC AAA ATT CGA GTG ACA A-3' (sense) and 5'-TGG GAG TAG ACA AGG TAC AAC CC-3' (anti-sense) both at a concentration of $200 \mathrm{nmol} / \mathrm{L}$, and internal fluorescencelabelled probe (FAM) 5'-CAC GTC GTA GCA AAC CAC CAA GTG GA-3' at a concentration of $100 \mathrm{nmol} / \mathrm{L}$. All primers and probes were obtained from Applied Biosystems.

\section{Renal function}

Blood urea nitrogen (BUN) was measured in serum obtained the time of sacrifice using a Urea 25 Kit (ABX Diagnostics, Eindhoven, Holland) in a Cobas Fara autoanalyzer (Roche, Basle, Switzerland). 


\section{Chapter 2}

\section{Statistical analysis}

Data are expressed as the mean $( \pm$ SEM), and statistical analysis was performed by Mann-Whitney $\mathrm{U}$-test. $\mathrm{P}<0.05$ was taken to denote statistical significance.

\section{ResULTS}

LPA Protects against Renal Dysfunction after Renal I/R Renal $I / R$ injury is characterized by loss of renal function. Renal function loss was measured by serum $B U N$. Mice treated with LPA showed a dose-dependent reduction in BUN values compared to control-treated animals.

A dose of $0.01 \mathrm{mg}$ of LPA already significantly reduced BUN levels [25.9 $\mathrm{mmol} / \mathrm{L}$ for LPA $(0.01 \mathrm{mg}$ ) versus $43.3 \mathrm{mmol} / \mathrm{L}$ for control PBS treatment, $\mathrm{P}<0.05]$, whereas higher doses of LPA dose dependently protected against renal function loss [15.7 mmol/L for LPA $(0.1 \mathrm{mg})$ and $10.4 \mathrm{mmol} / \mathrm{L}$ for LPA $(1 \mathrm{mg}), \mathrm{P}<0.01]$. Higher doses of LPA ( $2 \mathrm{mg}$ ) had no additional protective effects, thus at $1 \mathrm{mg}$ of LPA a plateau was reached regarding prevention of $\mathrm{I} / \mathrm{R}$-induced renal function loss (Figure 1). These data show that LPA is strongly protective against renal failure in the course of renal I/R injury.

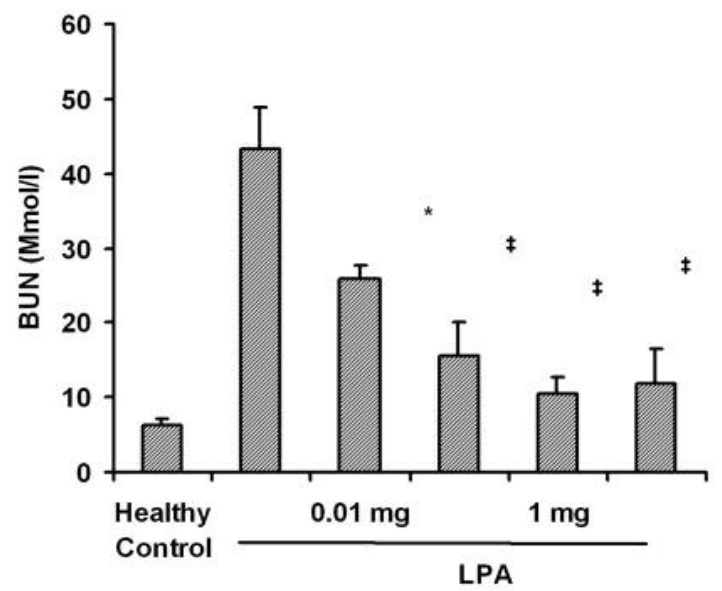

Figure 1. LPA dose dependently reduces loss of renal function after renal I/R. Compared to controltreated animals LPA significantly reduced BUN values as measured 24 hours after renal I/R. Statistical significance as compared to control-treated animals was denoted at $\mathrm{P}<0.05\left(^{*}\right)$ or $\mathrm{P}<0.01$ (*). The $^{\circ}$ data shown are means $( \pm$ SEM). 


\section{LPA prevents I/R-induced apoptosis in the course of renal I/R}

In vitro, LPA is known to have anti-apoptotic properties. This tempted us to study the effects of LPA in vivo on I/R-induced apoptosis, especially because apoptotic cell death has been shown to play a major role in renal $\mathrm{I} / \mathrm{R}$ injury. Here, we show that LPA is capable of inhibiting apoptosis in vivo (Figure 2). Compared to control-treated

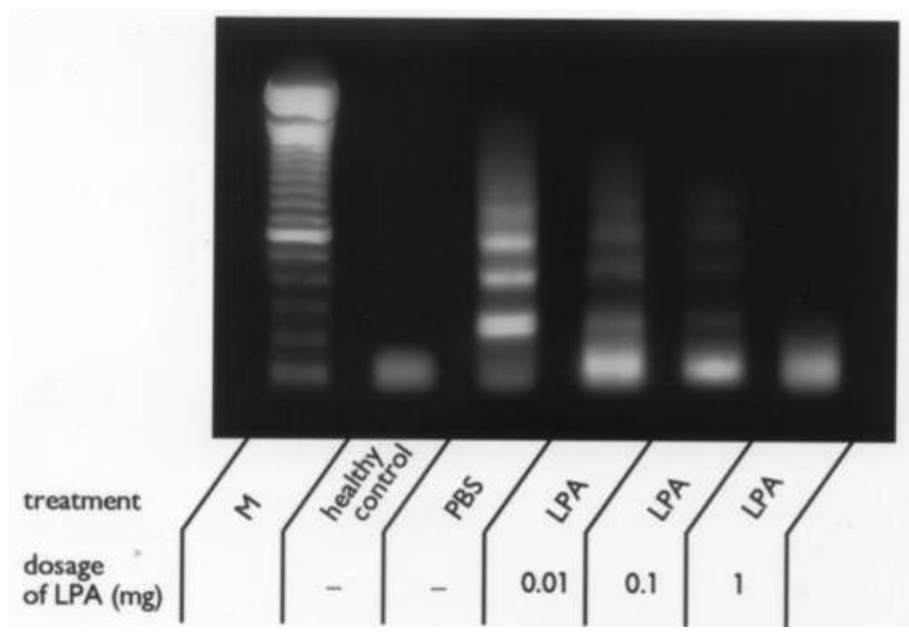

Figure 2. LPA treatment prevents I/R-induced apoptosis. The extent of renal apoptosis was reflected by fragmented DNA amplified by ligase-mediated PCR and visualized on ethidium-bromide-stained gel. In PBS-treated animals internucleosomal DNA cleavage was evident. LPA dose dependently reduced renal apoptosis. Data shown are representative for three independent assays on different renal samples ( $\mathrm{n}=3$ per group). M, 100-bp molecular weight marker.

animals, kidneys of animals treated with LPA, showed a dose-dependent reduction in internucleosomal DNA cleavage, a specific hallmark of apoptosis. To determine the apoptotic cell type in the course of renal I/R we used immunofluorescence staining for active caspase-7. Here we show that in control kidneys no activation of caspase7 is detectable (Figure 3, A and B). Ischemia followed by reperfusion, however, induced a significant activation of caspase-7 that localized specifically to tubular epithelial cells (Figure 3, C and D). Interestingly, apoptotic cells often co-localized within one tubule (Figure 3, C and D). An important hallmark of cellular injury in the course of renal $\mathrm{I} / \mathrm{R}$ injury is the disruption of brush border. ${ }^{17}$ We therefore stained renal tissue for filamentous actin (Factin), which is normally present in the brush border of tubular epithelial cells but is broken down during renal I/R injury under 


\section{Chapter 2}
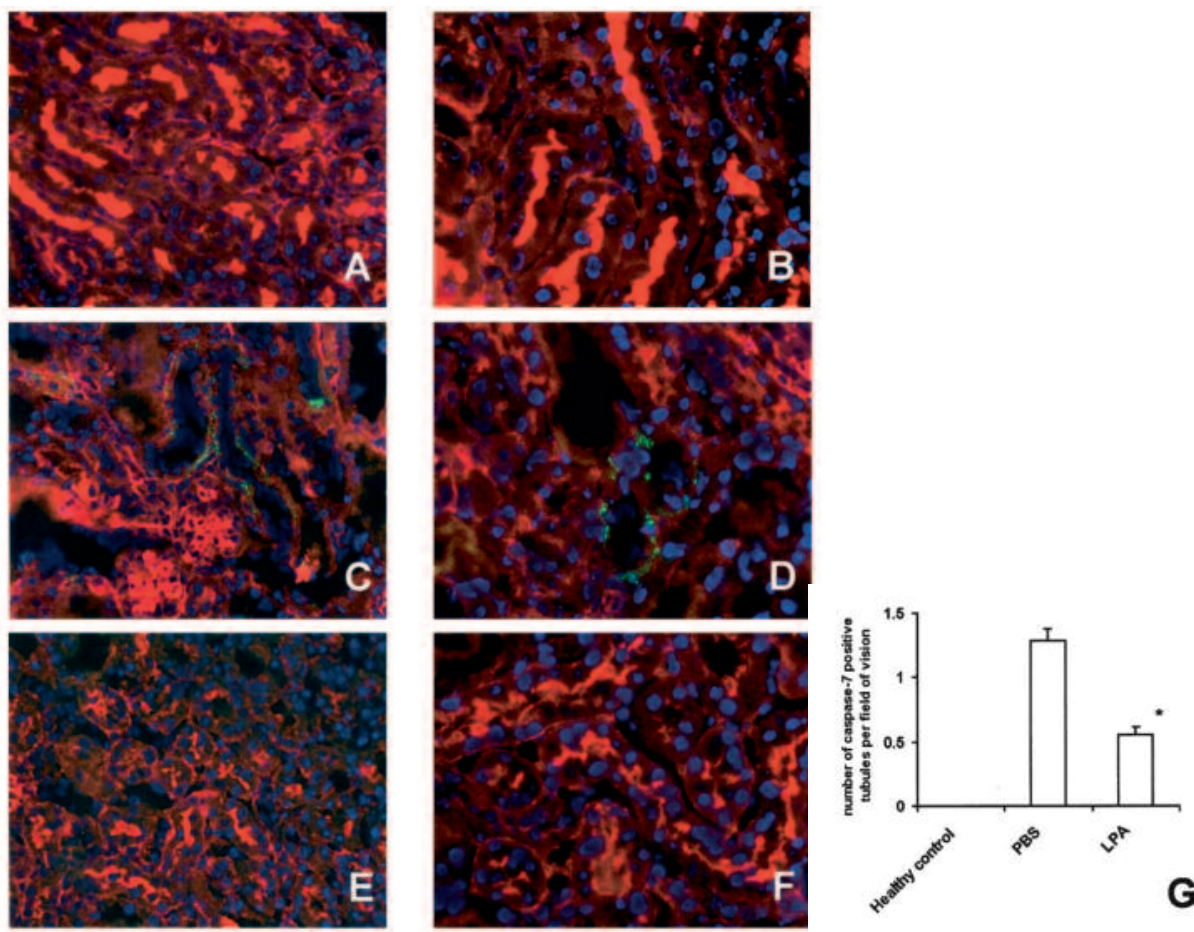

Figure 3. LPA significantly reduces $\mathrm{I} / \mathrm{R}$-induced caspase-7 activation and brush-border disruption. Kidneys of healthy animals (A and B) showed no activation of caspase-7 (green) and intact brush borders as determined by filamentous actin staining (red). Renal $\mathrm{I} / \mathrm{R}(\mathrm{C}$ and $\mathrm{D})$ induced caspase-7 activation localized to tubular epithelial cells. Caspase-7 activation was only present in tubular cells that lost brush-border integrity (C and D). LPA treatment ( $1 \mathrm{mg}$ ) evidently reduced the I/R-induced activation of caspase-7 that is accompanied with the preservation of brush-border integrity (E and F). To quantify caspase-7 activity positive tubules were counted after immunohistochemical staining (three sections per kidney, four kidneys per group). These data $(\mathrm{G})$ are expressed as the mean of number of positive tubules per field of vision $( \pm$ SEM). Statistical significance as compared to PBStreated animals was denoted at $\mathrm{P}<0.05\left({ }^{*}\right)$. Red staining, filamentous actin (Texas Red); green staining, active caspase-7 (fluorescein isothiocyanate); blue staining, nuclei (4,6-diamidino(2) phenylindole). Original magnifications: X400 (A, C, E); X600 (B, D, F).

influence of actin-depolymerizing factor. ${ }^{18}$ Indeed, in normal kidney sections F-actin is abundantly expressed in the brush border of tubular epithelial cells (Figure 3, A and $\mathrm{B})$. Renal $\mathrm{I} / \mathrm{R}$ induced a significant disruption of the brush border visible as the 
disappearance of tubular F-actin staining (Figure 3, C and D). Moreover, the data show that the activation of caspase- 7 is present in tubular cells that also showed a severe disruption of brush border (Figure 3, C and D). In animals treated with LPA (1 $\mathrm{mg}$ ), I/R-induced caspase-7 activation is significantly reduced as shown in Figure 3G. This reduction of tubular apoptosis by LPA is accompanied by a reduced loss of brush-border integrity (Figure 3, E and F).

\section{LPA prevents inflammation in the course of renal I/R}

A prominent feature of $\mathrm{I} / \mathrm{R}$-induced inflammation is the influx of neutrophils. Previously, we showed that the inhibition of apoptosis by caspase-inhibition or growth factor administration prevents massive neutrophil infiltration. ${ }^{5}$ To estimate the effects of LPA on inflammation we measured the influx of neutrophils by immunohistochemistry. To quantify the neutrophil infiltration NIMP-R14-positive cells were counted in tissue sections of kidneys in control and experimental groups at 24 hours of reperfusion. The data show that LPA treatment significantly reduced neutrophil influx in a dose-dependent manner at 24 hours of reperfusion (Figure 4).

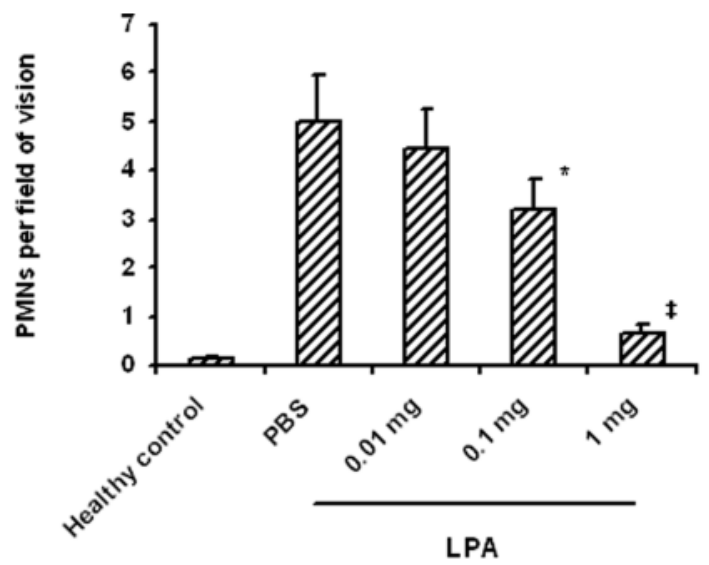

Figure 4. LPA significantly reduces I/R-induced neutrophil influx. Neutrophils were counted after immunohistochemical staining (three to four sections per kidney, four kidneys per group). Neutrophils were scarcely present in kidneys obtained from healthy mice, whereas ischemia followed by 24 hours of reperfusion led to a strong influx of neutrophils. Treatment with LPA dose dependently reduced the influx of neutrophils at 24 hours of reperfusion. Data are expressed as the mean of number of neutrophils per field of vision $( \pm$ SEM). Statistical significance as compared to PBS-treated animals was denoted at $\mathrm{P}<0.05\left({ }^{*}\right)$ and $\mathrm{P}<0.01(\neq)$. 


\section{Chapter 2}

Next, we investigated whether LPA reduces the induction of proinflammatory chemokines and cytokines involved in recruitment of inflammatory cells. We determined renal mRNA levels of TNF- $\alpha$ as well as the mouse CXC-chemokines KC and MIP-2. Here, we show that the induction of TNF- $\alpha$ is strongly inhibited after LPA treatment (1 mg LPA) (Figure 5A). Interestingly, the I/R induced up-regulation of the chemokines KC and MIP-2 was unaffected by LPA (Figure 5B).

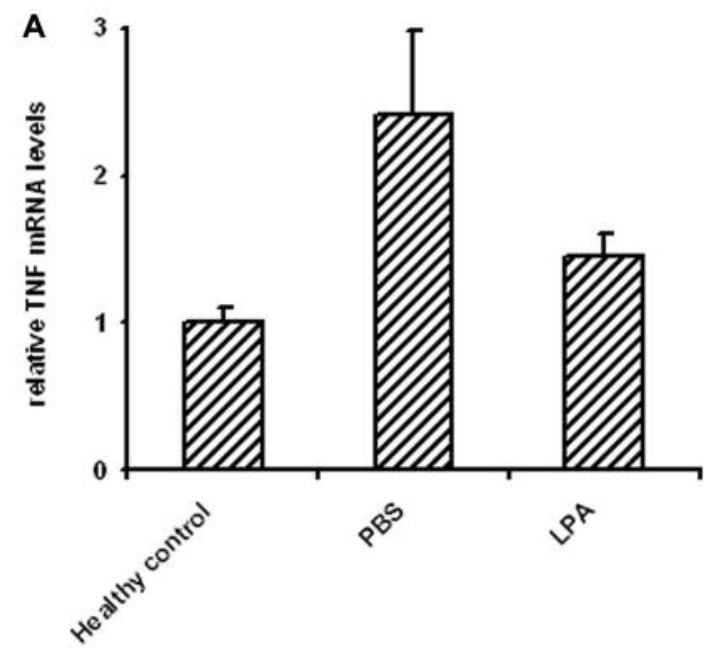

B

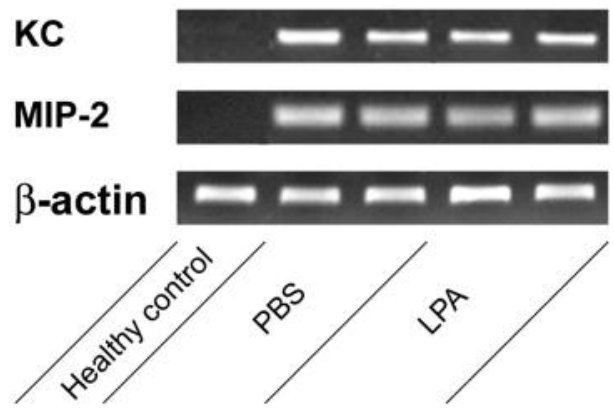

Figure 5. LPA treatment inhibits I/R-induced up-regulation of TNF- $\alpha$ whereas KC and MIP-2 mRNA levels are unaffected. Renal I/R induced a significant up-regulation of TNF- $\alpha$, as well as KC and MIP2, at 24 hours ( $A$ and B, respectively). Treatment with LPA (1 mg) strongly inhibited expression of TNF$\alpha$ at 24 hours of reperfusion (A). The induction of KC and MIP-2 was not effected by LPA treatment (B). Shown are representative samples ( $n=4$ per group) calibrated against equal amounts of $\beta$-actin mRNA. 


\section{LPA abrogates complement activation after renal I/R injury}

The data show that LPA significantly inhibits apoptosis as well as inflammation in the course of renal I/R injury. An important system that regulates inflammatory responses as well as apoptosis after renal I/R injury is the complement system. ${ }^{7}$ To investigate the effects of LPA on the activation of the complement system we stained renal tissue for early as well as late complement deposition. Here, we show that LPA strongly reduces C3 deposition.

Compared to healthy animals, in control-treated animals renal $\mathrm{I} / \mathrm{R}$ induces severe depositions of C3 (Figure 6, A and B). LPA dose dependently inhibits C3 deposition as shown for animals treated with 0.1 and $1 \mathrm{mg}$ of LPA (Figure 6, C and
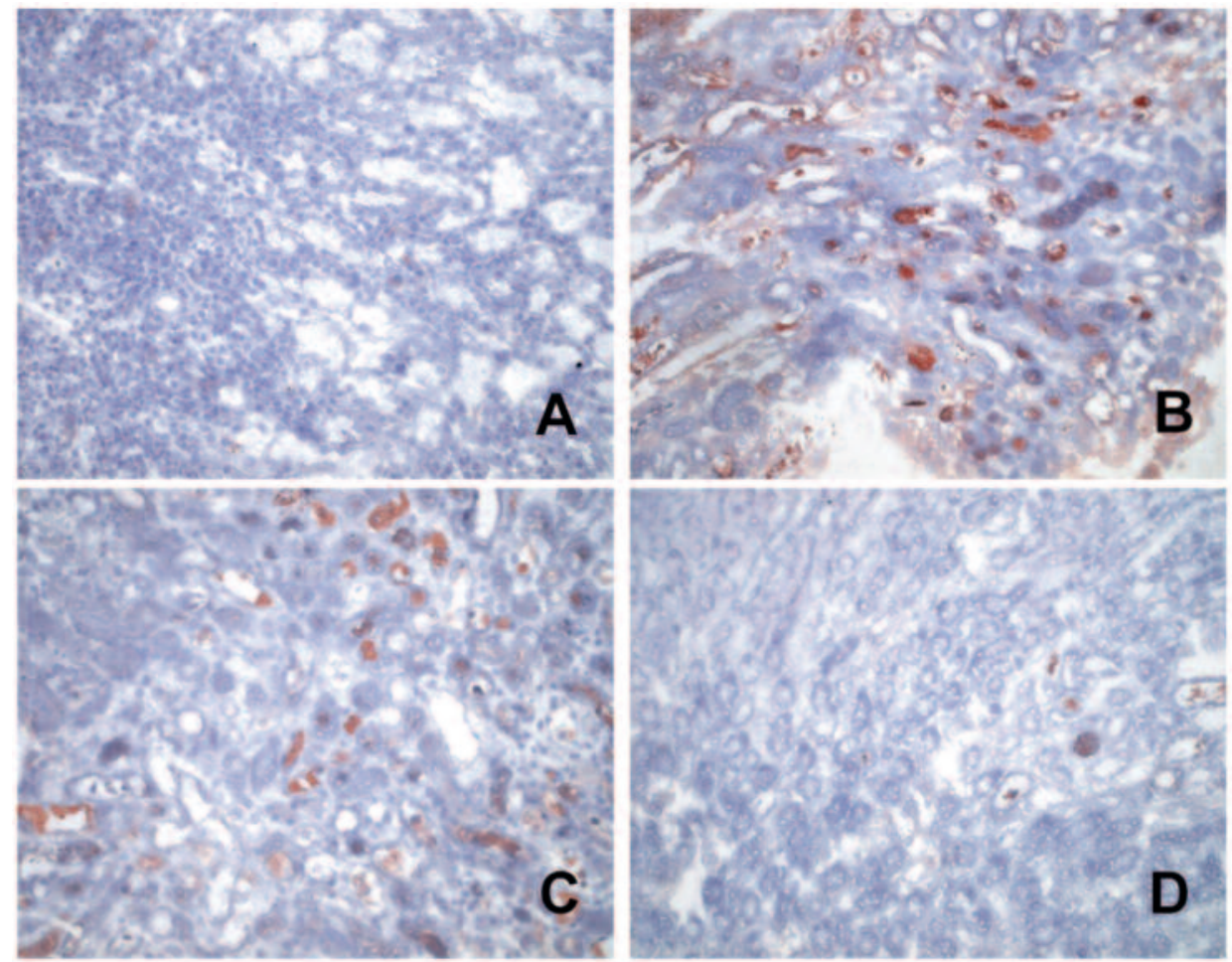

Figure 6. Treatment with LPA strongly reduces C3 deposition induced by renal ischemia reperfusion (I/R). Healthy animals (A) showed no staining for $C 3$, whereas $I / R$ induced an intense staining for C3 localized to injured tubular epithelium and tubular debris as shown at 24 hours of reperfusion (B). LPA treatment dose dependently reduced the I/R-induced deposition of C3 (C, $0.1 \mathrm{mg}$; D, 1 mg). Original magnifications, X200. 


\section{Chapter 2}

D, respectively). Moreover, LPA dose dependently reduces I/R-induced membrane attack complex (MAC) formation. Whereas the deposition of complement factor C6 (indicating MAC formation) is induced by renal $\mathrm{I} / \mathrm{R}$ (Figure $7, \mathrm{~A}$ and $\mathrm{B}$ ), administration of LPA clearly prevented $\mathrm{C} 6$ depositions at dosages of $0.1 \mathrm{mg}$ (Figure 7C) and $1 \mathrm{mg}$ (Figure 7D) of LPA. Staining for C9, also indicative for MAC formation, showed a similar inhibition of I/R-induced MAC deposition by LPA treatment (data not shown). In conclusion, this study provides evidence that the administration of LPA dose dependently abrogates renal failure after $\mathrm{I} / \mathrm{R}$ by inhibition of apoptosis and inflammation.
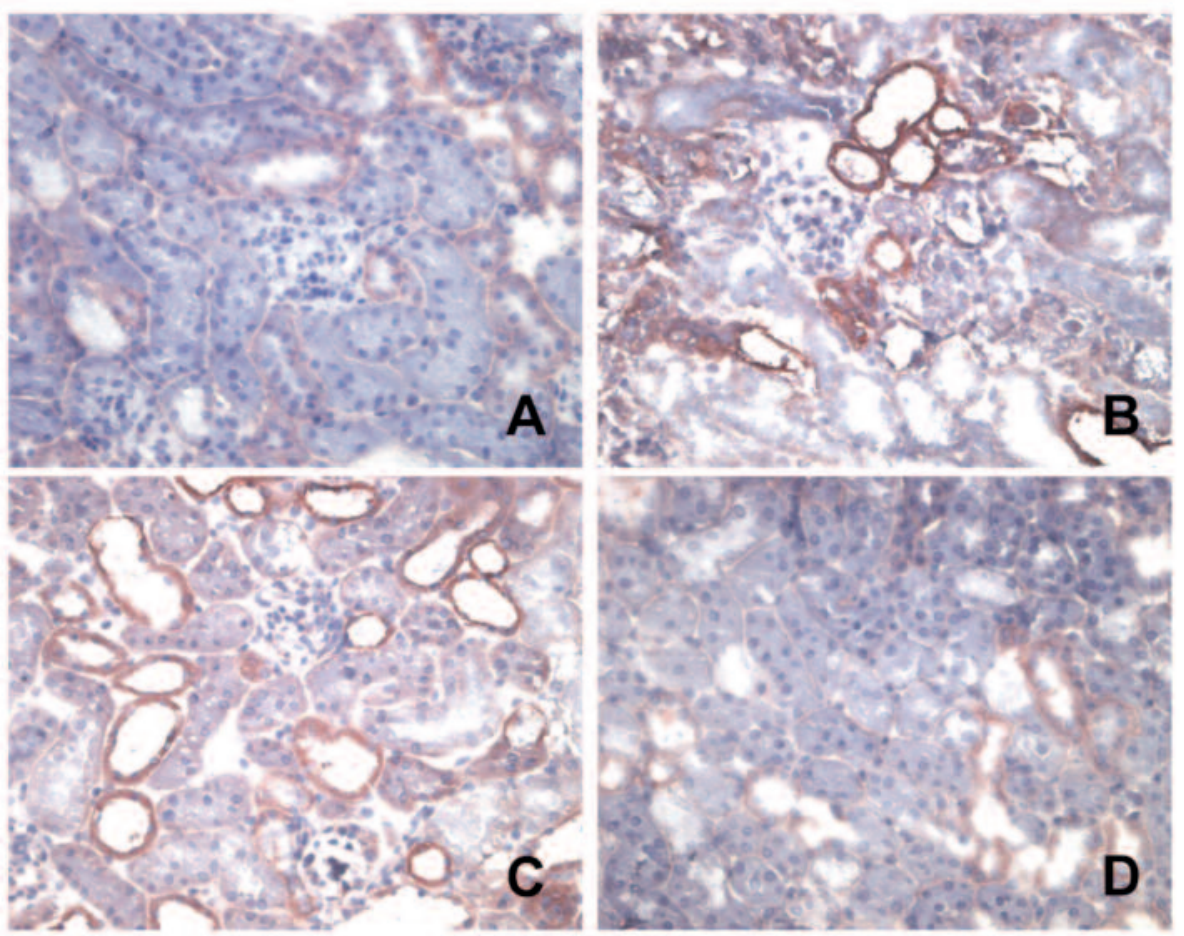

Figure 7. Ischemia followed by reperfusion leads to strong intrarenal deposition of C6, which is totally abrogated by LPA treatment. Healthy animals showed a faint linear staining for C6 at the basal aspect of tubular epithelium (A). I/R induced intense additional staining of C6 that was localized to damaged tubular epithelium (B). LPA treatment totally prevented I/R-induced deposition of C6 as shown at 24 hours of reperfusion in a dose-dependent manner (C, $0.1 \mathrm{mg} ; \mathrm{D}, 1 \mathrm{mg})$. Original magnifications, X400. 


\section{Discussion}

LPA is a naturally circulating phospholipid with numerous biological actions. LPA signals via three different $G$ protein-coupled receptors, until recently called Edg-2, Edg-4, and Edg-7; however, recently the nomenclature was changed to LPA1, LPA2, and LPA3, respectively. ${ }^{14,19}$ All three LPA receptors have been localized in murine renal tissue..$^{14,15} \mathrm{Also}$ in human kidney LPA receptors are present, although human and murine tissues have a different expression pattern of the LPA receptors. ${ }^{14}$ The present study is based on reported in vitro properties of LPA: enhancement of cell survival and cell proliferation, and in particular its function as a growth and survival factor for renal proximal tubular cells. ${ }^{16}$ This study is the first to show that LPA functions as a renal survival factor in vivo, abrogating ischemiainduced apoptosis, and moreover that LPA prevents function loss in the course of renal I/R injury. Earlier we showed that survival factors such as insulin-like growth factor-1 prevent apoptosis in vivo in the course of renal $\mathrm{I} / \mathrm{R}$ injury. ${ }^{5}$ These data suggest that administration of LPA could have beneficial effects in vivo in diseases that are mediated by apoptosis such as I/R injury. Besides the potent growth factor and antiapoptotic properties of LPA in vitro, this compound has been reported to have vasoactive effects in vivo. ${ }^{20,21}$ Interestingly, in rodents LPA appears to have vasoconstrictive effects, whereas in rabbits and cats LPA has vasodilatory properties..$^{20,21}$ The extent to which the vasoactive properties in vivo add to the growth factor and anti-apoptotic properties of LPA still needs to be elucidated. In vitro, LPA also stimulates cytoskeletal activation and remodeling. ${ }^{22}$ This cytoskeletal activation also seems to be of importance in ischemic injury, because disruption of the actin cytoskeleton has been implicated in the pathophysiology of renal I/R injury. ${ }^{17,18,23}$ Indeed, this study shows that F-actin, which is a major constituent of the epithelial brush border, is disrupted in the course of renal $\mathrm{I} / \mathrm{R}$ injury. LPA treatment evidently prevents this disruption of brush border.

In vitro studies have shown a clear relationship between caspase activation and changes in cell structure. ${ }^{24-26}$ Here, we show for the first time that caspase activation induced by renal $\mathrm{I} / \mathrm{R}$ is localized to tubular epithelial cells. Moreover, this study shows that caspase-7 activation is only present in tubular epithelial cells that have lost their brush border. Whether the protective effects of LPA in this study are primarily mediated by protection of cellular integrity or by direct inhibition of apoptosis remains to be established. In vitro studies have shown proinflammatory 


\section{Chapter 2}

functions of LPA, mainly mediated by the activation of nuclear factor- B. ${ }^{27-30}$ The activation of nuclear factor- $\mathrm{B}$ and the subsequent induction of proinflammatory genes could potentially deteriorate $\mathrm{I} / \mathrm{R}$ injury by enhancing the $\mathrm{I} / \mathrm{R}$-induced, tissuedamaging, inflammatory response. ${ }^{31,32}$ Thus, besides potential protective effects, LPA could also aggravate renal I/R injury. These in vitro data on LPA tempted us to study the role of LPA in I/R-induced inflammation in vivo. The present study demonstrates that LPA treatment has strong anti-inflammatory effects. We previously showed that the inhibition of apoptosis prevents the induction of chemokines and subsequently the influx of neutrophils after renal I/R.5,6 Our present data demonstrate that LPA prevents the induction of TNF- $\alpha$ and subsequent neutrophil influx. Interestingly, LPA did not affect the induction of chemokines, indicating that the abrogation of neutrophil influx by LPA is primary mediated by a reduction of both TNF- $\alpha$ production and complement activation. The observation that LPA does not inhibit the induction of chemokines is in contrast to the effects of apoptosis inhibition by the caspase inhibitor ZVAD-fmk on chemokine induction in the course of renal $\mathrm{I} / \mathrm{R}$ injury. ${ }^{6}$ This induction of chemokines during ischemia has been attributed to hypoxia and to the activation of caspase- 7 that can lead to the generation and release of the mature chemoattractant endothelial monocyteactivating polypeptide (EMAP-II). 5,6,33,34

Recent work indicates that activation of the complement system plays an important role in $\mathrm{I} / \mathrm{R}$ injury in the kidney as well as in other organs. ${ }^{35-41}$ We recently reported that inhibition of complement activation protects against renal $\mathrm{I} / \mathrm{R}$ injury by inhibition of chemokine induction, neutrophil influx as well as the inhibition of apoptosis. ${ }^{7}$ The present study is the first to show that LPA abrogates the renal deposition of early as well as late complement factors. LPA dose dependently reduced the deposition of $\mathrm{C} 3, \mathrm{C} 6$, as well as $\mathrm{C}$, the latter two indicating formation of the MAC. The MAC has been implicated in renal $I / R$ injury, by inducing proinflammatory cytokines, chemokines, promoting neutrophil influx, and moreover the induction of apoptotic as well as necrotic cell death. ${ }^{35,36,42,43}$ Recently, we showed that C5a also plays a major role in I/R injury of the kidney. ${ }^{44}$ Inhibition of $\mathrm{C} 5 \mathrm{a}$ activity, using a $\mathrm{C} 5$ a receptor $(\mathrm{C} 5 \mathrm{aR})$ antagonist, significantly reduced the renal induction of chemokines and the influx of neutrophils. Moreover, $\mathrm{C} 5 \mathrm{a} / \mathrm{C} 5 \mathrm{aR}$ interaction was shown to be primarily responsible for renal function loss after $\mathrm{I} / \mathrm{R}$. Also cardiac and intestinal $\mathrm{I} / \mathrm{R}$ injury are mediated by activation of the complement system and in particular by generation of $\mathrm{C} 5 \mathrm{a} .{ }^{37-41}$ 
The reduced deposition of C3 and MAC after LPA administration indicates that C5 activation is also prevented, and thus that $\mathrm{C} 5 \mathrm{a}$-mediated phenomena are inhibited by LPA. The mechanism that underlies the reduced complement activation in LPAtreated animals is as yet obscure. The activation of complement after ischemic injury has been attributed to mannose-binding lectin, to the classical pathway for the heart and also to the alternative pathway for the kidney. ${ }^{35,45,46}$ LPA may inhibit complement activation directly by inhibition of apoptosis because reoxygenation after hypoxia has been shown to induce complement activation by apoptotic cells in vitro. ${ }^{47}$ Necrotic cells are also recognized as an important inducer of complement activation. The LPA-mediated inhibition of apoptosis might also prevent secondary necrosis that occurs when apoptotic cells are not timely phagocytosed, which could also contribute to the abrogation of complement activation. ${ }^{48,49}$

Taken together, this study shows that LPA dose dependently inhibits inflammation by abrogation of complement activation, cytokine induction, and neutrophil infiltration in the course of renal I/R. The exact mechanism of this antiinflammatory capacity of LPA in vivo needs further investigation.

The aim of the present study was to characterize the in vivo effects of exogenous LPA in an experimental model for renal I/R injury. Local application of LPA has been shown to have beneficial effects on intestinal and cutaneous wound healing in rat models. ${ }^{50,51}$ Recently, oral administration of LPA also has been shown to have protective effects against radiation-induced apoptosis of intestinal epithelial cells in mice. ${ }^{52}$ These studies demonstrate the therapeutic potential of the naturally circulating phospholipid growth factor LPA in a wide variety of diseases in which apoptotic cell death as well as overwhelming inflammatory reactions play a pathophysiological role. Further in vivo studies are needed to delineate the LPA receptors responsible for the protective effects of LPA. Specific receptor agonists could be advantageous by having specific beneficial effects while abrogating potential side effects of LPA. ${ }^{53}$

In summary, this study is the first to show the protective effects of exogenous LPA against renal I/R injury. LPA abrogates renal apoptosis, TNF- $\alpha$ production, complement activation, and neutrophil influx. Moreover, exogenous LPA is capable of preventing organ failure because of $\mathrm{I} / \mathrm{R}$ and thus may provide new means to treat clinical conditions mediated by $\mathrm{I} / \mathrm{R}$ injury. 


\section{Chapter 2}

\section{ReFERENCES}

1. Thadhani R, Pascual M, Bonventre JV: Acute renal failure. N Engl J Med 1996, 334:1448-1460

2. Daemen MA, de Vries B, Buurman WA: Apoptosis and inflammation in renal reperfusion injury. Transplantation 2002, 73:1693-1700

3. Jassem W, Fuggle SV, Rela M, Koo DD, Heaton ND: The role of mitochondria in ischemia/reperfusion injury. Transplantation 2002, 73:493-499

4. Heinzelmann M, Mercer JM, Passmore JC: Neutrophils and renal failure. Am J Kidney Dis 1999, 34:384-399

5. Daemen MA, van 't Veer C, Denecker G, Heemskerk VH, Wolfs TG, Clauss M, Vandenabeele $\mathrm{P}$, Buurman WA: Inhibition of apoptosis induced by ischemia-reperfusion prevents inflammation. J Clin Invest 1999, 104:541-549

6. Daemen MA, de Vries B, van't Veer C, Wolfs TG, Buurman WA: Apoptosis and chemokine induction after renal ischemia-reperfusion. Transplantation 2001, 71:1007-1011

7. de Vries B, Matthijsen RA, Wolfs TG, Van Bijnen AA, Heeringa P, Buurman WA: Inhibition of complement factor $\mathrm{C} 5$ protects against renal ischemia-reperfusion injury: inhibition of late apoptosis and inflammation. Transplantation 2003, 75:375-382

8. Daemen MA, van de Ven MW, Heineman E, Buurman WA: Involvement of endogenous interleukin-10 and tumor necrosis factor-alpha in renal ischemia-reperfusion injury. Transplantation 1999, 67:792-800

9. Shimizu A, Masuda Y, Kitamura H, Ishizaki M, Ohashi R, Sugisaki Y, Yamanaka N: Complement-mediated killing of mesangial cells in experimental glomerulonephritis: cell death by a combination of apoptosis and necrosis. Nephron 2000, 86:152-160

10. Hughes J, Nangaku M, Alpers CE, Shankland SJ, Couser WG, Johnson RJ: C5b-9 membrane attack complex mediates endothelial cell apoptosis in experimental glomerulonephritis. Am J Physiol 2000, 278:F747-F757

11. Sato T, Van Dixhoorn MG, Prins FA, Mooney A, Verhagen N, Muizert Y, Savill J, Van Es LA, Daha MR: The terminal sequence of complement plays an essential role in antibodymediated renal cell apoptosis. J Am Soc Nephrol 1999, 10:1242-1252

12. Harris RC: Growth factors and cytokines in acute renal failure. Adv Ren Replace Ther 1997, 4:43-53

13. Eichholtz T, Jalink K, Fahrenfort I, Moolenaar WH: The bioactive phospholipid lysophosphatidic acid is released from activated platelets. Biochem J 1993, 291:677-680

14. Contos JJ, Ishii I, Chun J: Lysophosphatidic acid receptors. Mol Pharmacol 2000, 58:11881196 
15. Contos JJ, Chun J: The mouse Ip(A3)/Edg7 lysophosphatidic acid receptor gene: genomic structure, chromosomal localization, and expression pattern. Gene 2001, 267:243-253

16. Levine JS, Koh JS, Triaca V, Lieberthal W: Lysophosphatidic acid: a novel growth and survival factor for renal proximal tubular cells. Am J Physiol 1997, 273:F575-F585

17. Ashworth SL, Molitoris BA: Pathophysiology and functional significance of apical membrane disruption during ischemia. Curr Opin Nephrol Hypertens 1999, 8:449-458

18. Ashworth SL, Sandoval RM, Hosford M, Bamburg JR, Molitoris BA: Ischemic injury induces ADF relocalization to the apical domain of rat proximal tubule cells. Am J Physiol 2001, 280:F886-F894

19. Chun J, Goetzl EJ, Hla T, Igarashi Y, Lynch KR, Moolenaar W, Pyne S, Tigyi G: International Union of Pharmacology. XXXIV. Lysophospholipid Receptor Nomenclature. Pharmacol Rev 2002, 54:265-269

20. Tokumura A, Fukuzawa K, Tsukatani H: Effects of synthetic and natural lysophosphatidic acids on the arterial blood pressure of different animal species. Lipids 1978, 13:572-574

21. Tokumura A, Kume T, Fukuzawa K, Tsukatani H: Cardiovascular effects of lysophosphatidic acid and its structural analogs in rats. J Pharmacol Exp Ther 1981, 219:219-224

22. Hines OJ, Ryder N, Chu J, McFadden D: Lysophosphatidic acid stimulates intestinal restitution via cytoskeletal activation and remodeling. J Surg Res 2000, 92:23-28

23. Molitoris BA, Leiser J, Wagner MC: Role of the actin cytoskeleton in ischemia-induced cell injury and repair. Pediatr Nephrol 1997, 11: 761-767

24. Kruidering M, van de Water B, Zhan Y, Baelde JJ, Heer E, Mulder GJ, Stevens JL, Nagelkerke JF: Cisplatin effects on F-actin and matrix proteins precede renal tubular cell detachment and apoptosis in vitro. Cell Death Differ 1998, 5:601-614

25. Van de Water B, Kruidering M, Nagelkerke JF: F-actin disorganization in apoptotic cell death of cultured rat renal proximal tubular cells. Am J Physiol 1996, 270:F593-F603

26. Kothakota S, Azuma T, Reinhard C, Klippel A, Tang J, Chu K, Mc- Garry TJ, Kirschner MW, Koths K, Kwiatkowski DJ, Williams LT: Caspase-3-generated fragment of gelsolin: effector of morphological change in apoptosis. Science 1997, 278:294-298

27. Goetzl EJ, An S: Diversity of cellular receptors and functions for the lysophospholipid growth factors lysophosphatidic acid and sphingosine 1-phosphate. EMBO J 1998, 12:1589-1598

28. Palmetshofer A, Robson SC, Nehls V: Lysophosphatidic acid activates nuclear factor kappa $B$ and induces proinflammatory gene expression in endothelial cells. Thromb Haemost 1999, 82:1532-1537 


\section{Chapter 2}

29. Rizza C, Leitinger N, Yue J, Fischer DJ, Wang DA, Shih PT, Lee H, Tigyi G, Berliner JA: Lysophosphatidic acid as a regulator of endothelial/leukocyte interaction. Lab Invest 1999, 79:1227-1235

30. Chettibi S, Lawrence AJ, Stevenson RD, Young JD: Effect of lysophosphatidic acid on motility, polarisation and metabolic burst of human neutrophils. FEMS Immunol Med Microbiol 1994, 8:271-281

31. Chandrasekar B, Smith JB, Freeman GL: Ischemia-reperfusion of rat myocardium activates nuclear factor-kappaB and induces neutrophil infiltration via lipopolysaccharide-induced CXC chemokine. Circulation 2001, 103:2296-2302

32. Donnahoo KK, Meldrum DR, Shenkar R, Chung CS, Abraham E, Harken AH: Early renal ischemia, with or without reperfusion, activates NFkappaB and increases TNF-alpha bioactivity in the kidney. J Urol 2000, 163:1328-1332

33. Metinko AP, Kunkel SL, Standiford TJ, Strieter RM: Anoxia-hyperoxia induces monocytederived interleukin-8. J Clin Invest 1992, 90:791-798

34. Behrensdorf HA, van de Craen M, Knies UE, Vandenabeele P, Clauss M: The endothelial monocyte-activating polypeptide II (EMAP II) is a substrate for caspase-7. FEBS Lett 2000, 466:143-147

35. Zhou W, Farrar CA, Abe K, Pratt JR, Marsh JE, Wang Y, Stahl GL, Sacks SH: Predominant role for C5b-9 in renal ischemia/reperfusion injury. J Clin Invest 2000, 105:1363-1371

36. Vakeva AP, Agah A, Rollins SA, Matis LA, Li L, Stahl GL: Myocardial infarction and apoptosis after myocardial ischemia and reperfusion: role of the terminal complement components and inhibition by anti-C5 therapy. Circulation 1998, 97:2259-2267

37. Riley RD, Sato H, Zhao ZQ, Thourani VH, Jordan JE, Fernandez AX, Ma XL, Hite DR, Rigel DF, Pellas TC, Peppard J, Bill KA, Lappe RW, Vinten-Johansen J: Recombinant human complement $\mathrm{C} 5$ a receptor antagonist reduces infarct size after surgical revascularization. J Thorac Cardiovasc Surg 2000, 120:350-358

38. Amsterdam EA, Stahl GL, Pan HL, Rendig SV, Fletcher MP, Longhurst JC: Limitation of reperfusion injury by a monoclonal antibody to $\mathrm{C} 5$ a during myocardial infarction in pigs. Am J Physiol 1995, 268:H448-H457

39. Arumugam TV, Shiels IA, Woodruff TM, Reid RC, Fairlie DP, Taylor SM: Protective effect of a new $\mathrm{C} 5$ a receptor antagonist against ischemia-reperfusion injury in the rat small intestine. J Surg Res 2002, 103:260-267

40. Wada K, Montalto MC, Stahl GL: Inhibition of complement C5 reduces local and remote organ injury after intestinal ischemia/reperfusion in the rat. Gastroenterology 2001, 120:126-133 
41. Heller T, Hennecke M, Baumann U, Gessner JE, zu Vilsendorf AM, Baensch M, Boulay F, Kola A, Klos A, Bautsch W, Kohl J: Selection of a C5a receptor antagonist from phage libraries attenuating the inflammatory response in immune complex disease and ischemia/ reperfusion injury. J Immunol 1999, 163:985-994

42. Cragg MS, Howatt WJ, Bloodworth L, Anderson VA, Morgan BP, Glennie MJ: Complement mediated cell death is associated with DNA fragmentation. Cell Death Differ 2000, 7:48-58

43. Nauta AJ, Daha MR, Tijsma O, van De Water B, Tedesco F, Roos A: The membrane attack complex of complement induces caspases activation and apoptosis. Eur J Immunol 2002, 32:783-792

44. de Vries B, Kohl J, Leclerq WK, Wolfs TG, van Bijnen AA, Heeringa P, Buurman WA: Complement factor C52 mediates renal ischemiareperfusion injury independent from neutrophils. J Immunol 2003, 170:3883-3889

45. Jordan JE, Montalto MC, Stahl GL: Inhibition of mannose-binding lectin reduces postischemic myocardial reperfusion injury. Circulation 2001, 104:1413-1418

46. Buerke M, Schwertz H, Seitz W, Meyer J, Darius H: Novel small molecule inhibitor of c1s exerts cardioprotective effects in ischemiareperfusion injury in rabbits. J Immunol 2001, 167:5375-5380

47. Mold C, Morris CA: Complement activation by apoptotic endothelial cells following hypoxia/reoxygenation. Immunology 2001, 102:359-364

48. Leist M, Jaattela M: Four deaths and a funeral: from caspases to alternative mechanisms. Nat Rev Mol Cell Biol 2001, 2:589-598

49. Schwab BL, Guerini D, Didszun C, Bano D, Ferrando-May E, FavaE, Tam J, Xu D, Xanthoudakis S, Nicholson DW, Carafoli E, Nicotera P: Cleavage of plasma membrane calcium pumps by caspases: a link between apoptosis and necrosis. Cell Death Differ 2002, 9:818 -831

50. Balazs L, Okolicany J, Ferrebee M, Tolley B, Tigyi G: Topical application of the phospholipid growth factor lysophosphatidic acid promotes wound healing in vivo. Am J Physiol 2001, 280:R466-R472

51. Sturm A, Sudermann T, Schulte KM, Goebell H, Dignass AU: Modulation of intestinal epithelial wound healing in vitro and in vivo by lysophosphatidic acid. Gastroenterology 1999, 117:368-377

52. Deng W, Balazs L, Wang DA, Van Middlesworth L, Tigyi G, Johnson LR: Lysophosphatidic acid protects and rescues intestinal epithelial cells from radiation- and chemotherapyinduced apoptosis. Gastroenterology 2002, 123:206-216

53. Tigyi G: Selective ligands for lysophosphatidic acid receptor subtypes: gaining control over the endothelial differentiation gene family. Mol Pharmacol 2001, 60:1161-1164 


\section{Chapter 2.5}

\section{Autologous transplantation of ischemically injured kidneys in pigs.}

Maarten G. Snoeijs, Robert A. Matthijsen, Saskia Seeldrayers, Marco A. Marcus, Jan-Willem H. Daemen, Carine J. Peutz-Kootstra, Wim A. Buurman, Geert Willem H. Schurink, and L. W. Ernest van Heurn.

Published - Journal of Surgical Research. 2010 


\begin{abstract}
Background. Expansion of the organ donor pool can be obtained through novel interventions attenuating ischemic acute kidney injury, which will enable the use of kidneys that suffered prolonged ischemia. In basic science, new therapeutic targets are identified that should be tested in a relevant large animal model before use in human kidney transplantation.
\end{abstract}

Materials and Methods. The current paper provides a detailed description of the technique of autologous transplantation of ischemically injured kidneys in pigs with special emphasis on perioperative care.

Results. The animal model was validated by showing that renal function after transplantation was proportional to the duration of warm ischemia before organ recovery. The extent of renal dysfunction was reproducible following kidney transplantations with the same warm ischemia time.

Conclusions. Our experience may reduce the learning curves of other research groups taking an interest in the model and improve preclinical testing of novel interventions that modulate renal ischemia and reperfusion injury in kidney transplantation.

\title{
INTRODUCTION
}

A major challenge in the field of renal transplantation is expansion of the organ donor pool. ${ }^{1}$ Liberal utilization of donation after cardiac death (DCD) may expand the supply of kidney grafts sufficiently to reduce or even eliminate the waiting lists for transplantation. ${ }^{2}$ However, kidneys from DCD donors suffer ischemic injury from circulatory arrest until organ preservation, which results in a high incidence of early graft dysfunction after transplantation. ${ }^{3}$ Importantly, up to $15 \%-25 \%$ of DCD kidneys will never recover function, unnecessarily exposing their recipients to the risks of major surgery and immunologic sensitization. ${ }^{3}$ It is therefore of critical importance to develop novel interventions that attenuate ischemic acute kidney injury and allow increased use of DCD kidneys for transplantation. Over the past decade, a vast array of therapeutic targets for ischemic acute kidney injury has been identified in rodent models. Translation of these experimental findings 


\section{Chapter 2}

into effective interventions in human kidney transplantation requires clinically relevant large animal models. In this respect, pigs are highly useful because of their limited genetic variation and the close similarity of the renal anatomy and physiology between pigs and men. ${ }^{4}$

In the current paper, we provide a detailed description of the technique of autotransplantation of ischemically injured kidneys in the pig with special emphasis on perioperative management. Our experience may facilitate others to investigate interventions that reduce ischemic damage in a clinically relevant model of kidney transplantation in order to eventually improve the outcome of clinical transplantation of ischemically injured kidneys.

\section{Materials ANd Methods}

\section{Study Design}

This observational study compares the outcome of porcine renal autotransplantation using kidneys exposed to different warm ischemia times (0 [n $=1], 30[n=4]$, and $45[n=10] \mathrm{min})$. In vivo experiments were approved by the local laboratory animal review board (DEC 2005-057 and 2006-173) and were conducted in accordance with the NIH principles of laboratory animal care.

\section{Animals}

Male white pigs (Dutch landrace 3 Yorkshire crossbreed) weighing 35-45 kg and aged 16-20 wk were obtained from a commercial farm. The animals tested negative for infection with porcine reproductive and respiratory syndrome virus, Actinobacillus pleuropneumonia, and mycoplasma. One week before surgery, pigs were allowed to adapt to their housing $(2 \times 3 \mathrm{~m})$. Animals had free access to water and were fed 500 $\mathrm{g}$ of pellets for adult sows twice a day to limit their growth during the experiments. Pigs were kept in an environment at a temperature of $20^{\circ} \mathrm{C}$, at a humidity level of $55 \%$, and with $12 \mathrm{~h}$ of light per day. Environmental enrichment was provided by a ball and straw floor isolation. After surgery, the animals were housed individually.

\section{Donor Nephrectomy}

The abdomen and neck were shaved and washed with chlorhexidine before gently restraining the legs to obtain adequate surgical access. After topical application of iodine, a long midline abdominal incision was made running alongside the nipple 
line below the umbilicus to avoid injury to the penis. The peritoneum was opened, a retractor was placed and the bowel was packed in a wet towel and gently retracted by an assistant to expose the left kidney. The kidney was then mobilized and stripped of perirenal tissue. The renal vessels were gently dissected free up to the aorta and vena cava while dividing lumbar venous branches between ligatures; dissection of the renal hilum and ureter was avoided. The ureter was ligated and divided distally. Subsequently, the renal artery and vein were ligated and divided close to the aorta and vena cava, without administering heparin. The renal artery was ligated first to allow drainage of blood from the kidney. The kidney was left in the abdomen to obtain adequate warm ischemic injury. Induction of warm ischemia by clamping the renal artery and vein without transection resulted in extensive thrombosis. Baseline 16G needle biopsies (TSK Laboratory, Tochigi, Japan) were taken from the contralateral kidney to avoid injury to the donor kidney. The bowel was carefully placed back into the abdomen taking care not to twist the small bowel. The abdomen was then partly closed in two layers (fascia and skin) with multifilament polyester sutures to prevent heat and fluid loss during the warm ischemic period. Subsequently, a small right paratracheal incision was made and the internal carotid artery and internal jugular vein were exposed by blunt dissection. Tygon catheters (i.d. 1.16mm,o.d. 1.78mm,length $80 \mathrm{~cm}$; Norton Co., Akron, $\mathrm{OH}$ ) were advanced $10 \mathrm{~cm}$ into both vessels, carefully secured with sutures, and then subcutaneously tunnelled, exiting the skin behind the left ear. The neck incision was closed in two layers (subcutaneous tissue and skin) with multifilament polyester sutures. The catheters were filled with a mixture of gentamycin $(20 \mathrm{mg} / \mathrm{mL})$ and a-chymotrypsin (225 U/mL; Merck, Darmstadt, Germany) in saline. ${ }^{5}$

At the end of the warm ischemic period, the kidney was recovered from the abdomen and the renal artery was cannulated with a luerlock adapter (VBM Medizintechnik, Sulz am Neckar, Germany). The kidney was then weighed and flushed with $300 \mathrm{~mL}$ histidine tryptophan ketoglutarate preservation solution (Dr. F. Köhler Chemie, Bensheim, Germany) per $100 \mathrm{~g}$ of kidney weight at $4{ }^{\circ} \mathrm{C}$ at a pressure of $100 \mathrm{cmH}_{2} \mathrm{O}$ without topical cooling while the abdomen was being closed. The kidney was weighed again and connected to a PF-3B perfusion machine (Gambro, Lund, Sweden) primed with 500mL UW-MPS (Organ Recovery Systems, Des Plaines, IL). Hypothermic pulsatile perfusion at $4{ }^{\circ} \mathrm{C}$ was initiated with a systolic perfusion pressure of $55 \mathrm{mmHg}$ during the first hour of perfusion and perfusate flow was kept constant afterwards. 


\section{Chapter 2}

\section{Orthotopic Kidney Transplantation}

Twenty-four hours after the start of the first operation, animals were anesthetized again and the midline abdominal incision was reopened. A retractor was placed and the bowel was packed in a wet towel to be gently retracted by an assistant in order to expose the right kidney, taking care not to induce bowel ischemia. The vessels of the contralateral kidney were dissected free and the ureter was divided at the renal pelvis. The renal artery and vein were clamped at the aorta and vena cava. The vessels were divided in the renal hilum and the right kidney was retrieved. The right renal artery was now enlarged by transecting the inner curve of its bifurcation, allowing a wide anastomosis with the artery of the transplanted left kidney to be made (Fig. 1).

\section{ARTERIAL ANASTOMOSIS}

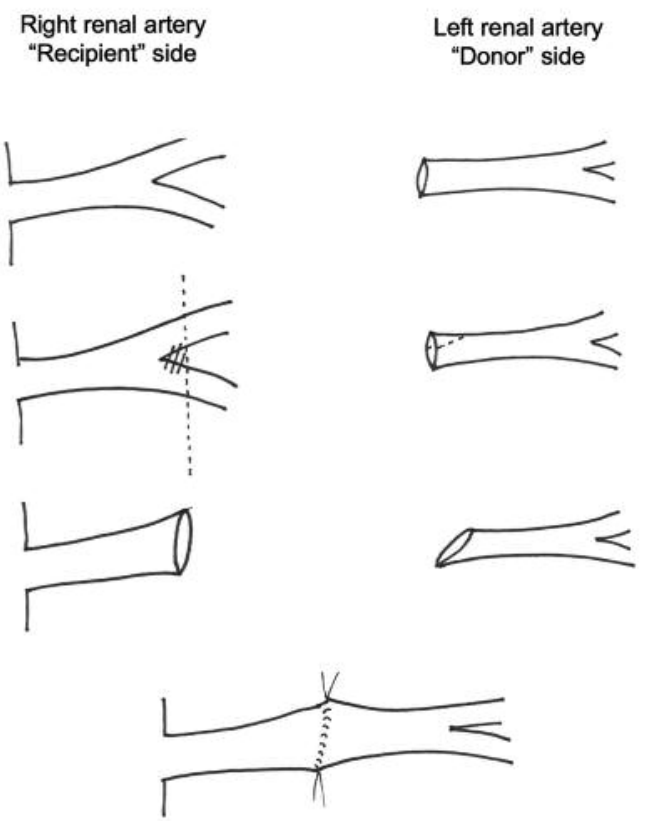

Figure 1. When anastomosing the renal artery and vein, generous spatulation of the vessels is necessary to avoid constriction at the anastomotic site. The right renal artery is enlarged by transecting the inner curve of its bifurcation. 
The donor kidney was then removed from the perfusion machine and grafted orthotopically at the contralateral site. Without administering heparin, the donor vein was anastomosed end-to-end to the contralateral renal vein. Two stay sutures were placed at the superior and inferior edges of the renal vein of the donor kidney. The posterior wall of the anastomosis was completed first with a running polypropylene 6-0 suture, everting the edge. Then, the anterior wall anastomosis was completed. Subsequently, the donor artery was anastomosed end-to-end to the contralateral renal artery using the same technique. Before closure of the anastomoses, the vessel lumina were flushed with saline to prevent thrombosis. The venous clamp was removed before the arterial clamp and reperfusion of the kidney was observed. If present, minor blood loss from the renal hilum resolved spontaneously after packing the kidney with gauze swabs for some minutes. Major or continuing blood loss from the kidney required additional individual stitches without clamping the vessels to maintain standard experimental conditions.

The proximal donor ureter was shortened and anastomosed end-to-end to the contralateral ureter with a running polypropylene 5-0 suture. A double-J catheter (26 cm, Ch4.8; Rüsch, Kernen-Rommelshausen, Germany) was placed in the ureter to prevent obstruction. The catheter was secured with a suture to prevent it from dislodging into the bladder. 16G Needle biopsies were taken from the kidney for histologic assessment of early reperfusion injury.

Biopsy holes were closed with a gently tied purse string suture. The abdomen was again closed in two layers and the animals were left to recover from surgery.

\section{Perioperative Management and Anesthesia}

The animals were starved $12 \mathrm{~h}$ before surgery but had free access to water. Before induction of anesthesia, pigs were sedated with azaperone $4 \mathrm{mg} / \mathrm{kg}$ and ketamine $15 \mathrm{mg} / \mathrm{kg}$ i.m. to allow ear vein cannulation. A baseline blood sample was drawn and anesthesia was induced by thiopental $\sim 6 \mathrm{mg} / \mathrm{kg}$ and fentanyl $8 \mathrm{~g} / \mathrm{kg}$ i.v. The animals were then intubated and ventilated with $1 \%$ isoflurane and $40 \%$ oxygen in room air. These concentrations should not be changed during surgery since both isoflurane and oxygen may affect the course of renal ischemia and reperfusion injury. 6,7 Animals were ventilated with tidal volumes of $10 \mathrm{~mL} / \mathrm{kg}$ at frequencies of $\sim 17$ breaths/min to obtain end tidal $\mathrm{CO}_{2}$ concentrations of 4-5 kPa. Atropine 10 $\mathrm{g} / \mathrm{kg}$ i.v. was administered at the start of surgery and was maintained with $5 \mathrm{~g} / \mathrm{kg}$ i.v. every 45 min thereafter. During surgery, fentanyl $8 \mathrm{~g} / \mathrm{kg} / \mathrm{h}$ i.v. was administered 


\section{Chapter 2}

by continuous infusion. Animals were monitored by oxymeter (saturation $>95 \%$ and heart rate $<100 \mathrm{bpm}$ ) and rectal thermometer $\left(>36^{\circ} \mathrm{C}\right)$. Body temperature was maintained by infusion heaters and heat pads on the operating table; room temperature was $22^{\circ} \mathrm{C}$. During donor nephrectomy, $40 \mathrm{~mL} / \mathrm{kg}$ Ringer's lactate i.v. was administered. During kidney transplantation, $10 \mathrm{~mL} / \mathrm{kg}$ gelofusine and Ringer's lactate as needed i.v. were administered in order to achieve central venous pressures (CVP) of $10 \mathrm{mmHg}$ and mean arterial pressures of $70-80 \mathrm{mmHg}$ at reperfusion of the kidney. Blood pressure and CVP were continuously monitored by pressure transducers on the central arterial and venous lines. Before reperfusion of the kidney, $100 \mathrm{~mL}$ mannitol $20 \%$ i.v. was administered. ${ }^{8}$

To maintain adequate hydration in the postoperative period, animals received $20 \mathrm{~mL} / \mathrm{kg}$ Ringer's lactate i.v. overnight after surgery and $10 \mathrm{~mL} / \mathrm{kg}$ Ringer's lactate i.v. twice a day during the first 2 postoperative day. For analgesia, $30 \mathrm{~g} / \mathrm{kg}$ buprenorphine i.v. was administered immediately after surgery and every $12 \mathrm{~h}$ on the first $2 \mathrm{~d}$ after surgery (half dose at the second postoperative day). Antibiotic prophylaxis was provided by 1000/200mg amoxicillin/clavulanate i.v. during donor nephrectomy and 500/100 mg (adjustment for reduced renal clearance) on the next three days. After transplant surgery, food was gradually restarted in order not to overfeed the animals. Rectal temperature was measured daily to check for infectious disease. Pigs were kept for $10 \mathrm{~d}$ after transplantation, and blood was taken every day for serum creatinine and blood urea nitrogen (BUN) measurements.

\section{Histologic Assessment of Renal Biopsies}

Renal biopsies were formalin-fixed and stained with periodic acid Schiff for blinded assessment of renal injury by an experienced nephropathologist. Tubular dilation, casts and debris, brush border loss, and necrosis were scored in 10 cortical fields at $400 \mathrm{X}$ magnification on a scale of 0 to 5 ( 0 is normal; 1 involves $<10 \%$ of cortex; 2 involves $10 \%-25 \%$ of cortex; 3 involves $25 \%-50 \%$ of cortex; 4 involves $50 \%-75 \%$ of cortex; and 5 involves $>75 \%$ of cortex).

\section{Statistics}

Continuous variables were presented as mean (standard error). For comparisons of continuous variables between groups, repeated measures ANOVA and independent samples t-tests were used. Coefficient of variation was calculated as standard deviation divided by mean. Sample size was calculated at a power of $80 \%$ according 
to Campbell et al. ${ }^{9}$ Results with $\mathrm{P}<0.05$ were considered statistically significant.

\section{Results}

All animals survived until the end of the observation period. Transplant characteristics are presented in Table 1. Duration of nephrectomy was $89 \pm 4$ min,

Table 1. Characteristics of Autologous Kidney Transplantations in Pigs

\begin{tabular}{lc} 
& Mean (SEM) \\
\hline Pig weight (kg) & $36(2)$ \\
Duration nephrectomy surgery (min) & $89(4)$ \\
Duration transplant surgery (min) & $97(4)$ \\
Machine perfusion time (h) & $23(0.2)$ \\
Anastomosis time (min) & $27(2)$ \\
Kidney weight at recovery (g) & $103(3)$ \\
Kidney weight after flush-out $(\mathrm{g})$ & $139(7)$ \\
Kidney weight at implantation (g) & $166(8)$ \\
Perfusion pressure (mmHg) & $25(2)$ \\
Perfusion flow rate (mL/min/100 g) & $32(4)$ \\
Resistance (mmHg/mL/min/100 g) & $0.89(0.11)$ \\
LDH concentration (IU/L/100 g) & $166(19)$ \\
\hline
\end{tabular}

whereas autologous kidney transplantation took $97 \pm 4 \mathrm{~min}$. Mean anastomosis time was $27 \pm 2 \mathrm{~min}$. Autologous transplantation of ischemically injured kidneys in pigs was followed by severe renal dysfunction as indicated by a temporary rise in serum creatinine in the first $10 \mathrm{~d}$ after transplantation (Fig. 2). Kidneys subjected to $45 \mathrm{~min}$ of warm ischemia before hypothermic organ preservation were associated with a trend towards higher serum creatinine concentrations than kidneys with 30 min of warm ischemia throughout the postoperative period $(P=0.07)$. This difference in creatinine concentration was statistically significant at $d 2(P=0.01)$, d $3(P=0.03)$, and at $d 4(P=0.03)$. This was also observed with BUN concentrations, but the differences between groups did not reach statistical significance (data not shown). As a reference, one animal that received a kidney without warm ischemia showed a minor and transient rise in serum creatinine concentration that 


\section{Kidney function after transplantation}

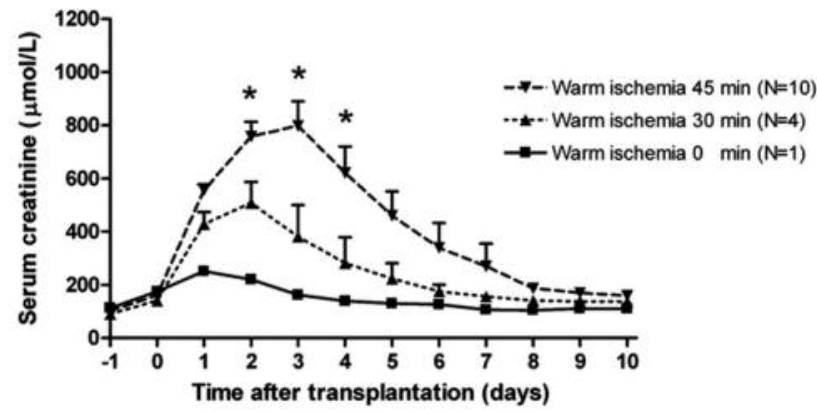

Figure 2. Serum creatinine over time for groups of kidneys with different warm ischemia times. Increased duration of warm ischemia before hypothermic organ preservation results in greater impairment of renal function after autologous kidney transplantation in pigs. Data are presented as means and standard errors. The asterisk denotes statistically significant differences between the 30 and 45 min warm ischemia group $(P=0.01$ at $d 2, P=0.03$ at $d 3$, and $P=0.03$ at $d 4)$.

\section{Variation in graft function between animals}

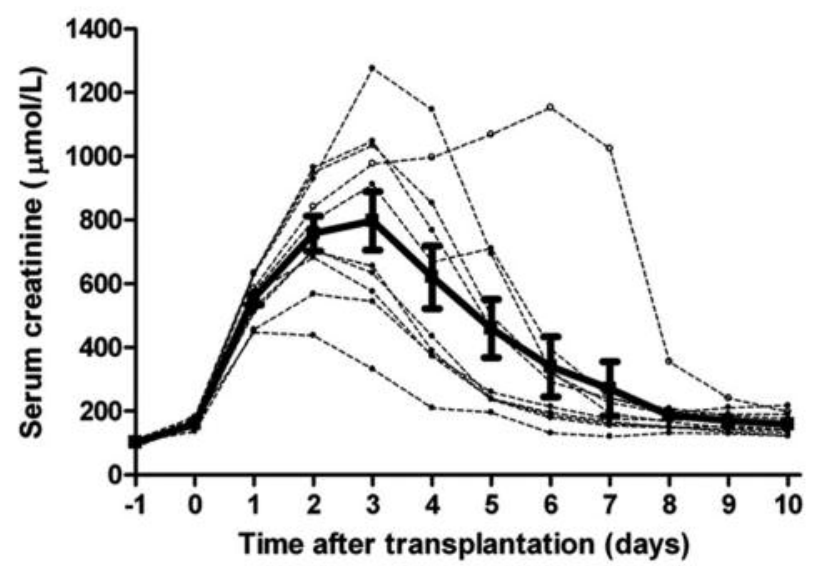

Figure 3. Variation in kidney function after autologous transplantation of porcine kidneys with 45 min of warm ischemia time $(n=10)$. The solid line denotes the mean and standard error of serum creatinine concentrations over time, whereas the dashed lines denote serum creatinine concentrations over time for the individual animals. The line with open rounds is an outlier that was removed for analysis of reproducibility. 
peaked on the first day after transplantation. These findings indicate that the duration of warm ischemia is closely related to the extent of renal dysfunction after autologous kidney transplantation in pigs.

The variation in graft function between animals with a warm ischemia time of 45 min was evaluated (Fig. 3).

\section{RENAL HISTOLOGY}
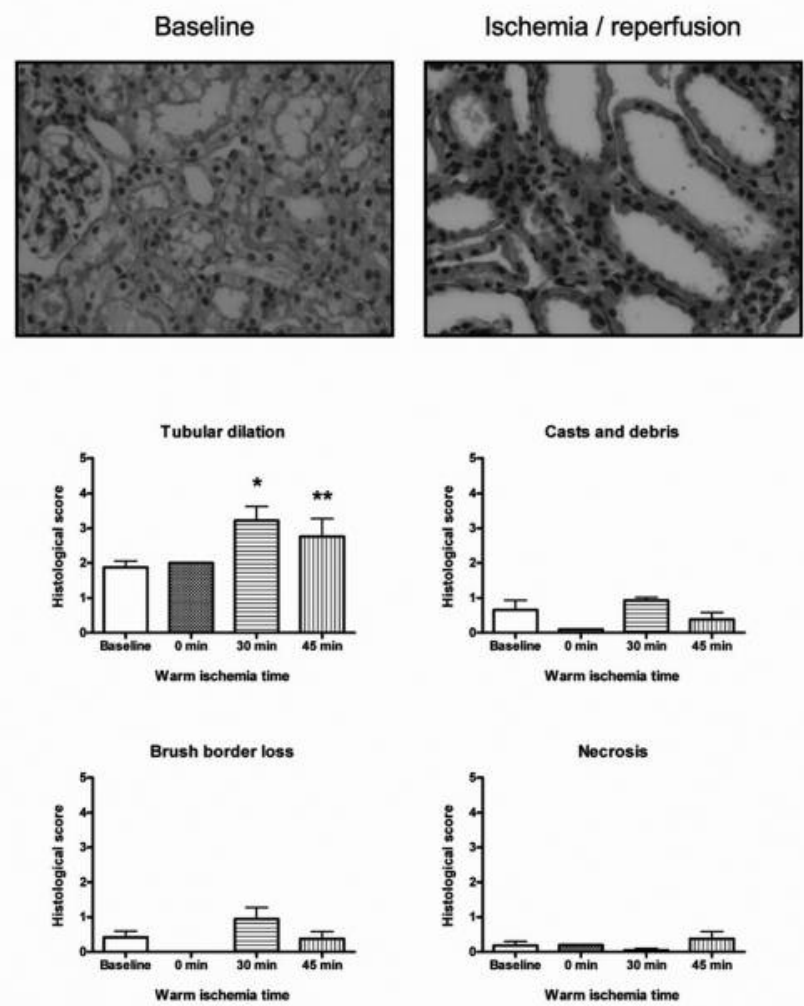

Figure 4. Renal histology before and after transplantation of kidneys exposed to variable periods of warm ischemia followed by hypothermic perfusion. Representative pictures of periodic acid Schiff stained tissue sections at 400X magnification are shown. Tubular dilation, casts and debris, brush border loss, and necrosis were blindly scored by an experienced nephropathologist on a scale of 0 to 5. Data are presented as means and standard errors. The single asterisk denotes statistical significance for the comparison with baseline scores $(P=0.004)$, whereas the double asterisk indicates a trend towards statistical significance for the comparison with baseline scores $(P=0.06)$. 


\section{Chapter 2}

After removal of a single outlier, the mean coefficient of variation for the daily serum creatinine measurements was $26 \%$. With this variation, five animals per group are required to detect a difference of $50 \%$ between treatment and controls with statistical significance. This indicates that the model can be used efficiently for preclinical testing of novel interventions for ischemic acute kidney injury in renal transplantation.

Histologic assessment of renal biopsies showed that transplantation of kidneys after warm ischemia and hypothermic preservation induced tubular dilation but did not cause tubular casts, brush border loss, or necrosis (Fig. 4). The extent of tubular dilation in kidneys exposed to 30 and $45 \mathrm{~min}$ of warm ischemia was similar $(P=0.51)$. A single kidney without warm ischemia did not show an increase in tubular dilation after transplantation.

\section{Discussion}

Pigs have been used as a large animal model for kidney transplantation since the early 1970s. ${ }^{10-14}$ In line with the major immunologic challenges facing organ transplantation at that time, these early studies largely focused on prevention of acute rejection after allogeneic transplantation of kidneys with minimal ischemic injury. With the advent of more effective immunosuppressive drugs and the increasing disparity between supply and demand of donor kidneys, scientific interest has shifted towards modulation of ischemic acute renal injury in order to enable transplantation of kidneys that have suffered prolonged ischemia. This interest is most readily addressed by autologous kidney transplantation models, which allow the study of ischemia and reperfusion injury without the potential for confounding by acute rejection or immunosuppressive drugs..$^{15-19}$

Autologous kidney transplantation in pigs compares favourably to other animal models of ischemic acute kidney injury. Temporary renal artery occlusion in mice or rats, the most frequently used small animal model, ${ }^{20}$ is followed by extensive necrosis of proximal tubules, which does not correspond to the much milder histologic changes in renal biopsies during human acute kidney injury. ${ }^{21}$ Therefore, large animal models of autologous kidney transplantation in pigs and dogs have been used to more accurately simulate the clinical situation. Canine kidneys are able to function immediately even after 5 to $6 \mathrm{~d}$ of hypothermic organ preservation, ${ }^{22,23}$, indicating that these kidneys are less vulnerable to ischemia and reperfusion injury than those of 
humans and pigs. In addition, public opinion has shifted against the use of dogs in laboratory experiments. Therefore, we consider the pig to be the most appropriate species for preclinical studies on renal transplantation with ischemically injured kidneys, in particular since their renal anatomy and physiology are highly comparable to humans and because inbred pigs have relatively little genetic variation. ${ }^{4}$ Still, these experiments are typically done in young and healthy animals that may not be entirely representative of wait-listed dialysis patients. In addition, large animal models of kidney transplantation are restricted by their considerable expense and complexity and by the limited availability of transgenic animals and reagents for immunologic assays on plasma and tissue samples. Critical steps in the protocol are the anastomoses of the renal blood vessels, the creation of permanent vascular access and the perioperative hemodynamic management. When anastomosing the renal artery and vein, generous spatulation of the vessels is necessary to avoid constriction at the anastomotic site. Constricted arterial or venous lumina will increase the risk of graft thrombosis, in particular in the context of reduced renal blood flow after acute ischemic injury. After unfavourable pilot experiments with small pigs weighing 20-30 kg and with heterotopic transplantation in the iliac fossa, we improved surgical success rates by using animals of at least $35 \mathrm{~kg}$ and by grafting the kidney orthotopically. ${ }^{24}$ Orthotopic kidney transplantation has the additional advantage of preventing ischemia of the hind leg due to iliac artery clamping. Surgery was further facilitated by the absence of accessory renal arteries in our experience. Permanent vascular access is essential for the experiments by enabling blood sampling and administration of fluids and drugs. To obtain vascular access, we implanted small handmade catheters in the internal carotid artery and jugular vein that were tunnelled subcutaneously and locked with antibiotics and proteases to prevent catheter obstruction and infection. ${ }^{5}$ Alternatively, a doublelumen Hickman catheter may be placed in the external jugular vein. Although the larger size of this catheter facilitates rapid administration of intravenous fluids, it is also more prone to infectious complications and is considerably more expensive. When performing autologous transplantation of ischemically injured kidneys in pigs, careful hemodynamic management is critical since the animals are transplanted within $24 \mathrm{~h}$ of the previous major surgery, and optimal renal perfusion is required to prevent further ischemic injury to the graft. After pilot experiments with restricted administration of fluids to prevent overload due to renal dysfunction, we increased the survival rate of the animals by implementing a standardized and liberal fluid regimen to avoid dehydration in the early postoperative period. During transplant surgery, fluids were 


\section{Chapter 2}

given as needed to maintain target mean arterial and central venous pressures. Administration of vasoactive drugs was not necessary in our experience, contributing to standardization of the experimental protocol.

In general, we adopted interventions known to improve graft function in human kidney transplantation: machine perfusion, hemodynamic optimization, and administration of mannitol at reperfusion. ${ }^{8,25,26}$ Renal function after kidney transplantation with this protocol was superior to previous reports from other laboratories, ${ }^{15-18}$ and was in line with expected results in human kidney transplantation from young organ donors. These findings indicate that results from this large animal model are highly applicable to clinical kidney transplantation. Early graft function after autologous transplantation of ischemically injured kidneys was evaluated by measuring serum creatinine concentrations. In pigs, these concentrations are strongly correlated to glomerular filtration rates, in particular when adjusted for animal weight. ${ }^{27,}{ }^{28} \mathrm{~A}$ more accurate assessment of renal function can be obtained by measuring creatinine clearance and sodium reabsorption in timed urine collections, which requires ureterocutaneostomy or suprapubic catheterization. ${ }^{29-31}$ Additional information on the extent of ischemic acute kidney injury can be obtained from histologic assessment of renal biopsies.

Although it is convenient to take open biopsies during transplant surgery, adequate assessment of renal injury and leukocyte infiltration requires biopsies to be taken at later time points. We therefore recommend taking percutaneous needle biopsies under ultrasound guidance and light anesthesia on the first or second day after transplantation, which we have done successfully in subsequent experiments.

In conclusion, the current paper provides a comprehensive description of a porcine model of autologous transplantation of ischemically injured kidneys with an emphasis on perioperative care. The animal model was validated by showing that renal function after transplantation was proportional to the duration of warm ischemia before organ recovery. We consider the extent of renal dysfunction to be well reproducible between kidney transplantations with the same warm ischemia time, particularly when it is taken into account that small variations in creatinine clearance cause relatively large differences in serum creatinine concentrations in case of severely depressed kidney function. Our experience may improve preclinical testing of novel interventions that modulate renal ischemia and reperfusion injury and thereby enable more widespread use of kidneys from donors after cardiac death that have suffered prolonged ischemia. 


\section{ACKNOWLEDGEMENTS}

The authors thank Joyce Suyk, Petra Dijkstra, and Noortje Peeters for expert technical assistance.

\section{REFERENCES}

1. Lechler RI, Sykes M, Thomson AW, et al. Organ transplantation - how much of the promise has been realized? NatMed 2005;11:605.

2. Terasaki PI, Cho YW, Cecka JM. Strategy for eliminating the kidney shortage. Clin Transpl $1997 ; 265$.

3. Wijnen RM, Booster MH, Stubenitsky BM, et al. Outcome of transplantation of non-heartbeating donor kidneys. Lancet 1995;345:1067.

4. Sachs DH. The pig as a potential xenograft donor. Vet Immunol Immunopathol 1994;43:185.

5. Palm U, Boemke W, Bayerl D, et al. Prevention of catheter related infections by a new, catheter-restricted antibiotic filling technique. Lab Anim 1991;25:142.

6. Lee HT, $\operatorname{Kim~M,~Kim~N,~et~al.~Isoflurane~protects~against~renal~ischemia~and~reperfusion~}$ injury and modulates leukocyte infiltration in mice. Am J Physiol Renal Physiol 2007;293:F713.

7. Zwemer CF, Shoemaker JL Jr, Hazard SW III, et al. Hyperoxic reperfusion exacerbates postischemic renal dysfunction. Surgery 2000;128:815.

8. TiggelerRG,Berden JH,HoitsmaAJ, et al. Prevention of acute tubular necrosis in cadaveric kidney transplantation by the combined use of mannitol and moderate hydration. Ann Surg 1985;201:246.

9. Campbell MJ, Julious SA, Altman DG. Estimating sample sizes for binary, ordered categorical, and continuous outcomes in two group comparisons. Bmj 1995;311:1145.

10. Golby M, White HJ. The operation of orthotopic renal allografting in the pig and its complications. Br J Surg 1971;58:287.

11. Calne RY, Sells RA, Marshall VC, et al. Multiple organ grafts in the pig. Techniques and results of pancreatic, hepatic, cardiac, and renal allografts. Br J Surg 1972;59:969.

12. Terblanche J, Hickman R, Uys CJ. Renal transplantation in the unimmuno suppressed pig: An abnormal response. Br J Surg 1975;62:474.

13. Kirkman RL, Colvin RB, FlyeMW,et al. Transplantation in miniature swine. VI. Factors influencing survival of renal allografts. Transplantation 1979;28:18.

14. Nerstrom B, Gyrd-Hansen N, Iversen Hansen R, et al. Renal autotransplantation in the pig: Surgical aspects. Scand J Urol Nephrol 1972;6:151. 


\section{Chapter 2}

15. Lodge JP, Perry SL, Skinner C, et al. Improved porcine renal preservation with a simple extracellular solution-PBS140. Transplantation 1991;51:574.

16. Killion D, Canfield C, Norman J, et al. Exogenous epidermal growth factor fails to accelerate functional recovery in the autotransplanted ischemic pig kidney. J Urol 1993;150:1551.

17. Nicholson ML, Hosgood SA, Metcalfe MS, et al. A comparison of renal preservation by cold storage and machine perfusion using a porcine autotransplant model. Transplantation 2004;78:333.

18. Maathuis MH, Manekeller S, van der Plaats A, et al. Improved Kidney Graft Function After Preservation Using a Novel Hypothermic Machine Perfusion Device. Ann Surg 2007;246:982.

19. Hauet T, Goujon JM, Vandewalle A, et al. Trimetazidine reduces renal dysfunction by limiting the cold ischemia/reperfusion injury in autotransplanted pig kidneys. J Am Soc Nephrol 2000;11:138.

20. Kennedy SE, Erlich JH. Murine renal ischemia-reperfusion injury. Nephrology (Carlton) 2008;13:390.

21. Rosen S, Heyman SN. Difficulties in understanding human "acute tubular necrosis": Limited data and flawed animal models. Kidney Int 2001;60:1220.

22. McAnulty JF, Ploeg RJ, Southard JH, et al. Successful 5-day perfusion preservation of the canine kidney. Transplantation 1989; 47:37.

23. Rijkmans BG, Buurman WA, Kootstra G. Six-day canine kidney preservation. Hypothermic perfusion combined with isolated blood perfusion. Transplantation 1984;37:130.

24. Treckmann J, Nagelschmidt M, Saad S, et al.Decreasing surgical complications in porcine kidney autotransplantation by a new technique of implantation. J Exp Anim Sci 2007;43:231.

25. Moers C, Smits JM, Maathuis MH, et al. Machine perfusion or cold storage in deceaseddonor kidney transplantation. N Engl J Med 2009;360:7.

26. Snoeijs MG, Wiermans B, Christiaans MH, et al. Recipient hemodynamics during nonheart-beating donor kidney transplantation are major predictors of primary nonfunction. Am J Transplant 2007;7:1158.

27. Waldmann $\mathrm{KH}$, Wendt $\mathrm{M}$, Bickhardt $\mathrm{K}$. [Creatinine clearance as the foundation for clinical determination of kidney function in swine]. Tierarztl Prax 1991;19:373.

28. Gofrit ON, Orvieto MA, Zorn KC, et al. Serum creatinine can be used as a surrogate for glomerular filtration rate in single renal unit models. Can J Urol 2009;16:4452.

29. Yanaga K, Makowka L, Shimada M, et al. Improved method of porcine renal allografting for transplantation research. J Invest Surg 1991;4:231. 


\section{Renal Ischemia Reperfusion Injury}

30. Treckmann JW, Paul A, Saad S, et al. Primary organ function of warm ischemically damaged porcine kidneys after retrograde oxygen persufflation. Nephrol Dial Transplant 2006;21:1803.

31. Treckmann J, Nagelschmidt M, Minor T, et al. Function and quality of kidneys after cold storage, machine perfusion, or retrograde oxygen persufflation. Results from a porcine autotransplantation model. Cryobiology 2009. 


\section{Chapter 2.6}

\section{Influence of the Donor MBL Genotype on Outcome of Non- Heart-Beating Donor Kidney Transplantation.}

Robert A. Matthijsen*, Maarten G.J. Snoeijs*, Dian Kuipers, Rudi Steffensen, Maarten H. L. Christiaans, Ella M. van den Berg-Loonen, Geert Willem H. Schurink, L.W. Ernest van Heurn and Wim A. Buurman

* Both authors contributed equally

Submitted. 


\section{Abstract}

Mannose-binding lectin (MBL) is an initiating complement component of which both function and plasma levels are determined by various polymorphisms in the $\mathrm{mb} / 2$ gene. Since MBL contributes to ischemia reperfusion injury in experimental models, we studied the influence of donor and recipient $\mathrm{mb} / 2$ genotypes on clinical outcome following donation after cardiac death (DCD) kidney transplantation. 237 consecutive DCD kidney transplantations performed at our institution between January 1995 and December 2006 were included. Donors and recipients were stratified according to $m b / 2$ genotype, associated with high, intermediate or low MBL plasma levels. Primary non-function (PNF) occurred in 44 recipients (19\%). Donor mb/2 genotype was associated with PNF, but not with death-censored graft survival. In multivariable analysis, kidneys from intermediate MBL donors had more than twice the odds of developing PNF as compared to grafts from low or high MBL donors. Mb/2 genotype of the recipient was not correlated to transplant outcome in DCD kidneys. After confirmation of our findings, these data suggest that assessment of donor $\mathrm{mb} / 2$ genotype may aid risk stratification of DCD kidneys before transplantation.

\section{INTRODUCTION}

Kidney transplantation is the preferred treatment for patients with end-stage renal disease, resulting in superior life expectancy and quality of life when compared to long-term dialysis treatment. With an ever increasing shortage of suitable donor organs, ways to increase the donor pool are sought continuously. Therefore, the use of living donors and deceased donors with extended donor criteria has increased over the past decade. Use of organs from donors after cardiac death, also known as nonheart-beating donors (NHBD), may further alleviate the organ shortage and substantially increase the donor pool, possibly as much as 4.5 times..$^{1,2}$ Inevitably, kidneys procured from NHBD have longer warm ischemia times than grafts from brain-dead, heart-beating donors (HBD). This additional warm ischemia increases cellular damage upon reperfusion and is associated with a higher rate of delayed graft function (DGF) and primary non-function (PNF) in kidneys procured from NHBD.

Activation of complement by the lectin pathway after reperfusion of renal allografts from NHBD was first shown by our group in 2004. ${ }^{3}$ Using biopsies taken 


\section{Chapter 2}

within 1 hour of reperfusion, mannose-binding lectin (MBL) was observed in glomeruli of NHBD kidneys with DGF and was deposited more extensively in peritubular capillaries and tubular epithelium of NHBD kidneys with PNF. In contrast, MBL was not found in pre-implantation biopsies of these kidneys or in reperfusion biopsies of HBD kidneys that did not suffer warm ischemia prior to recovery. In line, MBL was observed in peritubular capillaries and tubular epithelium within 1-2 hours after reperfusion of ischemic murine kidneys. MBL completely co-localized with downstream complement components C3, C6 and C9 that were deposited in the kidney at later time points after reperfusion. Furthermore, MBL-A and -C deficient mice had better renal function and tissue integrity than wild-type mice after ischemia and reperfusion of the kidney. ${ }^{4}$ Taken together, these findings indicate that the lectin pathway of complement is activated at reperfusion of ischemically injured donor kidneys and contributes to reperfusion injury. On the other hand, C4 deficient mice have similar kidney function after renal ischemia and reperfusion as wild-type mice. ${ }^{5}$ Whether these observations in experimental renal IR can be explained by in vitro results that demonstrate possible alternative complement pathway activating properties for bound MBL, without the involvement of $\mathrm{C} 2$ and possibly even C4, remains uncertain. ${ }^{6}$ Such in vivo and in vitro data do however provide a tentative view on a more prominent and complex role for MBL during renal IR.

$M B L$ is a plasma effector protein and functions as part of the innate immune system. Together with MBL-associated serine proteases (MASP) it binds various sugar structures on invading pathogens to initiate complement activity. ${ }^{7,8} \mathrm{MBL}$ may bind specific damage associated molecular patterns (DAMP) in the reperfused ischemic tissue. ${ }^{9}$ Following IR induced tissue damage, MBL can bind altered self-structures, specific danger associated molecular patterns. Possibly in association with a-specific deposition of IgM oligomer structures in the reperfused tissue, MBL is able to activate complement via the lectin pathway. ${ }^{10,11}$ Different experimental studies have linked functional $M B L$ and $M B L$ deposition in the reperfused tissue to the development of IR induced organ damage in renal, myocardial and intestinal experimental animal models., 12, 13 In man, such data are limited, since experimental IR organ models are lacking. Recently however, we were able to demonstrated a relationship between specific point mutations on the human $\mathrm{mb} / 2$ gene, associated with reduced functional MBL levels, and reduced levels of enterocyte damage in an experimental human small intestinal IR model. ${ }^{14}$ Both plasma level and function of MBL are 
strongly linked to point mutations in the structural (codons 52, 54 and 57 in exon 1) and regulatory part (position $-550(\mathrm{H} / \mathrm{L})$ and $-221(\mathrm{X} / \mathrm{Y})$ in the promoter region) of the MBL gene $(\mathrm{mb} / 2){ }^{8}$ Wildtype $(\mathrm{A})$ and variant $(\mathrm{O}) \mathrm{mb} / 2$ alleles located in the first exon of the $\mathrm{mb} / 2$ gene are in strong linkage disequilibrium with a limited number of polymorphisms in the promoter region $(\mathrm{H} / \mathrm{L}, \mathrm{X} / \mathrm{Y}$ and $\mathrm{Q} / \mathrm{P})$ giving rise to well characterized $\mathrm{mb} / 2$ haplotypes in the Caucasian population. Plasma concentrations in individuals are mainly controlled by $X / Y$ promoter mutations and the first exon variants $\mathrm{A} / \mathrm{O}$. Carriers of YA/YA and YA/XA mb/2 alleles have relatively high mean plasma levels of functional MBL of about $2450 \mathrm{ng} / \mathrm{ml}$ (1030-5450 ng/ml), whereas carriers of XA/XA and YA/YO mb/2 alleles have intermediate mean plasma levels of functional MBL of about $780 \mathrm{ng} / \mathrm{ml}(210-1440 \mathrm{ng} / \mathrm{ml})$. Carriers of XA/YO and YO/YO $\mathrm{mb} / 2$ alleles have low plasma levels of functional $\mathrm{MBL}$, with mean levels of approximately $20 \mathrm{ng} / \mathrm{ml}(10-60 \mathrm{ng} / \mathrm{ml}){ }^{15,16}$ Carriers of variant $\mathrm{mb} / 2$ alleles express low levels of a disrupted MBL protein without immunological function, which is associated with increased susceptibility to infectious disease. ${ }^{17-19}$ In contrast, individuals with low MBL plasma levels have superior graft survival of HBD kidneys and simultaneous pancreas-kidney transplants. ${ }^{20,21}$

Proximal tubular epithelial cells can act as immune accessory cells that are able to generate a variety of inflammatory mediators, including complement, cytokines, chemokines and pattern recognition receptors. ${ }^{22-24}$ Furthermore, the extensive network of resident dendritic cells in the renal interstitium has recently been shown to be a major source of inflammatory mediators after ischemia and reperfusion. ${ }^{25}$ The importance of local production of complement was demonstrated by transplantation of kidneys between C3-deficient and wild-type mice. Local synthesis of C3 by the allograft was found to induce ischemia reperfusion injury and acute rejection, whereas systemically circulating C3 had a negligible effect. ${ }^{26}$ In line with these experimental findings, donor C3 polymorphisms were associated with long-term graft survival in a cohort of clinical kidney transplantations. ${ }^{27}$

Considering the rapid deposition of MBL in reperfused NHBD kidneys after reperfusion, particularly in grafts with primary failure, and the strong association between $\mathrm{mb} / 2$ genotype and functional MBL concentration, we studied the association between donor and recipient $\mathrm{mb} / 2$ genotypes and clinical outcome of NHBD kidney transplantation to further delineate the role of $\mathrm{MBL}$ in renal ischemia and reperfusion injury. 


\section{Chapter 2}

\section{Patients and Methods}

\section{Patients}

237 consecutive NHBD kidney transplantations, performed at our institution between January $1^{\text {st }}, 1995$ and December 315t, 2006, were included in the current study. Transplant characteristics and outcomes were recorded in a prospectively updated database. Initial graft function was categorized as immediate function (IF: post-operative dialysis was not necessary), delayed graft function (DGF: dialysis was required in the first week post-transplant but life-supporting graft function was eventually achieved), or primary non-function (PNF: dialysis could never be discontinued). Patients were followed up until December 31 ${ }^{\text {st }}, 2006$; one patient was lost to follow up after graft failure. Primary endpoints of the study are PNF and death-censored graft survival and secondary endpoints were DGF, acute rejection, kidney function after transplantation as estimated by the MDRD formula and recipient survival.

\section{Kidney transplantation}

The NHB donation protocol was carried out as described before. ${ }^{28}$ In brief, under sterile conditions a double balloon triple lumen catheter was introduced into the abdominal aorta through the femoral artery. After inflation of both catheter balloons selective perfusion of the abdominal aorta was possible and ISP was commenced using cold histidine-tryptophan-ketoglutarate (HTK) solution. A Foley catheter was introduced unilaterally into the femoral vein to allow the perfusate to drain. Biopsies were taken for histologic assessment of graft quality after careful inspection of the graft by the transplant surgeon. NHBD kidneys were preserved by hypothermic machine pulsatile perfusion on a Gambro PF-3B machine (LifePort machine in case of ORS-trial) using UW-MPS (Belzer MPS, Trans-Med Corporation, Elk River, MN). Kidneys were allocated according to the Eurotransplant policy. ${ }^{29}$

The immunosuppressive regimen evolved over the study period. Immunosuppression was mainly based on a combination of prednisolone and a calcineurin inhibitor (cyclosporine or tacrolimus). Depending on the protocol at the time, these were combined with azathioprine, mycophenolate mofetil (MMF), sirolimus or daclizumab in recipients with an increased immunological risk (e.g. HLA immunization and re-transplants). Twenty percent of patients experienced an episode of biopsy-proven acute rejection. Patients with tubulo-interstitial rejection 
were given methylprednisolone; vascular and steroid-resistant rejections were treated with anti-thymocyte globulins.

\section{MBL genotyping}

Donor and recipient DNA were routinely collected before transplantation for HLAI and -II typing and stored at $-80^{\circ} \mathrm{C}$. Using the DNA samples, $\mathrm{mb} / 2$ genotypes were assessed as described earlier. ${ }^{15,16,30}$ In brief, sequence specific primers were developed to analyze single nucleotide polymorphisms in the $\mathrm{mb} / 2$ gene $(\mathrm{mb} / 2$ $550(\mathrm{H} / \mathrm{L}), \mathrm{mb} / 2-221(\mathrm{X} / \mathrm{Y}), \mathrm{mb} / 2+4(\mathrm{P} / \mathrm{Q})$, located in the promoter region and $\mathrm{mb} / 2$ codon 52(D), mb/2 codon 54(B), mb/2 codon 57(C) located in the first exon by LightCycler amplification (Roche Molecular Biochemicals). Using 50 ng of genomic DNA in a total volume of $20 \mu \mathrm{l}$ with set amounts of unlabelled primers, detection probe, anchor probe, $\mathrm{Mg}^{2+}$ and $2 \mu \mathrm{l}$ of $10 \mathrm{x}$ LightCycler-DNA master hybridization probes from Roche Diagnostics. Following amplification, a final melting curve was recorded. Genotypes were classified according to their association with high, intermediate or low MBL concentrations.

\section{Quantitative PCR analysis of MBL gene expression}

cDNA synthesized from human liver derived total RNA isolate served as positive control sample for hMBL. Specific primers (Sigma) for amplification of hMBL were designed using the Primer Express software package (Applied Biosystems, Foster City, CA) and tested for amplification of contaminating genomic DNA. ${ }^{31}$ To minimize the risk of genomic amplification the primers were positioned on different exons. Primer concentrations were optimalized and dilution curves were made from human liver cDNA standard pool to ensure an exponential TaqMan amplification for each primer set. The sequences of oligonucleotide primers were: MBL, 5' GGGTCACCAGGACCAAAGG-3' (forward) and 5'-CAGCCAGGCTACTATCACCAT3' (reversed). Quantitative real-time PCR was performed with the ABsolute SYBR Green Master Mix (ABgene, Leusden, the Netherlands) and the iQ5 iCycler (BioRad). Relative expression was assessed in duplicate by the delta cycle threshold method after normalization for ß-actin and ß2-microglobulin expression.

\section{Statistical Analysis}

Continuous variables are given as means \pm standard deviation (mean and range for standard MBL levels in M\&M section) $)^{15}$ or medians with minimum and maximum 


\section{Chapter 2}

values, depending on data distribution. Values were compared using the one-way analysis of variance (ANOVA) or Kruskal-Wallis test, respectively. Differences in categorical variables between groups were analyzed using the $\chi^{2}$ test and presented as percentages. Graft survival curves according to donor or recipient $\mathrm{mb} / 2$ genotype were constructed by the Kaplan-Meier method and compared using the log-rank test. Graft survival of NHBD kidneys was censored for recipient death with functioning graft and for PNF to study graft failure after the immediate postoperative period. To exclude confounding effects of other risk factors associated with PNF or graft survival, transplant characteristics not equally distributed between $\mathrm{mb} / 2$ genotype groups $(\mathrm{P}<0.20$ ) were further analyzed in a multivariable backward-stepwise logistic regression model (exclusion at P $>0.10$ ). P-values below 0.05 were considered as statistically significant. Data were analyzed using SPSS for Windows (Version 12.0.1; SPSS, Inc. Chicago, IL).

\section{Ethics}

Collection, storage and use of tissue and patient data were performed in agreement with the codes of conduct 'Use of data in health research' and 'Proper secondary use of human tissue' put forward by the federation of Dutch medical scientific societies (http://www.federa.org/) and the local institutional review board.

\section{Results}

\section{Transplant characteristics}

Between January $1^{\text {st }}, 1995$ and December 315t, 2006, 237 NHBD kidney transplantations were performed at our institution. Four transplants were excluded from analysis because initial graft function could not be assessed due to recipient death in the post-operative period ( $\mathrm{N}=3$ ) or graft removal for malignancy found at donor autopsy $(\mathrm{N}=1)$. Kidney donors and recipients were grouped according to $\mathrm{mb} / 2$ genotypes associated with high, intermediate or low plasma MBL levels. Transplant characteristics of these groups are presented in Table 1A and 1B.

\section{Association of donor mbl2 genotype with transplant outcomes}

Out of 233 NHBD kidney transplantations, 44 (19\%) recipients experienced primary non-function. Recipients of kidneys from MBL low donors had 19\% PNF, whereas grafts from MBL intermediate donors showed 26\% PNF and kidneys from 
Table 1A. Distribution of patient characteristics according to donor MBL genotype

\begin{tabular}{|c|c|c|c|c|}
\hline \multirow[t]{2}{*}{ 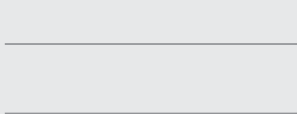 } & \multicolumn{4}{|c|}{ Donor MBL genotype } \\
\hline & $\begin{array}{l}\text { Low } \\
(n=38)\end{array}$ & $\begin{array}{l}\text { Intermediate } \\
(\mathrm{n}=82)\end{array}$ & $\begin{array}{c}\text { High } \\
(n=116)\end{array}$ & $p$-Value \\
\hline \multicolumn{5}{|l|}{ Donor characteristics } \\
\hline Sex (male) & $57 \%$ & $66 \%$ & $64 \%$ & 0.58 \\
\hline Age (yrs) & $44(15-71)$ & $50(2-74)$ & $49(14-74)$ & 0.57 \\
\hline Diabetes mellitus & $3 \%$ & $2 \%$ & $0 \%$ & 0.26 \\
\hline Hypertension & $17 \%$ & $12 \%$ & $16 \%$ & \\
\hline Creatinine (mmol/L) & $77(12-232)$ & $92(24-248)$ & $83(8-289)$ & 0.20 \\
\hline NHB-Category 2 & $40 \%$ & $38 \%$ & $30 \%$ & 0.36 \\
\hline Procurement center (local) & $51 \%$ & $63 \%$ & $57 \%$ & 0.43 \\
\hline Cardiovascular events & $8 \%$ & $23 \%$ & $23 \%$ & 0.32 \\
\hline \multicolumn{5}{|l|}{ Cause of death } \\
\hline Cardiovascular & $30 \%$ & $40 \%$ & $32 \%$ & \multirow{4}{*}{0.04} \\
\hline Neurological & $30 \%$ & $28 \%$ & $42 \%$ & \\
\hline Trauma & $40 \%$ & $22 \%$ & $21 \%$ & \\
\hline Other & $0 \%$ & $10 \%$ & $5 \%$ & \\
\hline \multicolumn{5}{|l|}{ Graft characteristics } \\
\hline Warm ischemic time (hrs) & $28 \pm 10$ & $26 \pm 11$ & $24 \pm 9$ & 0.11 \\
\hline Cold ischemic time (hrs) & $24 \pm 6$ & $26 \pm 7$ & $25 \pm 6$ & 0.22 \\
\hline Kidney weight (g) & $243 \pm 60$ & $247 \pm 68$ & $235 \pm 63$ & 0.54 \\
\hline Resuscitation time (min) & $33(10-60)$ & $48(0-286)$ & $30(0-438)$ & 0.08 \\
\hline Anastomosis time (min) & $35(24-60)$ & $34(16-175)$ & $35(19-91)$ & 0.76 \\
\hline \multicolumn{5}{|l|}{ Recipient characterisitcs } \\
\hline Sex (male) & $53 \%$ & $66 \%$ & $67 \%$ & 0.25 \\
\hline Age (yrs) & $53 \pm 11$ & $55 \pm 12$ & $53 \pm 14$ & 0.59 \\
\hline Dialysis time (yrs) & $4(0.6-19)$ & $3(0.3-25)$ & $3(0.5-20)$ & 0.04 \\
\hline Dialysis type (hemodialysis) & $53 \%$ & $67 \%$ & $66 \%$ & 0.25 \\
\hline Retransplants & $8 \%$ & $15 \%$ & $12 \%$ & 0.58 \\
\hline HLA-mismatches & $3(0-4)$ & $3(1-5)$ & $3(0-6)$ & 0.79 \\
\hline Average CVP & $8 \pm 4$ & $8 \pm 3$ & $8 \pm 3$ & 0.95 \\
\hline \multicolumn{5}{|l|}{ Kidney disease } \\
\hline Vascular & $18 \%$ & $21 \%$ & $18 \%$ & \multirow{3}{*}{0.96} \\
\hline Other & $71 \%$ & $67 \%$ & $69 \%$ & \\
\hline Unknown & $11 \%$ & $12 \%$ & $13 \%$ & \\
\hline \multicolumn{5}{|l|}{ Immunotherapie } \\
\hline Tacrolimus/cyclosporine & $90 \% 15 \%$ & $87 \% / 7 \%$ & $85 \% / 10 \%$ & $0.81 / 0.68$ \\
\hline MMF & $29 \%$ & $35 \%$ & $41 \%$ & 0.35 \\
\hline Sirolimus & $58 \%$ & $37 \%$ & $34 \%$ & 0.03 \\
\hline \multicolumn{5}{|l|}{ Graft Outcome } \\
\hline Immediate Function & $19 \%$ & $20 \%$ & $17 \%$ & 0.25 \\
\hline DGF & $62 \%$ & $54 \%$ & $69 \%$ & \\
\hline Duration DGF (days) & $22(4-93)$ & $13(1-101)$ & $16(1-121)$ & 0.13 \\
\hline PNF & $19 \%$ & $26 \%$ & $14 \%$ & 0.11 \\
\hline Rejection & $16 \%$ & $17 \%$ & $24 \%$ & 0.38 \\
\hline Survival-5y & $83 \%$ & $91 \%$ & $80 \%$ & 0.06 \\
\hline GFR-5y & $48 \pm 26$ & $38 \pm 17$ & $44 \pm 17$ & 0.27 \\
\hline
\end{tabular}




\section{Chapter 2}

Table 1B. Distribution of patient characteristics according to recipient MBL genotype

\begin{tabular}{|c|c|c|c|c|}
\hline & & & ient MBL gen & \\
\hline & $\begin{array}{l}\text { Low } \\
(n=39)\end{array}$ & $\begin{array}{c}\text { Intermediate } \\
(n=81)\end{array}$ & $\begin{array}{c}\text { High } \\
(n=116)\end{array}$ & $p$-Value \\
\hline Donor characteristics & & & & \\
\hline Sex (male) & $67 \%$ & $66 \%$ & $61 \%$ & 0.71 \\
\hline Age (yrs) & $48(3-68)$ & $48(2-74)$ & $50(3-74)$ & 0.76 \\
\hline Diabetes mellitus & $5 \%$ & $0 \%$ & $1 \%$ & 0.13 \\
\hline Hypertension & $19 \%$ & $11 \%$ & $18 \%$ & 0.49 \\
\hline Creatinine (mmol/L) & $90(27-289)$ & $91(12-248)$ & $95(8-248)$ & 0.28 \\
\hline NHB-Category 2 & $39 \%$ & $29 \%$ & $36 \%$ & 0.45 \\
\hline Procurement center (local) & $67 \%$ & $58 \%$ & $56 \%$ & 0.50 \\
\hline Cardiovascular events & $36 \%$ & $15 \%$ & $20 \%$ & 0.10 \\
\hline Cause of death & & & & \\
\hline Cardiovascular & $44 \%$ & $30 \%$ & $34 \%$ & \\
\hline Neurological & $36 \%$ & $35 \%$ & $36 \%$ & 049 \\
\hline Trauma & $21 \%$ & $27 \%$ & $24 \%$ & 0.49 \\
\hline Other & $0 \%$ & $9 \%$ & $6 \%$ & \\
\hline Graft characteristics & & & & \\
\hline Warm ischemic time (hrs) & $30(5-45)$ & $23(10-52)$ & $24(7-63)$ & 0.29 \\
\hline Cold ischemic time (hrs) & $24 \pm 5$ & $25 \pm 7$ & $26 \pm 7$ & 0.39 \\
\hline Kidney weight (g) & $249 \pm 57$ & $245 \pm 67$ & $235 \pm 66$ & 0.52 \\
\hline Resuscitation time (min) & $52(0-438)$ & $33(0-286)$ & $31(0-110)$ & 0.25 \\
\hline Anastomosis time (min) & $34(23-70)$ & $35(16-91)$ & $35(19-175)$ & 0.75 \\
\hline Recipient characterisitcs & & & & \\
\hline Sex (male) & $77 \%$ & $64 \%$ & $60 \%$ & 0.17 \\
\hline Age (yrs) & $57(26-72)$ & $58(22-73)$ & $56(20-75)$ & 0.67 \\
\hline Dialysis time (yrs) & $3(1-25)$ & $4(0.3-19)$ & $4(1-20)$ & 0.14 \\
\hline Dialysis type (hemodialysis) & $64 \%$ & $62 \%$ & $66 \%$ & 0.80 \\
\hline Retransplants & $8 \%$ & $16 \%$ & $11 \%$ & 0.38 \\
\hline HLA-mismatches & $3(1-5)$ & $3(0-5)$ & $2(0-6)$ & 0.13 \\
\hline Average CVP & $7 \pm 3$ & $8 \pm 4$ & $7 \pm 3$ & 0.42 \\
\hline Kidney disease & & & & \\
\hline Vascular & $15 \%$ & $16 \%$ & $22 \%$ & \\
\hline Other & $72 \%$ & $69 \%$ & $67 \%$ & 0.70 \\
\hline Unknown & $13 \%$ & $15 \%$ & $10 \%$ & \\
\hline Immunotherapie & & & & \\
\hline Tacrolimus/cyclosporine & $85 \% / 8 \%$ & $84 \% / 11 \%$ & $89 \% / 6 \%$ & 0.58 \\
\hline MMF & $33 \%$ & $41 \%$ & $36 \%$ & 0.69 \\
\hline Sirolimus & $36 \%$ & $40 \%$ & $39 \%$ & 0.92 \\
\hline Graft Outcome & & & & \\
\hline Immediate Function & $11 \%$ & $20 \%$ & $20 \%$ & 0.29 \\
\hline DGF & $63 \%$ & $58 \%$ & $65 \%$ & \\
\hline Duration DGF (days) & $16(1-52)$ & $14(1-74)$ & $24(1-121)$ & 0.54 \\
\hline PNF & $26 \%$ & $22 \%$ & $14 \%$ & 0.16 \\
\hline Rejection & $13 \%$ & $19 \%$ & $24 \%$ & 0.28 \\
\hline Survival-5y & $82 \%$ & $87 \%$ & $84 \%$ & 0.76 \\
\hline GFR-5y & $46 \pm 13$ & $38 \pm 21$ & $43 \pm 17$ & 0.38 \\
\hline
\end{tabular}


MBL high donors developed 14\% PNF (P = 0.11, Table 1A). Since not all transplant characteristics were distributed evenly among donor $\mathrm{mb} / 2$ genotypes, we corrected for these potential confounders by multivariable logistic regression (Table 2). After correction, the effect of donor mb/2 genotype on development of PNF was statistically significant $(P=0.05)$. Kidneys from $M B L$ intermediate donors had 2.5fold higher odds of PNF (95\% $\mathrm{Cl}$ : 1.2-5.4, $\mathrm{P}=0.02)$ compared to grafts from $\mathrm{MBL}$ high donors and 2.1-fold higher odds of PNF (95\% Cl: 0.7-5.9 P = 0.16) compared to kidneys from MBL low donors.

Table 2. Multivariable risk analysis for PNF of NHBD kidney transplants

\begin{tabular}{llccc} 
& $\begin{array}{l}\text { Univariate } \\
\text { OR }(95 \% \mathrm{Cl})\end{array}$ & P - value & AOR $(95 \% \mathrm{Cl})$ & P - value \\
\hline Donor MBL & & 0.11 & & 0.055 \\
$\quad$ Low vs. High & $1.4(0.54-3.8)$ & 0.46 & $1.2(0.42-3.4)$ & 0.75 \\
$\quad$ Intermediate vs. High & $2.2(1.0-4.5)$ & 0.04 & $2.5(1.2-5.4)$ & 0.02 \\
Cause of death & & 0.90 & & 0.97 \\
$\quad$ Neurological vs. Cardiovascular & $0.82(0.38-1.8)$ & 0.61 & $1.2(0.53-2.8)$ & 0.62 \\
$\quad$ Trauma vs. Cardiovascular & $0.73(0.31-1.7)$ & 0.47 & $1.1(0.42-2.9)$ & 0.86 \\
$\quad$ Other vs. Cardiovascular* & - & - & - & - \\
WIT (min) & $1.04(1.01-1.08)$ & 0.008 & $1.04(1.01-1.08)$ & 0.02 \\
Resuscitation time (min) & $1.00(1.00-1.01)$ & 0.22 & & 0.13 \\
Dialysis time (yrs) & $0.85(0.72-1.01)$ & 0.07 & $0.86(0.71-1.0)$ & 0.08 \\
Sirolimus (Yes vs. No) & $1.6(0.82-3.1)$ & 0.17 & $1.9(0.92-3.8)$ & \\
\hline
\end{tabular}

Subsequently, we studied the association of donor $\mathrm{mb} / 2$ genotype with deathcensored graft survival of functioning kidneys $(\mathrm{N}=189$, Figure 1$)$. Graft survival differed among kidneys from donors with different $\mathrm{mb} / 2$ genotypes with a trend towards statistical significance $(P=0.06$, Table $1 \mathrm{~A})$. Grafts from $\mathrm{MBL}$ intermediate donors had improved graft survival compared to grafts from MBL high and low donors $(83 \%, 91 \%$ and $80 \%$ at 5 years after transplantation for MBL low, intermediate and high donors, respectively). To validate these findings, multivariable Cox regression was used to correct for potentially confounding 


\section{Chapter 2}

transplant characteristics that were unevenly distributed among the study groups. With this analysis, the association between the donor MBL genotype and graft survival was no longer statistically significant for intermediate $(P=0.16)$ or high ( $P$ $=0.20) \mathrm{MBL}$ donors compared their low MBL counterparts (data not shown).

These data might imply that kidneys, derived from DCD donors carrying the heterozygous $\mathrm{mb} / 2$ genotype are more vulnerable to develop PNF, however demonstrate similar qualities in graft survival. What cause might explain these results remain speculative, but possibly involves the ability of renal grafts to express $M B L$, a powerful innate regulator of immunity.

\section{Association of recipient $m b / 2$ genotype with transplant outcomes}

MBL low recipients of NHB donor kidneys had 26\% PNF, whereas MBL intermediate patients showed 22\% PNF and MBL high recipients developed $14 \%$ PNF $(P=0.16$, Table 1B). Graft survival did not differ among recipients with different MBL genotypes $(82 \%, 87 \%$ and $84 \%$ at 5 years after transplantation, for low, intermediate and high donors respectively, $\mathrm{P}=0.76$, Table 1B). Lack of association of recipient MBL genotype with primary non-function and graft survival was confirmed after correction for potential confounders by multivariable logistic and Cox regression, respectively (Table 3 and Figure 1).

Table 3. Multivariable risk analysis for graft failure of NHBD kidney transplants

\begin{tabular}{llccc} 
& Univariate & & Multivariate & \\
& OR $(95 \% \mathrm{Cl})$ & P - value & AOR $(95 \% \mathrm{Cl})$ & P - value \\
\hline Recipient MBL & & 0.16 & & 0.21 \\
$\quad$ Low vs. High & $2.2(0.89-5.4)$ & 0.09 & $1.9(0.75-5.0)$ & 0.18 \\
$\quad$ Intermediate vs. High & $1.8(0.83-3.7)$ & 0.14 & $1.9(0.86-4.0)$ & 0.12 \\
Diabetes (Yes vs. No) & $8.3(0.73-94)$ & 0.09 & $5.9(0.49-71)$ & 0.16 \\
Cardiovascular events (Yes vs. No) & $1.9(0.83-4.2)$ & 0.13 & $1.6(0.67-3.7)$ & 0.30 \\
Recipient sex (Female vs. Male) & $1.1(0.58-2.3)$ & 0.69 & & \\
Dialysis time (yrs) & $0.85(0.72-1.01)$ & 0.07 & $0.89(0.75-1.0)$ & 0.16 \\
HLA-mismatches & $1.1(0.78-1.5)$ & 0.59 & & \\
\hline
\end{tabular}


A

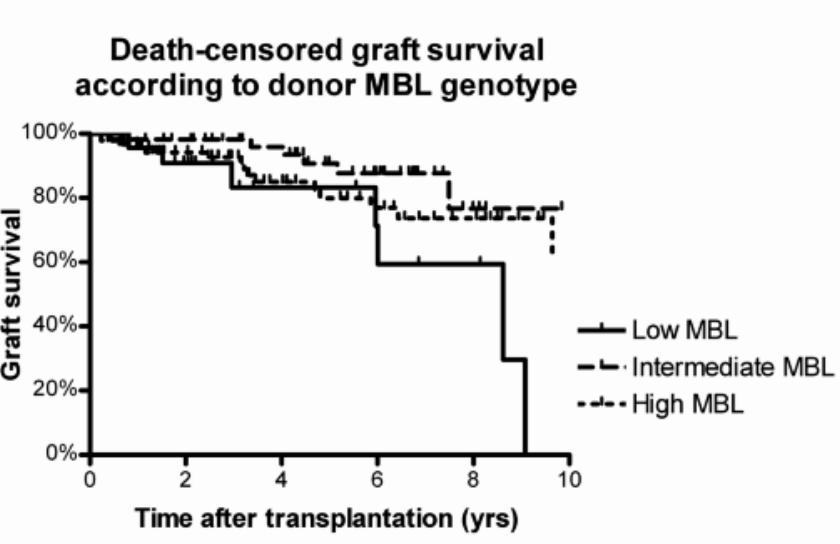

B

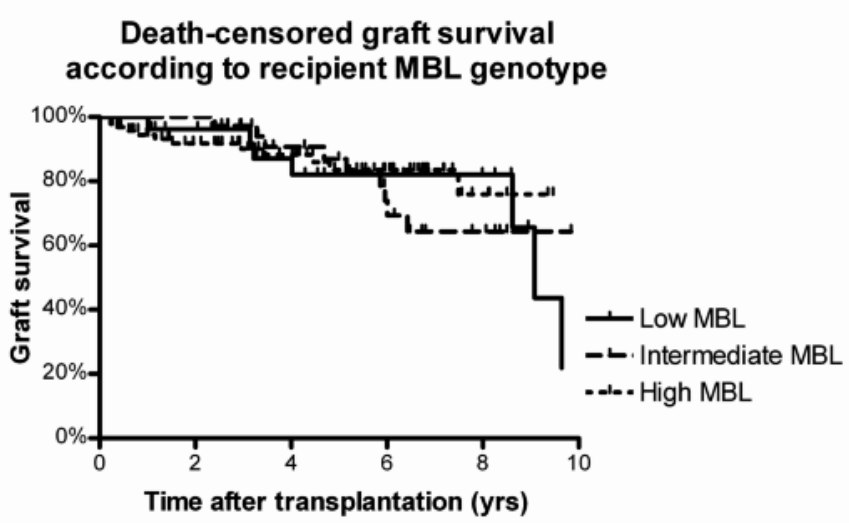

Figure 1. Death-censored graft survival according to donor (A) or recipient (B) $m b / 2$ genotype. Both donor and recipient $m b / 2$ genotype had no influence on death-censored graft survival following Cox regression analysis.

Kidney donor MBL gene expression

For the donor $\mathrm{mb} / 2$ genotype to influence the outcome of DCD kidney transplantation, local expression of MBL by transplanted renal allografts is critical. Renal MBL mRNA expression in man has however not been observed, when analyzed in healthy renal biopsies. ${ }^{32} \mathrm{Mb} / 2$ gene expression has in the past been demonstrated in murine renal samples and has been demonstrated to be 


\section{Chapter 2}

influenced by IR. ${ }^{3}$ In order to determine graft associated $\mathrm{mb} / 2$ gene expression, the presence of MBL specific mRNA was assessed in $4 \mathrm{~h}$ reperfusion donor kidney biopsies. Strikingly, 5 out of 8 investigated samples demonstrated expression of the $\mathrm{mb} / 2$ gene during early reperfusion (data not shown). Renal $\mathrm{mb} / 2$ gene expression following IR in man forms a prerequisite for a role of the donor $\mathrm{mb} / 2$ genotype on the outcome of DCD kidney transplantation in man. What cells are responsible for the renal $\mathrm{mb} / 2$ gene expression following IR remains to be investigated.

\section{Discussion}

The use of organs procured from donors after cardiac death holds great potential in reducing the increasing shortage of transplant organs. Due to their prolonged exposure to warm ischemia, kidneys from NHBD experience greater organ damage negatively influencing early transplant outcome. However, despite the increased incidence of PNF and DGF in these organs, long-term graft survival of functioning NHBD kidneys is similar to kidneys procured from HBD. ${ }^{33}$

Our group has previously reported that MBL is readily detected in reperfused ischemic kidneys and may initiate complement activation. ${ }^{3}$ The influence of MBL on the clinical course of NHBD kidney transplants remains unknown, however. $M B L$ function and plasma concentration are determined by variations in the $m b / 2$ gene. Therefore, we studied the association between donor and recipient $\mathrm{mb} / 2$ genotypes with transplant outcome. Our results show that donor $\mathrm{mb} / 2$ genotype is associated with primary non-function of NHBD kidneys, but not with deathcensored graft survival. Kidneys recovered from donors with intermediate $\mathrm{mb} / 2$ genotype have more than twice the odds of PNF compared to kidneys from donors with other $\mathrm{mb} / 2$ genotypes. These data indicate a role for local production of $\mathrm{MBL}$ by the transplanted kidney in the pathogenesis of PNF. Although MBL expression has not been observed in healthy human kidneys before, ${ }^{32}$ it is possible that our data demonstrate that ischemia and reperfusion induce expression of the $\mathrm{mb} / 2$ gene in the kidney. Human tubular epithelial cells have previously been shown to express several inflammatory mediators after reperfusion and experimental data indicate that MBL expression is induced in murine and rat kidneys after ischemia and reperfusion injury.,22-24 Furthermore, it has been demonstrated previously that local complement C3 expression by the transplanted kidney influences graft function and survival. ${ }^{26,27}$ These data might well illustrate that different immune 
modulatory proteins are expressed by the kidney in response to IR.

It remains to be elucidated why donor $\mathrm{mb} / 2$ genotypes associated with intermediate functional MBL plasma levels are associated with increased risk of PNF in NHBD kidney transplantation. MBL is a very diverse protein with various innate immune regulatory functions. It has been observed to contribute to several different pathophysiological mechanisms. Such contributions have mostly been linked by its wide range in protein plasma concentration as well as function among different $\mathrm{mb} / 2$ genotype carriers. On the one hand, variations in the $\mathrm{mb} / 2$ gene that compromise $\mathrm{MBL}$ activity and plasma quantity may be beneficial by attenuating the innate inflammatory response induced during surgery and ischemia reperfusion injury. 4,12,13,34 On the other hand, these variations have been demonstrated to compromise complement function and may induce susceptibility to infectious disease in children or render carriers of variant $\mathrm{mb} / 2$ alleles more susceptible to atherosclerosis development. ${ }^{31,35-39}$ Furthermore, MBL facilitates phagocytic removal of apoptotic cells and may therefore reduce inflammatory stimuli after ischemia and reperfusion. ${ }^{40,41}$ Classically, only wild-type MBL variant is considered to be biologically active. ${ }^{8}$ However, the presence of variant $\mathrm{mb} / 2$ genotypes in $40 \%$ of the Caucasian population gives rise to speculations on novel functions of MBL variants that confer biological advantage.8,42 In this regard, an intracellular form of MBL has recently been found that facilitates protein trafficking from the endoplasmic reticulum to the Golgi apparatus. ${ }^{43}$ Moreover, when compared to their wildtype $m b / 2$ haplotype controls, heterozygous and homozygous carriers of variant $\mathrm{mb} / 2$ alleles had reduced levels of enterocyte damage in response to small intestinal IR in man. ${ }^{14}$

In this study, we did not observe an association between recipient $\mathrm{mb} / 2$ genotype with the incidence of PNF or with graft survival of NHBD kidneys. These are possibly at variance with previous reports by Berger et al. on cohorts of patients that received kidneys or simultaneous kidney-pancreas grafts recovered from HBD. ${ }^{20,21}$ In these studies, recipients with high pre-transplant MBL plasma levels (>400 $\mathrm{ng} / \mathrm{ml}$ ) had reduced graft survival after HBD kidney transplantation as a result of an increased incidence of chronic rejection. In these studies the donor or recipient $\mathrm{mb} / 2$ genotype was not analyzed. Additionally, the possibility exists that recipients of simultaneous kidney-pancreas transplantation make up a specific study cohort, different from the more heterogeneous donor / recipient cohort analyzed in our studies. Effects of various MBL levels on disease development in 


\section{Chapter 2}

diabetic study cohorts have been analyzed, generating interesting results, possibly limited to this specific population. ${ }^{44,45}$ Considering the fact that MBL can act as an acute phase protein, mainly produced by the liver, and MBL plasma levels increase during acute and chronic disease, further analysis of both donor and recipient characteristics are warranted. ${ }^{44}$ Some authors consider analysis of $\mathrm{mb} / 2$ genotypes as superior to measurement of $\mathrm{MBL}$ plasma concentration for study of the longterm influence of MBL in human disease..$^{45}$ Especially, since systemic inflammation causes both increases in MBL plasma levels and chronic allograft nephropathy, the observations by Berger et al. may alternatively be explained by selection of recipients with more chronic inflammation in the study groups with high pretransplant MBL plasma levels.

In conclusion, our data show that the $m b / 2$ genotype of the donor is associated with short-term clinical outcome after NHBD kidney transplantation. Kidneys from intermediate MBL donors had more than twice the odds of developing PNF as compared to grafts from low or high MBL donors. Mb/2 genotype of the recipient was not correlated to transplant outcome in NHBD kidneys. These data suggest that assessment of donor $m b / 2$ genotype may aid risk stratification of a NHBD kidneys before transplantation.

\section{REFERENCES}

1. Cho YW, Terasaki PI, Cecka JM, Gjertson DW: Transplantation of kidneys from donors whose hearts have stopped beating, N Engl J Med 1998, 338:221-225

2. Kootstra G, Wijnen R, van Hooff JP, van der Linden CJ: Twenty percent more kidneys through a non-heart beating program, Transplant Proc 1991, 23:910-911

3. de Vries B, Walter SJ, Peutz-Kootstra CJ, Wolfs TG, van Heurn LW, Buurman WA: The mannose-binding lectin-pathway is involved in complement activation in the course of renal ischemia-reperfusion injury, Am J Pathol 2004, 165:1677-1688

4. Moller-Kristensen M, Wang W, Ruseva M, Thiel S, Nielsen S, Takahashi K, Shi L, Ezekowitz A, Jensenius JC, Gadjeva M: Mannan-binding lectin recognizes structures on ischaemic reperfused mouse kidneys and is implicated in tissue injury, Scand J Immunol 2005, 61:426-434

5. Zhou W, Farrar CA, Abe K, Pratt JR, Marsh JE, Wang Y, Stahl GL, Sacks SH: Predominant role for C5b-9 in renal ischemia/reperfusion injury, J Clin Invest 2000, 105:1363-1371 
6. Selander B, Martensson U, Weintraub A, Holmstrom E, Matsushita M, Thiel S, Jensenius JC, Truedsson L, Sjoholm AG: Mannan-binding lectin activates C3 and the alternative complement pathway without involvement of C2, J Clin Invest 2006, 116:1425-1434

7. Dommett RM, Klein N, Turner MW: Mannose-binding lectin in innate immunity: past, present and future, Tissue Antigens 2006, 68:193-209

8. Turner MW, Hamvas RM: Mannose-binding lectin: structure, function, genetics and disease associations, Rev Immunogenet 2000, 2:305-322

9. Ip WK, Takahashi K, Ezekowitz RA, Stuart LM: Mannose-binding lectin and innate immunity, Immunol Rev 2009, 230:9-21

10. Busche MN, Pavlov V, Takahashi K, Stahl GL: Myocardial ischemia and reperfusion injury is dependent on both IgM and mannose-binding lectin, Am J Physiol Heart Circ Physiol 2009, 297:H1853-1859

11. McMullen ME, Hart ML, Walsh MC, Buras J, Takahashi K, Stahl GL: Mannose-binding lectin binds IgM to activate the lectin complement pathway in vitro and in vivo, Immunobiology 2006, 211:759-766

12. Hart ML, Ceonzo KA, Shaffer LA, Takahashi K, Rother RP, Reenstra WR, Buras JA, Stahl GL: Gastrointestinal ischemia-reperfusion injury is lectin complement pathway dependent without involving C1q, J Immunol 2005, 174:6373-6380

13. Walsh MC, Bourcier T, Takahashi K, Shi L, Busche MN, Rother RP, Solomon SD, Ezekowitz RA, Stahl GL: Mannose-binding lectin is a regulator of inflammation that accompanies myocardial ischemia and reperfusion injury, J Immunol 2005, 175:541-546

14. Matthijsen RA, Derikx JP, Steffensen R, van Dam RM, Dejong CH, Buurman WA: Mannosebinding lectin null alleles are associated with preserved epithelial cell integrity following intestinal ischemia reperfusion in man, Mol Immunol 2009, 46:2244-2248

15. Steffensen R, Thiel S, Varming K, Jersild C, Jensenius JC: Detection of structural gene mutations and promoter polymorphisms in the mannan-binding lectin (MBL) gene by polymerase chain reaction with sequence-specific primers, J Immunol Methods 2000, 241:33-42

16. Steffensen R, Hoffmann K, Varming K: Rapid genotyping of MBL2 gene mutations using realtime PCR with fluorescent hybridisation probes, J Immunol Methods 2003, 278:191-199

17. Super M, Thiel S, Lu J, Levinsky RJ, Turner MW: Association of low levels of mannanbinding protein with a common defect of opsonisation, Lancet 1989, 2:1236-1239

18. Turner MW: Mannose-binding lectin (MBL) in health and disease, Immunobiology 1998, 199:327-339 


\section{Chapter 2}

19. Summerfield JA, Ryder S, Sumiya M, Thursz M, Gorchein A, Monteil MA, Turner MW: Mannose binding protein gene mutations associated with unusual and severe infections in adults, Lancet 1995, 345:886-889

20. Berger SP, Roos A, Mallat MJ, Fujita T, de Fijter JW, Daha MR: Association between mannose-binding lectin levels and graft survival in kidney transplantation, Am J Transplant 2005, 5:1361-1366

21. Berger SP, Roos A, Mallat MJ, Schaapherder AF, Doxiadis, II, van Kooten C, Dekker FW, Daha MR, de Fijter JW: Low pretransplantation mannose-binding lectin levels predict superior patient and graft survival after simultaneous pancreas-kidney transplantation, J Am Soc Nephrol 2007, 18:2416-2422

22. Bonventre JV, Zuk A: Ischemic acute renal failure: an inflammatory disease?, Kidney Int 2004, 66:480-485

23. Daha MR, van Kooten C: Is the proximal tubular cell a proinflammatory cell?, Nephrol Dial Transplant 2000, 15 Suppl 6:41-43

24. Wolfs TG, Buurman WA, van Schadewijk A, de Vries B, Daemen MA, Hiemstra PS, van 't Veer C: In vivo expression of Toll-like receptor 2 and 4 by renal epithelial cells: IFN-gamma and TNF-alpha mediated up-regulation during inflammation, J Immunol 2002, 168:12861293

25. Dong X, Swaminathan S, Bachman LA, Croatt AJ, Nath KA, Griffin MD: Resident dendritic cells are the predominant TNF-secreting cell in early renal ischemia-reperfusion injury, Kidney Int 2007, 71:619-628

26. Farrar CA, Zhou W, Lin T, Sacks SH: Local extravascular pool of C3 is a determinant of postischemic acute renal failure, Faseb J 2006, 20:217-226

27. Brown KM, Kondeatis E, Vaughan RW, Kon SP, Farmer CK, Taylor JD, He X, Johnston A, Horsfield C, Janssen BJ, Gros P, Zhou W, Sacks SH, Sheerin NS: Influence of donor C3 allotype on late renal-transplantation outcome, N Engl J Med 2006, 354:2014-2023

28. Snoeijs MG, Dekkers AJ, Buurman WA, van den Akker L, Welten RJ, Schurink GW, van Heurn LW: In situ preservation of kidneys from donors after cardiac death: results and complications, Ann Surg 2007, 246:844-852

29. Persijn GG: Allocation of organs, particularly kidneys, within Eurotransplant, Hum Immunol 2006, 67:419-423

30. Henckaerts L, Nielsen KR, Steffensen R, Van Steen K, Mathieu C, Giulietti A, Wouters PJ, Milants I, Vanhorebeek I, Langouche L, Vermeire S, Rutgeerts P, Thiel S, Wilmer A, Hansen TK, Van den Berghe G: Polymorphisms in innate immunity genes predispose to bacteremia and death in the medical intensive care unit, Crit Care Med 2009, 37:192-201, e191-193 
31. Matthijsen RA, de Winther MP, Kuipers D, van der Made I, Weber C, Herias MV, Gijbels MJ, Buurman WA: Macrophage-specific expression of mannose-binding lectin controls atherosclerosis in low-density lipoprotein receptor-deficient mice, Circulation 2009, 119:2188-2195

32. Seyfarth J, Garred P, Madsen HO: Extra-hepatic transcription of the human mannosebinding lectin gene $(\mathrm{mbl})$ and the MBL-associated serine protease 1-3 genes, Mol Immunol 2006, 43:962-971

33. Wijnen RM, Booster MH, Stubenitsky BM, de Boer J, Heineman E, Kootstra G: Outcome of transplantation of non-heart-beating donor kidneys, Lancet 1995, 345:1067-1070

34. Fiane AE, Videm V, Lingaas PS, Heggelund L, Nielsen EW, Geiran OR, Fung M, Mollnes TE: Mechanism of complement activation and its role in the inflammatory response after thoracoabdominal aortic aneurysm repair, Circulation 2003, 108:849-856

35. Madsen HO, Videm V, Svejgaard A, Svennevig JL, Garred P: Association of mannosebinding-lectin deficiency with severe atherosclerosis, Lancet 1998, 352:959-960

36. Ohlenschlaeger T, Garred P, Madsen HO, Jacobsen S: Mannose-binding lectin variant alleles and the risk of arterial thrombosis in systemic lupus erythematosus, $N$ Engl J Med 2004, 351:260-267

37. Keller TT, van Leuven SI, Meuwese MC, Wareham NJ, Luben R, Stroes ES, Hack CE, Levi M, Khaw KT, Boekholdt SM: Serum levels of mannose-binding lectin and the risk of future coronary artery disease in apparently healthy men and women, Arterioscler Thromb Vasc Biol 2006, 26:2345-2350

38. Hegele RA, Ban MR, Anderson CM, Spence JD: Infection-susceptibility alleles of mannosebinding lectin are associated with increased carotid plaque area, J Investig Med 2000, 48:198-202

39. Hansen TK: Mannose-binding lectin (MBL) and vascular complications in diabetes, Horm Metab Res 2005, 37 Suppl 1:95-98

40. Nauta AJ, Castellano G, Xu W, Woltman AM, Borrias MC, Daha MR, van Kooten C, Roos A: Opsonization with $\mathrm{C} 1 \mathrm{q}$ and mannose-binding lectin targets apoptotic cells to dendritic cells, J Immunol 2004, 173:3044-3050

41. Ogden CA, deCathelineau A, Hoffmann PR, Bratton D, Ghebrehiwet B, Fadok VA, Henson PM: $\mathrm{C} 1 \mathrm{q}$ and mannose binding lectin engagement of cell surface calreticulin and CD91 initiates macropinocytosis and uptake of apoptotic cells, J Exp Med 2001, 194:781-795

42. Hansson GK: Epidemiology complements immunology in the heart, Arterioscler Thromb Vasc Biol 2006, 26:2178-2180 


\section{Chapter 2}

43. Nonaka M, Ma BY, Ohtani M, Yamamoto A, Murata M, Totani K, Ito Y, Miwa K, Nogami W, Kawasaki N, Kawasaki T: Subcellular localization and physiological significance of intracellular mannan-binding protein, J Biol Chem 2007, 282:17908-17920

44. La Bonte LR, Dokken B, Davis-Gorman G, Stahl GL, McDonagh PF: The mannose-binding lectin pathway is a significant contributor to reperfusion injury in the type 2 diabetic heart, Diab Vasc Dis Res 2009, 6:172-180

45. Hansen TK, Gall MA, Tarnow L, Thiel S, Stehouwer CD, Schalkwijk CG, Parving HH, Flyvbjerg A: Mannose-binding lectin and mortality in type 2 diabetes, Arch Intern Med 2006, 166:2007-2013

46. Ezekowitz RA, Day LE, Herman GA: A human mannose-binding protein is an acute-phase reactant that shares sequence homology with other vertebrate lectins, J Exp Med 1988, 167:1034-1046

47. Garred P, Larsen F, Madsen HO, Koch C: Mannose-binding lectin deficiency--revisited, Mol Immunol 2003, 40:73-84 
Chapter 3

Principles of human intestinal ischemia reperfusion damage 


\section{Chapter 3}

\subsection{INTRODUCTION}

Gastro-intestinal hypoperfusion and ischemia are frequently associated with clinical conditions such as sepsis, shock, trauma or major surgical procedures in which part of the mesenteric vasculature is compromised over a period of time. In addition, it is inextricably linked to small intestinal organ transplantation. As an important contributor to immunity, intestinal damage induced by various periods of gut ischemia and reperfusion has major implications. Much of the knowledge we have today regarding the course of early intestinal ischemia reperfusion, has been derived from various animal models. However, knowledge of human intestinal ischemia reperfusion principles is lacking. This is especially important, not only because of its association with many clinical conditions as discussed before, but also since intestinal ischemia reperfusion in man is an important clinical entity on its own. Acute mesenteric ischemia is a hard to diagnose pathology and associated with high morbidity and mortality rates.

In order to study the second aim of this thesis, a new experimental intestinal ischemia reperfusion model was developed in man, which allowed for controlled small gut IR (Chapter 3.2). First and foremost the sequelae of early intestinal ischemia reperfusion damage in man were investigated and studied in detail (Chapter 3.3). It was demonstrated that the human intestine has a unique ability to shed its IR damaged epithelial cells and restore the important gut barrier function. Intestinal ischemia reperfusion has been associated with rapid and substantial intestinal epithelial damage. The relation between IR induced damage to the passive intestinal barrier as well as its swift repair during early reperfusion and the development of a subsequent inflammatory response were studied in Chapter 3.4. Work from experimental rodent models has demonstrated a link between functional MBL levels and the development of IR induced intestinal damage. ${ }^{1-3}$ In this context we analyzed the role of MBL in intestinal IR by assessing the association between different $\mathrm{mb} / 2$ haplotypes and the development of intestinal IR damage (Chapter 3.5). 


\section{ReferenCes}

1. Hart ML, Ceonzo KA, Shaffer LA, Takahashi K, Rother RP, Reenstra WR, Buras JA, Stahl GL: Gastrointestinal ischemia-reperfusion injury is lectin complement pathway dependent without involving C1q, J Immunol 2005, 174:6373-6380

2. McMullen ME, Hart ML, Walsh MC, Buras J, Takahashi K, Stahl GL: Mannose-binding lectin binds IgM to activate the lectin complement pathway in vitro and in vivo, Immunobiology 2006, 211:759-766

3. Lee H, Green DJ, Lai L, Hou YJ, Jensenius JC, Liu D, Cheong C, Park CG, Zhang M: Early complement factors in the local tissue immunocomplex generated during intestinal ischemia/reperfusion injury, Mol Immunol 2009, 47:972-981 


\section{Chapter 3.2}

\section{A new model to study intestinal ischemia-reperfusion damage in man}

Joep P.M. Derikx*, Robert A. Matthijsen*, Adriaan P. de Bruïne, Ronald M. van Dam, Wim A. Buurman, and Cornelis H.C. Dejong

*Both authors contributed equally 


\section{Abstract}

Background. This report describes a human in vivo ischemia reperfusion (IR) model of the small intestine. Animal models of intestinal IR are indispensable for our understanding of sequelae of IR induced organ damage. However, a functional experimental IR model of the human small intestine, allowing for translational research, can be considered critical for our pathophysiologic understanding of intestinal IR in man.

Materials and Methods. Patients with a healthy gut undergoing abdominal surgery with a Roux-Y or similar reconstruction were included, creating the opportunity to study IR of an isolated jejunal segment in a harmless model.

Results. Ischemia was induced by nontraumatic vascular clamping followed by reperfusion. This model can be adapted using variable ischemia and reperfusion times. Similarly, tissue and plasma can be collected at any given time point during ischemia until end of reperfusion, only determined by progress of the original, intended surgical procedure.

Conclusion. A unique and harmless human IR model of the jejunum was created, which enables the study of acute damage to the epithelial lining and its subsequent repair mechanisms.

\section{INTRODUCTION}

Acute mesenteric ischemia refers to an acute onset of hypoperfusion of the intestine, often associated with major vascular or abdominal surgical procedures, small intestinal transplantation, major trauma and blood loss, sepsis and necrotizing enterocolitis (NEC). ${ }^{1-3}$ Intestinal ischemia followed by reperfusion (IR) complicates the treatment of critically ill patients. Furthermore, acute mesenteric ischemia is a disease entity in itself, of which diagnosis remains difficult due to the lack of specific clinical markers. ${ }^{4,5}$ Current diagnosis of acute mesenteric ischemia largely depends on clinical suspicion and is mainly aimed at exclusion of different less urgent pathologies presenting with similar symptoms. Intestinal IR has been linked to local as well as peripheral organ damage, systemic inflammatory response syndrome 


\section{Chapter 3}

(SIRS), and multiple organ dysfunction syndrome (MODS), accounting for up to $70 \%$ mortality. ${ }^{1-3,6}$. At present, our knowledge regarding mechanisms involved in IR induced intestinal damage has evolved from research performed in animal models that attempt to simulate human disease. . $^{2,3,7,8}$ Different animal models have been developed in mice, rats, cats, dogs, and pigs, in which mainly ischemia of the small intestine is studied by transient clamping of the superior mesenteric artery. The use of animal models has identified important mechanisms contributing to IR induced organ damage. Indisputably, the data from animal models have demonstrated the multifactorial etiology of IR damage in the intestine. ${ }^{2,3,8,9}$ However, differences exist between various animals and between strains of the same species regarding the results of intestinal ischemia. ${ }^{10,11}$ Furthermore, early responses that drive human intestinal injury and organ failure in response to IR remain to be resolved. Therefore, we developed an experimental ischemia reperfusion model of the intestine in humans creating the possibility to address these points. ${ }^{12}$ Here we describe the development of such a model, the first results, and future implications.

\section{Material AND Methods}

\section{Patients and laboratory techniques}

As indicated in the introduction, patients with pylorus preserving pancreatico duodenectomy (PPPD) or Whipple's procedure, pancreatico jejunostomy, hepatico jejunostomy, or Frey procedure are included. Blood is collected routinely during surgery and from the studied piece of intestine. It is transferred to a pre-chilled EDTA vacuum tube (BD vacutainer; Becton Dickinson Diagnostics, Aalst, Belgium) and kept on ice. All blood is at the end of the study centrifuged at $4000 \mathrm{rpm}, 4^{\circ} \mathrm{C}$ for 15 minutes to obtain plasma. Plasma is kept on ice and immediately stored in aliquots at $-80^{\circ} \mathrm{C}$ until analysis. Intestinal fatty acid binding protein (I-FABP) arteriovenous concentration differences across studied jejunum are assessed in order to evaluate epithelial cell damage. ${ }^{13-15}$ In arterial and venous plasma, the concentrations of I-FABP are measured by means of the commercially available enzyme-linked immunosorbent assay (ELISA) used according to manufacturer's guidelines (Hycult Biotechnology, Uden, the Netherlands). The venous plasma levels are subtracted from the arterial plasma levels of I-FABP, which are collected at the same point, in order to obtain arteriovenous concentration differences across the studied jejunum. Next, tissue is collected at different time points in order to microscopically visualize the conse- 
quences of intestinal IR. The preoperative sampled tissue is cut into $0.5 \mathrm{~cm}$ thick ringlike fragments of the jejunum. Tissue rings are immediately immersed in $3.7 \%-4.0 \%$ formalin fixation (Unifix; Klinipath, Geel, Belgium) and incubated overnight at room temperature. After 18-24 hours of formalin fixation, the fragments of the jejunum are embedded in paraffin, after which $4 \mathrm{~m}$ paraffin cross-sections are prepared. Subsequently, sections are stained with haematoxylin and eosin using appropriate standard procedures. Besides, sections can be used for immunohistochemistry according to specific research questions.

\section{Ethics}

The study was approved by the Medical Ethics Committee of the Maastricht University Medical Centre. All individuals gave written informed consent.

\section{Model}

Positioning, anesthesia of the patient (including insertion of an arterial line), and incision of the skin is performed according to institutional routines. An arterial line is needed to sample systemic blood, which is used to measure arteriovenous concentration differences across the studied jejunum in order to explore local release and uptake of proteins. After induction of anesthesia, before surgery, the first 3cc blood sample is taken from the arterial line (mostly radial artery) using a 5cc syringe (Fig. 1). First part of surgery (opening of the abdominal wall, installation of a large selfretaining retractor) is according to standard procedures. The peritoneal surface, the liver, the area around the pancreas, the hepatoduodenal ligament, and the lymph nodes around the celiac axis are explored for metastases and localization of the major anatomical structures and tumor. From this moment, the $6 \mathrm{~cm}$ part of jejunum that can be studied, has to be identified (Fig. 2). Blood supply and drainage of the studied jejunum has to be clearly visible and to consist of one central mesenteric arteriole and venule. To prevent blood flow from adjacent parts of the studied jejunum, all collateral vessels are dissected, clamped, and cut. Therefore, the mesentery is opened using Ultracision Harmonic Ace Johnson and Johnson, cat. no. ACE23P, Amersfoort, the Netherlands) at the proximal and distal part of the suitable part of jejunum from the central mesenteric arteriole and venule until the serosa of the jejunum.

Isolation of the studied jejunum is performed by transsection at both ends with a linear cutting stapler (GIA 6038S; Covidien, Zaltbommel, the Netherlands) (Fig. 3). Both ends of the isolated jejunum are fixed with a single PDS 3-0 suture (Johnson 


\section{Chapter 3}

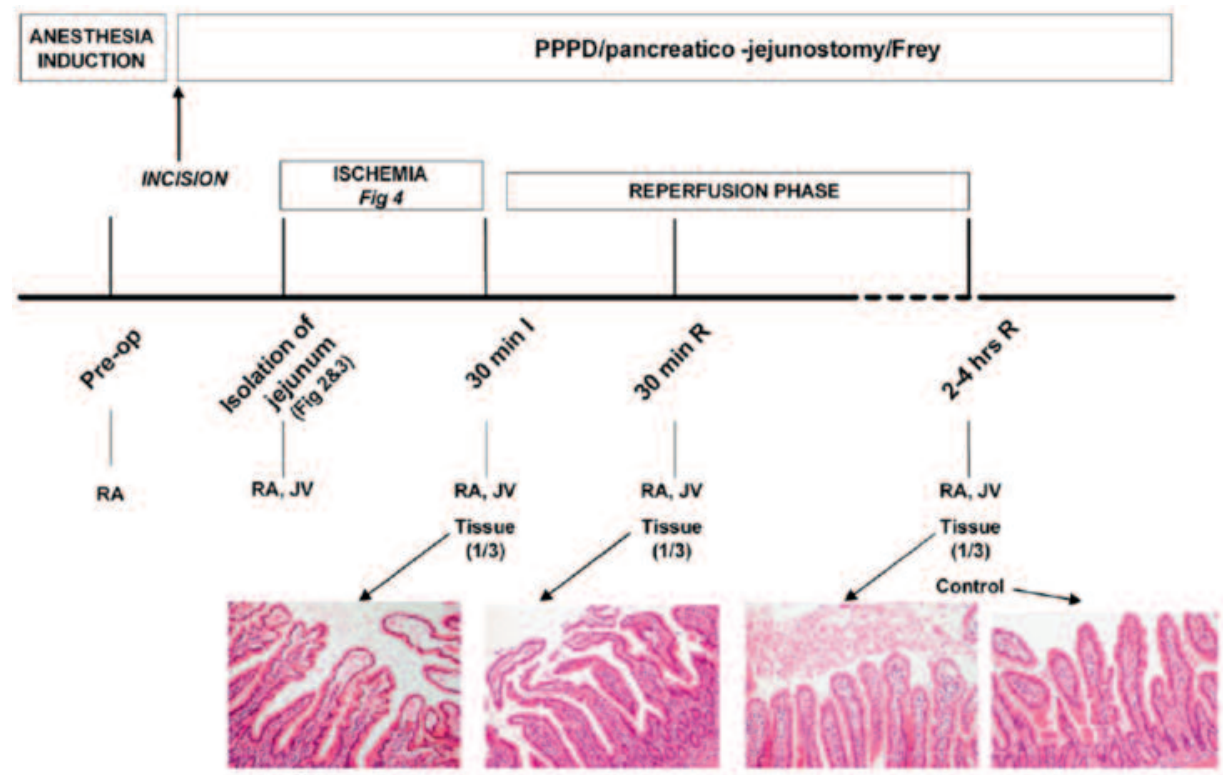

Figure 1. Diagram of the experiments. At given time-points blood was drawn from the radial artery (RA) line and jejunal venule (JV) in the mesentery, draining the isolated jejunum. At the lower level, representative $\mathrm{H}$ and $\mathrm{E}$ stained sections show the main histologic consequences of 30 minutes of jejunal ischemia (I), followed by reperfusion (R). PPPD = pylorus preserving pancreatico duodenectomy.

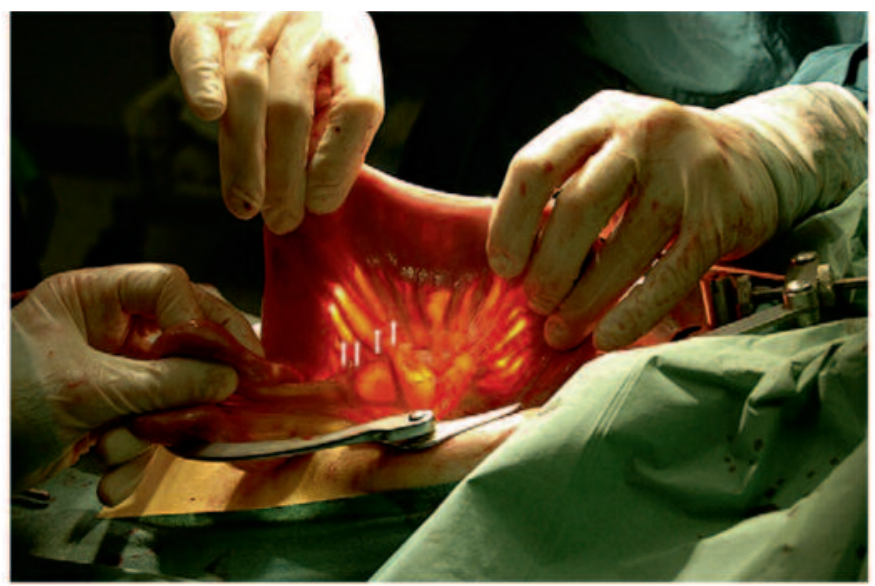

Figure 2. Identification of jejunum, which can be isolated for study purposes. Note the clearly visible mesenteric blood supply and drainage. White arrows indicate some of the mesenteric vessels. 


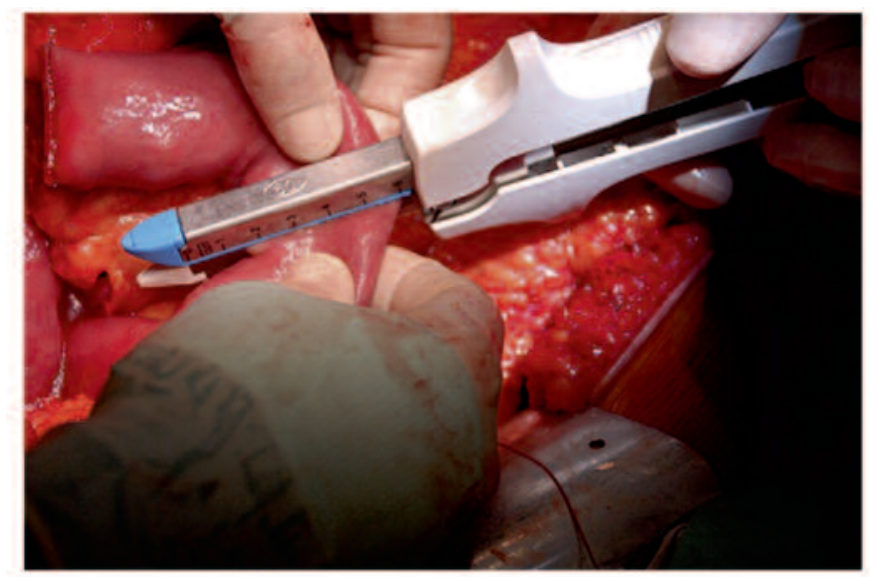

Figure 3. Isolation of the studied jejunum by a linear cutting stapler.

and Johnson) to the rest of the jejunum to prevent rotation. Leaving the isolated jejunum in the abdominal cavity without re-attaching to the proximal and distal parts of the jejunum may cause rotation around its axis, which causes disruption of the blood flow and, thus, re-introduce uncontrolled ischemia. The central mesenteric venule draining the isolated jejunum is dissected from its mesenteric surrounding to improve its accessibility for blood collection. A $5 \mathrm{cc}$ syringe, a $12 \mathrm{~cm}$ extension set, and a 25G needle are given under sterile conditions to the scrub nurse. The $5 \mathrm{cc}$ syringe is connected via the extension set to the $25 \mathrm{G}$ needle by the nurse. One surgeon takes the isolated jejunum with the left hand and inserts the needle into the venule, draining the isolated jejunum, while the other surgeon draws 3cc of blood using the syringe. It is difficult to draw blood from the venule by a single surgeon because holding the jejunum, inserting the needle and drawing of blood may become a rather uncontrolled procedure, which may cause the needle to perforate the venule. Hold a prolene 5-0 suture with a small needle holder in order to repair the vessel with sutures if there is continued bleeding after removal of the needle.

The syringe is handed over to the researcher. At the same time, blood is drawn from the arterial line, as described previously. The isolated jejunum is subjected to 30min ischemia with two atraumatic vascular clamps (Bulldog, cat. no. BH013R; Aesculap Inc., Oss, the Netherlands), which are placed from both sides over the mesentery (Fig. 4). The isolated ischemic jejunum is placed in the abdominal cavity to guarantee warm ischemia. The patient's temperature is constantly monitored and kept at $37^{\circ} \mathrm{C}$. The surgical procedure proceeds as planned. 


\section{Chapter 3}
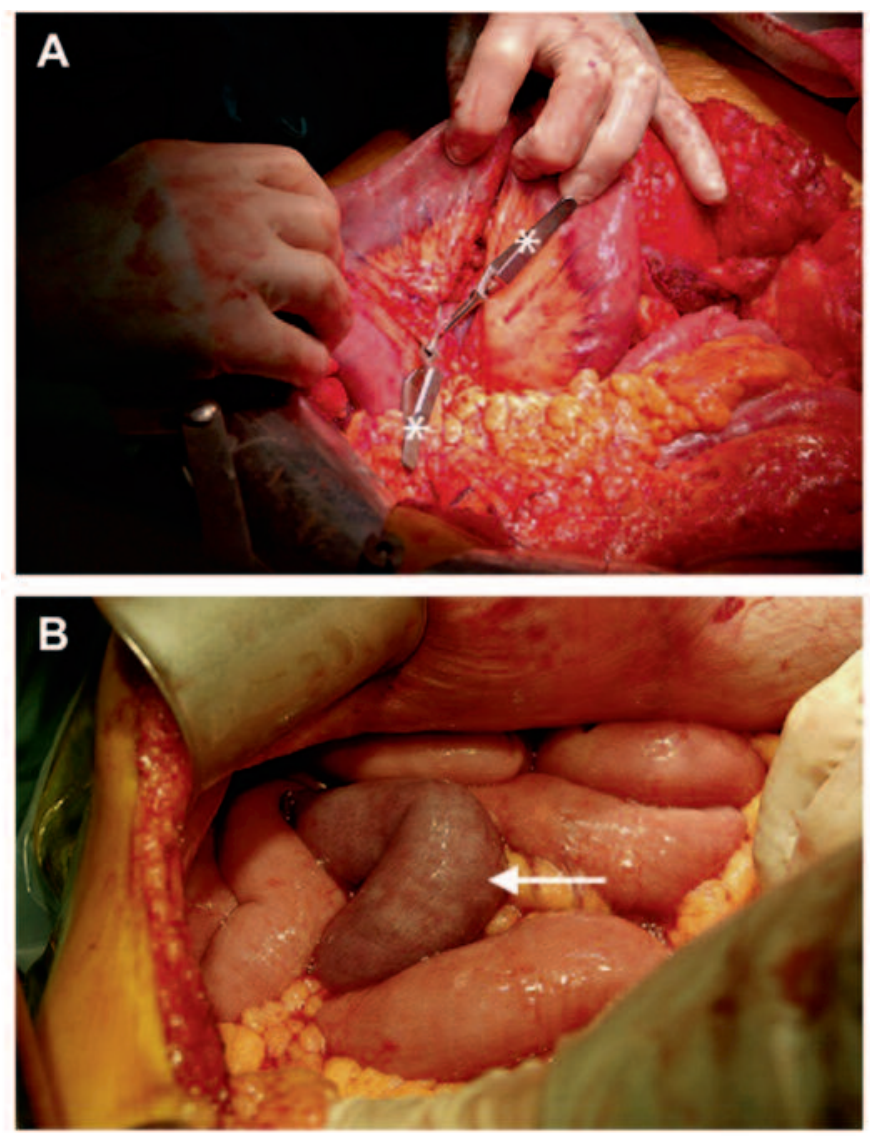

Figure 4. Clamping of the isolated jejunum with two atraumatic vascular clamps (indicated with an asterisk) (A), rapidly leads to discoloration of the jejunal wall (white arrow) (B).

After half an hour of ischemia, one-third $(2 \mathrm{~cm})$ of the isolated ischemic jejunum is resected for research purposes using linear cutting stapler. The mesentery, near the serosa of the distal $2 \mathrm{~cm}$ of isolated ischemic jejunum, is opened using electrocoagulation. The distal $2 \mathrm{~cm}$ of the isolated ischemic jejunum are dissected using a linear stapler. This distal ischemic jejunum is handed over to the researchers. Avoid manipulation of the intestine, because this may cause exogenous damage. Therefore, always use forceps. The staples at both ends of the tissue are cut off with clean scissors and the tissue is processed to obtain paraffinembedded sections, frozen sections, and electron microscopy and tissue samples 
for PCR analysis or protein-based applications. While the researcher prepares the tissue, the surgeon removes the vascular clamps.

The reperfusion is initiated. After removal of the clamp, the isolated jejunum is inspected for restoration of blood flow. Immediately thereafter, blood is collected from the jejunal venule in the mesentery and from the arterial line, as described previously. Isolated jejunum and arterial and venous blood can be collected at different time points, depending on the research questions. The maximum time of reperfusion of the isolated ischemic jejunum is dependent on the surgical procedure, i.e., the moment at which the surgeon decides that the pancreatico- or hepaticojejunal anastomosis has to be created. In the proposed surgical procedures, reperfusion time varies from 30 minutes to 4 hours. At the time the last isolated reperfused jejunum is obtained for the study, also $2 \mathrm{~cm}$ of the proximal jejunum, which was not isolated and remained untreated during the surgery, is resected using a GIA. This tissue is used as internal control tissue: it is from the same patient and experienced similar surgical handling as the isolated jejunum, while it was not subjected to IR. Surgery continues as anticipated.

\section{Results}

In this newly developed human experimental model to study intestinal IR, successful ischemia is observed almost directly after placement of the vascular clamp in the 29 patients studied so far by both discoloration of the small jejunum wall and termination of the peristalsis of the studied jejunum. Immediately upon reperfusion, the isolated jejunum regains its pinkish color and motility.

Histologic analysis of haematoxylin/eosin stained sections shows consistent results. ${ }^{12}$ The control jejunum, which is neither isolated nor subjected to IR, shows normal architecture (Fig. 1). Directly after ischemia, the intestinal epithelial lining is microscopically normal, while subepithelial spaces appear at the villus tip. However, after 25 minutes reperfusion, shedding of differentiated epithelial cells into the lumen is found with a compromised epithelial lining. Interestingly, within 60 minutes reperfusion the epithelial barrier reseals, while debris of apoptotic, shed epithelial cells is observed in the lumen. In order to further unravel the intestinal mucosal cell damage in this model, intestinal fatty acid binding protein (I-FABP) arteriovenous concentration differences are measured in plasma using ELISA before 


\section{Chapter 3}

and after ischemia (Table 1). I-FABP is a small cytosolic protein constitutively present in mature enterocytes and released upon cell membrane integrity loss. ${ }^{13-15}$ Mean $( \pm$ SEM) arteriovenous concentration gradients of I-FABP across studied jejunum in 20 patients reveal rapid epithelial cell damage. I-FABP release increased significantly from 328 (59) $\mathrm{pg} / \mathrm{mL}$ before ischemia to 4096 (543) $\mathrm{pg} / \mathrm{mL}$ immediately after ischemia $(\mathrm{P}<0.001$ versus before onset of ischemia) and declined gradually to 1204 (408) $\mathrm{pg} / \mathrm{mL}$ after 2 hours reperfusion $\left(\mathrm{P}>0.05\right.$ vs before onset of ischemia). ${ }^{12}$

Table 1. Arteriovenous Concentration Differences of I-FABP (Jejunal Venule Minus Radial Artery) Across the Isolated Jejunal Segment Before and After Ischemia

Mean (SEM) AV

\begin{tabular}{|c|c|c|}
\hline Time point & $\Delta$ I-FABP $(p g / m L)$ & $P\left(\right.$ versus $\left.t=30^{\prime}\right)$ \\
\hline$T=30^{\prime}$ (before I) & $328(59)$ & \\
\hline$T=0^{\prime}$ (after $\left.30 \mathrm{~min} I\right)$ & $4096(543)$ & $<0.001$ \\
\hline $\mathrm{T}=30^{\prime}$ (after $30 \mathrm{~min} \mathrm{R}$ ) & $1964(353)$ & $<0.05$ \\
\hline$T=60^{\prime}$ (after $60 \mathrm{~min} R$ ) & $1143(237)$ & NS \\
\hline $\mathrm{T}=90^{\prime}$ (after $90 \mathrm{~min} \mathrm{R}$ ) & $1342(193)$ & NS \\
\hline$T=120^{\prime}$ (after $120 \mathrm{~min} R$ ) & $1204(408)$ & NS \\
\hline $\mathrm{T}=180^{\prime}$ (after $180 \mathrm{~min} \mathrm{R}$ ) & $878(235)$ & NS \\
\hline
\end{tabular}

\section{Discussion}

We describe a newly developed human experimental model to study intestinal IR induced cell damage and its direct consequences. This new model first helps to understand the pathophysiology of human intestinal IR. Secondly, this model might lead to the evaluation of (new) markers for the early diagnosis of acute mesenteric ischemia. Finally, new agents that modulate IR can be tested in this model. Several determinants were important during model development: (1) no additional invasive procedures should be needed to execute this model; (2) a variable duration of ischemia and reperfusion should be possible; (3) the possibility to collect serial and different (tissue / plasma) samples should be created; (4) the studied intestine 
should be healthy and not affected by prior inflammatory pathology; (5) the small intestine should be studied. Considering these predetermined demand, a model was developed in patients who underwent major upper abdominal surgery with a Roux-Y or similar small intestinal reconstruction. We included patients with pylorus preserving pancreatico duodenectomy (PPPD) or Whipple's procedure, pancreatico jejunostomy, hepatico jejunostomy, or Frey procedure. This surgery takes about $3-6$ hours to complete and allows for a standardized ischemic period as well as reperfusion of up to 4 hours. Since part of the small intestine is resected according to normal surgical procedures, no extra part of the small intestine is removed from the patient solely for study purposes, limiting patient risk. The model described is comparable with currently existing animal models. Most animal models allow up to 3 hours of reperfusion after approximately 30 minutes of superior mesenteric artery clamping in order to induce ischemia and to study early alterations of the small intestine. The duration of the ischemic period, which is similarly induced by nontraumatic clamping of a superior mesenteric artery branch, is variable and followed by a chosen reperfusion time. The only determinant of the IR period is set by surgical boundaries imposed by surgical treatment of the patient. Additionally, it has to be kept in mind that besides ischemia-reperfusion of the small intestine, intestinal hypoperfusion could similarly be studied using a comparable setup. To study acute damage of the epithelial lining, it is recommended to take tissue and blood samples 15 - 30 minutes after start of reperfusion. To study repair of the epithelium, collect samples from 60 minutes after reperfusion onwards. In conclusion, this unique and harmless human IR model of the jejunum enables the study of acute damage to the epithelial lining and its subsequent repair mechanisms.

\section{ACKNOWLEDGMENTS}

The authors thank Jan Stoot, M.D. for his excellent technical assistance during pancreatico-duodenectomy procedures and sample collection.

\section{References}

1. Oldenburg WA, Lau LL, Rodenberg TJ, et al. Acute mesenteric ischemia: A clinical review. Arch Intern Med 2004;164:1054. 


\section{Chapter 3}

2. Fukatsu K, Sakamoto S, Hara E, et al. Gut ischemia-reperfusion affects gut mucosal immunity: A possible mechanism for infectious complications after severe surgical insults. Crit Care Med 2006;34:182.

3. Mallick IH, Yang W, Winslet MC, et al. Ischemia-reperfusion injury of the intestine and protective strategies against injury. Dig Dis Sci 2004;49:1359.

4. Vicente DC, Kazmers A. Acute mesenteric ischemia. Curr Opin Cardiol 1999;14:453.

5. Yasuhara H. Acute mesenteric ischemia: The challenge of gastroenterology. Surg Today 2005;35:185.

6. Fink MP, Delude RL. Epithelial barrier dysfunction: A unifying theme to explain the pathogenesis of multiple organ dysfunction at the cellular level. Crit Care Clin 2005;21:177.

7. Chiu CJ, McArdle AH, Brown R, et al. Intestinal mucosal lesion in low-flow states. I. A morphological, hemodynamic, and metabolic reappraisal. Arch Surg 1970;101:478.

8. CardenDL,GrangerDN.Pathophysiology of ischemia-reperfusion injury. J Pathol 2000;190:255.

9. Chen LW, Egan L, Li ZW, et al. The two faces of IKK and NF-kB inhibition: Prevention of systemic inflammation but increased local injury following intestinal ischemia-reperfusion. Nat Med 2003;9:575.

10. Robinson JW, Mirkovitch V, Winistorfer B, et al. Response of the intestinal mucosa to ischemia. Gut 1981;22:512.

11. Blikslager AT, Moeser AJ, Gookin JL, et al. Restoration of barrier function in injured intestinal mucosa. Physiol Rev 2007;87:545.

12. Derikx JP, Matthijsen RA, de Bruïne AP, et al. Rapid reversal of human intestinal ischemiareperfusion induced damage by shedding of injured enterocytes and reepithelialisation. PloS ONE 2008;3:e3428.

13. Kanda T, Fujii $\mathrm{H}$, Tani $\mathrm{T}$, et al. Intestinal fatty acid-binding protein is a useful diagnostic marker for mesenteric infarction in humans. Gastroenterology 1996;110:339.

14. Lieberman JM, Sacchettini J, Marks C, et al. Human intestinal fatty acid binding protein: Report of an assay with studies in normal volunteers and intestinal ischemia. Surgery 1997;121:335.

15. Derikx JP, Evennett NJ, Degraeuwe PL, et al. Urine based detection of intestinal mucosal cell damage in neonates with suspected necrotising enterocolitis. Gut 2007;56:1473. 


\section{Chapter 3.3}

\section{Rapid reversal of human intestinal ischemia-reperfusion induced damage by shedding of injured enterocytes and reepithelialisation.}

Joep P.M. Derikx, Robert A. Matthijsen, Adriaan P. de Bruïne, Annemarie A.J.H.M. van Bijnen, Erik Heineman, Ronald M. van Dam, Cornelis H.C. Dejong, and Wim A. Buurman

PLoS One. 2008, 3: e3428. 


\section{Chapter 3}

\section{Abstract}

Background. Intestinal ischemia-reperfusion (IR) is a phenomenon related to physiological conditions (e.g. exercise, stress) and to pathophysiological events (e.g. acute mesenteric ischemia, aortic surgery). Although intestinal IR has been studied extensively in animals, results remain inconclusive and data on human intestinal IR are scarce. Therefore, an experimental harmless model for human intestinal IR was developed, enabling us to clarify the sequelae of human intestinal IR for the first time.

Methods and Findings. In 30 patients undergoing pancreatico-duodenectomy we took advantage of the fact that in this procedure a variable length of jejunum is removed. Isolated jejunum $(5 \mathrm{~cm})$ was subjected to 30 minutes ischemia followed by reperfusion. Intestinal Fatty Acid Binding Protein (I-FABP) arteriovenous concentration differences across the bowel segment were measured before and after ischemia to assess epithelial cell damage. Tissue sections were collected after ischemia and at 25, 60 and 120 minutes reperfusion and stained with $\mathrm{H \& E}$, and for I-FABP and the apoptosis marker M30. Bonferroni's test was used to compare IFABP differences. Mean ( \pm SEM) arteriovenous concentration gradients of I-FABP across the jejunum revealed rapidly developing epithelial cell damage. I-FABP release significantly increased from $290(46) \mathrm{pg} / \mathrm{ml}$ before ischemia towards 3,997 $(554) \mathrm{pg} / \mathrm{ml}$ immediately after ischemia $(\mathrm{p}<0.001)$ and declined gradually to $1,143(237) \mathrm{pg} / \mathrm{ml}$ within 1 hour reperfusion $(\mathrm{p}<0.001)$. Directly after ischemia the intestinal epithelial lining was microscopically normal, while subepithelial spaces appeared at the villus tip. However, after 25 minutes reperfusion, enterocyte M30 immunostaining was observed at the villus tip accompanied by shedding of mature enterocytes into the lumen and loss of I-FABP staining. Interestingly, within 60 minutes reperfusion the epithelial barrier resealed, while debris of apoptotic, shedded epithelial cells was observed in the lumen. At the same time, M30 immunoreactivity was absent in intact epithelial lining.

Conclusions. This is the first human study to clarify intestinal IR induced cell damage and repair and its direct consequences. It reveals a unique, endogenous clearing mechanism for injured enterocytes: rapid detachment of damaged apoptotic enterocytes into the lumen. This process is followed by repair of the epithelial continuity within an hour, resulting in a normal epithelial lining. 


\section{INTRODUCTION}

Intestinal ischemia-reperfusion (IR) injury is an important (patho)physiological mechanism, potentially leading to a compromised mucosal barrier in numerous situations. ${ }^{1,2}$ Intestinal hypoperfusion occurs during exercise both in healthy relatively untrained volunteers and in highly trained athletes, which stresses the abdominal vasodilator reserve by diverting blood flow from the splanchnic circulation to the exercise muscles. ${ }^{3-5}$ This substantial reduction in blood flow is sometimes associated with symptoms of abdominal hypoperfusion, which are almost always reversible without intensive therapy. ${ }^{3-5}$ Stress may also lead to symptomatic intestinal ischemia via increased catecholamine release, resulting in severe splanchnic vasospasm. ${ }^{6}$ Furthermore, intestinal IR may be looked at as a common pathway in several pathologies, where temporary reduction in flow may result from inherent vascular disease (thrombosis, shock, embolism, vasculitis) or from inflammatory diseases affecting perfusion. An example of inherent vascular disease is acute mesenteric ischemia (AMI), which carries a high morbidity and mortality rate, both increased by frequent delays in diagnosis. Such diagnostic delays are mainly caused by non-specific signs and symptoms and limited diagnostic accuracy of the laboratory and radiological tests currently in use. Arterial and venous thromboembolisms are the main causes of AMI. ${ }^{1,2}$ More global hypoperfusion may result from shock. Along these lines, intestinal IR is considered to be a crucial phenomenon involved in the onset of necrotizing enterocolitis, in the pathogenesis of small intestinal transplantation and rejection, and in the potential development of postoperative or posttraumatic complications, such as systemic inflammatory response syndrome, sepsis and multiple organ failure., ${ }^{2,7,8}$ Here, inflammation and collateral damage may play a role. Generally, IR injury starts with affecting cell metabolism, ultimately resulting in cell death (apoptosis as well as necrosis). ${ }^{9-11}$ Upon reperfusion, ischemia primed cells are prone to generate toxic reactive oxygen metabolites and release of constitutive cellular proteins upon loss of cell membrane integrity, which can act as danger signals and activate the immune system. ${ }^{9-15}$ In the resulting inflammatory response, local expression of adhesion molecules, proinflammatory mediators and activation of neutrophils as well as the complement system are central mediators of IR induced tissue injury. ${ }^{10,11,13-16}$ This proinflammatory state increases tissue vulnerability to further injury, resulting in the amplification and derailment of the inflammatory response, 


\section{Chapter 3}

although it is meant to be a beneficial reaction to clear damaged cells. ${ }^{11,14,16}$ The pathophysiology of intestinal IR has hitherto mainly been studied in animal models (rodents, cats, dogs and pigs) by transient clamping of the superior mesenteric artery. ${ }^{17-19}$ First event after intestinal IR in all these animals is the appearance of subepithelial spaces at the villus tips, immediately followed by loss of the highly susceptible mature enterocytes. ${ }^{17,18}$ Depending on the duration of ischemia, this sloughing may continue toward the crypt, causing denuded villi. ${ }^{17,18}$ In line with general IR induced cell damage, also in intestinal IR, apoptosis is the major mode of cell death in the destruction of epithelial cells. ${ }^{20}$ Moreover, the disruption of the interaction between epithelial cells and extracellular matrix ('anoikis') may play an important role in the onset of apoptosis in detached enterocytes. ${ }^{20}$ Some studies report that after longer periods of reperfusion, migration of epithelial cells to seal the exposed basement membrane occurs, which closes the loss of epithelial continuity. ${ }^{19,21}$ Further studies show that reperfusion leads to inflammation, resulting in transmural infarction. ${ }^{19,22-24}$ This inflammatory response is comparable to the response of other organs to IR induced cell damage, including infiltration of neutrophils and activation of complement. ${ }^{22,24}$ The histological consequences of human gut IR are known from patients operated upon for different gastrointestinal disorders after obvious signs of clinical shock or from post-mortem studies. ${ }^{25}$ Microscopic examination of gut segments of these patients all showed characteristic mucosal lesions, ranging from epithelial lifting at the villus tip to denuded villi with disintegrated and hemorrhagic lamina propria. ${ }^{25}$ The histological findings concerned end-stages of diseases and were identical to the previously described ultimate phases of intestinal mucosal IR induced damage in animals. This study was directed at revealing the sequelae of intestinal IR in man in the course of time, using a newly developed human experimental, controlled model of 30 minutes intestinal ischemia, followed by variable periods of reperfusion.

\section{Methods}

\section{Patients and experimental, surgical procedure}

Thirty patients (12F:18M) with a median age of 68.5 years (range: $35-79$ years) undergoing pancreatic surgery were studied. Twenty-eight of these patients underwent a standard pylorus preserving or classical pancreatico-duodenectomy (Whipple's procedure) for benign or malignant disease, whilst two patients 
underwent a Frey procedure for chronic pancreatitis. During pancreaticoduodenectomy a variable length of jejunum is usually resected in continuity with the specimen. Similarly, in creating a Roux-limb for the pancreatico-jejunostomy in Frey's procedure, it is often necessary to resect a small segment of jejunum that is less well perfused. We took advantage of this, which enabled us to study IR induced cell damage in a harmless human jejunal IR model. To that purpose, the most distal part of the jejunum to be resected with the Whipple specimen, or the most proximal part of the Roux-limb to be used as a pancreatico-jejunostomy in the Frey procedure, was used to isolate a $6 \mathrm{~cm}$ segment of jejunum. The isolated jejunum $(6 \mathrm{~cm})$ was subjected to 30 minutes ischemia followed by a median reperfusion time of 128 minutes (range: $0-210$ minutes) according to the following experimental protocol. In short, the first part of surgery (opening of the abdominal wall, installation of a large self-retaining retractor and exploration for metastases and localization of the major anatomical structures and tumour) was according to standard procedures. From this moment the $6 \mathrm{~cm}$ part of jejunum, which was going to be studied was identified and care was taken that the vasculature of the studied jejunum consisted of 1 central mesenteric arteriole and venule. This was achieved by dissection, clamping and cutting of all collateral mesenterial vessels to the studied jejunum using Ultracision Harmonic Ace (Johnson\&Johnson, cat. no. ACE23P, Amersfoort, the Netherlands). Thereafter, the segment of jejunum was further isolated by transsection at both ends with a linear cutting stapler (GIA 6038S, Covidien, Zaltbommel, the Netherlands). The isolated jejunum was then subjected to 30 minutes ischemia with 2 atraumatic vascular clamps, which are placed over the mesentery (Bulldog, Aesculap, cat. no. BH013R, Tuttlingen, Germany). The isolated ischemic jejunum was subsequently placed in the abdominal cavity to guarantee warm ischemia. The surgical procedure proceeded as planned. After half an hour of ischemia, one third $(2 \mathrm{~cm})$ of the isolated ischemic jejunum was resected using linear cutting stapler to study early phenomena during ischemia. Reperfusion was initiated by removal of the clamps, and the isolated jejunum was inspected for restoration of blood flow. A further segment of isolated jejunum $(2 \mathrm{~cm})$ was resected similarly after 25 minutes of reperfusion to study early phenomena during reperfusion. The last part of studied jejunum was resected from 60 minutes after reperfusion onwards to investigate late phenomena during reperfusion. At the time the last isolated reperfused jejunum was obtained for the study, also $2 \mathrm{~cm}$ of jejunum, which had not been isolated and 


\section{Chapter 3}

remained untreated during the surgery, was resected using a linear cutting stapler. This tissue was used as internal control tissue: it was from the same patient and experienced similar surgical handling as the isolated jejunum, while it was not subjected to IR. Then, our study-protocol was ended and surgery continued as anticipated. Histological assessment

The tissue specimens obtained at four different time points during the study (after half an hour of ischemia, after 25 minutes of reperfusion, from 60 minutes reperfusion onwards and internal control) were immediately immersed in 3.7\%$4.0 \%$ formaldehyde fixation (Unifix, Klinipath, Duiven, the Netherlands) and incubated overnight at room temperature. Next, the formalin fixed samples were embedded in paraffin and $4 \mathrm{~mm}$ sections were cut. Sections were stained with haematoxylin and eosin (H\&E) using standard histological techniques. During the conduct of the experiments, it was noted that in every jejunal sample we collected at the time of maximal reperfusion, a milky substance appeared from the lumen. In order to study the content of this substance, we collected and fixed it according to the AgarCyto cell block procedure. ${ }^{26}$ Shortly, the collected cells were fixed in Unifix (Klinipath) for 24 hours. Fixed cells were centrifuged for 5 minutes at 1200 $\mathrm{rpm}$. The pellet was carefully resuspended in $1 \mathrm{ml} 2 \%$ liquid agarose at $65^{\circ} \mathrm{C}$ (LE, analytical grade; Promega, Madison, WI) and transferred into a 1.5-ml Eppendorf tube. The tube was centrifuged for 5 minutes at $1000 \mathrm{rpm}$ to concentrate the cells in the agar. The agar-cell pellet was solidified at $4 \mathrm{uC}$ for at least 1 hour. The agar cone was carefully taken out of the reaction tube with pointed forceps and divided in two halves in the sagittal plane of the cone. The two agar pieces were embedded in paraffin under standard conditions for surgical biopsies. This paraffin embedded agar-cell pellet is called AgarCyto. ${ }^{26}$ From the AgarCyto, 4 m sections were cut. For cytomorphologic examination, AgarCyto sections were stained with $\mathrm{H} \& \mathrm{E}$.

\section{Immunohistochemistry}

Paraffin sections were dewaxed in xylene and rehydrated in graded ethanol to distilled water. Endogenous peroxidase activity was blocked using $0.3 \%$ hydrogen peroxide in methanol for 12 minutes. Sections undergoing heat-mediated antigen retrieval were placed in a cooker filled with $10 \mathrm{mM}$ citrate buffer $(\mathrm{pH} \mathrm{6.0)}$ for 10 minutes for staining with collagen IV. After blocking the non-specific antibody binding using 5\% BSA, the sections were incubated with specific primary antibody at room temperature for 45 minutes. The following primary antibodies were used: 
mouse anti-cleaved cytokeratin 18 antibody, clone M30 (Catalogue no. 10700; Peviva, Bromma, Sweden); mouse anti-Collagen IV, clone CIV 22 (Catalogue no. M0785; DAKO, Glostrup, Denmark); mouse anti-smooth muscle actin (SMA), clone 1A4 (Catalogue no. M0851; DAKO); and chicken anti-intestinal-fatty acid binding protein (I-FABP, kindly provided by Hycult Biotechnology (HBT; Uden, the Netherlands)). After washing, an appropriate biotin conjugated secondary antibody was used. Binding of the primary antibody was demonstrated by the streptavidinbiotin system (DAKO) and visualized by applying 3-amino-9-ethylcarbazole (AEC; Sigma, St. Louis, MO). For I-FABP, peroxidase-conjugated rabbit anti-chicken IgY (Catalogue no. 303-035-003; Jackson ImmunoResearch Europe, Suffolk, UK) was used as secondary antibody and AEC was used as chromogen. For staining of collagen IV, labelled polymer detection agent (PowerVision Poly-HRP-antiMouse/Rabbit/Rat IgG (Immunologic; Duiven, The Netherlands)) was applied followed by AEC. Nuclei were counterstained with haematoxylin. The stained slides were photographed by a Nikon eclipse E800 microscope with a Nikon digital camera DXM1200F. No significant staining was detected in slides incubated with control rabbit serum and/or mouse IgG instead of the primary antibody indicating the absence of significant background staining.

\section{Immunofluorescence}

Cryostat sections (4 m) were cut and stained for Zona Occludens-1 (ZO-1). Briefly, slides were dried, fixed in 4\% paraformaldehyde for 15 minutes and non-specific antibody binding was blocked using $10 \%$ normal goat serum. Next, slides were stained with anti ZO-1 (catalogue no. 61-7300; Zymed Laboratories Inc., San Francisco, CA). Slides were incubated with a Texas Red labelled secondary antibody (Jackson, West-Grove, PA). Subsequently, slides were mounted using glycerol-PBS with 1, 4-diazabicyclo $(2,2,2)$ octane (DABCO) and 4, 6-diamidinol (2)-phenylindole (DAPI), and viewed with an immunofluorescence microscope.

\section{Blood sampling and I-FABP measurement}

Arterial blood was sampled preoperatively, before the isolated jejunum was subjected to ischemia, immediately upon reperfusion and every half hour during reperfusion until the end of the study protocol. Simultaneous with the second (i.e. before ischemia) and every next arterial blood sample, blood was drawn from the venule draining the isolated jejunal segment by direct puncture to assess 


\section{Chapter 3}

concentration gradients across the isolated jejunal segment. All blood samples were directly transferred to pre-chilled EDTA vacuum tubes (BD vacutainer, Becton Dickinson Diagnostics, Aalst, Belgium) and kept on ice. At the end of the study all blood samples were centrifuged at $4000 \mathrm{rpm}, 4^{\circ} \mathrm{C}$ for 15 minutes to obtain plasma. Plasma was kept on ice and immediately stored in aliquots at $-80^{\circ} \mathrm{C}$ until analysis. Intestinal Fatty Acid Binding Protein (I-FABP) concentrations were measured in plasma by means of the commercially available enzyme-linked immunosorbent assay (ELISA) used according to manufacture guidelines and kindly provided by HBT. I-FABP arteriovenous concentration differences were calculated (mesenteric venule minus radial artery) before and after ischemia to assess epithelial cell damage.

\section{Ethics}

The study was approved by the Medical Ethics Committee of the Maastricht University Medical Centre and all individuals gave written informed consent.

\section{Statistics}

Statistical analysis was performed using Prism 4.0 for Windows (Graphpad Software Inc. San Diego, CA). I-FABP arteriovenous concentration gradients were presented as mean6standard error ( \pm SEM). Normality of all data obtained was verified by Kolmogorov-Smirnov test. Bonferroni's multiple comparison test was used (after significant repeated measures ANOVA) to compare IFABP arteriovenous concentration differences in time. A p-value below 0.05 was considered to be statistically significant.

\section{Results}

Early phenomena during ischemia At the end of the ischemic period of 30 minutes, H\&E sections of the jejunum showed microscopically normal epithelial lining (Figure 1A, B). However, subepithelial spaces appeared at the villus tip. To study the epithelial cells in more detail, immunohistochemical staining of I-FABP was performed, a small protein present in the cytoplasma of differentiated enterocytes. ${ }^{27}$ Further, we stained ZO-1, a $225 \mathrm{kDa}$ membrane bound protein, binding the transmembrane tight junction proteins occludin and claudins and linking them to cytoskeletal actin. ${ }^{28}$ Intensive immunostaining for I-FABP was observed in the control jejunal epithelium, mainly in the cytoplasm of the mature 

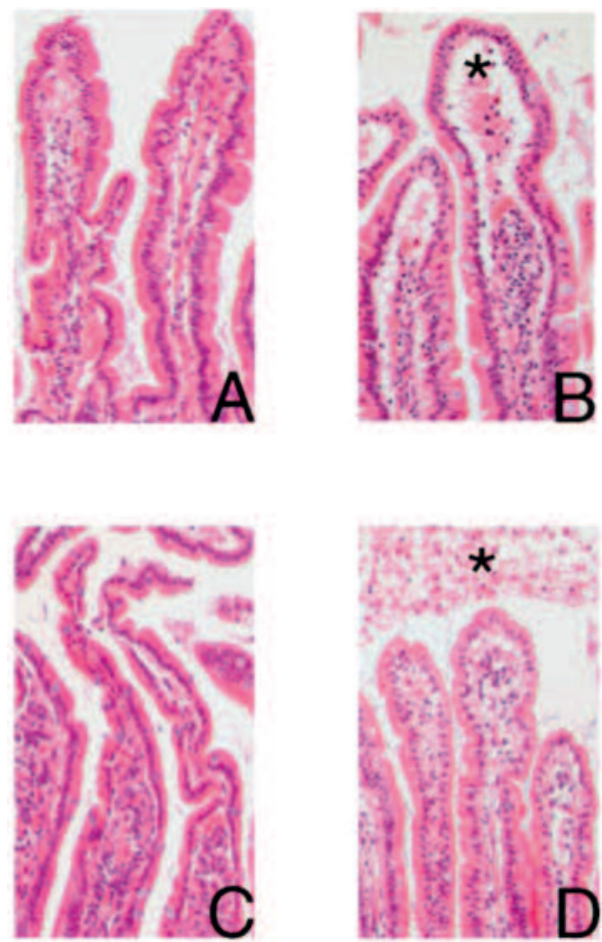

Figure 1. Histological analysis of H\&E-stained jejunal sections (100X) shows a normal epithelial lining in untreated tissue (A), and upon 30 minutes of ischemia (B). However, subepithelial spaces $\left(^{*}\right)$ appear after 30 minutes ischemia (B). After 25 minutes reperfusion shedding of mature enterocytes into the lumen is found $(\mathrm{C})$. Within 60 minutes of reperfusion the epithelial lining is resealed, while debris of apoptotic, shedded enterocytes $(*)$ are found in the lumen (D).

enterocytes and goblet cells in the upper half of the villi, whereas cells in the crypts were not stained, as previously observed in experiments by our group (unpublished results) (Figure $2 \mathrm{~A}$ ). A decreased staining of IFABP was observed in jejunal mature epithelial cells, after 30 minutes ischemia, while intense staining was found in the subepithelial spaces (Figure 2B), indicating early leakage of I-FABP from the cytoplasm of intestinal epithelial cells into the subepithelial space.

ZO-1 was detected at the apical pole of the epithelial cells in both the control jejunum and the jejunum after an ischemic period of 30 minutes (data not shown). To clarify the development of the subepithelial spaces, the basement membrane, demarcating the lamina propria from the epithelial cells, and the underlying 


\section{Chapter 3}
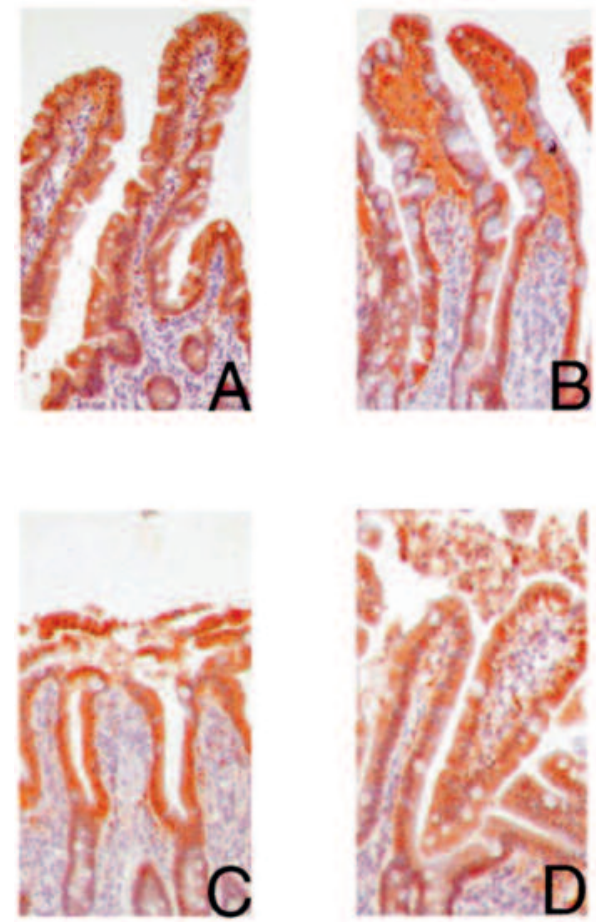

Figure 2. Immunolocalization of I-FABP in red (3-amino-9-ethylcarbazole, AEC) (100X) in the control jejunum not subjected to ischemia-reperfusion (A) shows an abundant cytosolic presence of I-FABP in the epithelial cells of the upper half of the villus. Upon 30 minutes ischemia (B), cytosolic I-FABP staining is decreased in mature enterocytes with abundant staining in the subepithelial spaces. A decreased cytosolic staining is still observed after 25 minutes reperfusion (C). Within 60 minutes reperfusion, I-FABP cytosolic positive cells are part of the resealed epithelial barrier (D), while shedded I-FABP containing enterocytes are found in the debris in the lumen.

network of myofibroblasts within the villus lamina propria were studied, by staining collagen IV and smooth muscle actin (SMA), respectively. ${ }^{29,30}$ A clear retraction of the basement membrane was found from the basal pole of the epithelial cells at the tip of the villi (Figure 3A, B). In line with this, shorter myofibroblasts were observed in a denser lamina propria (data not shown).

\section{Early phenomena during reperfusion}

To investigate loss of enterocyte membrane integrity, arteriovenous concentration 

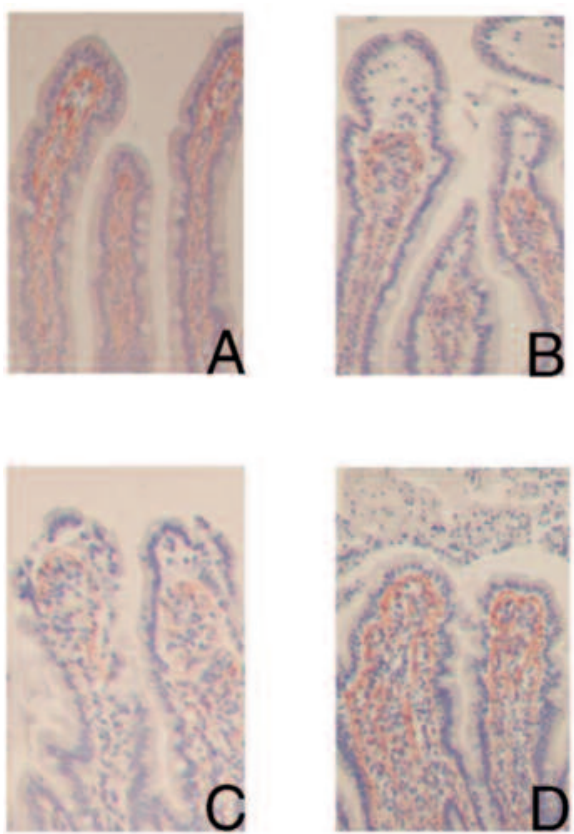

Figure 3. Characterization of the basement membrane with collagen IV staining in red (AEC) shows collagen IV positive cells directly beneath the epithelial layer in control jejunum (100X). (A). Upon 30 minutes of ischemia, a clear retraction is found of the collagen IV positive cells from the basal pole of the epithelial cells at the tip of the villus, causing subepithelial spaces (B). After 25 minutes reperfusion, the retracted basement membrane is still observed $(\mathrm{C})$. Within 60 minutes reperfusion, the collagen IV positive basement membrane is again attached to the epithelial lining (D).

differences of I-FABP across the studied jejunum were measured before ischemia and from reperfusion onwards. All individuals showed a basal release of mean ( \pm SEM) IFABP of 290 (46) $\mathrm{pg} / \mathrm{ml}$ from the isolated jejunal segment before ischemia, potentially reflecting the physiologic turnover of enterocytes (Figure 4). Interestingly, I-FABP release significantly increased towards 3,997 (554) pg/ml immediately after ischemia and upon reperfusion $(p<0.001)$, suggesting rapid epithelial cell damage following 30 minutes ischemia. A gradual, significant decline to $1,143(237) \mathrm{pg} / \mathrm{ml}$ of I-FABP release occurred within 1 hour reperfusion $(\mathrm{p}<0.001$, immediately upon ischemia vs. 1 hour reperfusion). 


\section{Chapter 3}

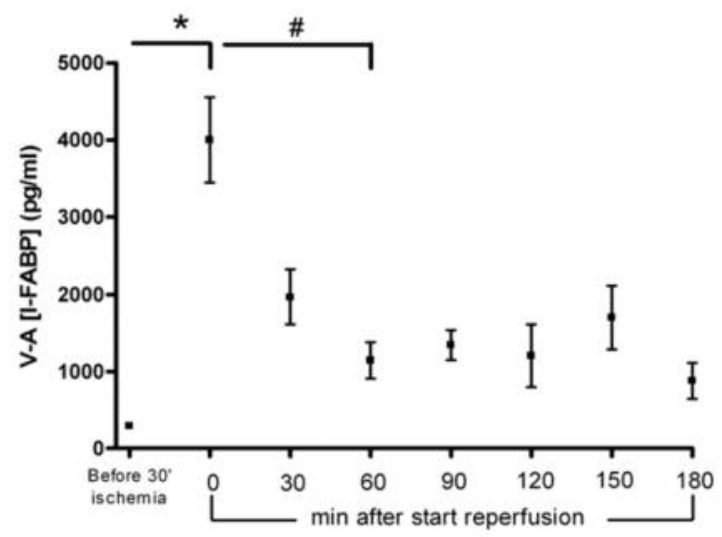

Figure 4. Arteriovenous concentration differences of I-FABP (mesenteric venule minus radial artery), a marker for acute enterocyte damage, across the isolated jejunal segment show rapid significant release of I-FABP after ischemia, while concentration differences of I-FABP gradually reduce following reperfusion. ${ }^{*} p<0.001, \# p<0.001$.

After 25 minutes of reperfusion, structural damage to the mucosa became apparent, consisting of detachment of epithelial cells, particularly in the apical regions of the villi, leading to shedding of (sheets of) mature epithelial cells into the lumen (Figure 1C). Intestinal villus epithelial cells, which had lost the contact with the underlying villous stroma, underwent a phenomenon called 'anoikis', which refers to detachment-induced apoptosis. ${ }^{31}$ Therefore, apoptosis was visualized in the jejunal sections using the apoptosis marker M30, which detects the Asp396 caspase cleavage site in cytokeratin-18. ${ }^{32}$ Intense M30 immunostaining was observed after 25 minutes of reperfusion at the villus tips, at the site where extensive desquamation of the epithelial cells from the villus tips into the intestinal lumen occurred, which was not detected in the earlier phase (Figure 5A-C). In the shortly reperfused jejunum a substantial loss of ZO-1 expression was shown in the sheets of shedded cells, which was accompanied by a decreased cytoplasmatic immunoreactivity of IFABP.

\section{Late phenomena during reperfusion}

As mentioned in the Materials and Methods section, a notable finding in all jejunal samples collected after 30 minutes ischemia and more than 60 minutes reperfusion 

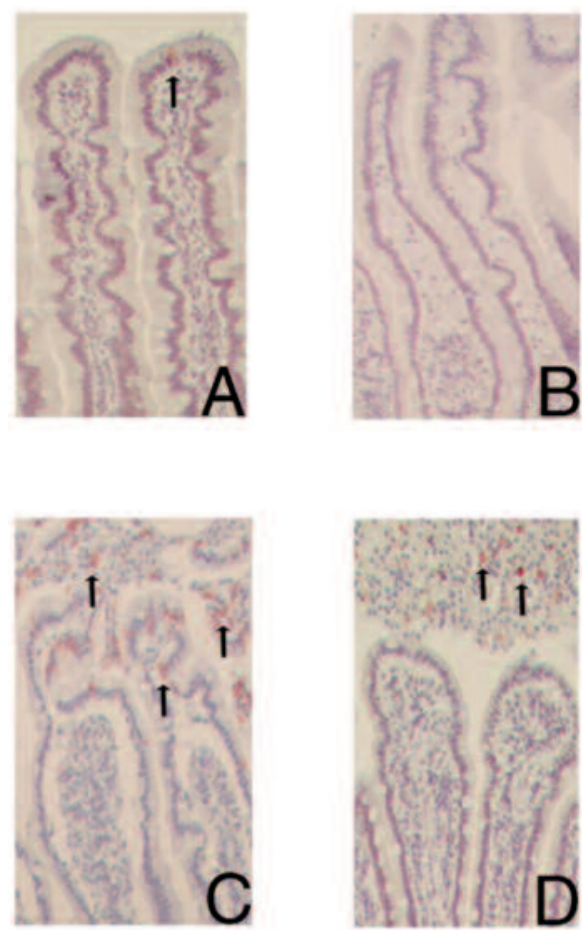

Figure 5. Apoptosis, assessed by M30 staining in red (AEC). An M30 positive cell (arrow) is observed at the top of the villus in normal jejunum (100X) (A). Upon 30 minutes ischemia, no M30 positive staining is found (B), while after 25 minutes reperfusion intense M30 immunostaining is observed at the villus tip near the shedding of mature epithelial cells into the lumen (arrows) (C). At 60 minutes reperfusion M30 immunoreactivity is no longer detectable in the intact, resealed epithelial barrier, while debris of M30 positive, shedded epithelial cells is observed in the lumen (D).

was the presence of a milky substance that appeared from the lumen. Histological analysis of this debris revealed sheets of enterocytes with numerous apoptotic cells, assessed by H\&E and M30 staining (Figure 6A, B).

The H\&E staining of the jejunum, which underwent 30 minutes ischemia and more than 60 minutes reperfusion, confirmed the debris of detached epithelial cells in the lumen (Figure 1D). Interestingly, within 60 minutes reperfusion the epithelial layer resealed and full confluent coverage of the villus tip by enterocytes was observed again, indicating a recovered epithelial barrier (Figure 1D). The cells coating the lamina propria were immunopositive for I-FABP and ZO-1, indicating 


\section{Chapter 3}
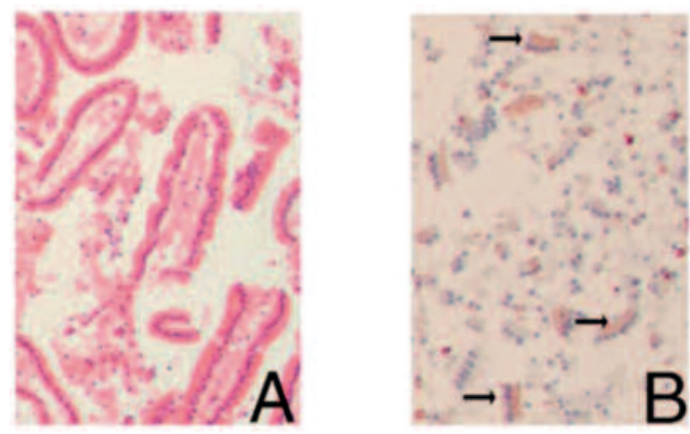

Figure 6. Histological analysis of H\&E stained AgarCyto-fixed debris, appearing from the lumen of the jejunum after 30 minutes ischemia and more than 60 minutes ischemia, shows sheets of enterocytes (100X). (A), containing many M30 positive cells (arrows) in red (AEC) (100X) (B).

that the epithelial continuity contained viable enterocytes with intact tight junctions (Figure 2D). Immunostaining with collagen IV showed that the basement membrane was again attached to the epithelial lining (Figure 3D). To investigate the status of these epithelial cells, M30 immunostaining was performed to assess apoptosis. M30 immunoreactivity was absent in the newly formed intact epithelium, while the debris of shedded epithelial cells in the lumen contained apoptotic cells (Figure 5D).

\section{Discussion}

This study for the first time provides insight in the sequence of events taking place during intestinal ischemia-reperfusion (IR) in man. Intestinal IR is often encountered in clinical practice, not only in patients presenting with abdominal complaints, but also during e.g. exercise, major surgery and trauma. ${ }^{1-4,8}$ Patients undergoing pancreatico-duodenectomy enabled us to create the first human experimental model allowing detailed studies of intestinal IR induced cell damage, because in this procedure a variable length of healthy jejunum is removed as part of the standard operative procedure. This controlled model completely equals the interruption of blood flow to the small intestine, which often occurs during repair of a (thoraco-) abdominal aneurysm of the aorta, cardiopulmonary bypass, and intestinal transplantation. 
Our study reveals that three phenomena can be distinguished following 30 minutes of human intestinal ischemia. Firstly, during the ischemic period the epithelial integrity remained seemingly intact, while subepithelial spaces appeared by detachment of the basement membrane from the enterocytes without any indication for the onset of apoptosis. The presence of I-FABP staining in the subepithelial spaces strongly indicates loss of membrane integrity of the intestinal epithelial cells at the site of formation of subepithelial spaces. These data are in line with the rapid increase of arteriovenous concentration differences of I-FABP immediately upon ischemia. Secondly, within 30 minutes reperfusion, desquamation of the intestinal epithelium at the tip of the villi was observed into the lumen, accompanied by apoptosis of mature epithelial cells. Thirdly, within 60 minutes reperfusion, a fully intact epithelial lining was found, indicating rapid restoration, whereas the apoptotic enterocytes had been shedded in the lumen. This reaction of the intestinal villi upon ischemia reperfusion, which collectively is called restitution, was also found in previous in vitro and in vivo animal studies after various insults, as recently reviewed by Blikslager et al. ${ }^{19}$ However, the consequences of intestinal IR in animal studies vary largely and seem to be dependent on the animal model, the animal strain, preoperative care (e.g. starvation/fasting, premedication) and duration of ischemia or hypoperfusion. ${ }^{17-19}$ Intestinal epithelial restitution is hypothesized to be directed at repairing the epithelial defect, which originates from the detachment of damaged enterocytes. The appearance of subepithelial spaces during ischemia is the actual start of the regeneration and aimed at reducing the effective size of the injured area. The development of subepithelial spaces after splanchnic hypoperfusion in animal studies was initially interpreted as an accumulation of cytoplasmic fluid from ischemic damaged cells. ${ }^{17}$ Later, evidence was provided by an in vitro model of chemically-induced injury to guinea pig ileal epithelium that the subepithelial space resulted from the retraction of the basement membrane by contraction of myofibroblasts. ${ }^{29}$ This retraction leads to a smaller and denser lamina propria accompanied by some seepage of fluid from the lamina propria cells into the newly formed subepithelial space. This is in line with our observations that the subepithelial spaces developing after 30 minutes of ischemia were associated with a dense lamina propria and a liquid-containing space between the basement membrane and enterocytes. Immediately after the start of the reperfusion, the IFABP staining of the subepithelial space strongly indicates a loss of enterocyte 


\section{Chapter 3}

membrane integrity, resulting in leakage of I-FABP into the subepithelial space. In line, we observed immediately upon ischemia strongly elevated arteriovenous concentration gradients of I-FABP, reflecting the membrane integrity loss of the epithelial cells of the villus. Therefore, we hypothesize that the enterocyte cell membrane must have lost its integrity during ischemia.

The mature enterocytes at the tip of the villus are the cells that are most susceptible to IR. ${ }^{33}$ This has classically been explained by their constant state of hypoxia due to the counter current exchange mechanism of oxygen in the villus microvasculature, wherein oxygen from arterial blood entering the villus diffuses across to neighbouring venules travelling from the tip down toward the base of the villus. ${ }^{33}$ As a result of this phenomenon, a steep oxygen gradient is present in the intestinal villus with substantially lower oxygen tensions in the villus tip than at the crypt. $^{33}$ In addition, desquamation occurs of the damaged mature enterocytes from the tip of the villi, resulting in shedding of sheets of epithelial cells into the lumen. Apoptosis is the major form of cell death observed after the onset of reperfusion and at the villus tip. Apoptosis of detaching enterocytes after intestinal IR is potentially caused by loss of contact between the epithelial cells and extracellular matrix, and between neighbouring epithelial cells ('anoikis'). 20,31,34 Extracellular matrix molecules provide a constant survival signal to epithelial cells via b1integrins and cadherins as well as their adhesion-mediated signalling pathways including focal adhesion kinase (p125fak), phosphatidylinositol 39-kinase (PI3K)/Akt and mitogen-activated protein kinase (MAPK; p38). ${ }^{34-37}$ However, senescent enterocytes gradually loosen cell anchorage by changes of integrin expression, cadherin binding and its signalling pathways, making them prone to be shedded from the villus tip at the end of their lifespan, a mechanism crucial for maintenance of homeostasis in this epithelium..$^{35-37}$ Moreover, acyl-coenzyme A synthetase 5, which is solely expressed at the villus tip, is able to sensitize epithelial cells to apoptosis specifically triggered by the death ligand TRAIL. ${ }^{38}$ Therefore, mature enterocytes are in an anti-adhesive and pro-apoptotic state when they reach the villus tip, culminating in the physiologic shedding. ${ }^{39}$ This may contribute to the rapid onset of apoptosis that we observed in the mature and damaged enterocytes after the ischemic period, upon reperfusion.

The ultimate reparative response to the lost epithelial continuity was observed within one hour of reperfusion, consisting of a complete resealing of the epithelial defect overlying the basement membrane by viable, ZO-1 and FABP containing, 
epithelial cells. The presence of tight junctions and endogenous cytosolic proteins in the repaired epithelial cells of the villus tip indicates that the epithelial lining is rapidly restored, which is of importance to reduce the opportunity for luminal microbiota and their products to translocate. The question remains whether this also leads to a reestablishment of the full barrier function, which will be assessed in future using physiological measurements by tracer or electrophysiological studies. Previous studies reported that the migration of epithelial cells involves alteration of enterocyte shape and phenotype, including extension of the plasma membrane in the direction of cell migration and assembly of new focal contacts at the leading edge. ${ }^{19,40,41}$ Epithelial migration during restitution is enhanced by luminal contents and a variety of systemic and local factors, including trefoil peptides, polyamines and transforming growth factor B. ${ }^{19,42}$

The clearing mechanism of IR-induced injured cells is unique to the intestine. In other organs or tissues, such as heart, brain, kidney, liver and skeletal muscle, IRinduced damaged and death cells remain in situ, since they cannot be removed from the organs or tissues and cleared from the body. In such organs, an inflammatory response is elicited amongst others to clear away the injured and death cells after IR. ${ }^{10,13-15,43}$ Subject of further studies is the investigation of the inflammatory response in our controlled, experimental model of human IR, which enabled us to clarify a gut-specific protective mechanism for IR-induced damaged cells. Our results might explain why the gut can tolerate 30 minutes of ischemia in events as exercise, trauma, repair of a (thoraco-) abdominal aneurysm of the aorta, and cardiopulmonary bypass.

\section{RefERENCES}

1. (2000) American Gastroenterological Association Medical Position Statement: guidelines on intestinal ischemia. Gastroenterology 118: 951-953.

2. Oldenburg WA, Lau LL, Rodenberg TJ, Edmonds HJ, Burger CD (2004) Acute mesenteric ischemia: a clinical review. Arch Intern Med 164: 1054-1062.

3. Jeukendrup AE, Vet-Joop K, Sturk A, Stegen JHJC, Senden J, et al. (2000) Relationship between gastro-intestinal complaints and endotoxaemia, cytokine release and the acutephase reaction during and after a long-distance triathlon in highly trained men. Clin Science 98: 47-55. 


\section{Chapter 3}

4. Perko MJ, Nielsen HB, Skak C, Clemmesen JO, Schroeder TV, et al. (1998) Mesenteric, coeliac and splanchnic blood flow in humans during exercise. J Physiol 513: 907-913.

5. Rokyta R, Matejovic M, Novak I, Zeman V, Krouzecky A, et al. (2002) Submaximal exercise in healthy volunteers: the relationship between gastric mucosal and systemic energy status. Pflügers Arch - Eur J Physiol 443: 852-857.

6. Veenstra R, Geelkerken R, Verhorst P, Huisman A, Kolkman J (2007) Acute stress-related gastrointestinal ischemia. Digestion 75: 205-207.

7. Fukatsu K, Sakamoto S, Hara E, Ueno C, Maeshima Y, et al. (2006) Gut ischemiareperfusion affects gut mucosal immunity: a possible mechanism for infectious complications after severe surgical insults. Crit Care Med 34: 182-187.

8. Mallick IH, Yang W, Winslet MC, Seifalian AM (2004) Ischemia-reperfusion injury of the intestine and protective strategies against injury. Dig Dis Sci 49: 1359-1377.

9. Semenza GL (2000) Series introduction: tissue ischemia: pathophysiology and therapeutics. J Clin Invest 106: 613-614.

10. Lee JM, Grabb MC, Zipfel GJ, Choi DW (2000) Brain tissue responses to ischemia. J Clin Invest 106: 723-731.

11. Carden DL, Granger DN (2000) Pathophysiology of ischaemia-reperfusion injury. J Pathol 190: 255-266.

12. Matzinger P (2007) Friendly and dangerous signals: is the tissue in control? Nat Immunol 8: $11-13$.

13. Jaeschke H (2003) Molecular mechanisms of hepatic ischemia-reperfusion injury and preconditioning. Am J Physiol Gastrointest Liver Physiol 284: G15-26.

14. Blaisdell FW (2002) The pathophysiology of skeletal muscle ischemia and the reperfusion syndrome: a review. Cardiovasc Surg 10: 620-630.

15. Daemen MA, de Vries B, Buurman WA (2002) Apoptosis and inflammation in renal reperfusion injury. Transplantation 73: 1693-1700.

16. Arumugam TV, Shiels IA, Woodruff TM, Granger DN, Taylor SM (2004) The role of the complement system in ischemia-reperfusion injury. Shock 21: 401-409.

17. Chiu CJ, McArdle AH, Brown R, Scott HJ, Gurd FN (1970) Intestinal mucosal lesion in lowflow states. I. A morphological, hemodynamic, and metabolic reappraisal. Arch Surg 101: 478-483.

18. Park PO, Haglund U, Bulkley GB, Falt K (1990) The sequence of development of intestinal tissue injury after strangulation ischemia and reperfusion. Surgery 107: 574-580.

19. Blikslager AT, Moeser AJ, Gookin JL, Jones SL, Odle J (2007) Restoration of barrier function in injured intestinal mucosa. Physiol Rev 87: 545-564. 
20. Ikeda H, Suzuki Y, Suzuki M, Koike M, Tamura J, et al. (1998) Apoptosis is a major mode of cell death caused by ischaemia and ischaemia/reperfusion injury to the rat intestinal epithelium. Gut 42: 530-537.

21. Park PO, Haglund U (1992) Regeneration of small bowel mucosa after intestinal ischemia. Crit Care Med 20: 135-139.

22. Hart ML, Ceonzo KA, Shaffer LA, Takahashi K, Rother RP, et al. (2005) Gastrointestinal ischemia-reperfusion injury is lectin complement pathway dependent without involving C1q. J Immunol 174: 6373-6380.

23. Chen LW, Egan L, Li ZW, Greten FR, Kagnoff MF, et al. (2003) The two faces of IKK and NFkappaB inhibition: prevention of systemic inflammation but increased local injury following intestinal ischemia-reperfusion. Nat Med 9: 575-581.

24. Panes J, Granger DN (1998) Leukocyte-endothelial cell interactions: molecular mechanisms and implications in gastrointestinal disease. Gastroenterology 114: 1066-1090.

25. Haglund U, Hulten L, Ahren C, Lundgren O (1975) Mucosal lesions in the human small intestine in shock. Gut 16: 979-984.

26. Kerstens HM, Robben JC, Poddighe PJ, Melchers WJ, Boonstra H, et al. (2000) AgarCyto: a novel cell-processing method for multiple molecular diagnostic analyses of the uterine cervix. J Histochem Cytochem 48: 709-718.

27. Pelsers MM, Hermens WT, Glatz JF (2005) Fatty acid-binding proteins as plasma markers of tissue injury. Clin Chim Acta 352: 15-35.

28. Fanning AS, Jameson BJ, Jesaitis LA, Anderson JM (1998) The tight junction protein ZO-1 establishes a link between the transmembrane protein occluding and the actin cytoskeleton. J Biol Chem 273: 29745-29753.

29. Powell DW, Mifflin RC, Valentich JD, Crowe SE, Saada JI, et al. (1999) Myofibroblasts. II. Intestinal subepithelial myofibroblasts. Am J Physiol 277: C183-201.

30. Kuhn K (1995) Basement membrane (type IV) collagen.Matrix Biol 14: 439-445.

31. Frisch SM, Francis H (1994) Disruption of epithelial cell-matrix interactions induces apoptosis. J Cell Biol 124: 619-626.

32. Leers MP, Kolgen W, Bjorklund V, Bergman T, Tribbick G, et al. (1999) Immunocytochemical detection and mapping of a cytokeratin 18 neo-epitope exposed during early apoptosis. J Pathol 187: 567-572.

33. Blikslager AT (2008) Life in the gut without oxygen: adaptive mechanisms and inflammatory bowel disease. Gastroenterology 134: 346-348.

34. Hofmann C, Obermeier F, Artinger M, Hausmann M, Falk W, et al. (2007) Cell-cell contacts prevent anoikis in primary human colonic epithelial cells. Gastroenterology 132: 587-600. 


\section{Chapter 3}

35. Fouquet S, Lugo-Martinez VH, Faussat AM, Renaud F, Cardot P, et al. (2004) Early loss of Ecadherin from cell-cell contacts is involved in the onset of Anoikis in enterocytes. J Biol Chem 279: 43061-43069.

36. Vachon PH, Harnois C, Grenier A, Dufour G, Bouchard V, et al. (2002) Differentiation stateselective roles of p38 isoforms in human intestinal epithelial cell anoikis. Gastroenterology 123: 1980-1991.

37. Dufour G, Demers MJ, Gagne D, Dydensborg AB, Teller IC, et al. (2004)Human intestinal epithelial cell survival and anoikis. Differentiation state-distinct regulation and roles of protein kinase B/Akt isoforms. J Biol Chem 279: 44113-44122.

38. Gassler N, Roth W, Funke B, Schneider A, Herzog F, et al. (2007) Regulation of enterocyte apoptosis by acyl-CoA synthetase 5 splicing. Gastroenterology 133: 587-598.

39. Bullen TF, Forrest S, Campbell F, Dodson AR, Hershman MJ, et al. (2006) Characterization of epithelial cell shedding from human small intestine. Lab Invest 86: 1052-1063.

40. Moore R, Carlson S, Madara JL (1989) Rapid barrier restitution in an in vitro model of intestinal epithelial injury. Lab Invest 60: 237-244.

41. Moore R, Madri J, Carlson S, Madara JL (1992) Collagens facilitate epithelial migration in restitution of native guinea pig intestinal epithelium. Gastroenterology 102: 119-130.

42. Podolsky DK (1997) Healing the epithelium: solving the problem from two sides. J Gastroenterol 32: 122-126.

43. Yellon DM, Hausenloy DJ (2007) Myocardial reperfusion injury. N Engl J Med 357: 11211135. 


\section{Chapter 3.4}

\section{Enterocyte shedding and epithelial lining repair following ischemia of the human small intestine attenuate inflammation}

Robert A. Matthijsen, Joep P.M. Derikx, Dian Kuipers, Ronald M. van Dam, Cornelis H.C. Dejong, Wim A. Buurman

PLoS One. 2009, 4: e7045. 


\section{Chapter 3}

\section{Abstract}

Background. Recently, we observed that small-intestinal ischemia and reperfusion was found to entail a rapid loss of apoptotic and necrotic cells. This study was conducted to investigate whether the observed shedding of ischemically damaged epithelial cells affects IR induced inflammation in the human small gut.

Methods and Findings. Using a newly developed IR model of the human small intestine, the inflammatory response was studied on cellular, protein and mRNA level. Thirty patients were consecutively included. Part of the jejunum was subjected to 30 minutes of ischemia and variable reperfusion periods (mean reperfusion time $120( \pm 11)$ minutes). Ethical approval and informed consent were obtained. Increased plasma intestinal fatty acid binding protein (I-FABP) levels indicated loss in epithelial cell integrity in response to ischemia and reperfusion ( $p$ $<0.001$ vs healthy). HIF-1 $\alpha$ gene expression doubled $(p=0.02)$ and C3 gene expression increased 4 -fold $(p=0.01)$ over the course of IR. Gut barrier failure, assessed as LPS concentration in small bowel venous effluent blood, was not observed ( $p=0.18$ ). Additionally, mRNA expression of HO-1, IL-6, IL-8 did not alter. No increased expression of endothelial adhesion molecules, TNF- $\alpha$ release, increased numbers of inflammatory cells $(p=0.71)$ or complement activation, assessed as activated C3 $(p=0.14)$, were detected in the reperfused tissue.

Conclusions. In the human small intestine, thirty minutes of ischemia followed by up to 4 hours of reperfusion, does not seem to lead to an explicit inflammatory response. This may be explained by a unique mechanism of shedding of damaged enterocytes, reported for the first time by our group.

\section{INTRODUCTION}

Recently, we demonstrated the ability of the human small intestine to rapidly restore its epithelial architecture after massive epithelial sloughing and gut barrier damage in response to a thirty minutes ischemic episode and variable reperfusion periods. ${ }^{1}$ Interestingly, analysis of the reperfused intestinal segment demonstrated that the epithelial brush border and epithelial tight junctions were restored within the first hour of reperfusion. ${ }^{1}$ The presence of apoptosis or cellular damage in 
reperfused ischemic organs has cardinal implications in the pathogenesis of ischemia reperfusion (IR). ${ }^{2,3}$ Massive apoptosis and subsequent necrosis are involved in the induction of inflammation after organ ischemia. This notion is based on the observation that therapeutic strategies aimed at preventing IR induced apoptosis can ameliorate IR induced inflammation. ${ }^{4-7}$ Numerous experimental studies have shown that the inflammatory response following IR mediates the development of additional reperfusion injury, further compromising organ function. ${ }^{4,8-12}$ Different strategies aimed at preventing IR induced inflammation can effectively reduce organ damage. ${ }^{13}$

The inflammatory response induced by IR is essentially characterized by different contributors. Early after cellular injury various cytokines, such as tumor necrosis factor-a, interleukin-1, $-6,-8$ or -10 and others, are expressed. ${ }^{14,15}$ Together with the rapid expression of adhesion molecules by activated endothelial cells, the activation, adhesion and sequestration of polymorphonuclear neutrophils (PMN) into the affected tissue is induced. ${ }^{16}$

Infiltrating PMN contribute substantially to IR induced inflammation, by locally releasing myeloperoxidase (MPO) or generating reactive oxygen species. ${ }^{10,17}$ Additionally the complement system is activated, thereby triggering the formation of reactive complement split products known as anaphylatoxins, which induce additional PMN chemotaxis and cause organ damage. ${ }^{18,19}$ Complement activation will lead to cell damage by membrane attack complex (MAC) formation..$^{9,19}$ Normally, under healthy conditions, these innate immune constituents protect the organism from harm by orchestrating a well mounted attack on invading microorganisms, but when faced with extensive I/R injury, sufficient means of control seem absent. In this respect, interventions aimed at preventing complement activation, ${ }^{8}$ MAC formation, ${ }^{20}$ expression of adhesion molecules $^{21}$ or PMN sequestration ${ }^{22,23}$ all prevent excessive reperfusion injury. The presence of apoptotic and necrotic cells following ischemia reperfusion of the small intestine appears to be of critical importance in the development of an inflammatory reaction that contributes to tissue injury. From this we hypothesized that the remarkable ability of the human small intestine to effectively shed apoptotic cells, is a way of losing an important endogenous inflammatory trigger. This may serve as a unique intestinal rescue mechanism, which potentially attenuates the development of an intense IR induced inflammatory reaction. Therefore, we studied time related characteristics of IR induced inflammation of 


\section{Chapter 3}

the human small intestine in a newly developed human ischemia reperfusion model of the jejunum. The results indicate that reperfused ischemic jejunum effectively discards apoptotic and damaged epithelium, restores the epithelial gut barrier and thereby prevents the development of a local inflammatory response.

\section{Methods}

\section{Patients and ethics}

The study was approved by the Maastricht University Medical Center ethical committee. Written consent of all patients was obtained before inclusion. Consecutively included patients were scheduled to undergo pancreatic surgery; twenty eight underwent a pylorus preserving pancreatico-duodenectomy (modified Whipple's procedure) for benign or malignant pancreatic disease and two underwent a Frey's procedure for chronic pancreatitis. During pancreaticoduodenectomy a variable length of jejunum is usually resected in continuity with the specimen. Similarly, in creating a Roux-limb for the pancreatico-jejunostomy in Frey's procedure, it is often necessary to resect a small segment of jejunum. We took advantage of this, which enabled us to study IR induced cell damage in a harmless human jejunal IR model. To that purpose, the most distal part of the jejunum to be resected with the Whipple specimen, or the most proximal part of the Roux-limb to be used as a pancreatico-jejunostomy in the Frey's procedure, was used to isolate a $6 \mathrm{~cm}$ segment of jejunum. The jejunum of all patients was carefully checked for any signs of underlying pathology and inflammation during operation and before the start of the IR procedure. Due to an incomplete reperfusion 2 patients were later excluded from further analysis, all having had a modified Whipple's procedure.

\section{Study model and blood sampling}

The first part of surgery (opening of the abdominal wall, installation of a large selfretaining retractor and exploration for metastases and localization of the major anatomical structures and tumor) was according to standard procedures. From this moment the $6 \mathrm{~cm}$ part of jejunum, which was going to be studied, was identified and care was taken that the vasculature of the studied jejunum consisted of 1 central mesenteric arteriole and venule. This was achieved as described before., ${ }^{1,24}$ In brief, clamping and cutting of all collateral mesenterial vessels to the studied 
segment of jejunum, using Ultracision Harmonic Ace (Johnson\&-Johnson, cat. no. ACE23P, Amersfoort, the Netherlands). Thereafter, the segment of jejunum was further isolated by transsection at both ends with a linear cutting stapler (GIA 6038S, Covidien, Zaltbommel, the Netherlands). The isolated jejunum was then subjected to 30 minutes ischemia using 2 a-traumatic vascular clamps, which are placed over the mesentery in opposed directions to ensure complete clamping (Bulldog, Aesculap, cat. no. BH013R, Tuttlingen, Germany). The isolated ischemic jejunum was subsequently kept in the abdominal cavity to guarantee warm ischemia. After half an hour of ischemia, one third $(2 \mathrm{~cm})$ of the isolated ischemic jejunum was resected to study early phenomena during ischemia. Reperfusion was initiated by removal of the clamps. Adequacy of reperfusion was confirmed by the gut regaining color and restoration of peristalsis. Subsequently, the venous outflow was sampled. A further segment of isolated jejunum $(2 \mathrm{~cm})$ was resected similarly after 25 minutes of reperfusion to study early phenomena during reperfusion. The last part of studied jejunum was resected from 60 minutes after reperfusion onwards, to investigate late phenomena during reperfusion. At the time the last isolated reperfused segment of jejunum was obtained for the study, also $2 \mathrm{~cm}$ of jejunum, which had not been isolated and remained untreated during surgery, was resected using a linear cutting stapler. This tissue was used as internal control tissue: it was from the same patient and experienced similar surgical handling as the isolated jejunum, while it was not subjected to IR. Arterial blood was sampled preoperatively, before the isolated jejunum was subjected to ischemia, immediately upon reperfusion and every half hour during reperfusion until the last part of the isolated jejunum was collected at the end of the study protocol. Simultaneous with the second (i.e. before ischemia) and every next arterial blood sample, blood was drawn from the venule draining the isolated jejunal segment by direct puncture to assess concentration gradients across the isolated jejunal segment. All blood samples were directly transferred to pre-chilled EDTA vacuum tubes (BD vacutainer, Becton Dickinson Diagnostics, Aalst, Belgium) and kept on ice. At the end of the study all blood samples were centrifuged at $4000 \mathrm{rpm}, 4^{\circ} \mathrm{C}$ for 15 minutes to obtain plasma. Plasma was kept on ice and immediately stored in aliquots at $-280^{\circ} \mathrm{C}$ until analysis. The total reperfusion time was determined by the duration of the surgical procedure, with a maximum of 240 minutes. Reperfused ischemic intestine samples were obtained from every patient $(n=28)$. Healthy jejunum samples, serving as internal controls, were obtained from 12 patients. 


\section{Chapter 3}

\section{Immunohistochemistry}

Paraffin-embedded sections $(4 \mathrm{~m})$ were prepared from healthy and the final IR jejunum sample. These sections were stained using haematoxylin and eosin or immunostained for endothelial adhesion molecules E-selectin (CD-62-E, monoclonal antibody ENA1, kindly provided by Hycult Biotechnology (Hbt, Uden, the Netherlands)), intercellular adhesion molecule-1 (ICAM-1, monoclonal antibody HM1, Hbt) and mucosal vascular addressin cell adhesion molecule 1 (MADCAM-1, monoclonal antibody 314G8, Hbt), neutrophils by myeloperoxidase staining (polyclonal antibody, A0398, DakoCytomation, Glostrup, Denmark) or human neutrophil defensin 1-3 (monoclonal antibody, D21, Hbt) and complement component C3C (A0062, DakoCytomation). Sections were deparaffinized, rehydrated and blocked for 1 hour at room temperature using 5\% BSA in phosphate buffered saline (PBS) or tris buffered saline (TBS) for HM1 and MPO. Properly diluted primary antibodies were incubated in PBS or TBS supplemented with $0.1 \%$ BSA for 1 hour at room temperature. After washing, specific antibody binding was detected using specific peroxidase conjugated secondary antibodies (Jackson ImmunoResearch, West Grove, PA) or a biotinylated swine anti rabbit secondary antibody (E0432, DakoCytomation) for detecting MPO specific binding. Next, signal enhancement was achieved by peroxidase conjugated avidin biotin complexes. Staining was visualized by 3-amino-9-ethylcarbazole (AEC) followed by a haematoxylin (Sigma, St. Louis, MO) nuclear counterstaining. Microscopic analysis of several high power fields $(n=5)$ from different paraffin embedded tissue samples was carried out by a blinded observer.

\section{ELISA}

Arteriovenous concentration differences of plasma Intestinal-Fatty Acid Binding Protein (I-FABP) levels were determined by Enzyme-Linked Immunosorbent Assay (ELISA) before and after ischemia to measure intestinal mucosal cell damage. ${ }^{25}$ Plasma IFABP was determined in all samples, collected at pre-fixed time points. The I-FABP ELISA (HK406, Hbt) was performed according to the manufacturer's guidelines. Myeloperoxidase (MPO) was measured in tissue samples (healthy vs the final IR jejunum sample) that were homogenized according to the later described Western blot protocol. MPO was measured using a commercially available solid-phase ELISA kit based on the sandwich principle (Hbt) in aliquots containing equal amounts (10 ng) of total protein. The assay was performed in 
accordance with the manufacturer's guidelines. Arteriovenous concentration differences in plasma tumor necrosis factor- $\alpha$ (TNF- $\alpha$ ) levels were determined by ELISA before and after ischemia as well as during reperfusion. The TNF- $\alpha$ ELISA was performed as described before. ${ }^{26}$ Arteriovenous concentration differences in plasma lipopolysacharide (LPS) levels were determined using a Limulus Amoebocyte Lysate (LAL) assay before and after ischemia as well as during reperfusion. The LAL assay (HIT 302, Hbt) was performed in accordance with the manufacturer's guidelines. Plasma LPS was determined in all samples, collected at pre-fixed time points.

\section{Western Blot}

Western blot analyses for human C3 deposition on reperfused ischemic tissue samples and healthy controls was performed as described before, with minor modifications. ${ }^{4}$ Jejunal samples were homogenized in lysis buffer $(200 \mathrm{mM} \mathrm{NaCl}$, $10 \mathrm{mM}$ Tris base, $5 \mathrm{mM}$ EDTA, 10\% Glycerin, $1 \mathrm{mM}$ PMSF, $0.1 \mathrm{U} / \mathrm{ml}$ Aprotinin and $1 \mathrm{mg} / \mathrm{ml}$ Leupeptin). Tissue homogenates were centrifuged. Protein concentrations of the different lysates were determined using Bradford analyses. Aliquots containing equal amounts (10 g) of total protein were heated and reduced, transferred to an $8 \%$ SDS-polyacrylamide gel and blotted on an Immobilon-P Polyvinylidene Difluoride (PVDF) membrane (Millipore, Bedford, MA). Blocking was performed in phosphate buffered saline (PBS) containing $5 \%$ bovine serum albumin and 0.1\% Tween-20 (Sigma). C3 was detected in PBS 0.1\% BSA 0.1\% Tween-20 after overnight incubation of the properly diluted rabbit anti human $\mathrm{C} 3 \mathrm{C}$ (A0062, DakoCytomation, Glostrup, Denmark). Binding of the primary antibody was detected using a biotinylated secondary antibody to rabbit IgG (E0353, Dako) and streptavidin conjugated peroxidase. Positive bands were visualized using chemiluminescence (Supersignal (pico:femto 9:1), Pierce, Rockford, IL).

\section{Real-Time Quantitative - PCR analysis}

Total RNA was extracted from healthy and all IR damaged jejunum samples using a SV Total RNA Isolation System according to manufacturer's guidelines (Promega, Madison, WI). Total cDNA was synthesized with oligo (dT) primers and Moloney murine leukemia virus reverse transcriptase. Specific primers (Sigma) for amplification of hemoxygenase-1, hypoxia inducible factor 1- $\alpha$ (HIF-1 $\alpha$ ), interleukin- 6 and -8 , TNF- $\alpha$ and complement component C3 specific cDNA were 


\section{Chapter 3}

designed (Table 1) using the Primer Express software package (Applied Biosystems, Foster City, CA) and tested for amplification of contaminating genomic DNA. To minimize the risk of genomic amplification the primers were positioned on different exons. Primer concentrations were optimalized and dilution curves were made from human liver cDNA standard pool to ensure an exponential TaqMan amplification for each primer set. After normalization to endogenous reference genes, RPLP0 and cyclophylin-A, the level of expression of different proteins in healthy or IR damaged samples was determined by the comparative DDCT method of relative quantification. Primer specifications are listed in Table 1.

Table 1. Sequence of primers for Q-PCR analysis.

\begin{tabular}{lll} 
Proteins & Primers & \\
& Forward & Reversed \\
\hline HIF-1a & 3-TGAACATAAAGTCTGCAACATGGA-5 & 5-TGAGGTTGGTTACTGTTGGTATCATATA-3 \\
H0-1 & 3-CTTCTTCACCTTCCCCAACA-5 & 5-GCTCTGGTCCTTGGTGTCAT-3 \\
TNFa & 3-TCAATCGGCCCGACTATCTC-5 & 5-CAGGGCAATGATCCCAAAGT-3 \\
IL-6 & 3-TCCAGGAGCCCAGCTATGAA-5 & 5-GAGCAGCCCCAGGGAGA-3 \\
IL-8 & 3-CTGGGCGTGGCTCTCTTG-5 & 5-TTAGCACTCCTTGGCAAAACTC-3 \\
C3 & 3-CCCTCATCATCTACCTGGACAAG-5 & 5-GCTGGATAAGCTCTACATTAAAGTATTGG-3 \\
RPLP-0 & 3-GCAATGTTGCCAGTGTCTG-5 & 5-GCCTTGACCTTTTCAGCAA-3 \\
Cycophilin A & 3-CTCGAATAAGTTTGACTTGTGTTT-5 & 5-CTAGGCATGGGAGGGAACA-3 \\
\hline
\end{tabular}

\section{Statistical analysis}

Data are expressed as means ( \pm SEM) and were analyzed by either paired or unpaired two-tailed Student $T$-test depending on sample collection. Bonferroni's multiple comparison test was used (after significant repeated measures ANOVA) to compare I-FABP or LPS arteriovenous concentration differences in time. Data were analyzed using Prism 4.01 for Windows (Graphpad Software, San Diego, CA). A pvalue $<0.05$ was considered statistically significant. 


\section{Results}

\section{Patient outcome and reperfusion period}

The mean $( \pm$ SEM) age of included patients $(n=28)$ was $65(2)$ years and $64 \%$ were male. Isolated jejunum samples were subjected to 30 minutes of ischemia followed by a mean total reperfusion time of 120 (11) minutes (Fig. 1).

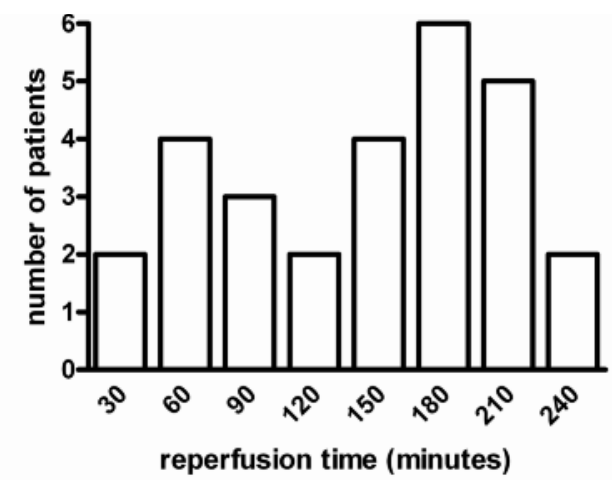

Figure 1. Reperfusion times. Distribution of maximal reperfusion times of the isolated jejunum, following 30 minutes of ischemia $(n=28)$.

\section{Intestinal epithelial damage}

Epithelial cell integrity was lost in response to 30 minutes of ischemia followed by various periods of reperfusion. This was illustrated by increased plasma I-FABP levels in the venous outflow of the reperfused jejunum, when compared to arterial circulating levels and I-FABP levels prior to the IR period ( ${ }^{*} p<0.001$. Fig. 2A). As described by Derikx et al. rapid sloughing of intestinal epithelial cells, during the first thirty minutes of reperfusion, was observed. Shedding of epithelial cells was followed by a full and rapid repair of the damaged intestinal epithelial barrier within the first hour of reperfusion (Fig. 2B-C). ${ }^{1}$

\section{Plasma LPS levels following IR}

Disruption of the gut barrier may lead to translocation of microbiota and proinflammatory microbial products, such as endotoxin associated with gram negative bacteria (lipopolysacharide (LPS)). Therefore we assessed the translocation of LPS following the rapid and temporary disruption of the epithelial lining in response to 


\section{Chapter 3}
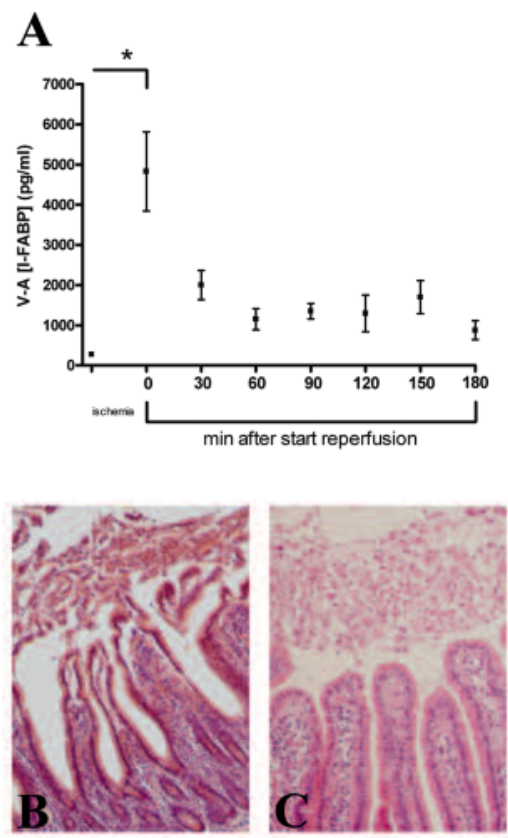

Figure 2. Epithelial cell damage. A) Arteriovenous concentration differences of I-FABP (mesenteric venule minus radial artery) across the isolated ischemic jejunal segment show rapid release of I-FABP into the circulation at reperfusion (early $\mathrm{R}$ vs healthy $* p<0.001$ ). B) Shedding of damaged epithelial cells into the intestinal lumen during the first thirty minutes of reperfusion. C) Rapid repair of the intestinal epithelial lining, observed following 1 hour of reperfusion.

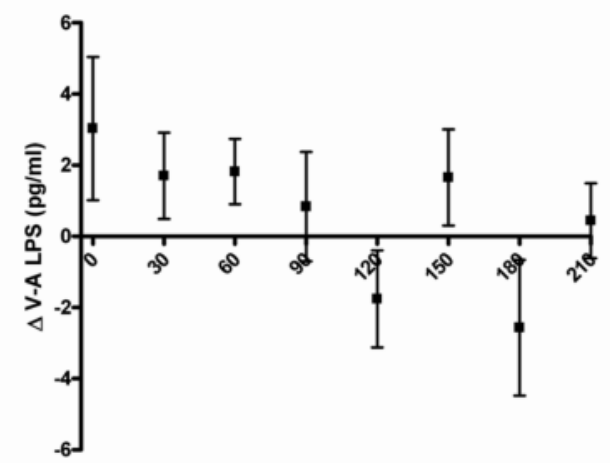

Figure 3. Tissue response to IR. Illustrative of rapid gut barrier repair, no translocation of LPS could be detected during the IR procedure. Translocation of LPS was calculated from arteriovenous differences in LPS plasma levels across the isolated bowel segment during reperfusion ( (V-A). $p=0.18$ ). 
IR observed in our model. ${ }^{1}$ LPS translocation from the intestinal lumen was assessed by measuring arterio-venous (AV) differences in LPS concentration across the jejunal segment, using the LAL-assay. Surprisingly, no translocation of LPS ( $p=0.18$, $\mathrm{n}=28$ ) was detected at any time point during reperfusion (Fig. 3 ). The temporary loss of gut wall integrity observed during reperfusion, which is induced by massive shedding of apoptotic epithelial cells, does not lead to the translocation of LPS.

\section{Stress response}

In order to demonstrate a physiological response to anoxia and to reperfusion stress, the mRNA expression profiles of hypoxia inducible factor- $1 \alpha$ (HIF-1 $\alpha$ ) and heme oxygenase-1 (HO-1) were determined in healthy and IR damaged whole jejunum samples $(n=12)$. The HIF-1 $\alpha$ expression, which regulates both physiologic and pathophysiologic responses to ischemia, increased during reperfusion (Table 2). In contrast, local mRNA expression of $\mathrm{HO}-1$ was unaltered by IR (Table 2).

Table 2. mRNA expression profiles in response to IR, calculated by comparative DDCT method of relative quantification.

\begin{tabular}{lllll} 
Gene & Healthy & IR & Fold increase $(95 \%-\mathrm{Cl})$ & $\mathrm{P}$ - value \\
\hline HIF-1a & 1.00 & 1.91 & $1.91(1.15-2.67)$ & $0.02^{*}$ \\
HO-1 & 1.00 & 1.58 & $1.58(0.22-2.94)$ & 0.34 \\
TNFa & 1.00 & 1.18 & $1.18(0.56-1.80)$ & 0.54 \\
IL-6 & 1.00 & 12.31 & $12.31(25.29229 .91)$ & 0.18 \\
IL-8 & 1.00 & 15.86 & $15.86(0.59-31.13)$ & 0.06 \\
C3 & 1.00 & 4.09 & $4.09(1.74-6.43)$ & $0.01^{*}$ \\
\hline
\end{tabular}

${ }^{*} \mathrm{p}$-value\#0.05 was considered statistically significant $(n=12)$.

\section{Cytokine expression and endothelial activation}

In order to assess the inflammatory reaction over the course of IR, serial venous blood samples from the reperfused jejunum were analyzed for different inflammatory markers. Additionally, the cytokine response in reperfused whole jejunum tissue samples was studied using Q-PCR. Endothelial cell activation was assessed by immunohistochemistry on paraffin embedded whole jejunum tissue samples before and after IR. No increase in TNF- $\alpha$ protein levels was detected in 


\section{Chapter 3}

venous plasma samples, collected from the isolated jejunum during the procedure; e.g. prior to ischemia, directly after ischemia and every 30 minutes during reperfusion. Compared to the TNF- $\alpha$ levels in arterial circulation, AV differences in TNF- $\alpha$ levels revealed no release of TNF- $\alpha$ from the gut (data not shown). In line, no increase in TNF- $\alpha$ mRNA was detected in IR damaged jejunum samples, when compared to healthy jejunum controls from the same patient (Table 2). mRNA expression of cytokines IL-6 (Table 2) and IL-8 (Table 2) in response to IR differed widely and failed to show an increase $(n=12)$. The reperfusion length did not show any relation with maximal IL-6 or IL-8 mRNA levels (data not shown). Classic in the development of extensive IR damage is the early expression of various adhesion molecules by activated endothelial cells. Presence of E-selectin, ICAM-1 and MADCAM-1 were analyzed using immunohistochemistry. Only 3 patient samples demonstrated sporadic and minimal expression of E-selectin (data not shown), ICAM-1 and MADCAM-1 (Fig. 4) following maximal reperfusion.

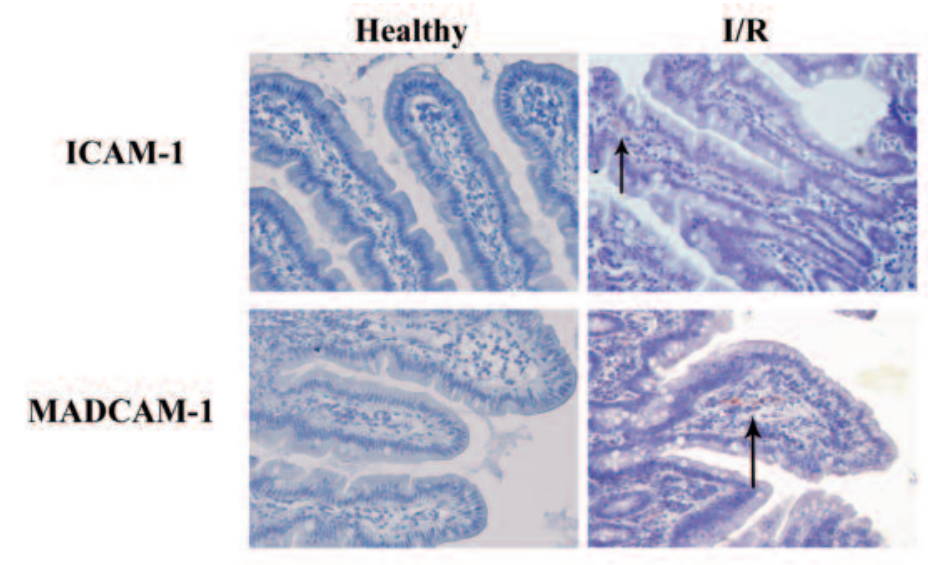

Figure 4. Endothelial activation. Compared to healthy control jejunum tissue, reperfused jejunum samples in response to 30 minutes of ischemia show an only moderate increase in ICAM-1 (upper panel) and MADCAM-1 (lower panel) expression demonstrated by terracotta red staining of the AEC (indicated by arrows). Original magnification 200x.

\section{Neutrophil infiltration and release of myeloperoxidase}

Critical in the induction of reperfusion injury is the influx of neutrophils as well as the release of their reactive constituents. The presence of neutrophils was assessed 
using two different and widely used neutrophil markers, human neutrophil defensin 1-3 (HNP1-3) and myeloperoxidase (MPO), both stored in abundance in azurophilic granules of neutrophils.

Analysis of immunostained tissue sections showed that the number of PMN in the reperfused jejunum was similar to the number of PMN observed in healthy control jejunum samples, as detected by immunohistochemical analysis of HNP13 (Fig. 5A. $\mathrm{p}=0.90, \mathrm{n}=10$ ). In concordance, analysis of whole jejunum samples for total MPO content by ELISA revealed no increase in MPO protein in the reperfused jejunum, when compared to healthy jejunum control samples (Fig. 5B. $\mathrm{I} / \mathrm{R}=101.0 \pm 31.3 \mathrm{ng} / \mathrm{mg}$ vs Healthy $=75.9 \pm 32.6 \mathrm{ng} / \mathrm{mg} \cdot \mathrm{p}=0.71, \mathrm{n}=12) . \mathrm{A}$
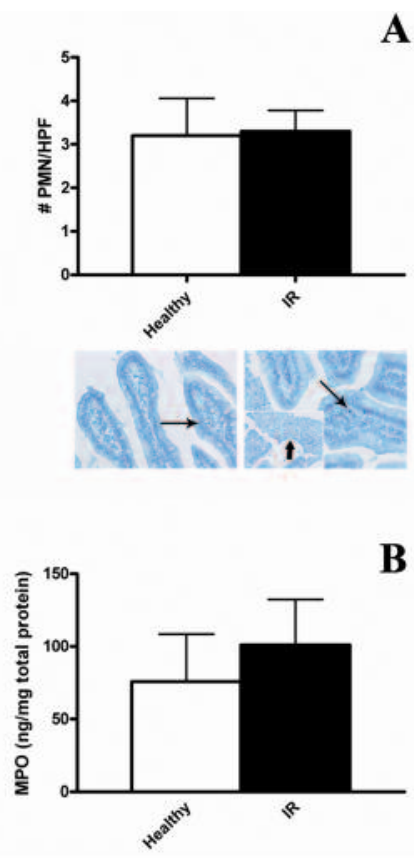

Figure 5. Neutrophil recruitment. A) No increase of PMN was observed over the course of reperfusion in response to 30 minutes of ischemia. Detected by specific HNP1-3 staining (AEC, indicated by arrows) the number of PMN in reperfused jejunum did not increase in comparison to healthy tissue $(p=0.90)$. Original magnification 200x. Clearly the PMN concentrated around the cellular debris collecting in the safe intestinal lumen (right insert in Fig 4A indicated by arrow. Original magnification 200x). B) Tissue MPO, assessed by ELISA, did not increase substantially over the course of IR $(p=0.71)$. 


\section{Chapter 3}

small number of HNP1-3 positive PMN were observed in cellular debris in the intestinal lumen (Fig. 5A. Picture insert, broad arrow). The presence of these PMN in the intestinal lumen was apparently of no considerable consequence to the remaining jejunum.

\section{Complement activation and expression in response to IR of the jejunum}

As a central mediator of IR induced inflammation, complement is involved in the development of organ damage. Complement component C3 is an important constituent of the complement system, of which activation and deposition indicate complement activity. Immunohistochemical analysis of healthy and IR damaged

A

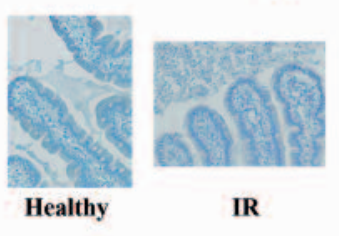

B

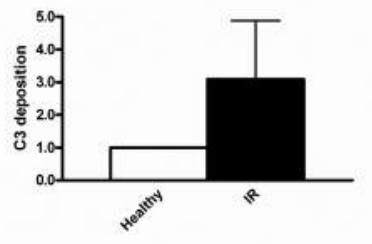

C

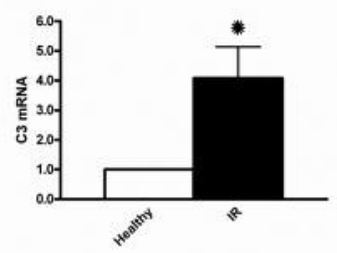

Figure 6. Complement activation. A) C3 was not be detected in the reperfused jejunum using immunohistochemistry. Original magnification 200x. B) Western blot analysis, under reducing conditions, revealed no increase in activated human $\mathrm{C} 3( \pm 75 \mathrm{kD})$ in whole reperfused jejunum samples, when compared to healthy control tissue $(p=0.14)$. C) C3 mRNA expression increased over 4-fold during IR of the human jejunum $(p=0.01)$. 
jejunum sections revealed no increase in C3 deposition in response to IR (Fig. 6A). In order to validate these data, human C3 protein in total jejunum tissue after reperfusion was additionally analyzed by Western blot. In keeping with the above results, jejunum tissue specimens showed no increase in the presence of activated C3 over the course of IR, when compared to their healthy controls (Fig. 6B. $1 / R=$ $3.09 \pm 1.79$ relative intensity vs Healthy $=1.00$ relative intensity. $p=0.14, n=12$ ).

Interestingly, subsequent analysis of the response to IR by the jejunum involving C3 mRNA, using Q-PCR analysis, clearly detected C3 mRNA levels in both healthy and IR damaged whole jejunum samples. During reperfusion, the amount of $\mathrm{C} 3$ specific mRNA increased over 4 times in response to 30 minutes of ischemia $(p=0.01$, Table 2$)$.

\section{Discussion}

The present data demonstrate that rapid shedding of IR damaged intestinal epithelial cells attenuates the development of a classically observed vigorous inflammatory response in the reperfused jejunum. When analyzed over a prolonged reperfusion period, no increase in TNF- $\alpha$, HO-1, IL-6, IL-8 gene expression, expression of adhesion molecules, PMN influx or activation and deposition of complement were observed. However, HIF1- $\alpha$ and C3 gene expression were up-regulated during reperfusion. This possibly illustrated an IR induced regenerative response, aimed at intestinal barrier restoration and prevention of bacterial translocation. Development of IR induced organ damage is generally described to be characterized by an excessive and vigorous inflammatory response. ${ }^{27}$ This inflammatory response is mainly triggered by apoptosis of cells that cannot be resolved in time by phagocytic cells and will become necrotic in time. ${ }^{4}$ Such necrotic cells are a source of damage associated molecular patterns (DAMPS) or alarmins which recruit and activate innate immune cells, aimed at restoration of homeostasis and tissue repair. ${ }^{28,29}$ However, in the context of ischemia and reperfusion such an inflammatory reaction often results in additional tissue damage. It has been demonstrated in the kidney as well as other organs that IR induced inflammation and subsequent organ damage are dependent on the development of widespread apoptosis. ${ }^{4}$ Rapid clearance of apoptotic cells as well as therapeutic strategies to reduce apoptosis have been shown to be critical in preventing the mostly harmful IR induced inflammatory response. ${ }^{2-7,30}$ 


\section{Chapter 3}

Conclusive data on intestinal ischemia and reperfusion pathophysiology have been obtained from experimental animal studies. Cytokine activity of TNF- $\alpha$, IL-6 and IL8 have been associated with the inflammatory reaction following IR. ${ }^{31}$ As a prototypic member of the TNF-family, TNF- $\alpha$ is a key mediator of acute inflammation of which expression is readily induced following ischemia reperfusion of the small intestine..$^{32}$ Interestingly, we did not detect an increase in TNF- $\alpha$ message in our experiments. Similarly, IL- 6 was demonstrated as an important component of the acute phase reaction, able to induce tissue injury and inflammation following mesenteric ischemia and reperfusion in IL-6 knockout (KO) mice. ${ }^{33} \mathrm{IL}-6$ controls endothelial cell injury, mediating successive neutrophil influx. Similarly, the chemokine IL-8 is involved in intestinal ischemia reperfusion induced inflammation.

Administration of an inhibitory anti IL-8 antibody over the course of mesenteric IR in rats prevented neutrophil infiltration and protected the small intestine from IR injury. ${ }^{34}$ In keeping with these data, IL-6, IL-8 and TNF- $\alpha$ gene expression did not increase in the absence of apoptotic cells, which were shed into the intestinal lumen immediately upon reperfusion.

E-Selectin (CD-62-E and formerly known as endothelial leukocyte adhesion molecule-1 (ELAM-1)) has an important role in the recruitment of leukocytes to sites of tissue injury. Its expression by vascular endothelial cells in response to injury is readily induced by cytokines IL- 1 and TNF- $\alpha$. Interestingly, our data suggest that despite initial presence of damaged epithelial cells in response to an IR period, the rapid shedding of damaged epithelial debris largely averts endothelial cell activation. Consistent with this observation, PMN infiltration, assessed by total MPO tissue levels or the presence of HNP1-3 positive cells, in IR was not detected in our experiments. MPO, most abundantly released upon PMN activation, has been demonstrated to have a clear effect on the development of IR induced organ damage. Renal IR studies have demonstrated that MPO itself is able to contribute to the development of organ damage. ${ }^{35}$

As a central innate immune regulator, the complement system is activated during intestinal IR and contributes substantially to IR induced inflammation, organ damage and failure. ${ }^{8,9,36}$ Preventing complement activation has been proven to be beneficial to organ function after IR in general and intestinal IR more specifically. ${ }^{8,12,20}$ Central in the activation of complement is the formation of C3a, an anaphylatoxin with the ability to attract inflammatory cells into the reperfused 
ischemic tissue. In our model no deposition of activated C3 in reperfused jejunum was detected, using immunohistochemical and Western blot analysis. Interestingly, our results do however suggest C3 gene expression in healthy jejunum tissue as well as an increased synthesis of $\mathrm{C} 3$ in response to IR. The lack of activated complement components as well as a clear increase in local C3 mRNA expression levels may illustrate the intestines response aimed at protection and preservation. The ability of small intestinal epithelial cells to express biological mediators such as C3 in response to IR was to be expected since previous work demonstrated C3 gene expression in inflamed small intestine. ${ }^{37}$ To the best of our knowledge, however, these are the first results that demonstrate C3 mRNA expression in the healthy jejunum. Further analysis will have to elucidate whether increased expression of immune regulatory proteins is directed at preventing gut barrier bacterial translocation. However, when faced with massive intestinal barrier failure, increased expression of immune regulatory proteins able to prevent gut barrier bacterial translocation might be exceedingly useful.

The recently discovered molecular mechanism that recognizes and responds to excessive cell death consisting of SAP130 and the macrophage inducible C-type lectin (Mincle) fits in our observations. ${ }^{38}$ The loss of excessive numbers of dead cells into the gut lumen prevents SAP130 released by the dead cells to reach tissue macrophages thus largely preventing the production of inflammatory cytokines driving rapid neutrophil infiltration. Similarly activation of complement by dead cells is prevented and maybe therefore the PMN chemotactic factors C3a en C5a will not be produced.

A mechanism of protection was suggested by the enhanced expression of HIF$1 \alpha$ in the surviving epithelium. Expression of HIF-1 $\alpha$ in response to low oxygen tension during ischemia and early reperfusion triggers physiologic responses characterized by activation of functional proteins mucin, P-glycoprotein, intestinal trefoil factor and adenosine $\mathrm{A} 2 \mathrm{~B}$ receptor, aimed at preventing mucosal inflammation. ${ }^{39}$ The role in preserving gut wall integrity in response to IR as well as the exciting role of HIF- $1 \alpha$ in different cardiac and brain pre-conditioning IR models underlines a possibly protective influence of increased HIF- $1 \alpha$ mRNA expression as detected in our model in response to IR of the human intestine..$^{39-42}$ Taken together, ischemia, sensed by the small intestine, induces normal physiological and IR induced responses. Our data provide new and compelling evidence of increased HIF- $1 \alpha$ and also C3 gene expression during the reperfusion 


\section{Chapter 3}

period. However, these responses are not paralleled by an IR induced inflammatory response, since important conditions to an inflammatory reaction have not been met by the absence of dead cells in the reperfused tissue. It is important to realize that these data indicate that the human intestine is more resistant to IR than initially thought. Its ability to shed damaged epithelial cells and repair its ever important barrier function without triggering massive inflammation can be seen as key features that prevent the gut from inflammation following splanchnic ischemia and reperfusion.

\section{ACKNOWLEDGMENTS}

The authors wish to thank Jan H. Stoot, MD for his excellent technical assistance during pancreatico-duodenectomy procedures and sample collection.

\section{RefERENCES}

1. Derikx JPM, Matthijsen RA, de Bruïne AP, van Bijnen AA, Heineman E, et al. (2008) Rapid Reversal of Human Intestinal Ischemia-Reperfusion Induced Damage by Shedding of Injured Enterocytes and Reepithelialisation. PLoS ONE 3: e3428.

2. Yellon DM, Hausenloy DJ (2007) Myocardial reperfusion injury. N Engl J Med 357: 11211135.

3. de Groot H, Rauen U (2007) Ischemia-reperfusion injury: processes in pathogenetic networks: a review. Transplant Proc 39: 481-484.

4. Daemen MA, van 't Veer C, Denecker G, Heemskerk VH, Wolfs TG, et al. (1999) Inhibition of apoptosis induced by ischemia-reperfusion prevents inflammation. J Clin Invest 104: 541-549.

5. Donath S, Li P, Willenbockel C, Al-Saadi N, Gross V, et al. (2006) Apoptosis repressor with caspase recruitment domain is required for cardioprotection in response to biomechanical and ischemic stress. Circulation 113: 1203-1212.

6. Yaoita H, Ogawa K, Maehara K, Maruyama Y (1998) Attenuation of ischemia/reperfusion injury in rats by a caspase inhibitor. Circulation 97: 276-281.

7. Restifo NP (2000) Building better vaccines: how apoptotic cell death can induce inflammation and activate innate and adaptive immunity. Curr Opin Immunol 12: 597-603.

8. Hart ML, Ceonzo KA, Shaffer LA, Takahashi K, Rother RP, et al. (2005) Gastrointestinal ischemia-reperfusion injury is lectin complement pathway dependent without involving C1q. J Immunol 174: 6373-6380. 
9. Zhou W, Farrar CA, Abe K, Pratt JR, Marsh JE, et al. (2000) Predominant role for C5b-9 in renal ischemia/reperfusion injury. J Clin Invest 105: 1363-1371.

10. Romson JL, Hook BG, Kunkel SL, Abrams GD, Schork MA, et al. (1983) Reduction of the extent of ischemic myocardial injury by neutrophil depletion in the dog. Circulation 67: 1016-1023.

11. Libby P, Maroko PR, Bloor CM, Sobel BE, Braunwald E (1973) Reduction of experimental myocardial infarct size by corticosteroid administration. J Clin Invest 52: 599-607.

12. Wada K, Montalto MC, Stahl GL (2001) Inhibition of complement C5 reduces local and remote organ injury after intestinal ischemia/reperfusion in the rat. Gastroenterology 120: 126-133.

13. Litt MR, Jeremy RW, Weisman HF, Winkelstein JA, Becker LC (1989) Neutrophil depletion limited to reperfusion reduces myocardial infarct size after 90 minutes of ischemia. Evidence for neutrophil-mediated reperfusion injury. Circulation 80: 1816-1827.

14. Daemen MA, van de Ven MW, Heineman E, Buurman WA (1999) Involvement of endogenous interleukin-10 and tumor necrosis factor-alpha in renal ischemiareperfusion injury. Transplantation 67: 792-800.

15. Frangogiannis NG, Smith CW, Entman ML (2002) The inflammatory response in myocardial infarction. Cardiovasc Res 53: 31-47.

16. Takada M, Nadeau KC, Shaw GD, Marquette KA, Tilney NL (1997) The cytokine-adhesion molecule cascade in ischemia/reperfusion injury of the rat kidney. Inhibition by a soluble P-selectin ligand. J Clin Invest 99: 2682-2690.

17. Lucchesi BR (1990) Modulation of leukocyte-mediated myocardial reperfusion injury. Annu Rev Physiol 52: 561-576.

18. de Vries B, Kohl J, Leclercq WK, Wolfs TG, van Bijnen AA, et al. (2003) Complement factor $\mathrm{C} 5 \mathrm{a}$ mediates renal ischemia-reperfusion injury independent from neutrophils. J Immunol 170: 3883-3889.

19. Guo RF, Ward PA (2005) Role of C5a in inflammatory responses. Annu Rev Immunol 23: 821-852.

20. De Vries B, Matthijsen RA, Wolfs TG, Van Bijnen AA, Heeringa P, et al. (2003) Inhibition of complement factor $\mathrm{C} 5$ protects against renal ischemia-reperfusion injury: inhibition of late apoptosis and inflammation. Transplantation 75: 375-382.

21. Murohara T, Delyani JA, Albelda SM, Lefer AM (1996) Blockade of platelet endothelial cell adhesion molecule-1 protects against myocardial ischemia and reperfusion injury in cats. J Immunol 156: 3550-3557.

22. Schoenberg MH, Poch B, Younes M, Schwarz A, Baczako K, et al. (1991) Involvement of neutrophils in postischaemic damage to the small intestine. Gut 32: 905-912. 


\section{Chapter 3}

23. Ma XL, Tsao PS, Lefer AM (1991) Antibody to CD-18 exerts endothelial and cardiac protective effects in myocardial ischemia and reperfusion. J Clin Invest 88: 1237-1243.

24. Matthijsen RA, Derikx JP, Steffensen R, van Dam RM, Dejong CH, et al. (2009) Mannosebinding lectin null alleles are associated with preserved epithelial cell integrity following intestinal ischemia reperfusion in man. Mol Immunol 46: 2244-2248

25. Kanda T, Fujii H, Tani T, Murakami H, Suda T, et al. (1996) Intestinal fatty acid-binding protein is a useful diagnostic marker for mesenteric infarction in humans. Gastroenterology 110: 339-343.

26. Engelberts I, Stephens S, Francot GJ, van der Linden CJ, Buurman WA (1991) Evidence for different effects of soluble TNF-receptors on various TNF measurements in human biological fluids. Lancet 338: 515-516.

27. Vedder NB, Winn RK, Rice CL, Chi EY, Arfors KE, et al. (1990) Inhibition of leukocyte adherence by anti-CD18 monoclonal antibody attenuates reperfusion injury in the rabbit ear. Proc Natl Acad Sci U S A 87: 2643-2646.

28. Bianchi ME (2007) DAMPs, PAMPs and alarmins: all we need to know about danger. J Leukoc Biol 81: 1-5.

29. Lotze MT, Zeh HJ, Rubartelli A, Sparvero LJ, Amoscato AA, et al. (2007) The grateful dead: damage-associated molecular pattern molecules and reduction/oxidation regulate immunity. Immunol Rev 220: 60-81.

30. Huynh ML, Fadok VA, Henson PM (2002) Phosphatidylserine-dependent ingestion of apoptotic cells promotes TGF-beta1 secretion and the resolution of inflammation. J Clin Invest 109: 41-50.

31. Grotz MR, Deitch EA, Ding J, Xu D, Huang Q, et al. (1999) Intestinal cytokine response after gut ischemia: role of gut barrier failure. Ann Surg 229: 478-486.

32. Salvemini D, Wang ZQ, Zweier JL, Samouilov A, Macarthur H, et al. (1999) A nonpeptidyl mimic of superoxide dismutase with therapeutic activity in rats. Science 286: 304-306.

33. Cuzzocrea S, De Sarro G, Costantino G, Ciliberto G, Mazzon E, et al. (1999) IL-6 knock-out mice exhibit resistance to splanchnic artery occlusion shock. J Leukoc Biol 66: 471-480.

34. Tsuruma T, Yagihashi A, Tarumi K, Hirata K (1998) Anti-rat IL-8 (CINC) monoclonal antibody administration reduces ischemia-reperfusion injury in small intestine. Transplant Proc 30: 2644-2645.

35. Matthijsen RA, Huugen D, Hoebers NT, de Vries B, Peutz-Kootstra CJ, et al. (2007) Myeloperoxidase is critically involved in the induction of organ damage after renal ischemia reperfusion. Am J Pathol 171: 1743-1752. 
36. Arumugam TV, Shiels IA, Woodruff TM, Granger DN, Taylor SM (2004) The role of the complement system in ischemia-reperfusion injury. Shock 21: 401-409.

37. Laufer J, Oren R, Goldberg I, Horwitz A, Kopolovic J, et al. (2000) Cellular localization of complement C3 and C4 transcripts in intestinal specimens from patients with Crohn's disease. Clin Exp Immunol 120: 30-37.

38. Yamasaki S, Ishikawa E, Sakuma M, Hara H, Ogata K, et al. (2008) Mincle is an ITAMcoupled activating receptor that senses damaged cells. Nat Immunol 9: 1179-1188.

39. Taylor CT, Colgan SP (2007) Hypoxia and gastrointestinal disease. J Mol Med 85: 1295-1300.

40. Bergeron M, Gidday JM, Yu AY, Semenza GL, Ferriero DM, et al. (2000) Role of hypoxiainducible factor- 1 in hypoxia-induced ischemic tolerance in neonatal rat brain. Ann Neurol 48: 285-296.

41. Cai Z, Manalo DJ, Wei G, Rodriguez ER, Fox-Talbot K, et al. (2003) Hearts from rodents exposed to intermittent hypoxia or erythropoietin are protected against ischemiareperfusion injury. Circulation 108: 79-85.

42. Patel A, van de Poll MC, Greve JW, Buurman WA, Fearon KC, et al. (2004) Early stress protein gene expression in a human model of ischemic preconditioning. Transplantation 78: 1479-1487. 


\section{Chapter 3.5}

\section{Mannose-binding lectin null alleles are associated with preserved epithelial cell integrity following intestinal ischemia reperfusion in man}

Robert A. Matthijsen, Joep P.M. Derikx, Rudi Steffensen, Ronald M. van Dam, Cornelis H.C. Dejong, Wim A. Buurman 


\section{ABStRACt}

Mannose-binding lectin (MBL) deficiency is associated with reduced intestinal ischemia-reperfusion (IR) damage in rodents. We set out to investigate an association between frequently observed $M B L$ deficiency and IR associated intestinal cell damage in man. Using a newly developed IR model of the human small intestine 29 patients were consecutively included. Part of the jejunum was subjected to $30 \mathrm{~min}$ of ischemia and reperfusion. The MBL genotype was assessed by means of quantitative-PCR analysis. Enterocyte loss was explored by measuring plasma intestinal-fatty acid binding protein (I-FABP) levels. Arterial and venous MBL plasma levels were measured to assess MBL consumption, MBL deposition was analyzed by immunofluorescence. Ethical approval and informed consent were obtained. The amount of epithelial cell damage varied significantly between the carriers of different $m b / 2$ genotypes (ANOVA, $p=0.02$ ). I-FABP release, representing disintegration of differentiated enterocytes, observed in homozygous wildtype individuals was twice $(p=0.03)$ that measured in heterozygous and ten times $(p=0.04)$ that observed in homozygous variant individuals. No MBL deposition was observed over the course of reperfusion. The data indicate that MBL influences intestinal epithelial cell integrity in an immediate and non-complement dependent manner during ischemia and reperfusion.

\section{INTRODUCTION}

Intestinal ischemia reperfusion (I-IR) injury has a multifactorial etiology, involving activation of complement. Mannose-binding lectin (MBL) is a potent member of our innate immune system and considered to be an important initiating complement component (Turner, 1998). There is a considerable variation in MBL activating properties and MBL plasma levels between individuals (Turner and Hamvas, 2000). These variations, which result in a relative or complete MBL deficiency, are caused by three frequently occurring first exon mutations (at codons 52, 54 and 57) and polymorphisms in the promoter region (at position $-550(\mathrm{H} / \mathrm{L})$ and $-221(\mathrm{X} / \mathrm{Y})$ ) of the structural gene ( $\mathrm{mb} / 2)$ (Turner and Hamvas, 2000). Homozygous or heterozygous carriers of variant $\mathrm{mb} / 2$ alleles express different levels of a disrupted MBL protein without apparent complement activating properties that confers an increased susceptibility to infectious diseases (Summerfield et al., 1995). Theoretically, this 


\section{Chapter 3}

increased susceptibility to infection would be anticipated to be eliminated as a consequence of evolutionary pressure. Considering the high prevalence of nearly $40 \%$ of MBL null variants in the Caucasian population, a broader role of MBL with a significant biological advantage for such variant alleles should be considered.

Pathophysiological mechanisms contributing to I-IR damage have hitherto been studied in various animal models, predominantly by transient clamping of the superior mesenteric artery. Superior mesenteric clamping in MBL deficient mice has demonstrated that MBL deficiency in case of I-IR is beneficial by reducing overall complement activation, gastrointestinal barrier dysfunction and preventing both neutrophil activation and distant pulmonary injury (referred to as Acute Respiratory Distress Syndrome (ARDS)) (Hart et al., 2005).

Considering the frequently occurring $\mathrm{mb} / 2$ gene variations in man, we set out to investigate differences in epithelial cell damage in MBL sufficient as well as deficient individuals. Intestinal-fatty acid binding protein (I-FABP) plasma levels to mark intestinal epithelial cell damage were compared between homozygous wildtype, heterozygous and homozygous variant $\mathrm{mb} / 2$ allele carriers after transient I-IR.

\section{Materials and Methods}

\section{Patients and ethics}

The study was approved by the Medical Ethics Committee of the Maastricht University Medical Centre and all individuals gave written informed consent. Twenty nine patients over 18 years of age, both male and female, were consecutively included. The included patients were scheduled to undergo pancreatic surgery; twenty seven underwent a pylorus preserving pancreaticoduodenectomy (modified Whipple's procedure) for benign or malignant pancreatic disease and two underwent a Frey's procedure for chronic pancreatitis. The proximal jejunum of all patients was carefully checked for any signs of underlying pathology during operation and before the start of the IR procedure. Due to an incomplete reperfusion 2 patients were excluded for further analysis, all having had a modified Whipple's procedure.

\section{The model}

The model was described previously (Derikx et al., 2008). In brief, patients were anesthetized according to institutional routines using isoflurane and propofol. 
Operation was initiated by a subcostal bilateral incision. A large self-retaining retractor was used to improve exposure. Per operatively echographic confirmation of diagnosis and disease progression was obtained. Approximately six centimeters of the small intestine (jejunum) resection specimen, just proximal to the ligament of Treitz at the duodenal-jejunal transition were mobilized and transsected using proximal and distal universal straight endo-GIA (GIA 6038S, Covidien, MA). Both afferent and efferent mesenteric vascular structures were previously dissected from their surrounding tissues and remain intact. To prevent bowel rotation, compromising segmental blood flow, the isolated segment was fixed to both the proximal and distal small bowel continuum. Ischemia was induced using two non-traumatic vascular clamps, bilaterally clamping both afferent and efferent branches of the vasculature. Ischemia was objectivated macroscopically by discoloration of the jejunum outer wall and termination of the peristalsis of the studied jejunum, the ischemic jejunum was kept in the abdominal cavity to guarantee warm ischemia. Reperfusion was initiated by removal of the clamps, immediately checking reperfusion signs (regaining of color, restoration of gut motility and sampling of the venous outflow). For the remainder of the procedure the IR specimen was kept in the abdominal cavity.

\section{Sample collection}

Sample collection was described previously (Derikx et al., 2008). In brief, after half an hour of ischemia, one third $(2 \mathrm{~cm})$ of the isolated ischemic jejunum was resected using linear cutting stapler to study early phenomena during ischemia. A further segment of isolated jejunum $(2 \mathrm{~cm})$ was resected similarly after 25 minutes of reperfusion to study early phenomena during reperfusion. The last part of studied jejunum was resected from 60 minutes after reperfusion onwards to investigate late phenomena during reperfusion. At the time the last isolated reperfused jejunum was obtained for the study, also $2 \mathrm{~cm}$ of jejunum, which had not been isolated and remained untreated during the surgery, was resected using a linear cutting stapler. This tissue was used as internal control tissue: it was from the same patient and experienced similar surgical handling as the isolated jejunum, while it was not subjected to IR ( $n=12$ due to surgical procedure determinants).

Serial blood samples were drawn before ischemia, on reperfusion and every thirty minutes during reperfusion from the afferent vein draining the isolated and ischemically damaged jejunum. Timed to the venous blood samples, blood samples from an arterial line places in the arteria radialis were collected to 


\section{Chapter 3}

represent arterial intestinal inflow. The total reperfusion time was determined by the duration of the surgical procedure, with a maximum of 240 minutes.

\section{Epithelial cell damage and MBL plasma levels}

As a measure for intestinal epithelial cell damage arteriovenous plasma differences in intestinal-fatty acid binding protein (I-FABP) levels were assessed before ischemia, directly upon and every thirty minutes during reperfusion in afferent (A) and efferent (V) mesenteric blood samples drawn from the isolated bowel segment ( (V-A)) (Derikx et al., 2008; Kanda et al., 1996). By subtracting arterial I-FABP concentration from detected venous levels, either release or consumption can be easily assessed. In addition, arteriovenous plasma differences in MBL levels were established by ELISA (HK323. Kindly provided by Hycult Biotechnology, Hbt, Uden, the Netherlands). The I-FABP and MBL ELISA kit were used according to the manufacturer's guidelines.

\section{Immunofluorescence}

Paraffin-embedded sections from healthy and IR damaged jejunum were prepared. The sections ( $5 \mathrm{~m}$ ) were deparaffinized, rehydrated and blocked for 1 hour at room temperature using 5\% BSA in phosphate buffered saline (PBS) and stained for MBL deposition using a rabbit anti-human MBL antibody (ATLAS antibodies, Stockholm, Sweden) according to the manufacturer's guidelines. Antibody specificity was determined by western blotting under reduced conditions ( $\mathrm{hMBL}$, specific band at $\pm 31 \mathrm{kDa}$ ), inhibiting primary antibody binding by specific protein blockage (hMBL), incubating slides with isotype control rabbit serum (hMBL) or secondary antibody only. After immunofluorescent staining of jejunum sections, deposition of MBL was scored arbitrarily as negative $(-)$, slightly positive $(+)$, moderately positive $(++)$ and intensively positive (+++) by a blinded observer.

\section{Genotyping}

The MBL genotype of included individuals was assessed retrospectively by means of quantitative-PCR analysis as described earlier, using sequence-specific primers (Henckaerts et al., 2009; Steffensen et al., 2000). Included patients were classified according to their first exon structural genotype; $\mathrm{A} / \mathrm{A}, \mathrm{A} / \mathrm{O}$ and $\mathrm{O} / \mathrm{O}$, where any of the three first exon variations is coded as $\mathrm{O}$. 


\section{Statistics}

Data from 27 remaining individuals were analyzed by one-way analysis of variance (ANOVA) and unpaired two-tailed Student $T$-test.

\section{Results}

\section{Patient outcome and reperfusion period}

The mean $( \pm$ SEM) age of included patients $(n=27)$ was $64(2)$ years and $56 \%$ were male. Isolated jejunum samples were subjected to 30 minutes of ischemia followed by a mean reperfusion time of 126 (11) minutes (Fig. 1). Jejunum samples subjected to IR were analyzed from 27 patients. Healthy control samples of the jejunum were obtained from 12 patients (44\%).

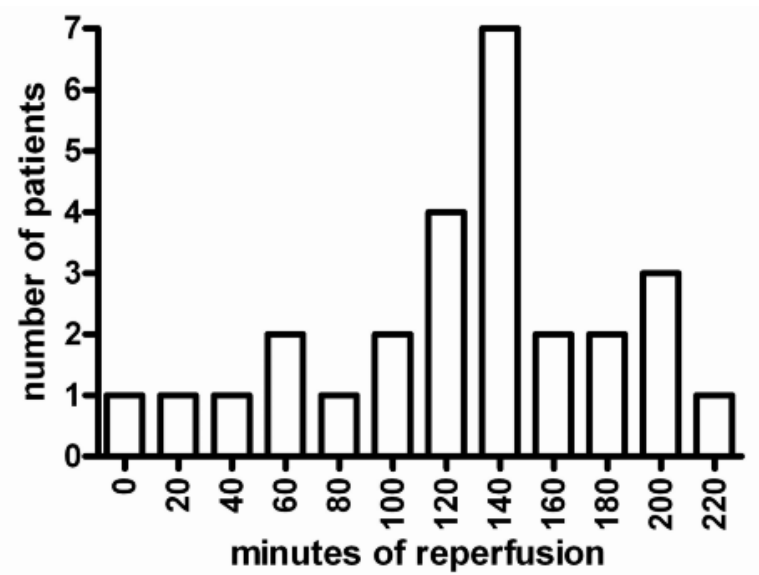

Figure 1. Reperfusion times. Distribution of total reperfusion times following 30 minutes of intestinal ischemia $(n=27)$.

\section{Intestinal epithelial cell damage}

The amount of epithelial cell damage varied significantly between the carriers of different $m b / 2$ genotypes (ANOVA, $\mathrm{p}=0.02$ ), with peak levels in I-FABP release detected immediately upon reperfusion in every included individual. Homozygous wildtype individuals (A/A, $n=14 ; 64 \%$ men) showed a maximal mean ( \pm SEM) IFABP release of $4960 \mathrm{pg} / \mathrm{ml}(780 \mathrm{pg} / \mathrm{ml})$ immediately after reperfusion. Interestingly, heterozygous $(\mathrm{A} / \mathrm{O}, \mathrm{n}=11 ; 55 \%$ men) and homozygous $(\mathrm{O} / \mathrm{O}, \mathrm{n}=2$; two women) carriers of variant $\mathrm{MBL}$ alleles showed maximal mean I-FABP release 


\section{Chapter 3}

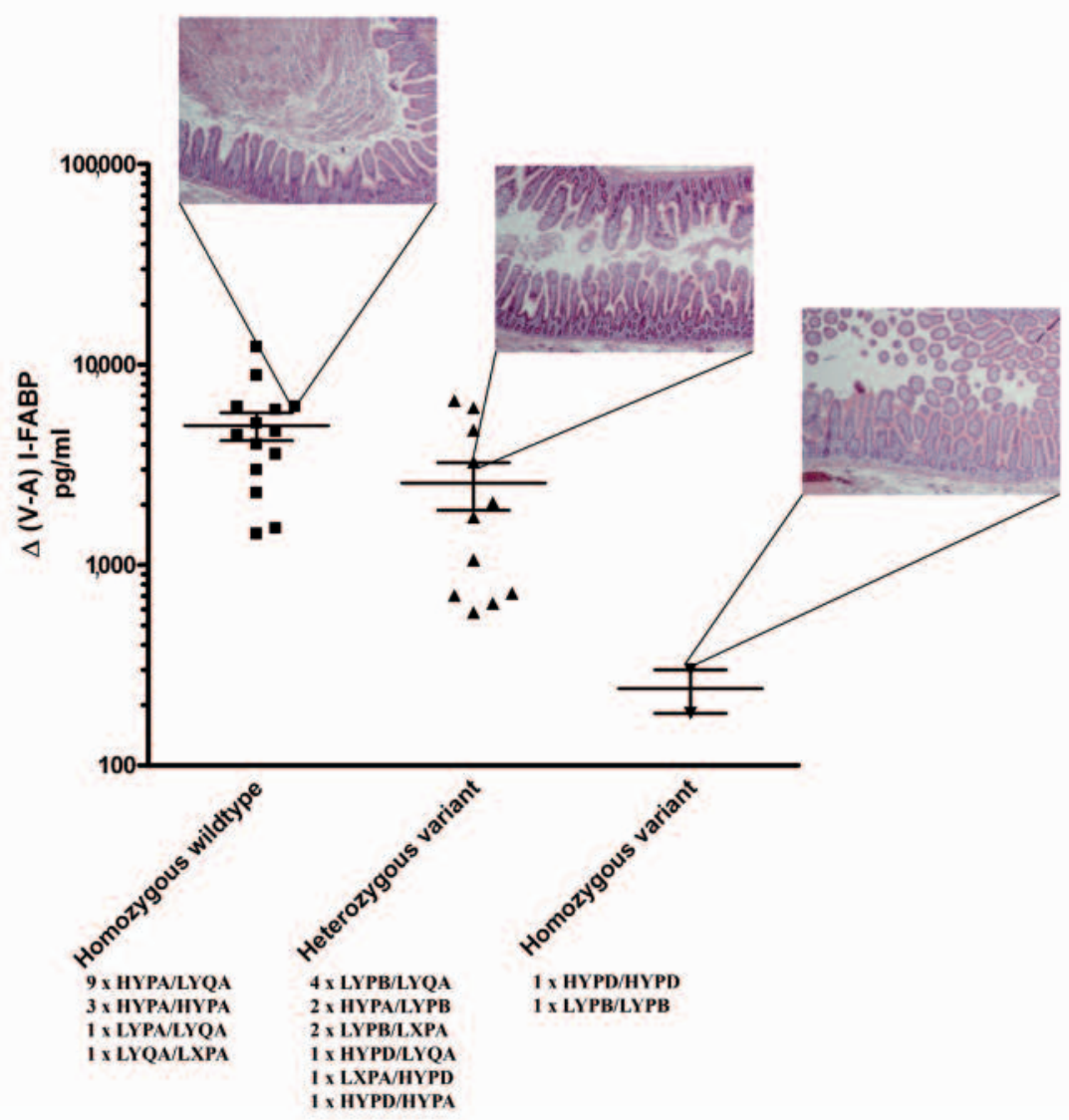

Figure 2. Intestinal epithelial damage. Maximal epithelial damage, represented by peak I-FABP levels observed at the very beginning of reperfusion, was calculated from the arteriovenous difference in IFABP levels across an isolated bowel segment before and after ischemia $(\Delta(\mathrm{V}-\mathrm{A}))$. Epithelial damage was virtually absent in homozygous $(p=0.03)$ and reduced in heterozygous $(p=0.04)$ carriers of variant mbl2 alleles when compared to their homozygous wildtype counterparts. Peak I-FABP levels of heterozygous variant and homozygous variant individuals were similar $(p=0.19)$. Inserts show microphotographs of shed intestinal epithelial cells. Original magnification 100x. Microphotographs are taken from indicated individuals after maximal (at least one hour) reperfusion. Left microphotograph shows maximal epithelial cell damage. The middle microphotograph shows reduced epithelial cell damage. The right microphotograph shows minimal epithelial cell damage, observed in homozygous variant individuals. Genotypes have been listed for all carriers. 

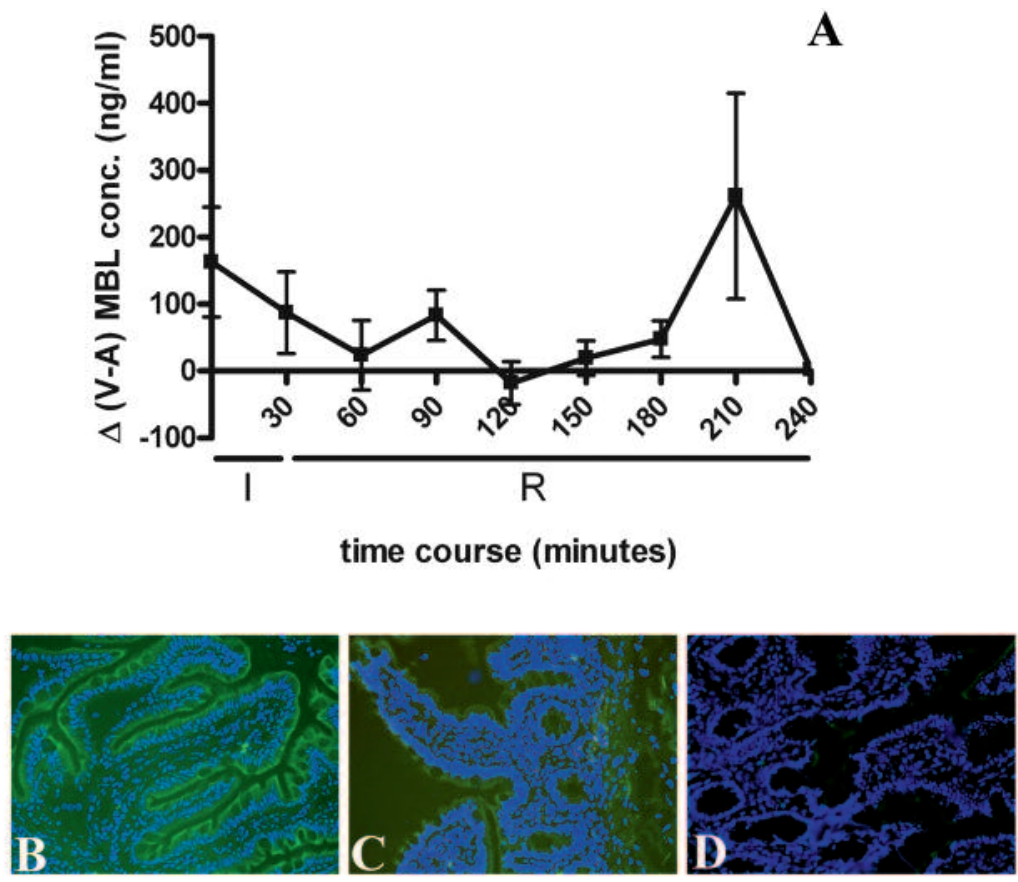

Figure 3. Plasma MBL. A) No consumption of plasma MBL, indicating MBL activation and tissue deposition, was detected when analyzing arteriovenous concentration differences $(\Delta(\mathrm{V}-\mathrm{A}))$ over the isolated jejunum segment during IR $(p=0.19)$ by MBL ELISA. B - C) No apparent increase in MBL deposition (fluorescent green) was observed in reperfused ischemic jejunum samples when compared to healthy control samples (relative scoring of MBL staining intensity: Healthy (B) +/- vs IR (C) +/-). D) Negative MBL control staining on healthy jejunum tissue.

of $2560 \mathrm{pg} / \mathrm{ml}(690 \mathrm{pg} / \mathrm{ml})(\mathrm{p}=0.03$ compared to $\mathrm{A} / \mathrm{A})$ and $240 \mathrm{pg} / \mathrm{ml}(60 \mathrm{pg} / \mathrm{ml})$ $(p=0.04$ compared to $A / A)$, respectively (Fig. 2).

I-FABP levels between $\mathrm{A} / \mathrm{O}$ and $\mathrm{O} / \mathrm{O}$ individuals were statistically similar $(\mathrm{p}=$ 0.19). The data were corroborated by histological analysis of tissue samples collected at the end of reperfusion. Large amounts of epithelial cellular debris in $\mathrm{A} / \mathrm{A}$ individuals, whereas lesser debris was observed in $\mathrm{A} / \mathrm{O}$ and $\mathrm{O} / \mathrm{O}$ genotype carriers (Inserts, Fig. 2).

MBL plasma levels and tissue deposition

Next, arterial and venous levels of circulating MBL plasma levels were measured in 


\section{Chapter 3}

order to assess the effects of I-IR on MBL. Analysis of the MBL levels in afferent and efferent blood samples from the reperfused ischemic jejunum during both early and prolonged reperfusion, revealed no MBL consumption (Fig. 3. $p=0.19$ ). This suggests that activation and consumption of plasma MBL during reperfusion in the ischemic tissue did not occur. In order to confirm the absence of MBL deposition in reperfused jejunum, presence of $M B L$ was analyzed by immunofluorescence in paraffin-embedded tissue sections. Analysis of these samples confirmed the absence of MBL deposition in the reperfused jejunum tissue samples (Fig. 3). These data indicate a protective role for the MBL variant gene products, possibly on the intracellular level.

\section{Discussion}

The data demonstrate that $M B L$ influences intestinal epithelial cell integrity in an immediate and non-complement dependent manner during ischemia, considering the different peak I-FABP levels upon reperfusion between carriers of various $\mathrm{mb} / 2$ alleles and their wildtype $\mathrm{mb} / 2$ counterparts as well as the lack in MBL activation or tissue deposition during reperfusion.

As an innate regulator of immunity, $M B L$ is a highly versatile protein. $M B L$ function ranges from complement activation, to regulation of monocytes cytokine expression as well as a potent pattern recognition molecule, able to enhance the phagocytosis of pathogens, cellular debris, and apoptotic cells in vitro and in vivo (Ogden et al., 2001; Nauta et al., 2004). Additionally, an intracellular MBL variant has been described of which first studies indicate that it may function as a cargo transport lectin facilitating ER-to-Golgi traffic in glycoprotein quality control (Nonaka et al., 2007).

The knowledge that the variation in plasma MBL levels in man is regionally distributed around the world, with approximately $5-10 \%$ lacking functional MBL, has led to many studies that investigated MBL as a modifier of disease (Turner and Hamvas, 2000; Hansson, 2006). Over time, mb/2 variant genotypes have been considered both advantageous as well as disadvantageous to human development or the onset of human disease. On the one hand, variant $\mathrm{mb} / 2$ alleles are suggested to be protective against the development of leprosy (Dornelles et al., 2006). On the other hand, variant $\mathrm{mb} / 2$ alleles have been linked to an increased risk of developing, atherosclerosis (Madsen et al., 1998), thrombosis (Ohlenschlaeger et al., 2004) and 
susceptibility to infectious diseases (Summerfield et al., 1995). In addition to these previous findings, recent studies on ICU patients demonstrate a protective effect of heterozygosity for $\mathrm{mb} / 2$ alleles on the overall fatal outcome for ICU patients, suggesting heterosis (Hellemann et al., 2007). Then again when studying the effects of heterozygosity of polymorphisms of innate immune genes on bacteremia or death in ICU patients, no association with $\mathrm{mb} / 2$ variant alleles and associated deficiencies in MBL plasma levels was observed (Henckaerts et al., 2009). This once again illustrates the wide range in effects associated with immuneregulatory effector proteins such as MBL, observed in population based studies.

Synthesis of MBL is mainly attributed to the liver as well as the small intestine and results in two MBL forms, namely plasma and intracellular MBL (Nonaka et al., 2007; Uemura et al., 2002; Seyfarth et al., 2006). The epithelial localization of $M B L$ in the small intestine might suggest a role for $M B L$ in mucosal innate immunity or epithelial barrier function (Uemura et al., 2002). However, no in vivo function of intracellular MBL has been determined. Ischemia reperfusion studies of the heart and kidney have revealed an important contribution to the development of IR induced cellular damage by meprins or zinc metalloproteinases (Carmago et al., 2002; Cheung et al., 2000). When isolated from epithelial cells, the proteolytic activity and matrix-degrading ability of meprins are potently reduced by MBL binding (Hirano et al., 2005). This ability of MBL has been attributed to N-linked oligosaccharides, ligands for MBL binding and critical to meprin function (Kadowaki et al., 2000). Since both MBL and meprins are expressed by the intestinal epithelial cell lining (Bond et al., 2005), such intracellular protein interactions, may well point towards a new protective mechanisms that preserve intestinal barrier function in response to IR injury.

MBL proteins, expressed by carriers of variant $\mathrm{mb} / 2$ alleles, differ in immunological capacity, compared to their wildtype MBL counterparts, as they are either less abundantly produced and or less likely to oligomerize, critical to MBL function (Summerfield et al.,1995). Whether their capacities to block meprin activity vary similarly, will remain point of future research. However, if confirmed in a larger patient cohort, our data may well explain why mutations in the MBL coding sequence, resulting in a defective immune regulatory function as well as reduced levels of one of our prominent innate regulators of immunity, have survived selection pressure during human evolution.

Taken together the data point towards ischemia protective properties of variant 


\section{Chapter 3}

and intracellular MBL, associated with far-reaching beneficial qualities of an individual's response to intestinal IR without an apparent immunological implication.

\section{ACKNOWLEDGEMENTS}

The authors thank Dian Kuipers and Annemarie van Bijnen for their excellent technical assistance and Dr. Erik Heineman for critical reading.

\section{ReferenCES}

Bond, J.S., Matters, G.L., Banerjee, S., et al., 2005. Meprin metalloprotease expression and regulation in kidney, intestine, urinary tract infections and cancer. FEBS Lett. 579, 33173322.

Carmago, S., Shah, S.V.,Walker, P.D., 2002. Meprin, a brush-border enzyme, plays an important role in hypoxic/ischemic acute renal tubular injury in rats. Kidney Int. 61, 959-966. Cheung, P.Y., Sawicki, G.,Wozniak, M., et al., 2000. Matrix metalloproteinase-2 contributes to ischemia-reperfusion injury in the heart. Circulation 101, 1833-1839.

Derikx, J.P., Matthijsen, R.A., de Bruine, A.P., et al., 2008. Rapid reversal of human intestinal ischemia-reperfusion induced damage by shedding of injured enterocytes and reepithelialisation. PLoS ONE 3, e3428.

Dornelles, L.N., Pereira-Ferrari, L., Messias-Reason, I., 2006. Mannan-binding lectin plasma levels in leprosy: deficiency confers protection against the lepromatous but not the tuberculoid forms. Clin. Exp. Immunol. 145, 463-468.

Hansson, G.K., 2006. Epidemiology complements immunology in the heart. Arterioscler. Thromb. Vasc. Biol. 26, 2178-2180.

Hart, M.L., Ceonzo, K.A., Shaffer, L.A., et al., 2005. Gastrointestinal ischemiareperfusion injury is lectin complement pathway dependent without involving C1q. J. Immunol. 174, 6373-6380.

Hellemann, D., Larsson, A., Madsen, H.O., et al., 2007. Heterozygosity of mannosebinding lectin (MBL2) genotypes predicts advantage (heterosis) in relation to fatal outcome in intensive care patients. Hum. Mol. Genet. 16, 3071-3080.

Henckaerts, L., Nielsen, K.R., Steffensen, R., et al., 2009. Polymorphisms in innate immunity genes predispose to bacteremia and death in the medical intensive care unit. Crit. Care Med. 37, 192-201, e1-3.

Hirano, M., Ma, B.Y., Kawasaki, N., et al., 2005. Mannan-binding protein blocks the 
activation of metalloproteases meprin alpha and beta. J. Immunol. 175, 3177-3185.

Kadowaki, T., Tsukuba, T., Bertenshaw, G.P., et al., 2000. N-Linked oligosaccharides on the meprin A metalloprotease are important for secretion and enzymatic activity, but not for apical targeting. J. Biol. Chem. 275, 25577-25584.

Kanda, T., Fujii, H., Tani, T., et al., 1996. Intestinal fatty acid-binding protein is a useful diagnostic marker for mesenteric infarction in humans. Gastroenterology 110, 339-343.

Madsen, H.O., Videm, V., Svejgaard, A., et al., 1998. Association of mannose-bindinglectin deficiency with severe atherosclerosis. Lancet 352, 959-960.

Nauta, A.J., Castellano, G., Xu,W., et al., 2004. Opsonization with C1q and mannosebinding lectin targets apoptotic cells to dendritic cells. J. Immunol. 173, 3044-3050.

Nonaka, M., Ma, B.Y., Ohtani, M., et al., 2007. Subcellular localization and physiological significance of intracellular mannan-binding protein. J. Biol. Chem. 282, 17908-17920.

Ogden, C.A., deCathelineau, A., Hoffmann, P.R., et al., 2001. C1q and mannose binding lectin engagement of cell surface calreticulin and CD91 initiates macropinocytosis and uptake of apoptotic cells. J. Exp. Med. 194, 781-795.

Ohlenschlaeger, T., Garred, P.,Madsen, H.O., et al., 2004.Mannose-binding lectin variant alleles and the risk of arterial thrombosis in systemic lupus erythematosus. N. Engl. J. Med. $351,260-267$.

Seyfarth, J., Garred, P.,Madsen, H.O., 2006. Extra-hepatic transcription of the human mannose-binding lectin gene ( $\mathrm{mbl}$ ) and the MBL-associated serine protease 1-3 genes. Mol. Immunol. 43, 962-971.

Steffensen, R., Thiel, S., Varming, K., et al., 2000. Detection of structural gene mutations and promoter polymorphisms in the mannan-binding lectin (MBL) gene by polymerase chain reaction with sequence-specific primers. J. Immunol.Methods 241, 33-42.

Summerfield, J.A., Ryder, S., Sumiya, M., et al., 1995. Mannose binding protein gene mutations associated with unusual and severe infections in adults. Lancet 345, 886-889.

Turner, M.W., 1998. Mannose-binding lectin (MBL) in health and disease. Immunobiology 199, 327-339.

Turner, M.W., Hamvas, R.M., 2000. Mannose-binding lectin: structure, function, genetics and disease associations. Rev. Immunogenet. 2, 305-322.

Uemura, K., Saka, M., Nakagawa, T., et al., 2002. L-MBP is expressed in epithelial cells of mouse small intestine. J. Immunol. 169, 6945-6950. 


\section{Chapter 4}

Innate immune regulation of chronic vascular tissue damage 


\section{Chapter 4}

\subsection{INTRODUCTION}

Cardiovascular disease remains one of the foremost overall causes of death in the Netherlands, with over 41,000 deaths recorded in 2007. ${ }^{1}$ For both sexes, women and men, ischemic cardiac disease and cerebro-vascular adverse events accounted for $50 \%$ and $54 \%$ of deaths respectively within the cardiac diseased population. ${ }^{1}$ Although the overall trend is declining over the past years when compared to other causes of death like cancer, cardiovascular disease still accounted for $8 \%$ of the annual health budget in the Netherlands, or 5.5 billion euros, in $2005 .{ }^{2}$

Cardiovascular disease, or more specifically atherosclerosis, is considered an inflammatory disorder of the vascular wall. It is characterized by inflammation, lipid accumulation, cell death and smooth muscle cell proliferation in the vascular inner structure, the intima. ${ }^{3}$ It is a chronic process in which the role of inflammatory factors has recently been identified as determinant in atherosclerosis development.

In 1989 a comparison of two different cohorts consisting of healthy on the one hand and cardiovascular diseased individuals on the other, revealed a possible role for the complement component Mannose-Binding Lectin (MBL) in atherosclerosis development. ${ }^{4}$ Since then conflicting reports have arisen from different population cohorts. The lack of substantial experimental data on the role of MBL in atherosclerosis led us to formulate the third and final aim of this thesis; to study the role of the immune regulatory protein $\mathrm{MBL}$ in the chronic vascular disease atherosclerosis. Chapter 4.2 highlights the contribution of $\mathrm{MBL}$ in atherosclerosis and demonstrates its expression during different stages of atherosclerosis as well as elucidates a critical role for myeloid derived MBL during atherosclerosis development.

\section{RefERENCES}

1. Vaartjes I, Peters RJG, van Dis SJ, Bots ML: Hart- en Vaatziekten in Nederland, 2008. Edited by Hartstichting N. Mouthaan Grafisch Bedrijf, 2008, p. 148

2. RIVM: Kosten van ziekten 2005. Edited by Sport MvVWe. 2008, p.

3. Hansson GK, Libby P: The immune response in atherosclerosis: a double-edged sword, Nat Rev Immunol 2006, 6:508-519

4. Madsen HO, Videm V, Svejgaard A, Svennevig JL, Garred P: Association of mannosebinding-lectin deficiency with severe atherosclerosis, Lancet 1998, 352:959-960 


\section{Chapter 4.2}

\section{Macrophage-specific expression of mannose-binding lectin controls atherosclerosis in low-density lipoprotein receptor-deficient mice.}

Robert A. Matthijsen, Menno P.J. de Winther, Dian Kuipers, Ingeborg van der Made, Christian Weber, M. Veronica Herias, Marion J.J. Gijbels, Wim A. Buurman.

Circulation. 2009, 119: 2188-2195. 


\section{Chapter 4}

\section{Clinical Perspective}

Since an initial publication in 1998, population-based studies identified mannosebinding lectin (MBL) as a modifier of atherosclerosis development; both proatherogenic and antiatherogenic roles of $\mathrm{MBL}$ were demonstrated. However, as stated by G.K. Hansson in his 2006 Arteriosclerosis, Thrombosis, and Vascular Biology editorial, "confusion prevails."

The mechanisms by which MBL influences atherosclerosis development are unknown, and epidemiological data are conflicting, emphasizing the need for additional experimental studies. MBL is considered to be an important initiating complement component with immune regulatory properties and considerable variation in plasma levels between individuals. Its function ranges from complement activation to the MBL-mediated uptake of late apoptotic cells, cellular debris, and foreign organisms by macrophages. In the present study, local MBL-A and $\mathrm{MBL}-\mathrm{C}$ gene expressions were demonstrated in murine atherosclerotic lesions. Interestingly, mice carrying MBL-A and -C double deficient macrophages had increased (30\%) atherosclerotic lesions compared with wild-type controls. Furthermore, the MBL-A and -C distribution pattern observed in the present study suggests that MBL may play a differential role in the atherogenic process. Low MBL levels, although possibly disadvantageous during early atherosclerosis development because of a defect in removal, may well be able to reduce inflammation and subsequent atherosclerosis development in advanced stages of atherosclerosis. This hypothesis would support in large part the previous and often conflicting studies on the role of MBL in atherosclerosis development.

\section{ABSTRACT}

Background. With consideration of the central role of the innate immune system in atherogenesis and mannose-binding lectin $(\mathrm{MBL})$ as an innate regulator of immunity, the role of $\mathrm{MBL}$ in experimental and human atherosclerosis was assessed.

Methods and Results. With the use of immunohistochemistry and polymerase chain reaction, deposition and gene expression of MBL-A and -C were assessed in murine atherosclerosis from mice deficient for the low-density lipoprotein receptor 
(LDLR $\%$ ) after 10 or 18 weeks of high-fat feeding. MBL was present and was produced in 10-week-old lesions, whereas deposition and gene expression were minimal after 18 weeks of high-fat feeding and absent in healthy vasculature. Interestingly, deposition of MBL-A and -C differed: MBL-A predominantly localized in upper medial layers, whereas MBL-C was found in and around intimal macrophages. To further study the role of local MBL production by monocytic cells in atherosclerosis, LDLR $\%$ mice with MBL-A and -C $\%$ monocytic cells were construed by bone marrow transplantation. Mice carrying MBL-A and -C double deficient macrophages had increased (30\%) atherosclerotic lesions compared with wild-type controls $(P=0.015)$ after 10 weeks of high-fat diet. Subsequently, analysis of $\mathrm{MBL}$ deposition and gene expression in advanced human atherosclerotic lesions revealed the presence of $\mathrm{MBL}$ protein in ruptured but not stable atherosclerotic lesions. Putatively in agreement with murine data, no MBL gene expression could be detected in advanced human atherosclerotic lesions.

Conclusions. These results are the first to show that $\mathrm{MBL}$ is abundantly present and locally produced during early atherogenesis. Local MBL expression, by myeloid cells, is shown to critically control development of atherosclerotic lesions.

\section{INTRODUCTION}

Recently, the concept that different elements of the innate immune system mediate atherosclerosis has gained significance. ${ }^{1,2}$ In this respect, it is not surprising that complement components were detected in atherosclerotic lesions and shown to be of importance during atherogenesis from the earliest stages of plaque formation to the progression of advanced lesions. ${ }^{3,4}$

Mannose-binding lectin (MBL) is a C-type or $\mathrm{Ca}^{2+}$-dependent lectin that can act as an opsonin and can activate complement through its own and evolutionary conserved lectin pathway. ${ }^{5}$ There is considerable variation in activating properties and plasma levels between individuals. These variations are caused by 3 first exon mutations (at codons 52, 54, and 57) and polymorphisms in the promoter region (at positions $-550[\mathrm{H} / \mathrm{L}]$ and $-221[\mathrm{X} / \mathrm{Y}])$ of the structural gene $(\mathrm{mb} / 2) .{ }^{6}$ Studies on the development of vascular diseases, including atherosclerosis in MBL-sufficient and insufficient human subjects, suggested that the MBL C-type lectin influences vascular disease. ${ }^{7-13}$ Frequently, low MBL levels in MBL-deficient patients have been 


\section{Chapter 4}

associated with an earlier disease onset or a more progressive disease course compared with their MBL-sufficient counterparts. However, opposing contributions by MBL to atherogenesis have been proposed as well. MBL-mediated modulation of Chlamydia pneumoniae infection, differences in complement activation, deficiencies in MBL-opsonizing capacities, and unknown sex-related differences may explain frequently observed associations between cardiovascular disease and $\mathrm{mb} / 2$ gene variations. ${ }^{7,10,14,15}$

The long-existing tenet that merely centrally produced complement components drive inflammatory reactions has recently been challenged. ${ }^{16-19}$ Locally synthesized complement proteins such as $\mathrm{C} 1 \mathrm{q}$ and $\mathrm{C} 3$ greatly determine the innate immune response, contributing to, for example, ischemia/reperfusioninduced tissue damage. ${ }^{19}$ First reports suggest similar effects of locally produced complement components over the course of not only ischemia/reperfusion injury but also during development of atherosclerosis and neointima formation after arterial injury. ${ }^{17,18,20,21}$

The ostensible contradiction that remains regarding either a proatherogenic or antiatherogenic effect of MBL in atherosclerosis led us to investigate basic MBL characteristics over the course of atherogenesis in atherosclerosis-prone mice and human atherosclerotic lesions. Our data demonstrate the presence and distribution of $M B L$ in experimental and human atherosclerotic lesions and provide compelling evidence for a controlling role of local myeloid-derived MBL expression in atherosclerosis development. The importance of MBL expression by myeloid cells in atherosclerosis development creates new insights into the role of this versatile immune regulatory protein during atherogenesis.

\section{MethodS}

For additional details, please see the online-only Data Supplement.

\section{Mice and preparation of tissues}

Mice were kept according to University of Maastricht animal facility regulations, and all experiments were approved by the local Animal Ethical Committee. Mice deficient for the low-density lipoprotein receptor (LDLR/-) on a C57BL/6J background, 10 weeks old and weighing $25 \mathrm{~g}$, were purchased at Jackson Laboratories (Bar Harbor, Me). Hearts and aortic arches were excised and embedded 
in OCT compound and frozen on dry ice and subsequently stored at $-80^{\circ} \mathrm{C}$.

\section{Immunohistochemical staining}

Immunohistochemical stainings were performed with the use of a monoclonal antibody to murine macrophages (FA-11), which was kindly provided by Dr S. Gordon (Sir William Dunn School of Pathology, University of Oxford, Oxford, United Kingdom); to murine smooth muscle actin (1A4), which was purchased from Sigma (St Louis, Mo); to MBL-A (8G6) and MBL-C (14D12), all kindly provided by Hycult Biotechnology (Hbt, Uden, Netherlands); and to human MBL (ATLAS Antibodies, Stockholm, Sweden). Sirius red staining was performed to visualize collagen, and toluidine staining was used to visualize lesion structure. Colocalization studies were conducted by staining serial sections.

\section{Reverse transcription polymerase chain reaction}

Total RNA was extracted from differently staged murine atherosclerotic lesions and healthy vascular tissue with the use of the SV Total RNA isolation system (Promega Corporation, Madison, Wis). DNA contamination was eliminated by treating isolates with RQ1 RNase- Free DNase (Promega). Total RNA was reversetranscribed with oligo(dT) primer and Moloney murine leukemia virus reverse transcriptase (Invitrogen, Carlsbad, Calif). cDNA synthesized from murine liverderived total RNA isolate served as positive control sample for both MBL-A and MBL-C. The amount of amplified product was measured by the Nano-drop absorption measurement. The polymerase chain reaction conditions and visualization were described earlier. ${ }^{22}$

\section{Bone marrow transplantation}

Forty 9-week-old female littermate LDLR $\%$ mice on a C57BL/6 background (Jackson Laboratories) were put in filter-top cages. The mice received acidified water supplemented with neomycin $(100 \mathrm{mg} / \mathrm{L})$ and polymyxin B sulfate $(60,000$ $\mathrm{U} / \mathrm{L}$ ) starting the week before bone marrow transplantation until 5 weeks after bone marrow transplantation. Bone marrow was transplanted 2 weeks after antibiotic treatment was ended. One day before the actual transplantation, the mice were irradiated with a lethal dose of 10-Gy radiation. The bone marrow of 5 female wild-type (WT) mice (C57BL/6 from Taconic, Germantown, NY) and 5 female transgenic MBL-A and $-\mathrm{C}$ double knockout mice $(\mathrm{C} 57 \mathrm{BL} / 6$, kindly provided by $\mathrm{Dr}$ 


\section{Chapter 4}

S. Thiel, Institute of Medical Microbiology and Immunology, Aarhus University, Aarhus, Denmark) was collected. Bone marrow cells were harvested by flushing of the murine femur. For transplantation, 20 mice received WT bone marrow (WT-Tx), and 20 mice received transgenic bone marrow (KO-Tx). Bone marrow cells $\left(10^{6}\right)$ were injected into the tail vein of each mouse.

\section{Blood and chimerism analysis}

Seven weeks after transplantation, the mice were put on a high-fat diet for 10 weeks. Chimerism was analyzed as described before, ${ }^{23} 7$ weeks after transplantation and before start of high-fat feeding. After 10 weeks of high-fat diet, blood was collected from the mice after overnight fasting to determine plasma cholesterol and plasma triglyceride concentration. Plasma cholesterol and triglycerides were determined with the use of the CHOD_PAP enzymatic essay kit (Roche, Basel, Switzerland) and GPO-Trinder kit (Sigma), respectively, according to the manufacturer's guidelines. Peripheral blood leukocyte levels were analyzed after 5 weeks of high-fat feeding.

\section{Atherosclerosis Assessment and Lesion Analysis}

After 10 weeks of high-fat diet, the mice were killed. Atherosclerosis was analyzed as described before. ${ }^{23}$

\section{Human atherosclerotic lesions}

Atherosclerotic lesions (total $n=17$; stable $[n=8]$ and ruptured $[n=9]$ ) were collected during surgical procedures (carotid eversion endarterectomy) from individuals suffering end-stage symptomatic occlusive vascular disease. Tissue specimens were fixated in formalin or immediately frozen in liquid nitrogen and stored until analysis at $-80^{\circ} \mathrm{C}$.

\section{Statistical Analysis}

Data are expressed as mean $( \pm$ SEM) and were analyzed by unpaired 2-tailed Student $T$-test. Data were analyzed with the use of Prism 4.01 for Windows (Graphpad Software, San Diego, Calif). A probability value $<0.05$ was considered statistically significant.

The authors had full access to and take full responsibility for the integrity of the data. All authors have read and agreed to the manuscript as written. 


\section{Results}

MBL Deposition in Developing Atherosclerotic Lesions

To assess the deposition of the murine $M B L$ variants $-A$ and $-C$, atherosclerotic lesions from LDLR ${ }^{--}$mice after 10 weeks of high-fat feeding were analyzed. The lesions displayed known characteristics with a considerable influx of macrophages into the subendothelial space (Figure 1A).

Macrophages infiltrating the developing lesions were detected by macrophage-specific CD68 expression. Medial collagen filaments as well as the development of a thin fibrous cap covering the intima were shown by Sirius red staining (Figure 1B). Both murine MBL variants were widely present in atherosclerotic plaques at this stage after 10 weeks of Western diet feeding. Surprisingly, staining of the $2 \mathrm{MBL}$ variants, with the use of serial sections, displayed different distribution patterns throughout 10-week lesions. MBL-A was frequently detected in the lower intimal layers directly above the media around the aortic sinus (Figure 1C). In addition, MBL-A was deposited on fibroblasts in the developing fibrous cap (Figure 1C, arrow). MBL-C, on the other hand, was detected solely in and around macrophages present in the intima (Figure 1D). Colocalization of MBL-A and -C occurred at sites of necrosis (as shown by the asterisk in Figure 1C and 1D). Healthy vasculature did not show staining for MBLA (not shown) or MBL-C (Figure 1E).

\section{MBL deposition in advanced atherosclerotic lesions}

Next, the course of MBL deposition in atherosclerosis after prolonged high-fat feeding (18 weeks) was studied. General characteristics of advanced lesions were similar to those observed in younger lesions, containing a substantial number of invading macrophages (Figure 2A). A more developed fibrous cap covered sizable parts of the advanced lesion (Figure 2A, indicated by arrows). Together these structures composed the better part of the advanced atherosclerotic plaque. In these lesions, MBL-A and -C staining was generally decreased compared with the 10-week fat-fed mice. Moreover, the distinct distribution of MBL-A in the upper medial layers directly under the plaque as well as on the fibrous cap covering the lesion was decreased or was no longer observed (Figure 2B). The typical distribution observed for MBL-C in and around CD68-positive macrophages, seen in early atherosclerosis, was similarly diminished (Figure 2C). After 18 weeks of 


\section{Chapter 4}
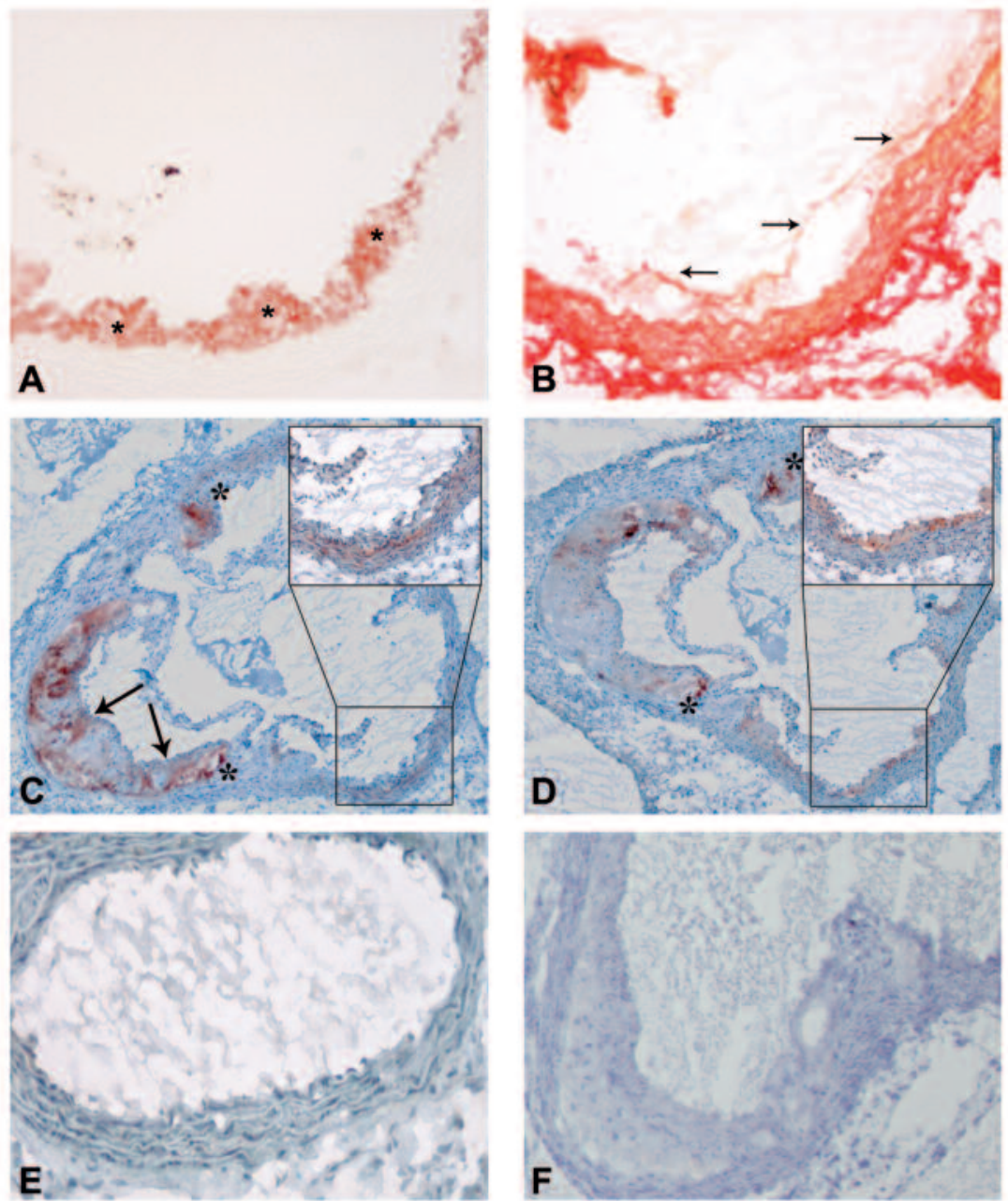

Figure 1. Characterization of MBL-A and MBL-C deposition in developing atherosclerotic lesions following 10 weeks of Western diet feeding. (A) CD68+ macrophages shown by AEC staining (terracotta red, *). (B) Sirius red staining showing fibrous cap formation (arrows). (C) MBL-A deposition. Arrow indicates the deposition of MBL-A along the fibrous cap. (D) MBL-C deposition. (E) MBL staining of healthy vascular tissue. (F) Control staining, omitting the primary antibody (not shown) or using an isotype control antibody remained negative. Original magnification microphotographs 100x (A, B, E and F), 40x C and D (inserts 100x). 
high-fat feeding, MBL-A and -C localized predominantly to sites of necrosis that were positively identified by a pathologist specifically trained in the field of murine pathology (Figure 2B and 2C, indicated by asterisk).
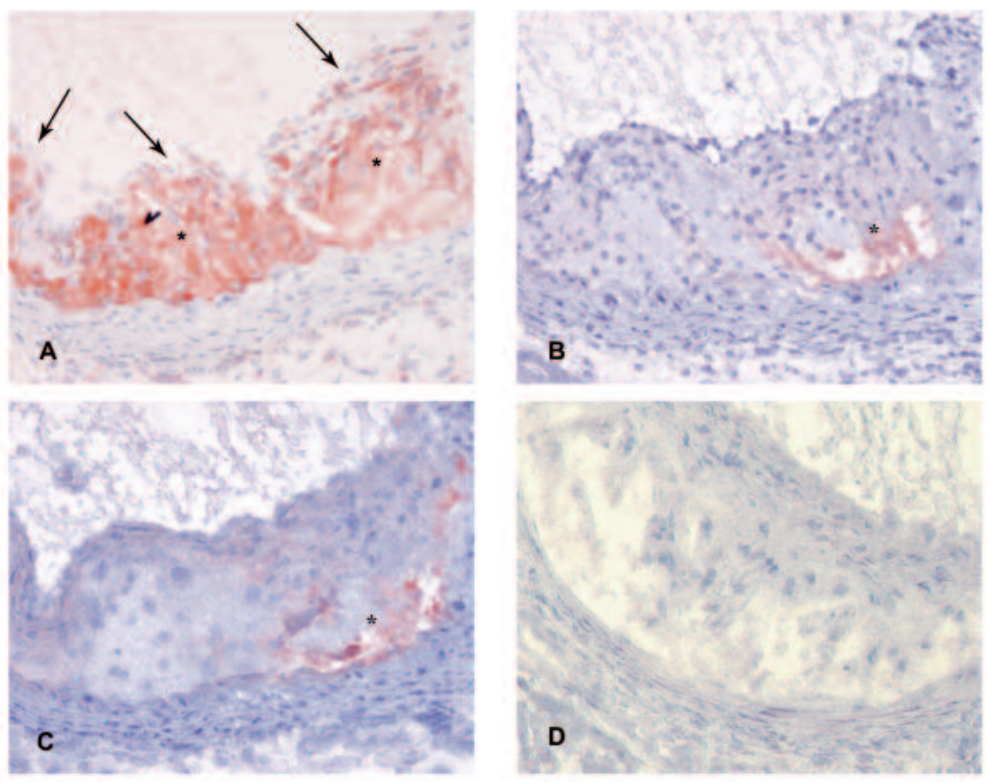

Figure 2. Characterization of MBL-A and MBL-C deposition in developing atherosclerotic lesions following 18 weeks of Western Diet feeding. (A) CD68+ inflammatory cells in advanced atherosclerotic lesions $(*)$. Fibrous cap covering the lesion (arrows). (B) MBL-A deposition observed in necrotic core $\left({ }^{*}\right)$. (C) MBL-C deposition observed in necrotic core ${ }^{*}$ ). (D) Control staining, omitting the primary antibody (not shown) or using an isotype control antibody remained negative. Original magnification microphotographs 100x.

\section{MBL-A and MBL-C gene expression in atherosclerotic lesions}

To study local cellular MBL-A and -C production, MBL-A and -C gene expressions were assessed in total RNA, isolated from lesions obtained from LDLR ${ }^{-/}$mice after various periods of high-fat feeding (10 or 18 weeks). Data were compared with data obtained from healthy vascular tissue. Figure 3 shows MBL-A and -C gene expression in 4 of 6 developing atherosclerotic lesions from LDLR ${ }^{-/}$mice that were analyzed after 10 weeks of high-fat feeding. Surprisingly, only minimal MBL expression was detected in advanced lesions obtained from mice after 18 weeks of 


\section{Chapter 4}

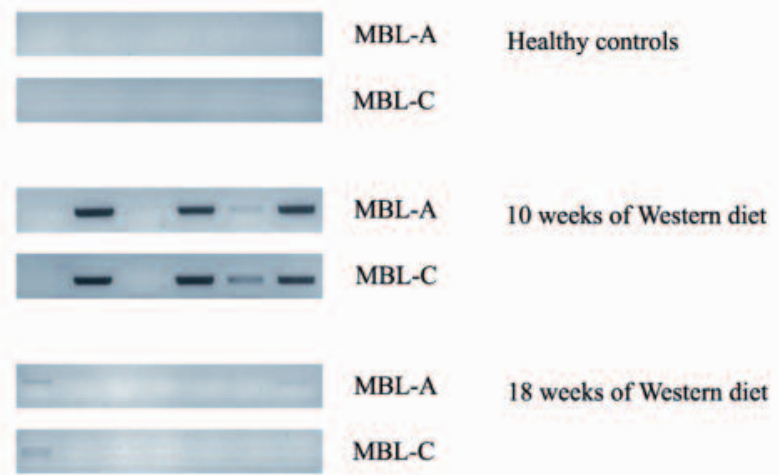

Figure 3. MBL synthesis was observed in 4 out of 6 developing atherosclerotic lesions from LDLR-/mice in response to 10 weeks of high fat feeding $(n=6)$. Remarkably, MBL synthesis was strongly reduced in atherosclerotic lesions from LDLR mice after 18 weeks of high fat feeding $(n=7)$. No MBL synthesis was shown in healthy vasculature derived from LDLR mice after 10 weeks of normal chow feeding $(n=5)$.

high-fat feeding. In agreement with the absence of cellular infiltrates in healthy vasculature, no MBL-A or -C mRNA was detectable. The data on MBL expression are supported by the immunohistochemical data that demonstrated abundant MBL presence in developing lesions, whereas only small amounts of $\mathrm{MBL}$ were detected in advanced atherosclerotic lesions, and no MBL was seen in healthy vascular tissue. Our reverse transcription polymerase chain reaction data suggest local MBL synthesis during early atherogenesis.

\section{Bone marrow transplantation}

Considering the distribution of $\mathrm{MBL}$ and the $\mathrm{MBL}$ gene expression in developing atherosclerotic lesions, we hypothesized that macrophages might be a local source of MBL. Earlier, Seyfarth et $\mathrm{al}^{24}$ demonstrated $\mathrm{mb} / 2$ gene expression in differentiated and lipopolysacharide-treated THP-1 cells, a human monocyte cell line. Studies performed at our laboratory confirmed these findings (unpublished data). To study the significance of macrophage-derived MBL transcription in atherosclerosis, a bone marrow transplantation was performed with the use of 2 groups of 20 atherosclerosis-prone mice (female, LDLR $\%$ ) as recipients and WT or $\mathrm{MBL}-\mathrm{A}^{-/}$and $-\mathrm{C}^{-1}$ donors. At the start of the high-fat feeding period, chimerism was similar in both groups (Table 1). 
Table 1. Chimerism, Total Cholesterol, Triglycerides, and Peripheral Blood Leukocytes in LDLR Mice Transplanted With WT or MBL-A ${ }^{-/}$and -C - - Donor Bone Marrow*

\begin{tabular}{lccc} 
& WT-Tx & KO-Tx & $P$ \\
\hline Chimerism, \% & $97.7 \pm 1.2$ & $99.1 \pm 0.9$ & 0.28 \\
Total cholesterol, mmol/L & $31.5 \pm 1.7$ & $35.3 \pm 2.0$ & 0.16 \\
Triglycerides, mmol/L & $1.2 \pm 0.2$ & $1.2 \pm 0.1$ & 0.77 \\
T cells, \% & $14.7 \pm 1.1$ & $16.2 \pm 0.9$ & 0.32 \\
B cells, \% & $54.9 \pm 2.0$ & $56.7 \pm 1.5$ & 0.47 \\
Monocytes, \% & $6.5 \pm 0.3$ & $5.8 \pm 0.4$ & 0.22 \\
Granulocytes, \% & $4.2 \pm 0.5$ & $4.4 \pm 0.2$ & 0.73 \\
\hline
\end{tabular}

*Percentages given of total white blood cell count.

At the end of the high-fat feeding period (10 weeks), total cholesterol and triglyceride plasma concentrations were statistically similar between groups (Table $1 ; \mathrm{P}=0.16$ and $\mathrm{P}=0.77$, respectively).

Total T-cell, B-cell, monocyte/macrophage, and granulocyte cell counts were similar between groups 11 weeks after bone marrow transplantation (Table 1). Interestingly, measurement of the total lesion area revealed a 30\% increase in plaque size in $\mathrm{LDLR}^{-/}$mice transplanted with MBL-A and - $\mathrm{C}^{-1-}$ bone marrow (KO-Tx) after 10 weeks of high-fat feeding compared with $\mathrm{LDLR}^{--}$mice transplanted with WT bone marrow (WT-Tx) as the controls (Figure $4 ; * \mathrm{P}=0.015$ ). Figure 4 demonstrates microphotographs of representative atherosclerotic lesions from WT-Tx (Figure 4B) and $\mathrm{KO}-\mathrm{Tx}$ (Figure 4C) mice. These data strongly suggest a determinative role for locally expressed MBL in the development of atherosclerosis. Immunohistochemical staining for MBL-A and -C demonstrated reduced levels of both murine MBL variants in KO-Tx atherosclerotic lesions compared with WT-Tx controls (asterisk, Figure 4D and Figure 4E). In KO-Tx lesions, MBL-C did not display its typical distribution around intimal macrophages (WT-Tx in Figure 4D and KO-Tx in Figure 4E inserts). In $\mathrm{KO}-\mathrm{Tx}, \mathrm{MBL}$ was predominantly present around areas of necrosis, thereby resembling MBL distribution observed in 18-week lesions, in which no local MBL-A and $-\mathrm{C}$ gene expressions were observed, indicating the plasma origin at this stage.

\section{Human atherosclerosis}

Human atherosclerotic lesions were obtained during elective surgical procedures. 


\section{Chapter 4}
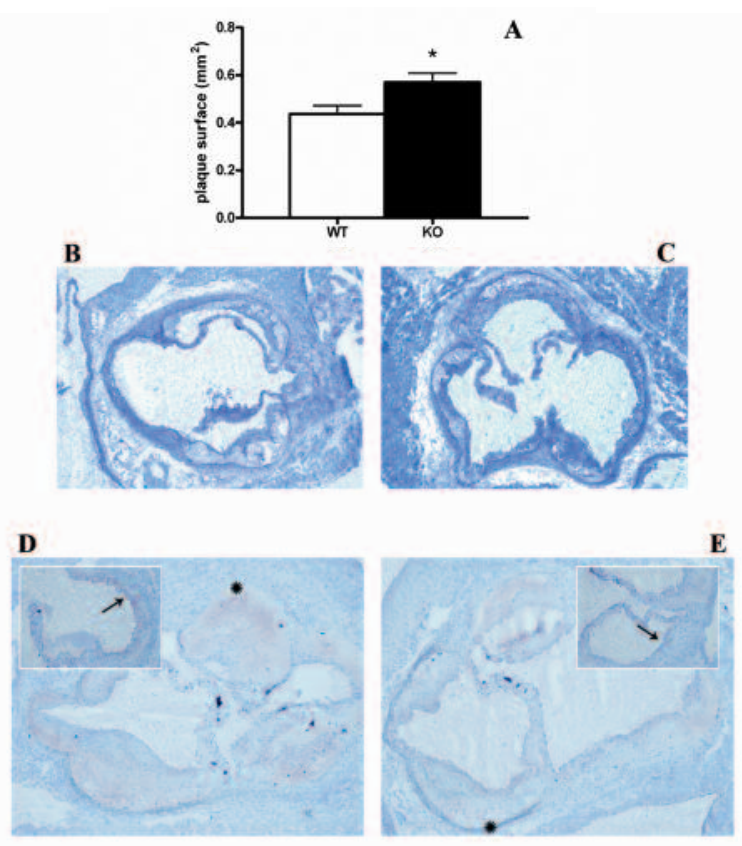

Figure 4. Development of atherosclerosis in WT-Tx and KO-Tx mice after 10 weeks of high fat feeding. (A) Increased lesion size (30\%, p = 0.015) was observed in KO-Tx animals when compared to their WT-Tx controls after 10 weeks of high fat feeding. (B) Representative example of WT-Tx lesion (40x). (C) Representative example of KO-Tx lesion (40x). (D) MBL-A and MBL-C (insert) deposition in WT-Tx atherosclerotic lesions. MBL-C was mainly detected around intimal macrophages (arrow). (E) MBL-A and MBL-C (insert) deposition were generally reduced in $\mathrm{KO}-\mathrm{Tx}$ atherosclerotic lesions (*). MBL-C did not display its characteristic deposition around intimal macrophages in KO-TX lesions (arrow). Original magnification microphotographs 40x (inserts 100x).

The collected lesions were divided into 2 distinct groups, stable $(n=8)$ and ruptured $(n=9)$, as assessed by a skilled pathologist on a haematoxylin-eosin staining (data not shown). Paraffin sections stained for human MBL deposition showed, interestingly, MBL deposition in ruptured lesions (Figure 5). MBL deposits were located within the enlarged intima, along ill-defined necrotic segments of the atherosclerotic plaque. Cholesterol crystals (indicated by an asterisk in Figure 5), frequently observed within intimal lesions, did not colocalize with MBL deposits. In stable lesions, no human MBL staining was observed (Figure 5, insert). To determine the origin of human MBL in ruptured lesions, quantitative polymerase chain 
reaction analysis was performed on cDNA from total RNA isolates of both stable and ruptured atherosclerotic lesions. Interestingly, human MBL gene expression was observed neither in ruptured nor in stable end-stage human atherosclerotic lesions (Table 2). Similar to the murine data, these data indicate that MBL deposition detected in advanced stages of atherosclerosis might well be plasma derived.

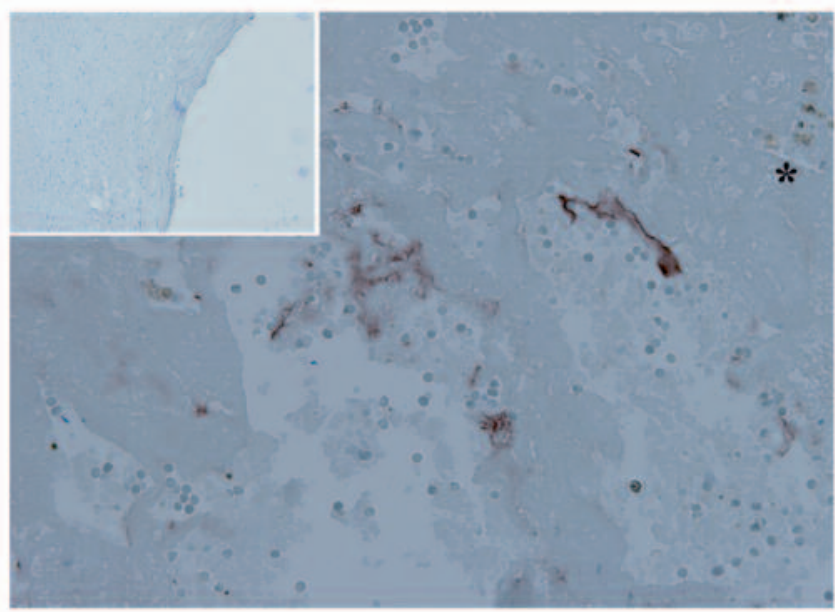

Figure 5. Human MBL (AEC, terracotta red) was detected by immunohistochemical analysis in ruptured atherosclerotic lesions. MBL predominantly localized around necrotic debris. No MBL was detected in stable lesions (insert). Original magnification microphotographs 100x.

Table 2. Local MBL Gene Expression in Human Liver and Stable (n8) or Ruptured (n9) Atherosclerotic Plaques (40 Cycles)

\begin{tabular}{lc} 
& Mb/2 Gene Expression $\left(C_{t}\right)$ \\
\hline Human liver & 27.3 \\
Stable lesions & $N D^{*}$ \\
Ruptured lesions & $\mathrm{ND}^{*}$ \\
\hline
\end{tabular}

${ }^{*} \mathrm{MBL}$ gene expression was not detected in individually assessed lesions. 


\section{Chapter 4}

\section{Discussion}

The importance of complement in the development of atherosclerosis was first shown around the time that MBL was discovered in $1979^{25}$ and has been corroborated since then. In 1998, 19 years after the detection of complement in atherosclerosis, a role for the lectin pathway was first proposed in atherogenesis.? Since then, various contrasting reports suggested an intricate role for MBL in atherosclerosis. The apparently complex role of MBL during atherogenesis underscores the necessity for further study of the thus far poorly understood characteristics of MBL in atherosclerosis. ${ }^{26}$

Our results describe for the first time the deposition and distribution characteristics of MBL in early and advanced atherosclerotic lesions. More importantly, the data clearly suggest that the ability of myeloid cells to express MBL during atherogenesis influences atherosclerosis development.

The knowledge that the variation in plasma MBL levels in humans is regionally distributed around the world, with approximately $5 \%$ to $10 \%$ lacking functional $M B L$, has led to many studies that investigated MBL as a modifier of disease. ${ }^{6,27}$ Individuals that carry variant MBL alleles have an increased risk of infection and acute respiratory tract infections during early childhood, systemic lupus erythematosus, and meningococcal disease. ${ }^{28-31}$ In selected patient populations, well characterized MBL gene variants have also been associated with an increased risk of thrombosis in systemic lupus erythematosus patients and heterosis in relation to mortality in patients in intensive care. ${ }^{32,33}$ Population-based studies addressing the role of $M B L$ in atherosclerosis analyzed either $M B L$ genotypes or resulting $M B L$ serum levels in numerous different patient cohorts. From this work, it has been suggested that functional MBL might control atherosclerosis by ensuring the rapid clearance infectious agents, such as $\mathrm{C}$ pneumoniae, associated with atherosclerosis development. ${ }^{7,34}$ Moreover, there is an extensive search for the evolutionary advantage of low functional MBL plasma levels. ${ }^{35,36}$

To understand a possible role of MBL in atherogenesis, different known functions of MBL must be considered. Besides an effective regulator of complement activation, functional MBL can act as a potent opsonin of exogenous (infectious agents) or endogenous danger signals, such as late apoptotic and necrotic cells and cellular debris, which are associated with atherosclerosis 
development and plaque stability. ${ }^{37}$ Consequently, our results might indicate a differential role of $\mathrm{MBL}$ in atherogenesis. On the one hand, $\mathrm{MBL}$ expression during early atherogenesis may facilitate the rapid clearance of endogenous danger signals in the early atherogenic process, possibly constraining atherosclerosis development. ${ }^{38,39}$ On the other hand, increased levels of $\mathrm{MBL}$ expression in more advanced atherosclerotic lesions may have a proinflammatory role, as described earlier for coronary artery disease, myocardial infarction, and the risk of cardiac death in patients with type 2 diabetes and rheumatoid arthritis. ${ }^{15,40,41}$ Reduced levels of MBL expression, as demonstrated in advanced human and murine atherosclerotic lesions, may illustrate a futile effort to control complement activation, inflammation, and atherosclerosis progression. Interestingly, in its opsonizing capacity, MBL largely resembles the complement component C1q. Recently, C1q was found to reduce atherosclerosis development in atherosclerosisprone $\mathrm{LDLR}^{-/-}$mice in comparison with $\mathrm{C} 1 \mathrm{q} / \mathrm{LDLR}^{-/}$experimental controls. These findings were largely attributed to the ability of $\mathrm{C} 1 \mathrm{q}$ to opsonize apoptotic cells and to facilitate phagocytic clearance in atherosclerotic lesions, a quality similarly observed for MBL. ${ }^{38,39}$ Moreover, the $\mathrm{C} 1$ complement complex has been shown to bind modified LDL, a major cause of inflammation in arterial vascular disease. ${ }^{42}$ Whether these observations also account for the contribution of $\mathrm{MBL}$ to atherosclerosis development will be a matter of future research.

Several other complement components have been associated with atherosclerosis development. Reduced complement activity, as seen in C3-, C5-, or C6-deficient mice or rabbit animal models, clearly affects atherosclerosis development. ${ }^{3,43-46}$ Atherosclerosis development in C3-deficient LDLR $^{-/}$as well as $\mathrm{LDLR}^{-/}$/apolipoprotein $\mathrm{E}^{-/}$mice was shown to be dependent on an altered lesion progression and lipid metabolism, resulting in increased lesion size compared with normal $\mathrm{LDLR}^{-/}$and $\mathrm{LDLR}^{-/ /} /$apolipoprotein $\mathrm{E}^{-/-}$control mice. ${ }^{43,44}$

Our findings suggest an important contribution of extrahepatic, myeloidderived $M B L$ gene expression to atherosclerosis development. $M B L$ gene expression by myeloid-derived cells has been reported before. ${ }^{24}$ Moreover, the importance of extrahepatic MBL expression was clearly demonstrated from work on allogeneic hemopoietic stem cell transplantations. Recipients of bone marrow from MBL variant donors had a $>4$-fold increased risk of serious infection compared with recipients of bone marrow derived from individuals without coding mutations in the $\mathrm{mb} / 2$ gene. ${ }^{47}$ The importance of extrahepatic complement, 


\section{Chapter 4}

including MBL expression, in various pathologies led us to investigate the role of macrophagespecific MBL expression in atherosclerosis development. However, a systemic role of MBL in atherosclerosis should be further addressed by generation of $\mathrm{MBL} \mathrm{A} / \mathrm{C}^{-1-\kappa}$ triple knockout animals. Such data could provide further insight into the role of circulating $M B L$ in the epidemiological findings of $M B L$ in vascular disease. ${ }^{14,15,40,41}$

Preliminary analysis of advanced human atherosclerotic lesions and MBL gene expression and $M B L$ deposition supports our experimental murine data. Similar to observations in experimental atherosclerotic lesions, no MBL gene expression was observed in advanced human atherosclerotic plaques, suggesting a plasma origin of MBL during advanced stages of atherosclerosis development in mice and humans. In conclusion, our data clearly demonstrate the deposition and local gene expression of MBL over the course of atherosclerosis development. Deposition and gene expression of MBL-A and -C were putatively attributed to a protective role for intimal macrophages in murine atherogenesis. The observation that MBL gene expression by myeloid cells controls lesion development is of major importance in unravelling cause and effect mechanisms between MBL and atherosclerosis development. Further studies on the role of versatile immunoregulatory proteins as complement proteins in atherosclerosis will undoubtedly generate new insights that increase our understanding of atherosclerosis as well as augment future treatment possibilities.

\section{ACKNOWLEDGMENTS}

The authors wish to thank Nicole Hoebers and Monique N. Vergouwe for their excellent technical assistance. Dr de Winther is an established investigator of the Netherlands Heart Foundation (2007T067).

\section{REFERENCES}

1. Hansson GK. Inflammation, atherosclerosis, and coronary artery disease. N Engl J Med. 2005;352:1685-1695.

2. Libby P. Inflammation in atherosclerosis. Nature. 2002;420:868-874.

3. Niculescu F, Rus H. The role of complement activation in atherosclerosis. Immunol Res. 2004;30:73-80. 
4. Seifert PS, Hugo F, Tranum-Jensen J, Zahringer U, Muhly M, Bhakdi S. Isolation and characterization of a complement-activating lipid extracted from human atherosclerotic lesions. J Exp Med. 1990;172:547-557.

5. Fujita T. Evolution of the lectin-complement pathway and its role in innate immunity. Nat Rev Immunol. 2002;2:346-353.

6. Turner MW, Hamvas RM. Mannose-binding lectin: structure, function, genetics and disease associations. Rev Immunogenet. 2000;2:305-322.

7. Madsen HO, Videm V, Svejgaard A, Svennevig JL, Garred P. Association of mannosebinding-lectin deficiency with severe atherosclerosis. Lancet. 1998;352:959-960.

8. Best LG, Davidson M, North KE, MacCluer JW, Zhang Y, Lee ET, Howard BV, DeCroo S, Ferrell RE. Prospective analysis of mannosebinding lectin genotypes and coronary artery disease in American Indians: the Strong Heart Study. Circulation. 2004;109:471-475.

9. Saevarsdottir S, Oskarsson OO, Aspelund T, Eiriksdottir G, Vikingsdottir T, Gudnason V, Valdimarsson $\mathrm{H}$. Mannan binding lectin as an adjunct to risk assessment for myocardial infarction in individuals with enhanced risk. J Exp Med. 2005;201:117-125.

10. Rugonfalvi-Kiss S, Endresz V, Madsen HO, Burian K, Duba J, Prohaszka Z, Karadi I, Romics L, Gonczol E, Fust G, Garred P. Association of Chlamydia pneumoniae with coronary artery disease and its progression is dependent on the modifying effect of mannose-binding lectin. Circulation. 2002;106:1071-1076.

11. Hegele RA, Ban MR, Anderson CM, Spence JD. Infection-susceptibility alleles of mannosebinding lectin are associated with increased carotid plaque area. J Investig Med. 2000;48:198-202.

12. Limnell V, Aittoniemi J, Vaarala O, Lehtimaki T, Laine S, Virtanen V, Palosuo T, Miettinen A. Association of mannan-binding lectin deficiency with venous bypass graft occlusions in patients with coronary heart disease. Cardiology. 2002;98:123-126.

13. Rugonfalvi-Kiss S, Dosa E, Madsen HO, Endresz V, Prohaszka Z, Laki J, Karadi I, Gonczol E, Selmeci L, Romics L, Fust G, Entz L, Garred P. High rate of early restenosis after carotid eversion endarterectomy in homozygous carriers of the normal mannose-binding lectin genotype. Stroke. 2005;36:944 -948.

14. Hansen TK. Mannose-binding lectin (MBL) and vascular complications in diabetes. Horm Metab Res. 2005;37(suppl 1):95-98.

15. Keller TT, van Leuven SI, Meuwese MC, Wareham NJ, Luben R, Stroes ES, Hack CE, Levi M, Khaw KT, Boekholdt SM. Serum levels of mannose-binding lectin and the risk of future coronary artery disease in apparently healthy men and women. Arterioscler Thromb Vasc Biol. 2006;26:2345-2350. 


\section{Chapter 4}

16. Pratt JR, Basheer SA, Sacks SH. Local synthesis of complement component C3 regulates acute renal transplant rejection. Nat Med. 2002;8: 582-587.

17. Cao W, Bobryshev YV, Lord RS, Oakley RE, Lee SH, Lu J. Dendritic cells in the arterial wall express C1q: potential significance in atherogenesis. Cardiovasc Res. 2003;60:175-186.

18. Yasojima K, Schwab C, McGeer EG, McGeer PL. Complement components, but not complement inhibitors, are upregulated in atherosclerotic plaques. Arterioscler Thromb Vasc Biol. 2001;21:1214-1219.

19. Farrar CA, Zhou W, Lin T, Sacks SH. Local extravascular pool of C3 is a determinant of postischemic acute renal failure. FASEB J. 2006;20: 217-226.

20. Bhatia VK, Yun S, Leung V, Grimsditch DC, Benson GM, Botto MB, Boyle JJ, Haskard DO. Complement c1q reduces early atherosclerosis in low-density lipoprotein receptor-deficient mice. Am J Pathol. 2007;170: 416-426.

21. Shagdarsuren E, Bidzhekov K, Djalali-Talab Y, Liehn EA, Hristov M, Matthijsen RA, Buurman WA, Zernecke A, Weber C. C1-esterase inhibitor protects against neointima formation after arterial injury in atherosclerosis-prone mice. Circulation. 2008;117:70 -78.

22. de Vries B, Walter SJ, Peutz-Kootstra CJ, Wolfs TG, van Heurn LW, Buurman WA. The mannose-binding lectin-pathway is involved in complement activation in the course of renal ischemia-reperfusion injury. Am J Pathol. 2004;165:1677-1688.

23. Kanters E, Pasparakis M, Gijbels MJ, Vergouwe MN, Partouns-Hendriks I, Fijneman RJ, Clausen BE, Forster I, Kockx MM, Rajewsky K, Kraal G, Hofker MH, de Winther MP. Inhibition of NF-kappaB activation in macrophages increases atherosclerosis in LDL receptor-deficient mice. J Clin Invest. 2003;112:1176-1185.

24. Seyfarth J, Garred P, Madsen HO. Extra-hepatic transcription of the human mannosebinding lectin gene $(\mathrm{mbl} 2)$ and the MBL-associated serine protease 1-3 genes. Mol Immunol. 2006;43:962-971.

25. Hollander W, Colombo MA, Kirkpatrick B, Paddock J. Soluble proteins in the human atherosclerotic plaque: with spectral reference to immunoglobulins, C3-complement component, alpha 1-antitrypsin and alpha 2-macroglobulin. Atherosclerosis. 1979;34:391405.

26. Hansson GK. Epidemiology complements immunology in the heart. Arterioscler Thromb Vasc Biol. 2006;26:2178 -2180.

27. Holmskov $U$, Thiel S, Jensenius JC. Collections and ficolins: humoral lectins of the innate immune defense. Annu Rev Immunol. 2003;21: 547-578.

28. Super M, Thiel S, Lu J, Levinsky RJ, Turner MW. Association of low levels of mannanbinding protein with a common defect of opsonisation. Lancet. 1989;2:1236 -1239. 
29. Koch A, Melbye M, Sorensen P, Homoe P, Madsen HO, Molbak K, Hansen CH, Andersen LH, Hahn GW, Garred P. Acute respiratory tract infections and mannose-binding lectin insufficiency during early childhood. JAMA. 2001;285:1316 -1321.

30. Davies EJ, Snowden N, Hillarby MC, Carthy D, Grennan DM, Thomson W, Ollier WE. Mannose-binding protein gene polymorphism in systemic lupus erythematosus. Arthritis Rheum. 1995;38:110 -114.

31. Hibberd ML, Sumiya M, Summerfield JA, Booy R, Levin M; Meningococcal Research Group. Association of variants of the gene for mannosebinding lectin with susceptibility to meningococcal disease. Lancet. 1999;353:1049 -1053.

32. Ohlenschlaeger T, Garred P, Madsen HO, Jacobsen S. Mannose-binding lectin variant alleles and the risk of arterial thrombosis in systemic lupus erythematosus. $\mathrm{N}$ Engl J Med. 2004;351:260 -267.

33. Hellemann D, Larsson A, Madsen HO, Bonde J, Jarlov JO, Wiis J, Faber T, Wetterslev J, Garred P. Heterozygosity of mannose-binding lectin (MBL2) genotypes predicts advantage (heterosis) in relation to fatal outcome in intensive care patients. Hum Mol Genet. 2007; 16:3071-3080.

34. Aittoniemi J, Fan YM, Laaksonen R, Janatuinen T, Vesalainen R, Nuutila P, Knuuti J, Hulkkonen J, Hurme M, Lehtimaki T. The effect of mannanbinding lectin variant alleles on coronary artery reactivity in healthy young men. Int J Cardiol. 2004;97:317-318.

35. Fiane AE, Videm V, Lingaas PS, Heggelund L, Nielsen EW, Geiran OR, Fung M, Mollnes TE. Mechanism of complement activation and its role in the inflammatory response after thoracoabdominal aortic aneurysm repair. Circulation. 2003;108:849-856.

36. Dornelles LN, Pereira-Ferrari L, Messias-Reason I. Mannan-binding lectin plasma levels in leprosy: deficiency confers protection against the lepromatous but not the tuberculoid forms. Clin Exp Immunol. 2006;145:463-468.

37. Bjorkerud S, Bjorkerud B. Apoptosis is abundant in human atherosclerotic lesions, especially in inflammatory cells (macrophages and T cells), and may contribute to the accumulation of gruel and plaque instability. Am J Pathol. 1996;149:367-380.

38. Nauta AJ, Castellano G, Xu W, Woltman AM, Borrias MC, Daha MR, van Kooten C, Roos A. Opsonization with $\mathrm{C} 1 \mathrm{q}$ and mannose-binding lectin targets apoptotic cells to dendritic cells. J Immunol. 2004;173:3044-3050.

39. Ogden CA, deCathelineau A, Hoffmann PR, Bratton D, Ghebrehiwet B, Fadok VA, Henson PM. C1q and mannose binding lectin engagement of cell surface calreticulin and CD91 initiates macropinocytosis and uptake of apoptotic cells. J Exp Med. 2001;194:781-795. 


\section{Chapter 4}

40. Troelsen LN, Garred P, Madsen HO, Jacobsen S. Genetically determined high serum levels of mannose-binding lectin and agalactosyl IgG are associated with ischemic heart disease in rheumatoid arthritis. Arthritis Rheum. 2007;56:21-29.

41. Hansen TK, Gall MA, Tarnow L, Thiel S, Stehouwer CD, Schalkwijk CG, Parving HH, Flyvbjerg A. Mannose-binding lectin and mortality in type 2 diabetes. Arch Intern Med. 2006;166:2007-2013.

42. Biro A, Thielens NM, Cervenak L, Prohaszka Z, Fust G, Arlaud GJ. Modified low density lipoproteins differentially bind and activate the C1 complex of complement. Mol Immunol. 2007;44:1169-1177.

43. Buono C, Come CE, Witztum JL, Maguire GF, Connelly PW, Carroll M, Lichtman AH. Influence of C3 deficiency on atherosclerosis. Circulation.2002;105:3025-3031.

44. Persson L, Boren J, Robertson AK, Wallenius V, Hansson GK, Pekna M. Lack of complement factor $\mathrm{C} 3$, but not factor $\mathrm{B}$, increases hyperlipidemia and atherosclerosis in apolipoprotein E-/- low-density lipoprotein receptor-/- mice. Arterioscler Thromb Vasc Biol. 2004;24:10621067.

45. Schmiedt W, Kinscherf R, Deigner HP, Kamencic H, Nauen O, Kilo J, Oelert H, Metz J, Bhakdi S. Complement C6 deficiency protects against diet-induced atherosclerosis in rabbits. Arterioscler Thromb Vasc Biol. 1998;18:1790 -1795.

46. Patel S, Thelander EM, Hernandez M, Montenegro J, Hassing H, Burton C, Mundt S, Hermanowski-Vosatka A, Wright SD, Chao YS, Detmers PA. ApoE(-/-) mice develop atherosclerosis in the absence of complement component C5. Biochem Biophys Res Commun. 2001;286:164-170.

47. Mullighan CG, Heatley S, Doherty K, Szabo F, Grigg A, Hughes TP, Schwarer AP, Szer J, Tait BD, Bik To L, Bardy PG. Mannose-binding lectin gene polymorphisms are associated with major infection following allogeneic hemopoietic stem cell transplantation. Blood. 2002;99:3524-3529.

\section{Data Supplement}

\section{Mice and preparation of tissues}

In order to limit the use of experimental animals some LDLR 1 - animals enrolled in these studies served as controls in experiments as described before. ${ }^{1}$ Animals were fed a high-fat Western diet $(n=10)$ without cholate containing $16 \%$ fat, $0.15 \%$ cholesterol (Arie Blok B.V., Woerden, the Netherlands) diet for 10 (early) or 18 (advanced) weeks. After anaesthesia the hearts and aortic arches were excised and 
embedded in OCT compound and frozen on dry ice and subsequently stored at $70^{\circ} \mathrm{C}$. Cryostat sections $(7 \mathrm{~m})$ were cut with a $42 \mathrm{~m}$ interval, subsequently dried and stored. Sections were fixed in $-20^{\circ} \mathrm{C}$ acetone before immunohistochemistry.

\section{Immunohistochemical staining}

Primary antibodies were incubated $(1-10 \mathrm{~g} / \mathrm{ml})$ overnight at $4{ }^{\circ} \mathrm{C}$ in TBS containing $2 \%$ normal goat serum (NGS) or $0.1 \%$ BSA. Secondary peroxidase or biotin conjugated goat anti rat or goat anti rabbit polyclonal antibodies (Jackson ImmunoResearch, West Grove, PA) were incubated in their appropriate dilutions. Following signal enhancement in case of biotin conjugated secondary antibodies (hMBL) using peroxidase conjugated avidin-biotin complexes (Dako, Glostrup, Denmark), antibody binding was visualized using 3-amino-9-ethylcarbazole (AEC) with $\mathrm{H}_{2} \mathrm{O}_{2}$ as substrate. Antibody specificity was determined by western blotting under reduced conditions ( $\mathrm{hMBL}$, specific band at $\pm 31 \mathrm{kD}$ ), inhibiting primary antibody binding by specific protein blockage ( $\mathrm{hMBL})$, incubating slides with isotype control rat IgG (Macrophage, MBL-A, MBL-C), control rabbit serum (hMBL) or secondary antibody only.

\section{Reverse Transcription-Polymerase Chain reaction}

PCR reactions (40 cycle standard) with specific primers were performed using 2 I standard dilutions of CDNA (5ng/l). The sequences of oligonucleotide primers were: MBL-A, 5'-CCA AAG GGG AGA AGG GAG AAC-3' (forward) and 5'-GCC TCG TCC GTG ATG CCT AG-3' (reversed); MBL-C, 5'-GAC GTG ACG GTG CCA AGG G-3' (forward) and 5'-CTT TCT GGA TGG CCG AGT TTT C-3' (reversed). ${ }^{2}$

\section{Blood and chimerism analysis}

Cells were stained either with Mac1-PE and Gr1-FiTC or with 6B2-PE and KT3FiTC (BD Sciences, San Diego, CA) in PBS 5\% normal mouse serum and 1\% FCS. After 1 hour, cells were washed and analyzed by FACS analysis (Facssort, BD Sciences) according to following principles: T-cells KT3 positive, B-cells 6B2, monocytes Mac1 positive/GR1 negative, and granulocytes Mac1/GR1 positive. Chimerism was determined as described before. ${ }^{3}$

\section{Atherosclerosis assessment and lesion analysis}

The animals were dissected, and hearts and aortic arches were removed and 


\section{Chapter 4}

bisected perpendicularly to the heart axis, just below the atrial tips. The tissue was frozen in Tissue-Tec (Shandon, Veldhoven, the Netherlands) with the base facing downward. Cryostat sections were prepared as described above. The aortic lesion area was analyzed using serial sections with $42 \mathrm{~m}$ intervals, beginning from the onset of the aortic valves until the valves had disappeared. The collected sections were stained with toluidine blue and digitally photographed and quantified using Adobe Photoshop (Adobe Systems, San Jose, CA).

\section{Human atherosclerotic lesions}

$4 \mathrm{~m}$ sections were cut from paraffin embedded tissue specimens. Total RNA was isolated as described above. cDNA synthesized from human liver derived total RNA isolate served as positive control sample for hMBL. Specific primers (Sigma) for amplification of hMBL were designed using the Primer Express software package (Applied Biosystems, Foster City, CA) and tested for amplification of contaminating genomic DNA. To minimize the risk of genomic amplification the primers were positioned on different exons. Primer concentrations were optimalized and dilution curves were made from human liver cDNA standard pool to ensure an exponential TaqMan amplification for each primer set. The sequences of oligonucleotide primers were: MBL, 5'-GGGTCACCAGGACCAAAGG-3' (forward) and 5'-CAGCCAGGCTACTATCACCAT-3' (reversed).

\section{RefERENCES}

1. Ghesquiere SA, Gijbels MJ, Anthonsen M, van Gorp PJ, van der Made I, Johansen B, Hofker $\mathrm{MH}$, de Winther MP. Macrophage-specific over expression of group Ila sPLA2 increases atherosclerosis and enhances collagen deposition. J Lipid Res. 2005;46:201-210.

2. de Vries B, Walter SJ, Peutz-Kootstra CJ, Wolfs TG, van Heurn LW, Buurman WA. The mannose-binding lectin-pathway is involved in complement activation in the course of renal ischemia-reperfusion injury. Am J Pathol. 2004;165:1677-1688.

3. Kanters E, Pasparakis M, Gijbels MJ, Vergouwe MN, Partouns-Hendriks I, Fijneman RJ, Clausen BE, Forster I, Kockx MM, Rajewsky K, Kraal G, Hofker MH, de Winther MP. Inhibition of NF-kappaB activation in macrophages increases atherosclerosis in LDL receptor-deficient mice. J Clin Invest. 2003;112:1176-1185. 
Chronic Vascular Tissue Damage 
Chapter 5

Discussion and Summary 


\section{Chapter 5}

Our immune system has evolved over many millions of years. It has developed a sophisticated interplay between various barriers, cells, peptides, proteins and enzymes in order to protect us from pathogen invasion and altered self as well as to enhance tissue repair after injury.

Many clinical conditions have been associated with aggravated tissue damage and loss of organ function as a result of an inflammatory reaction. Over years, by using predominantly animal experimental models, that resemble clinical conditions, we have learnt a great deal about the role of the innate immune system in many progressive and sometimes life threatening diseases. Complete recovery or even control over disease progression remains a great challenge. Especially, since we still lack complete understanding of many important innate immune contributors to disease progression. An example to illustrate this situation is best given by organ transplant biology. Many organs develop pre-transplant organ damage as a result of tissue ischemia. This ischemic organ damage can effect post transplant short term as well as long term function and even affect overall transplant survival. The extend of these effects are still today not easily predicted. The assessment of function of an organ to be used for transplantation is more based on circumstantial parameters instead of evidence based tests. Another example is given by severely ill ICU (Intensive Care Unit) patients. Many ICU patients suffer from a Systemic Inflammatory Response Syndrome (SIRS). This syndrome, also called sepsis when caused by an infection, is characterized by an immune reaction affecting vulnerable tissues of the lung, kidney, liver and intestine. Sepsis induced SIRS affects about 750,000 US patients yearly and is associated with high mortality rates of up to $40 \%$, prolonged hospital stay and tremendous in-hospital costs of approximately $\$ 200,000$ per patient. ${ }^{1}$ SIRS and sepsis are associated with tissue hypo-perfusion and can lead to focal or generalized ischemia and reperfusion injury. Poor local hemodynamic conditions contribute to the development of organ damage, disease progression, organ dysfunction and reduce the chance of a favourable patient outcome. ${ }^{2}$ In order to better understand the development of organ damage, organ dysfunction and disease progression in cases of IR (as a result of SIRS, major surgery, trauma or organ transplantation), strategies have to be developed that allow for a better understanding of key players involved in control of innate immune activation.

In this thesis the role of different innate immune cells and proteins were evaluated during the course of acute and chronic organ damage development. This was done 
in order to gain insight in underlying mechanisms that contribute to disease progression and IR injury development. To this end, three different aims were formulated focussed on underlying innate immune pathophysiologic mechanisms. The different aims as well as their subsets of specific scientific quests were investigated in both animal and human experimental in- or ex-vivo models.

The first aim of this thesis was to gain more insight in prominent innate immune components in renal IR in order to develop strategies that preserve renal function following Non-Heart Beating kidney transplantation or following renal IR associated with other pathologies like SIRS, sepsis, shock and trauma.

In order to do so we first analyzed the role of MPO as innate immune modulator in an experimental murine renal IR model (as described in Chapter 2.2). $\mathrm{MPO}^{-/}$animals (mice deficient in MPO) were protected from IR induced renal failure when compared to WT controls subjected to an identical protocol of tissue IR. Renal function was assessed by total blood urea nitrogen (BUN) levels following 40 minutes of ischemia and 24 hours of reperfusion. In an attempt to analyse the mechanism by which the absence of MPO contributed to renal preservation, it was demonstrated that apoptotic levels, tissue preservation following 24 hours of reperfusion and complement activation levels at 2 hours or 24 hours of reperfusion were similar in both groups. However, PMN influx into the affected area differed substantially in both experimental groups following 24 hours of reperfusion. Less PMN were detected in the reperfused renal tissue from $\mathrm{MPO}^{-1-}$ mice, when compared to their WT counterparts. This suggested that some of the in vitro properties described for MPO, such as apoptosis induction or complement activation at the level of $\mathrm{C} 5$, are less likely to contribute substantially to IR induced renal damage in vivo. Much more, MPO is suggested to play an important role in the activation and sequestration of PMN into the affected tissue, possibly by its $\alpha_{m} \beta_{2}$-integrin (MAC-1) interaction. ${ }^{3}$ The results presented in Chapter 2.2 may imply that neutrophil activation and sequestration along with MPO release represent an adjunct pathophysiological event in renal IR-injury that is distinctly different from other innate immune contributors such as the complement system. Similar observations have been made in patients suffering from acute coronary syndrome, where MPO levels are thought to be associated with overall PMN activation, disease progression and importantly future risk of adverse myocardial events possibly by enhanced $\mathrm{NO}$ catabolism in the affected myocardial tissue. ${ }^{4,5}$

Chapter 2.3 described the deposition of MAC following renal IR and the protective 


\section{Chapter 5}

effects of complement inhibition at the level of the common complement component $\mathrm{C} 5$ by a specific mouse monoclonal antibody (mAb) BB5.1. Animals, subjected to unilateral renal IR, 45 minutes of ischemia and 24 hours of reperfusion, were protected from renal function loss when treated with BB5.1 prior to reperfusion. This effect was not observed in control animals treated with an isotype $\mathrm{mAb}$ or physiologic saline. It was demonstrated that renal IR induced complement activation and deposition of C3, C6 and C9. Treatment with BB5.1 prevented the production of different cytokines and chemokines which regulate the influx of PMN. Additionally, the deposition of early complement components (C3) and downstream common pathway complement components (C6 and C9) after 24 hours of reperfusion as well as PMN influx were reduced by BB5.1 treatment. BB5.1 was not able to reduces early apoptotic levels following 2 hours of reperfusion. The inhibition of complement activation not only preserved long term renal function, but similarly prevented the induction of inflammation and secondary apoptosis, thereby preserving overall renal tissue integrity. This illustrates that activation of complement in response to initial IR induced apoptotic cell death, contributes to the development of secondary apoptosis and tissue damage and leads to loss of organ function. However, use of a C5 inhibitory antibody (Pexelizumab) in man proved to be more complicated. Pexelizumab has generated less favorable results over the course of myocardial infarction. Although it reduced overall 90 day mortality rates by $4 \%$, the primary end-point of infarct size was not reduced, as expected based on experimental animal models, following different treatment modalities. ${ }^{6,7}$ Similar results were obtained in cardiac surgical patients undergoing cardiopulmonary bypass. ${ }^{8}$ These disappointing results might however be attributable to a heterogeneous population included, warranting further research.

In subsequent experiments by de Vries et al. it was demonstrated that the effects of BB5.1, by which C5 activation is inhibited, might not only be attributed to the effects of reduced MAC formation. ${ }^{9}$ The inhibition of the interaction between C5a and its G-protein linked receptor, C5aR, attenuated IR induced renal damage through effects on both neutrophil dependent as well as independent pathways, such as chemokine production. Preventing C5a formation might well influence cellular dysfunction rather than cell death which plays an important role in the pathophysiology of renal I/R injury.

In order to attenuate post reperfusion renal damage, the possibility of 
lysophosphatidic acid induced renal preservation following IR was investigated (Chapter 2.4). Lysophosphatidic acid (LPA) is a member of the phospholipid growth factor family. It has G-protein linked receptors which exert pleiotropic effects like cell survival and cell proliferation. Its effects on IR induced renal function loss were investigated. Previous in vitro observations had demonstrated an inhibitory effect of LPA on proximal tubular cell apoptosis. ${ }^{10}$ Male swiss mice, subjected to unilateral renal IR (45 minutes ischemia and 24 hours of reperfusion), demonstrated preserved renal function upon treatment with LPA, when compared with PBS treated controls, BUN levels $25.9 \mathrm{mmol} / \mathrm{L}$ for LPA $(0.01 \mathrm{mg})$ versus $43.3 \mathrm{mmol} / \mathrm{L}$ for control saline treatment, $\mathrm{P}<0.05$. LPA was administered prior to reperfusion and effects were demonstrated to be dose dependent, with a plateau reached at $40 \mathrm{mg} / \mathrm{kg}$ LPA. Positive effects on renal function were accompanied by reduced levels of apoptosis, reduced loss in brush border integrity and reduced levels of activated caspase-7. Moreover, PMN influx into the reperfused tissue was reduced along with tissue mRNA levels of TNF- $\alpha$. Surprisingly, tissue mRNA levels of different chemokines like CXCL1 (chemokine (C-X-C motif) ligand 1, previously named $\mathrm{KC}$ ) and CXCL2 (chemokine (C-X-C motif) ligand 2, previously MIP-2), both involved in inflammatory cell recruitment, were unaffected. In addition the effects of LPA administration on renal IR induced complement were analyzed. LPA dose dependently prevented $\mathrm{C} 3, \mathrm{C} 6$ and MAC deposition in animals treated with 0.1 and $1 \mathrm{mg}$ of LPA. Intervention in IR induced inflammatory mechanisms at an early stage might well prove successful in tissue protection. LPA has been described as a renal tubular survival factor in several studies indicating its potent preservative properties. Future studies will have to elucidate its effects on other organ IR like myocardial and gut IR.

Translation of therapeutic targets identified in basic science into effective interventions for human kidney transplantation requires clinically relevant large animal models. Ultimately, novel interventions, such as LPA, that attenuate ischemic acute kidney injury will enable expansion of the donor pool with kidneys that have suffered prolonged ischemia. Therefore, we took on the challenge to develop a comprehensive model of autologous transplantation of ischemically injured kidneys in pigs with special emphasis on peri-operative care. This model (as described in Chapter 2.5) enables translation of therapeutic targets from small animal experimental models to pigs, which are highly useful considering their limited genetic variation and close similarity of the renal anatomy and physiology 


\section{Chapter 5}

with humans. From this work it was concluded that careful hemodynamic management both peri- and post-operatively is of critical importance in graft and recipient survival. The importance of these observations were corroborated by Snoeijs et al. during studies on recipient hemodynamics over the course of nonheart-beating donor kidney transplantation in man. ${ }^{11}$

Complement activation has been implicated in renal function loss over the course of renal IR and during renal transplantation. As innate complement activating protein, MBL is considered important. De Vries et al. and MollerKristensen et al. demonstrated MBL deposition over the course of experimental murine IR as well as its role in renal function loss. ${ }^{12,}{ }^{13}$ Moreover, the deposition of MBL in human post reperfusion Donation after Cardiac Death (DCD) renal transplant biopsies was demonstrated. These MBL deposits co-localized with more downstream complement proteins, such as $\mathrm{C} 6$, indicating both activation and a functional role of MBL over the course of human DCD renal transplantation. By using MASP-2 deficient as well as WT mice in an isogenic renal transplant model, Farrar et al. where able to demonstrate that complement activation following renal IR is mediated predominantly by the lectin pathway instead of the classical pathway of complement activation (presented at the 12th European Meeting on Complement in Human Disease 2009. Abstract \#041). In 2007 low pre-transplant MBL plasma levels were demonstrated to be associated with improved outcome, as assessed by both patient and graft survival. ${ }^{14}$ Of interest in this respect are findings by the group of Sacks that demonstrate an explicit role of extra-hepatic and extra vascular complement component C3 in overall graft function as well as graft survival during kidney transplantation. Experimental studies using C3-knockout animals as well as human population based studies using renal allograft pairs, demonstrated a role of renal C3 synthesis in renal allograft survival. ${ }^{15,16}$ This triggered us the determine the role of different human MBL gene allotypes in DCD renal graft survival (Chapter 2.6). By determining the $\mathrm{mbl}-2$ genotype of 237 consecutively included Non-Heart-Beating (NHB) donor pairs over an eleven year inclusion period we were able to demonstrate a role for the donor intermediate $\mathrm{mbl}-2$ genotype on primary non-function. Additionally, an effect of the intermediate $\mathrm{mbl}-2$ genotype on death-censored graft survival showed a trend towards significance $(p=0.06)$. Surprisingly the recipient $m b l-2$ genotype did not correlate to primary non-function and death-censored graft survival. In favor of our findings is the observation made by quantitative PCR analysis that demonstrated 
the ability of allografts to express $m b l-2$ mRNA suggestive for local MBL protein expression.

In conclusion we demonstrated a critical role for several innate contributors to immunity to renal IR or renal function loss following Non-Heart Beating kidney transplantation. LPA was found to reduce IR induced renal damage in a murine model of experimental IR. Whether such promising results can be translated to a large animal model or even man will have to be focus of future research. In man the mbl-2 haplotype influenced graft survival following DCD kidney transplantation. True, MPO, C5 and MBL are only a few of many possible inflammatory mediators involved in IR induced organ damage. However, control over inflammatory initiating events over the course of IR might offer future interventions aimed at reducing IR induced renal damage and organ failure.

The second aim of this thesis was to study the sequelae of intestinal ischemiareperfusion in man and elucidate the role of regulatory innate immune processes on subsequent passive and active barrier failure.

During major surgical procedures, septic episodes, SIRS or in case of local peripheral arterial occlusive disease, altered splanchnic perfusion has been observed. ${ }^{17-21}$ Human mesenteric ischemia is a potentially life threatening disease entity, which can be hard to diagnose in every day clinical practice. So far, animal studies have been used to study effects of hypoperfusion and ischemia on intestinal function and gut wall integrity. However, a human experimental model which allows for detailed studies on molecular mechanisms contributing to the development of IR induced enterocyte damage, gut wall integrity and individual contributions of innate immune regulators is lacking. Therefore we developed a human small intestinal ischemia reperfusion model. During the pancreaticoduodenectomy procedure a variable length of small bowel is resected as part of the total resection specimen. This part of the small bowel was used to study small bowel ischemia reperfusion responses. As described in Chapter 3.2, a small $6 \mathrm{~cm}$ part of the isolated jejunum was subjected to 30 minutes of ischemia followed by various lengths of reperfusion with a mean of 120 minutes. At fixed time points from both arterial and specific venous, draining the isolated jejunum tissue, blood samples were drawn in order to study possible protein release or deposition in the affected tissue. Small intestine enterocyte damage was measured by mean $( \pm$ SEM) arteriovenous concentration gradients of I-FABP levels across the studied jejunum. In the first 20 patients, which were included consecutively, mean I-FABP plasma 


\section{Chapter 5}

levels increased from 328 (59) $\mathrm{pg} / \mathrm{ml}$ before ischemia to 4,096 (543) $\mathrm{pg} / \mathrm{ml}$ immediately upon reperfusion $(\mathrm{p}<0.001)$. I-FABP plasma levels declined towards $1,200(204) \mathrm{pg} / \mathrm{ml}$ after 2 hours of reperfusion. A human model of small intestinal ischemia reperfusion might not only broaden our understanding of human small intestinal ischemia reperfusion and important contributors, but will undoubtedly generate new treatment opportunities. In addition to the model design chosen for these first papers, extensions aimed at possible interventions or labelling strategies in order to image ongoing cellular damage might well be developed.

Ischemia reperfusion of the small intestine in man induces a surprising as well as ingenious response. Chapter 3.3 describes the small intestines ability to shed damaged enterocytes from their basal membrane into the relative safety of the small intestine luminal space. Surprisingly, within 60 minutes of reperfusion the intestinal enterocyte barrier had closed again, restoring its important integrity. No apoptotic remnants (M30 positive staining) were detected in the epithelial lining. However, analysis of the luminal contents after reperfusion, revealed sheets of damaged and apoptotic epithelial cells. This mechanism might illustrate the small intestine's ability to get rid of highly immunostimulatory DAMPs in order to prevent a vigorous post ischemic inflammatory response. Other organs, lacking an internal luminal space, might be less successful in using similar techniques, although possible similar efforts might be observed in the reperfused kidney. Although observed not only in response to IR, kidney damaged epithelial cells are shed into the small luminal space of the renal tubular system following IR. These renal specific mechanisms of so called cast formation are poorly understood. Whether this epithelial shedding illustrates protective mechanism of the kidney in response to IR, warrants future research. Other organs, that lack sufficient luminal space might not be able to shed it damaged cells and trigger an inflammatory response, inducing secondary tissue damage.

Whether the ability of the human small intestine to shed its damaged enterocytes into the inert safety of the intestinal lumen, prevents to onset of an IR inflammatory response was questioned. This is addressed in Chapter 3.4. It was demonstrated that reperfusion of the ischemic small intestine following 30 minutes of ischemia was not paralleled by an IR induced inflammatory reaction. From these data we postulate that important criteria to induce an IR inflammatory reaction have not been met, due to the intestines ability to shed damaged enterocytes into the intestinal lumen immediately upon reperfusion. Additionally, the response 
observed in the reperfused jejunum might possibly be aimed at tissue regeneration instead. It is important to realize, however, that until today no cause and effect relationship has been described for the loss of gut wall integrity and development of severe sepsis and secondary multiple organ failure. Rather the loss of enterocyte integrity observed during major surgery, trauma, hypoperfusion and infection might well illustrate generalized tissue damage of organs like the lung, kidney and intestine instead. Whether the small intestinal rescue mechanisms are preserved following longer ischemic periods will have to be addressed in detail. First results illustrate that increased ischemic periods of 45 minutes increases tissue damage upon reperfusion, induces basal membrane exposure, substantial arteriovenous differences in endotoxin levels as well as an immune response characterized by endothelial cell activation and complement activation (C3) and cytokine release.22 So far, the small intestine has been the main focus of interest concerning the development of IR induced organ damage. Whether similar responses can be made in the colon will be point of future research.

MBL has been associated with intestinal IR damage in various experimental animal models. Animals deficient in MBL and subjected to different small intestinal IR regimes developed little IR induced inflammation and less organ damage. In some cases functional MBL was reconstituted, aggravating IR induced organ damage. ${ }^{23}$ Since MBL levels differ among humans as a result of various specific $\mathrm{mb} / 2$ gene mutations, we questioned whether the onset of IR induced enterocyte damage would vary among carriers of different $\mathrm{mb} / 2$ allotypes. Contributing to this hypothesis were earlier observations by Mollnes et al. who demonstrated a reduced inflammatory response in carriers $\mathrm{mb} / 2$ gene variants following major TAAA surgery, when compared to their wildtype allele carrying counterparts. ${ }^{24}$ Additionally, our laboratory showed the onset of intestinal epithelial damage during non-abdominal major surgical procedures such as TAAA repair or spinal column surgery. ${ }^{20,21}$ In response to 30 minutes of ischemia followed by reperfusion we observed great differences in enterocyte damage between different $\mathrm{mb} / 2$ allotype carriers. Interestingly, carriers of $\mathrm{mb} / 2$ null alleles, associated with low functional MBL plasma levels, experienced reduced levels of enterocyte damage upon reperfusion of the ischemic jejunum. This was not linked to any MBL deposition in the ischemic jejunum over time. Implications of this observation remain speculative, but might well suggest a non complement mediating role for extra hepatic small intestinal MBL synthesis. ${ }^{25}$ Although the thought of an underlying immunomodulatory 


\section{Chapter 5}

function attributed to local MBL expression in the small intestine is tempting, results by Kawasaki et al. might illustrate different possibilities. Kawasaki demonstrated in 1999, that MBL has cytotoxic effects on human colorectal carcinoma cells. These effects were observed for wildtype as well as variant $\mathrm{mb} / 2$ gene variants when transfected into tumour cells by viral constructs. This illustrates a non-complement mediated effect, termed MBL-dependent cell-mediated cytotoxicity (MDCC). Subsequently, another possibly non-complement mediated function of MBL was described. Functional MBL, purified over a mannose column, was found to inhibit meprin function. Meprins are membrane-bound and secreted zinc metalloproteases detected in renal and intestinal epithelial cells. The authors propose a possible function of intestinal and intra-cellular MBL in tumour progression and migration by meprin inhibition. ${ }^{26,27}$ A preservative function of $\mathrm{MBL}$ is hypothesized in renal epithelial cells over the course of renal function failure in case of inflammatory dysfunction. However plausible, evidence remains speculative in this respect and no in vivo function of intracellular MBL has been determined as yet.

In conclusion, these results are first to elucidate early responses of the human small intestine to IR. A unique mechanism was revealed, aided by the small intestines anatomical structure and immunological tolerance to its luminal contents. Furthermore, a contribution of MBL in enterocyte integrity has been proposed over the course of IR which does not appear to be determined by immunologic means or to be complement dependent. These results might illustrate why the gut is able to tolerate brief periods of ischemia during major surgical procedures, trauma, hypoperfusion or sepsis. Further analysis of human intestinal responses to IR is of pivotal importance and will result in new diagnostic tools and treatment modalities for intestinal ischemia.

The third and final aim of this thesis was to study the functional contribution of $\mathrm{MBL}$, as a regulatory innate immune protein during chronic tissue damage, in atherosclerosis development in mice and men.

Atherosclerosis is a vascular disease in which the inner part of the arterial vascular wall is subjected to an occlusive build up of plaques, damaging the normal anatomical arterial structure. It is a chronic disease, characterized by a progressive plaque build-up. Over time, still dependent on factors that are poorly understood, chances of plaque instability increase. A ruptured plaque exposes the pro-coagulant plaque content to the bloodstream, causing blood coagulation and thrombus formation at the rupture site, occluding the remaining luminal space of 
the diseased artery. Acute interruption of vital blood and oxygen supply to downstream tissue causes ischemia, most likely followed by reperfusion once the occluding blood clot is dissolved by fibrinolytic medication, intervention or local endogenous thrombolytic mechanisms. Acute plaque ruptures are frequently observed during myocardial, cerebral and intestinal IR and are associated with high morbidity and mortality rates (discussed in Chapter 4.1).

Not only IR induced organ damage has been associated with innate immune activation. Recently, the understanding that atherosclerosis progression and plaque stability are largely influenced by innate immune activation has gained significance. ${ }^{28,} 29$ This led to the third aim of this thesis (Chapter 4.2).

We demonstrated that MBL is present in atherosclerotic lesions over the course of early, 10 week, murine plaque development. Levels as well as distribution of $\mathrm{MBL}$ in advanced murine atherosclerotic lesions changed, where MBL was only detected in necrotic core lesions. Parallel analysis of human atherosclerotic lesions ( $n=17$, both stable and ruptured) revealed MBL deposits only in ruptured plaque areas, whereas stable human atherosclerotic lesions demonstrated no MBL deposition. Deposition of other complement components, both downstream common pathway (C6 - C9) and early complement activating proteins such as $\mathrm{C} 1 \mathrm{q}$ as well as the involvement of complement regulatory proteins in atherosclerosis development have previously been demonstrated. ${ }^{30-33}$ Interestingly, MBL-A and -C (the two known murine MBL variants) demonstrated distinctly different distribution patterns in 10 week old lesions. MBL-A was situated more around the intima to media transition borer, whereas MBL-C was detected around intimal macrophages. Both variants were detected in necrotic core lesions by immunohistochemical staining.

Analysis of MBL-A and -C mRNA levels after ten weeks of high fat feeding in atherosclerotic lesions demonstrated clear MBL-A and $-C$ gene expression. Interestingly, both MBL-A and -C gene and protein expression dropped markedly in advanced lesions and was absent in healthy vascular tissue. Since atherosclerotic lesions are characterized by a tremendous influx of macrophages and differentiated monocytes (THP-1 cells) were shown to express MBL, we questioned whether local MBL expression as well as gene transcription would be attributable to myeloid derived cells and control atherosclerosis development. Selectively knocking out MBL wildtype myeloid cells in atherogenic LDLR ${ }^{-/-}$mice, by a bone marrow transplant using a $\mathrm{MBL}^{-/-}$hemopoietic system, increased atherosclerosis 


\section{Chapter 5}

development by $30 \%$. This might well demonstrate that $\mathrm{MBL}$ derived from plaque infiltrating myeloid cells influences atherosclerosis development, much more than hepatically derived MBL.

The observation that MBL deposits were only detected in ruptured lesions without any local MBL mRNA expression indicates a plasma origin of the detected MBL.

Despite earlier conflicting reports on a possible role of MBL in atherosclerosis development, these are convincing data that demonstrate the deposition and more importantly an inhibitory role of myeloid derived MBL during atherosclerosis development. ${ }^{34-36}$ In explanation of the data, MBL might have opsonizing effects; possibly controlling inflammation, plaque growth or even plaque stability. ${ }^{33,37-40}$ Which targets are bound by $M B L$, or which function $M B L$ has in early and advanced atherosclerotic lesions need to be resolved.

\section{REFERENCES}

1. Marini JJW, Arthur P: Critical Care Medicine. Edited by Philadelphia, Lippincott Williams \& Wilkins, 2006, p

2. Sakr Y, Dubois MJ, De Backer D, Creteur J, Vincent JL: Persistent microcirculatory alterations are associated with organ failure and death in patients with septic shock, Crit Care Med 2004, 32:1825-1831

3. Lau D, Mollnau H, Eiserich JP, Freeman BA, Daiber A, Gehling UM, Brummer J, Rudolph V, Munzel T, Heitzer T, Meinertz T, Baldus S: Myeloperoxidase mediates neutrophil activation by association with CD11b/CD18 integrins, Proc Natl Acad Sci U S A 2005, 102:431-436

4. Baldus S, Heeschen C, Meinertz T, Zeiher AM, Eiserich JP, Munzel T, Simoons ML, Hamm CW: Myeloperoxidase serum levels predict risk in patients with acute coronary syndromes, Circulation 2003, 108:1440-1445

5. Baldus S, Heitzer T, Eiserich JP, Lau D, Mollnau H, Ortak M, Petri S, Goldmann B, Duchstein HJ, Berger J, Helmchen U, Freeman BA, Meinertz T, Munzel T: Myeloperoxidase enhances nitric oxide catabolism during myocardial ischemia and reperfusion, Free Radic Biol Med 2004, 37:902-911 
6. Granger CB, Mahaffey KW, Weaver WD, Theroux P, Hochman JS, Filloon TG, Rollins S, Todaro TG, Nicolau JC, Ruzyllo W, Armstrong PW: Pexelizumab, an anti-C5 complement antibody, as adjunctive therapy to primary percutaneous coronary intervention in acute myocardial infarction: the COMplement inhibition in Myocardial infarction treated with Angioplasty (COMMA) trial, Circulation 2003, 108:1184-1190

7. Mahaffey KW, Granger CB, Nicolau JC, Ruzyllo W, Weaver WD, Theroux P, Hochman JS, Filloon TG, Mojcik CF, Todaro TG, Armstrong PW: Effect of pexelizumab, an anti-C5 complement antibody, as adjunctive therapy to fibrinolysis in acute myocardial infarction: the COMPlement inhibition in myocardial infarction treated with thromboLYtics (COMPLY) trial, Circulation 2003, 108:1176-1183

8. Shernan SK, Fitch JC, Nussmeier NA, Chen JC, Rollins SA, Mojcik CF, Malloy KJ, Todaro TG, Filloon T, Boyce SW, Gangahar DM, Goldberg M, Saidman LJ, Mangano DT: Impact of pexelizumab, an anti-C5 complement antibody, on total mortality and adverse cardiovascular outcomes in cardiac surgical patients undergoing cardiopulmonary bypass, Ann Thorac Surg 2004, 77:942-949; discussion 949-950

9. de Vries B, Kohl J, Leclercq WK, Wolfs TG, van Bijnen AA, Heeringa P, Buurman WA: Complement factor $\mathrm{C} 5 \mathrm{a}$ mediates renal ischemia-reperfusion injury independent from neutrophils, J Immunol 2003, 170:3883-3889

10. Levine JS, Koh JS, Triaca V, Lieberthal W: Lysophosphatidic acid: a novel growth and survival factor for renal proximal tubular cells, Am J Physiol 1997, 273:F575-585

11. Snoeijs MG, Wiermans B, Christiaans MH, van Hooff JP, Timmerman BE, Schurink GW, Buurman WA, van Heurn LW: Recipient hemodynamics during non-heart-beating donor kidney transplantation are major predictors of primary nonfunction, Am J Transplant 2007, 7:1158-1166

12. de Vries B, Walter SJ, Peutz-Kootstra CJ, Wolfs TG, van Heurn LW, Buurman WA: The mannose-binding lectin-pathway is involved in complement activation in the course of renal ischemia-reperfusion injury, Am J Pathol 2004, 165:1677-1688

13. Moller-Kristensen M, Wang W, Ruseva M, Thiel S, Nielsen S, Takahashi K, Shi L, Ezekowitz A, Jensenius JC, Gadjeva M: Mannan-binding lectin recognizes structures on ischaemic reperfused mouse kidneys and is implicated in tissue injury, Scand J Immunol 2005, 61:426-434

14. Berger SP, Roos A, Mallat MJ, Schaapherder AF, Doxiadis, II, van Kooten C, Dekker FW, Daha MR, de Fijter JW: Low pretransplantation mannose-binding lectin levels predict superior patient and graft survival after simultaneous pancreas-kidney transplantation, J Am Soc Nephrol 2007, 18:2416-2422 


\section{Chapter 5}

15. Brown KM, Kondeatis E, Vaughan RW, Kon SP, Farmer CK, Taylor JD, He X, Johnston A, Horsfield C, Janssen BJ, Gros P, Zhou W, Sacks SH, Sheerin NS: Influence of donor C3 allotype on late renal-transplantation outcome, N Engl J Med 2006, 354:2014-2023

16. Farrar CA, Zhou W, Lin T, Sacks SH: Local extravascular pool of C3 is a determinant of postischemic acute renal failure, Faseb J 2006, 20:217-226

17. de Haan JJ, Lubbers T, Derikx JP, Relja B, Henrich D, Greve JW, Marzi I, Buurman WA: Rapid development of intestinal cell damage following severe trauma: a prospective observational cohort study, Crit Care 2009, 13:R86

18. Derikx JP, Bijker EM, Vos GD, van Bijnen AA, Heineman E, Buurman WA, van Waardenburg DA: Gut mucosal cell damage in meningococcal sepsis in children: relation with clinical outcome, Crit Care Med 38:133-137

19. Derikx JP, Poeze M, van Bijnen AA, Buurman WA, Heineman E: Evidence for intestinal and liver epithelial cell injury in the early phase of sepsis, Shock 2007, 28:544-548

20. Derikx JP, van Waardenburg DA, Thuijls G, Willigers HM, Koenraads M, van Bijnen AA, Heineman E, Poeze M, Ambergen T, van Ooij A, van Rhijn LW, Buurman WA: New Insight in Loss of Gut Barrier during Major Non-Abdominal Surgery, PLoS One 2008, 3:e3954

21. Hanssen SJ, Derikx JP, Vermeulen Windsant IC, Heijmans JH, Koeppel TA, Schurink GW, Buurman WA, Jacobs MJ: Visceral injury and systemic inflammation in patients undergoing extracorporeal circulation during aortic surgery, Ann Surg 2008, 248:117-125

22. Grootjans J, Derikx JP, Lenaerts K, Matthijsen RA, Bruïne APd, Bijnen AAv, Dam RMv, Dejong $\mathrm{CH}$, Buurman WA: Prolonged human intestinal ischemia-reperfusion injury results in intestinal barrier integrity loss and inflammation, Am J Pathol 2010, in press

23. Hart ML, Ceonzo KA, Shaffer LA, Takahashi K, Rother RP, Reenstra WR, Buras JA, Stahl GL: Gastrointestinal ischemia-reperfusion injury is lectin complement pathway dependent without involving C1q, J Immunol 2005, 174:6373-6380

24. Fiane AE, Videm V, Lingaas PS, Heggelund L, Nielsen EW, Geiran OR, Fung M, Mollnes TE: Mechanism of complement activation and its role in the inflammatory response after thoracoabdominal aortic aneurysm repair, Circulation 2003, 108:849-856

25. Seyfarth J, Garred P, Madsen HO: Extra-hepatic transcription of the human mannosebinding lectin gene $(\mathrm{mbl})$ and the MBL-associated serine protease 1-3 genes, Mol Immunol 2006, 43:962-971

26. Ma Y, Uemura K, Oka S, Kozutsumi Y, Kawasaki N, Kawasaki T: Antitumor activity of mannan-binding protein in vivo as revealed by a virus expression system: mannan-binding proteindependent cell-mediated cytotoxicity, Proc Natl Acad Sci U S A 1999, 96:371-375 
27. Hirano M, Ma BY, Kawasaki N, Okimura K, Baba M, Nakagawa T, Miwa K, Kawasaki N, Oka S, Kawasaki T: Mannan-binding protein blocks the activation of metalloproteases meprin alpha and beta, J Immunol 2005, 175:3177-3185

28. Hansson GK: Inflammation, atherosclerosis, and coronary artery disease, N Engl J Med 2005, 352:1685-1695

29. Libby P: Inflammation in atherosclerosis, Nature 2002, 420:868-874

30. Wu G, Hu W, Shahsafaei A, Song W, Dobarro M, Sukhova GK, Bronson RR, Shi GP, Rother RP, Halperin JA, Qin X: Complement regulator CD59 protects against atherosclerosis by restricting the formation of complement membrane attack complex, Circ Res 2009, 104:550-558

31. Schmiedt W, Kinscherf R, Deigner HP, Kamencic H, Nauen O, Kilo J, Oelert H, Metz J, Bhakdi S: Complement C6 deficiency protects against diet-induced atherosclerosis in rabbits, Arterioscler Thromb Vasc Biol 1998, 18:1790-1795

32. Niculescu F, Rus H: The role of complement activation in atherosclerosis, Immunol Res 2004, 30:73-80

33. Bhatia VK, Yun S, Leung V, Grimsditch DC, Benson GM, Botto MB, Boyle JJ, Haskard DO: Complement c1q reduces early atherosclerosis in low-density lipoprotein receptor-deficient mice, Am J Pathol 2007, 170:416-426

34. Madsen HO, Videm V, Svejgaard A, Svennevig JL, Garred P: Association of mannosebinding-lectin deficiency with severe atherosclerosis, Lancet 1998, 352:959-960

35. Hegele RA, Ban MR, Anderson CM, Spence JD: Infection-susceptibility alleles of mannosebinding lectin are associated with increased carotid plaque area, J Investig Med 2000, 48:198-202

36. Best LG, Davidson M, North KE, MacCluer JW, Zhang Y, Lee ET, Howard BV, DeCroo S, Ferrell RE: Prospective analysis of mannose-binding lectin genotypes and coronary artery disease in American Indians: the Strong Heart Study, Circulation 2004, 109:471-475

37. Nauta AJ, Raaschou-Jensen N, Roos A, Daha MR, Madsen HO, Borrias-Essers MC, Ryder LP, Koch C, Garred P: Mannose-binding lectin engagement with late apoptotic and necrotic cells, Eur J Immunol 2003, 33:2853-2863

38. Nauta AJ, Castellano G, Xu W, Woltman AM, Borrias MC, Daha MR, van Kooten C, Roos A: Opsonization with $\mathrm{C} 1 \mathrm{q}$ and mannose-binding lectin targets apoptotic cells to dendritic cells, J Immunol 2004, 173:3044-3050

39. Ogden CA, deCathelineau A, Hoffmann PR, Bratton D, Ghebrehiwet B, Fadok VA, Henson PM: $\mathrm{C} 1 \mathrm{q}$ and mannose binding lectin engagement of cell surface calreticulin and CD91 initiates macropinocytosis and uptake of apoptotic cells, J Exp Med 2001, 194:781-795

40. Ghiran I, Barbashov SF, Klickstein LB, Tas SW, Jensenius JC, Nicholson-Weller A: Complement receptor 1/CD35 is a receptor for mannan-binding lectin, J Exp Med 2000, 192:1797-1808 
Chapter 6

Nederlandse Samenvatting 


\section{Chapter 6}

\section{Nederlandse Samenvatting}

In dit proefschrift werd de rol van enkele onderdelen van het aangeboren afweersysteem, in het ontstaan van zowel acute als chronische weefselschade bestudeerd.

Het menselijk afweersysteem heeft zich over een periode van miljoenen jaren ontwikkeld tot een complex en verfijnd systeem. Het wordt onderverdeeld in twee systemen; het aangeboren afweersysteem en het aangeleerde immuunsysteem. Het aangeboren afweersysteem is zoals de naam suggereert vanaf de geboorte aanwezig en bestaat onder andere uit diverse mechanische barrières zoals de huid en slijmvliezen. Bovendien bestaat het uit een groot aantal cellen en eiwitten met een zeer divers scala aan specifieke immunologische eigenschappen. Deze, in het gehele lichaam aanwezige cellen en eiwitten, worden vrijwel direct geactiveerd indien contact optreedt met lichaamsvreemde materialen. Hierdoor kunnen binnendringende ziekteverwekkers snel en efficiënt worden herkend en opgeruimd nadat ze een organisme zijn binnengedrongen.

Het aangeleerde afweersysteem vormt een meer specifieke afweerreactie. Deze afweerreactie wordt gekenmerkt door de betrokkenheid van zeer gespecialiseerde aanvallende cellen (T-cellen) en de productie van ziekteverwekker specifieke antilichamen (door B-cellen) tegen een breed scala aan bedreigingen. De productie van deze specifieke antilichamen vergt enige tijd, waardoor een effectieve reactie van het aangeleerde immuunsysteem pas na enkele dagen opgang komt. Het aangeleerde afweersysteem heeft echter door de veelal blijvende aanwezigheid van geheugen T- en B-cellen een 'geheugen' voor latere infecties door een zelfde ziekteverwekker. Door een dergelijk 'geheugen' kan nog jaren later, bij een tweede contact met een zelfde ziekteverwekker, een doeltreffende afweerreactie middels de productie van specifieke antilichamen snel worden gestart; het organisme wordt niet ziek en is daarmee 'immuun' voor deze ziekteverwekker.

Voor dit proefschrift werden verschillende onderdelen van ons aangeboren immuunsysteem bestudeerd. De onderdelen van ons aangeboren immuunsysteem vormen een effectieve bescherming tegen een breed scala aan bedreigingen. De bekendste bedreigingen worden gevormd door diverse ziekteverwekkers. Experimentele studies laten zien dat ons aangeboren immuunsysteem echter niet alleen reageert op en bescherming biedt tegen diverse ziekteverwekkers van buitenaf, maar ook geactiveerd wordt als gevolg van schade aan het eigen 
organisme. De reactie van het aangeboren immuunsysteem is voornamelijk gericht op het opruimen van potentiële bedreigingen en het herstel van de geleden schade om zo de functionele balans in het organisme te herstellen. Dit verloopt na het optreden van ernstige schade en daardoor een sterke activatie van het aangeboren immuunsysteem onvoldoende gecontroleerd. Uit onderzoek blijkt dat zo een sterke reactie van het aangeboren immuunsysteem op uitgebreide acute orgaan- en weefselschade leidt tot additionele, ofwel secundaire schade aan het getroffen orgaan of weefsel. Dit ontstaat bijvoorbeeld na een periode van gebrekkige of afwezige doorbloeding van een orgaan (ischemie) welke wordt gevolgd door een terugkeer van de normale doorbloeding (reperfusie). Een voorbeeld van ischemie en reperfusie (IR) schade is de schade die optreedt aan het hart tijdens een hartinfarct. Een vaak levensreddende dotter procedure herstelt de gebrekkige doorbloeding van de hartspier, waarmee een periode van ischemie wordt gevolgd door reperfusie. Het blijkt juist deze combinatie van ischemie en reperfusie te zijn, welke door een overmatige activatie van het aangeboren immuunsysteem aanleiding geeft tot extra schade in bijvoorbeeld de getroffen hartspier. Hoewel het herstel van de bloedtoevoer van levensgroot belang is voor de patiënt, is de totale schade aan het hart, juist door de reperfusie groter dan alleen door de korte periode van ischemie mag worden verwacht. Niet alleen bij een hart infarct speelt dit een belangrijke rol. Ook bij de transplantatie van organen treedt aanzienlijke IR-schade op. Het stoppen van de circulatie bij het overlijden van de donor of het uitnemen van een transplantatieorgaan leidt tot ischemie. Deze wordt na het herstel van de bloed doorstroming in het transplantaat direct gevolgd door reperfusie. De ontwikkeling van IR-schade beïnvloedt het functioneren van een getransplanteerd orgaan en is in sterke mate bepalend voor het succes van de transplantatie. De uitgebreidheid van IR-schade bij en daarmee het post-operatief functioneren van een orgaan of weefsel na bijvoorbeeld een transplantatie vallen nog niet te voorspellen.

Ischemie en reperfusie schade komt met regelmaat voor in de dagelijkse chirurgische praktijk. Grote operatieve ingrepen in de transplantatie-, vaat-, tumorof traumachirurgie gaan veelal samen met een tijdelijke vermindering van de orgaan doorbloeding met als gevolg lokale ischemie. Dit kan optreden door bijvoorbeeld bloedverlies, een verlaging van de bloeddruk door de gegeven anesthesie of door het afsluiten of tijdelijk klemmen van bloedvaten tijdens een operatieve procedure. Hierdoor zijn grote operatieve ingrepen vaak geassocieerd 


\section{Chapter 6}

met het optreden van IR schade. Ook bij dergelijke schade zal het aangeboren immuunsysteem worden geactiveerd en wordt het postoperatieve beloop door de ontwikkeling van additionele orgaan- of weefselschade beïnvloedt.

Het is inmiddels duidelijk dat verschillende onderdelen van ons aangeboren immuunsysteem een belangrijk rol spelen in de ontwikkeling van deze additionele IR-schade. Hoe de verschillende componenten van het aangeboren immuunsysteem precies worden geactiveerd door weefselschade blijft veelal onduidelijk. Ook is de rol van vele regulatoire componenten van het aangeboren immuunsysteem in de ontwikkeling van additionele weefselschade nog onvoldoende begrepen.

Dit proefschrift gaat vooral over de rol van verschillende cellen en eiwitten van het aangeboren immuunsysteem in de ontwikkeling van acute, vaak additionele, en chronische orgaan- of weefselschade. Om hierover duidelijkheid te verkrijgen werden drie verschillende doelen geformuleerd.

Het eerste doel van dit proefschrift was het om meer inzicht te verkrijgen in de rol van enkele aangeboren immuuncomponenten in het ontstaan van additionele schade na nier ischemie en reperfusie. Een beter begrip van de ontwikkeling van dit fenomeen maakt het mogelijk om strategieën te ontwikkelen die nieren kunnen beschermen rondom transplantatie. Tevens zal dat naar verwachting leiden tot strategieën die de complicaties verminderen die het gevolg zijn van de slechte orgaandoorbloeding die geassocieerd is met grote operaties en ziektebeelden als systemic inflammatory response syndrome (SIRS), sepsis, shock en trauma.

In hoofdstuk 2.2 wordt de rol van myeloperoxidase (MPO) belicht in het ontstaan van additionele orgaanschade en orgaanfunctie verlies in een model van experimentele nier ischemie en reperfusie. De afwezigheid van MPO, dat normaal door o.a. neutrofiele witte bloedcellen wordt gebruikt om binnendringende bacteriën te doden, voorkomt nierfunctie verlies na ischemie en reperfusie. Dit effect wordt veroorzaakt door de rol van MPO bij het binnendringen van neutrofiele witte bloedcellen in het beschadigde weefsel. Een verminderde aanwezigheid van deze witte bloedcellen en hun immunologische functies is geassocieerd met een verbeterde orgaanfunctie.

Het complement systeem bestaat uit ongeveer 30 verschillende eiwitten die kunnen worden geactiveerd door de binding aan ziekteverwekkers of beschadigde eigen cellen. Het systeem wordt geactiveerd door drie onderling verschillende activatie routes; te weten de klassieke, alternatieve en lectine route. ledere route 
beschikt over eigen factoren die het complement systeem kunnen activeren. Voor de klassieke route is dit de complement factor $\mathrm{C} 1 \mathrm{q}$ met zijn cofactoren $\mathrm{C} 1 \mathrm{r}$ en $\mathrm{C} 1 \mathrm{~s}$. Complement factor C3 activeert de alternatieve complement activatie route. De lectine route echter wordt geactiveerd door mannose-binding lectin (MBL) of ficolins (H-, L- en M-ficolin) met cofactoren MASP-1, -2, -3, Map19 en Map44. De factoren $\mathrm{C} 1 \mathrm{q}, \mathrm{C} 3, \mathrm{MBL}$ en ficolins binden allen aan verschillende, specifieke eiwitten op ziekteverwekkers of beschadigde eigen cellen. Activatie van complement leidt tot de vorming van enkele immunologisch actieve bijproducten en een groot ringvormig eind complex, het membrane attack complex. Dit membrane attack complex of MAC perforeert de membraan van binnendringende bacteriën. Het MAC, bestaande uit aan elkaar geschakelde complement eiwitten, veroorzaakt daarmee lysis van de binnendringende bacterie. Complement factor 5 fungeert als de eerste bouwsteen van deze ring structuur.

Activatie van $\mathrm{C} 5$ als gevolg van nier ischemie en reperfusie bleek essentieel in de ontwikkeling van secundaire IR schade en het optreden van nierfunctie verlies na nier IR (hoofdstuk 2.3). Het voorkomen van de activatie van C5, voorkwam de activatie van andere complement facturen en de vorming van het MAC. Deze vermindering in complement activatie was essentieel in het voorkomen van additionele weefselschade in de nier na IR. Deze bescherming ging samen met een verbeterde nierfunctie.

Een beter begrip van de betrokkenheid van regulatoire immuun componenten van het aangeboren immuunsysteem in de ontwikkeling van additionele weefselschade zal leiden tot de ontwikkeling therapeutische mogelijkheden waarmee weefselschade na ischemie en reperfusie kan worden voorkomen.

Lysophosphatidic acid (LPA) is een lichaamseigen groeifactor met bekende beschermende eigenschappen waardoor wellicht het optreden van celsterfte rondom de ischemie en reperfusie kan worden voorkomen. De effecten van toegediend LPA op de ontwikkeling van nier IR waren opmerkelijk (hoofdstuk 2.4). Hoewel initiële orgaanschade ten gevolge van de ischemie niet kon worden voorkomen, bleek LPA zeer wel in staat het ontstaan van additionele orgaanschade ten gevolge van uitgebreide immuun activiteit te voorkomen met een verbeterde nierfunctie na IR als resultaat.

Om dergelijke hoopvolle resultaten uit kleine proefdier modellen verder te ontwikkelen en om te komen tot de ontwikkeling van nieuwe therapeutische mogelijkheden uit basaal wetenschappelijk onderzoek is het noodzakelijk nieuwe 


\section{Chapter 6}

inzichten te testen in een relevant groot proefdiermodel. Om in deze vraag te voorzien werd een autoloog niertransplantatie model in varkens ontwikkeld (hoofdstuk 2.5). Eerste data, waaruit wellicht een humane toepassingsvorm kan worden ontwikkeld, zullen hopelijk snel uit dit model volgen.

Recente studies tonen aan dat lokaal in het getroffen orgaan geproduceerde regulatoren van het aangeboren immuunsysteem belangrijk zijn in het ontstaan van de additionele schade na ischemie en reperfusie.

Hoewel het merendeel van het lichaamseigen MBL geproduceerd wordt in de lever is ook een extra-hepatische of lokale productie van MBL sinds enige tijd gekend. Er bestaan voor MBL verschillende en goed gedocumenteerd MBL genotypen die de productie van het eiwit alsook de immunologische werkzaamheid van MBL in de mens bepalen. Dragers van deze verschillende genotypen, beschikken over verschillende genetische informatie, waardoor het plasma eiwit MBL zowel in immunologische functie als in aanwezige hoeveelheid tussen individuen sterk kan verschillen. Een rol voor MBL in het ontstaan van nier IR schade kon eerder in proefdieren worden aangetoond. Of de met het transplantaat mee getransplanteerde genotypen geassocieerd zijn met uitkomsten van de transplantatie is nog onduidelijk. Om een mogelijke invloed van het donor MBL genotype te onderzoeken op de uitkomst van niertransplantaties werden 237 opeenvolgende niertransplantaties uit het Maastricht Universitair Medisch Centrum onderzocht. $\mathrm{Na}$ een niertransplantatie van donoren overleden na een hartstilstand blijken verschillende MBL genotypen van de donor geassocieerd te zijn met de ontwikkeling van primair transplantaat falen (hoofdstuk 2.6). Een gemengd, heterogeen, MBL genotype van de donor gaat samen met een verhoogd risico op het ontwikkelen van primair transplantaat falen in de ontvanger. Deze bevindingen kunnen additioneel bewijs vormen dat kenmerken van de donor niet alleen voor, maar ook na de transplantatie van invloed zijn op het slagen van de transplantatie. Of daarbij organen van donoren met een heterogeen MBL genotype te lijden hebben onder een afgenomen opsoniserende capaciteit van lokaal geproduceerd $\mathrm{MBL}$, danwel onder een persisterende mogelijkheid van MBL om het complement systeem te activeren zal door nader aanvullend onderzoek belicht moeten worden.

Het tweede deel van het proefschrift beschrijft de gevolgen van darm ischemie en reperfusie in de mens. Ischemie en reperfusie van de darm is veelal geassocieerd met grote chirurgische ingrepen en de daarbij optredende doorbloedingveranderingen in de darm. Deze doorbloedingbeperkingen treden 
ook op bij ernstige ziekte of sepsis bij bijvoorbeeld intensive care patiënten. Bovendien is darm ischemie een moeilijk te diagnosticeren ziektebeeld, met een hoog risico op mortaliteit. Darm IR kan verstrekkende gevolgen hebben voor de belangrijke cellulaire barrière tussen het darmlumen vol met schadelijke stoffen en bacteriën en het milieu interieur van het organisme. Door de ontwikkeling van een humaan darm ischemie en reperfusie model kon de tweede doelstelling van dit proefschrift worden onderzocht.

Het model kon worden ontwikkeld in patiënten die werden onderworpen aan een grote chirurgische ingreep, een pancreatico-duodenectomie (hoofdstuk 3.2). Hierbij worden een deel van de alvleesklier en de twaalfvingerige darm verwijderd, veelal ten gevolge van een kwaadaardige tumor. Eerste resultaten uit het model laten zien dat het optreden van darmschade goed kan worden bepaald aan de hand van een nieuwe marker, het fatty acid binding protein (I-FABP). In het model kon worden aangetoond dat de darm beschikt over een waarschijnlijk uniek mechanisme dat de darm in staat stelt beperkte perioden van ischemie te tolereren en de geleden schade ten gevolge van IR snel te herstellen (hoofdstuk 3.3). De door de IR beschadigde darmbarrière wordt daarbij snel en zorgvuldig hersteld en gesloten. Dit proces verloopt zo efficiënt dat beschadigde of dode cellen, welke het aangeboren immuunsysteem kunnen activeren, snel worden geëlimineerd door ze af te stoten in het lumen van de darm. Een plaats waar aanpassingen van het immuunsysteem het mogelijk hebben gemaakt de constante bedreigingen vanuit het luminale milieu, zoals bacteriën, cel resten en voedsel, te tolereren en laten passeren. Dat deze beschermende reactie na een periode van IR inderdaad zorgt voor het uitblijven van een overmatige activatie van het aangeboren immuunsysteem en dus additionele schade na IR kon voorkomen (hoofdstuk 3.4) vormde een belangrijke stap in het verdere onderzoek.

Zoals eerder al aangegeven voor de nier speelt de aanwezigheid van MBL in proefdieren een rol in het ontwikkelen van additionele IR schade in de nier, het hart en de darm. Hierbij speelt de aan- of afwezigheid van MBL ten tijde van IR een belangrijke rol. Zoals hierboven vermeld zijn er enkele veel voorkomende variaties in het MBL-gen (mutaties) bekend. Hierdoor varieert tussen individuen de functie van het plasma eiwit MBL alsook de in het plasma aanwezige hoeveelheid van het functionele eiwit. De complement activerende en immuunregulatoire eigenschappen van MBL in individuen die drager zijn van deze genetische variaties zijn vaak verminderd of vrijwel afwezig. Met deze wetenschap hebben we de invloed van de bekende MBL gen variaties in de ontwikkeling van darm schade na 


\section{Chapter 6}

IR onderzocht. Hoofdstuk 3.5 laat zien dat dragers van MBL gen variaties minder darmschade ontwikkelden ten gevolge van IR dan de proefpersonen met het normale of wildtype MBL gen. In verhouding tot dier experimentele studies, waar de afwezigheid van MBL na IR de ontwikkeling van additionele orgaanschade kon beperken, ontwikkelden de dragers van verschillende $M B L$ gen variaties in ons humane IR model al nauwelijks primaire schade. Deze data demonstreren een brede en zeer vroege rol van MBL in de ontwikkeling van epitheelschade in de humane darm na IR. Eerste suggesties voor een dergelijke nieuwe kwaliteit van MBL beperken zich op dit moment nog tot in vitro werk en dier experimenteel onderzoek. In vitro is MBL namelijk in staat om de degeneratie van de voor cellen essentiële cellulaire matrix door meprins, matrix afbrekende enzymen, te beperken. Dit zou komen de aanwezigheid N-linked oligosaccharides op meprins welke een interactie met MBL mogelijk maken.

Voor het beantwoorden van de derde en laatste doelstelling van dit proefschrift werd onderzocht of MBL betrokken is bij de ontwikkeling van chronische weefselschade. Hierbij is de rol van MBL onderzocht in de ontwikkeling van atherosclerose of aderverkalking. Het treft daarbij uitsluitend slagaders, of arteriën. Atherosclerose is een vorm van chronische weefselschade waarbij vetten, cholesterol, cellen en dode cel resten zich stapelen in een deel van de vaatwand, de intima. Deze stapeling vernauwt het arteriële lumen waardoor de bloedtoevoer naar een orgaan ernstig kan worden beperkt en er in het achterliggende orgaan door een beperkte bloedtoevoer of ischemie weefselschade kan ontstaan. Atherosclerose is een vorm van chronische schade waarbij het immuunsysteem de voortgang van de ziekte bepaald.

De resultaten hebben duidelijk aangetoond dat MBL aanwezig is in de door atherosclerose getroffen vaatwand. Bovendien werd tijdens de vroege ontwikkelingsfase van atherosclerose, MBL lokaal in de aangedane vaatwand geproduceerd. De data uit de verschillende experimenten hebben aangetoond dat de lokale productie van $\mathrm{MBL}$, door specifieke ontstekingscellen van het aangeboren immuunsysteem, de ontwikkeling van atherosclerose beïnvloedt (hoofdstuk 4.2). Proefdieren waarbij de lokale MBL productie werd uitgeschakeld ontwikkelden tot $30 \%$ meer atherosclerose dan gezonde proefdieren in dezelfde tijdsperiode. Deze resultaten laten zien dat de aanwezigheid van lokaal geproduceerd MBL gedurende de ontwikkeling van atherosclerose een remmend effect heeft op de ontwikkeling van atherosclerose. Dit zou kunnen worden verklaard door de opsoniserende 
eigenschappen van MBL. De opsoniserende werking van $M B L$ berust op de kwaliteit om zich als 'pathogen recognition molecule' (PRM) te binden aan activatoren van het aangeboren immuunsysteem zoals ziekteverwekkers en beschadigde eigen cellen. Deze binding bespoedigt de essentiële verwijdering van dergelijke dreigingen door daarvoor geschikte cellen. De aanwezigheid van MBL tijdens vroege atherosclerose zou daardoor een rol kunnen spelen in het verwijderen schadelijke atherosclerotische producten in de arteriële intima. In het geval van ver gevorderde atherosclerose echter, lijkt de situatie veranderd te zijn. Juist in deze gevorderde vormen van atherosclerose zou MBL door zijn complement activerende werking aanleiding kunnen geven tot overmatige activatie van het complementsysteem en daarmee zorgen voor ontsteking en progressie van de atherosclerotische plaques. De aanwezigheid van MBL in een later stadium van atherosclerose ontwikkeling lijkt daarom ongewenst. Interessant in dit kader is dat onderzoek in zowel muizen als mensen geen lokale MBL productie heeft aangetoond in de oudere, gevorderde atherosclerotische afwijkingen of plaques.

Op welke wijze deze inzichten in de rol van MBL gedurende atherosclerose aanleiding kunnen leiden tot de ontwikkeling van nieuwe therapeutische interventies in patiënten met hart- en vaatziekten zal toekomstig onderzoek moeten uitwijzen. 


\section{Chapter 7 Dankwoord}




\section{Chapter 7}

Het proefschrift is klaar. Een moment waarvan ik lange tijd heb gedacht dat het nog ver in de toekomst zou liggen is dan opeens daar. Een goed moment om alle belangrijke mensen en betrokkenen bij dit onderzoek aan u voor te stellen en te danken.

Mijn promotor, prof. dr. W.A. Buurman.

Beste Wim, het zal rond 1999 geweest zijn dat ik aan je werd voorgesteld als een jonge student met de ambitie om chirurg te worden. Zeker ik niet, kon op dat moment vermoeden dat er een zo langdurige en mooie samenwerking zou ontstaan uit deze ontmoeting. Eerst als student en later als promovendus heb ik je leren kennen. De sfeer die je door de jaren heen op jouw laboratorium hebt weten te creëren is uniek en goud waard. Je unieke kwaliteit om onverwacht, creatief en vlijmscherp wetenschappelijke kennis te combineren tot nieuw onderzoek heeft zich al over vele jaren bewezen. Het was niet altijd gemakkelijk en ik denk nog steeds dat ons originele idee zou moeten kunnen werken. Ik ben er trots op om een van jouw promovendi te zijn.

Veel dank ben ik verschuldigd aan de beoordelingscommissie, professor Daemen, professor ten Cate, professor Hofstra, professor Jensenius en professor Weber voor de samenwerking en het beoordelen van mijn proefschrift.

Geen enkel artikel waarover $\mathrm{u}$ in het voorliggende boekwerk hebt kunnen lezen was mogelijk geweest zonder de fantastische en belangeloze inzet van vele patiënten, donoren en proefdieren. Allen waren ze onmisbaar.

Het lab. Die twee woorden, 'het lab', kregen in de periode van dit proefschrift zo enorm veel betekenis voor niet alleen mijzelf, maar voor een heleboel anderen in mijn omgeving. Er zijn veel mensen in de laatste jaren voorbij gekomen. De belangrijkste zijn toch wel mijn trouwe kamergenoten, de mannen van 5.348. Beste Joep, zelf inmiddels dr. Een half jaar voor me was jij op het lab begonnen, net als ik een beginnende onderzoeker in een wereld van pipetten, verdunningen, ELISA's en kleuringen. De euforie bij onze eerste fantastische darmdata, onze reizen naar Denemarken en Oostenrijk, maar vooral je gort droge humor blijven me altijd bij. Ik ben er trots op dat ik je paranimf mocht zijn en ben blij dat jij deze rol ook voor mij op je wilt nemen. 
Beste Ruud, zelf inmiddels bijna dr. en volleerd kenner van de Toppers. Ik had onze fietstochten, het skiën in Frankrijk en het duiken in Egypte nooit willen missen. Je eindeloze inbreng aan mooie wetenschap, muziek, games, ontspanning, zin en fantastische onzin zijn al wijd geroemd. Dank je, voor onze vriendschap en samenwerking. Ik ben blij dat ook jij naast mij zal staan als paranimf.

Beste Tip, zelf inmiddels dr. Ik denk dat iedereen het echte laboratorium ambacht en zeker de PCR's bij jou heeft geleerd. Samen met Mo vormde jij de backbone van het lab, klaar om met je humor en grappen iedere tegenslag en frustratie over tegenvallende proeven te verlichten.

Beste Joep(-ie), de nieuwste aanwinst van 5.348. Je hebt op onnavolgbare wijze een verdiende en stevig verankerde plek verworven op het lab. Ik ben blij dat het humane darm onderzoek door jou is overgenomen en dat we samen paranimf waren op de promotie van Joep.

Beste Mo, ook al zat je op een andere kamer kan ik het natuurlijk niet nalaten je hier te noemen. Als echte Eindhovenaar ben je, in twee-eenheid met je maatje Tim, al voor vele generaties van onderzoekers een steunpilaar op het lab. Je lach, streken en uitgesproken eigen mening zijn legendarisch.

Een laboratorium kan niet draaien zonder een trouwe club mensen die de continue aanwas aan promovendi met stoïcijns geduld scholen in alle basale technieken, nodig voor een compleet manuscript. Ik heb het gelukkige voorrecht hier een aantal mensen te mogen danken zonder wiens inzet dit manuscript nog niet de helft had kunnen omvatten.

Trudi, je eindeloze geduld waarmee je mij als verse onderzoeker het kweken van cellen, het zuiveren van antilichamen en het werken op een lab hebt kunnen bijbrengen waren legendarisch. Je vertrek werd nodig gemist.

Dian, helaas was onze samenwerking te kort, door je vertrek naar Tanzania. Voor al je inzet ben ik je veel dank verschuldigd. Heerlijk was het gevoel toen het werk en de resultaten opeens een geweldige vlucht namen.

Nicole, ik ben je ongelooflijk dankbaar voor je eindeloze geduld en doorzettingsvermogen in moeilijke tijden op het lab. Ik wens je een toekomst in alle gezondheid. Kim, geroemd om je eindeloos geduld en altijd tijd voor een update van alle gebeurtenissen. Dank je voor het overnemen van kleine Kees en je rotsvast beheer van Wim's agenda. 


\section{Chapter 7}

Gedurende de jaren op het lab werk je samen met een heel leger aan verschillende mensen aan de meest uiteenlopende projecten. Dit gebeurt zowel binnen het lab als dichtbij in Maastricht of ver daarbuiten. Helaas kan ik niet iedereen uitgebreid de revue laten passeren, al denk ik dat een ieder dit op zijn eigen manier wel zou hebben verdiend. Al tijden komen de meest uiteenlopende momenten, grappen, experimenten, reizen, mensen en situaties in mijn gedachten terug.

Mijn voorgangers in het onderzoek Marc Daemen en Bart de Vries. Groot waren de schoenen die ik in het begin moest gaan vullen. Ik hoop dat dit is gelukt. Dank voor jullie hulp.

Tevens ben ik dank verschuldigd aan Ferdinand leNoble (dank voor de eerste lessen in het onderzoek), Misha (bedankt voor alle mooie momenten op de fiets en in de kroeg), François (Quake koning), Jacco (de internist), Kees, Marcel (de echte fietser), Yvonne, Annemarie, Jeroen, Yanti, Caroline, Bas, Iris, Geertje, Johanne, Maarten, Eva, Wim de Jong, Sander, Kaatje, Sarah, Martien, Nicholas, Silvia, Maartje, Ruben, Froukje, Kirsten, Kim, Mark, Femke, Mick, Hans, Sedigheh, Marcella, Dennis \& Dennis, Bart, Martijn, Steven (de Marmotte was geweldig), Marcella, Chris, Nicole, Heidi, Alma, Veronica, Dennis H., Peter Heeringa, Sarah L., Carien Peutz, Adriaan deBruïne, Peter Vandenabeele en Dieter, Gabri en Loek. Er hebben gedurende de jaren onderzoek een heel aantal enthousiaste studenten bijgedragen aan de humor rondom het onderzoek, de proeven en de resultaten. Mijn dank gaat uit naar Alexander, Sebastiaan, Dave, Jellie, Frederique, Van Lai, Isabelle en Joep.

De chirurgen Kees Dejong, Ernst van Heurn, Geert Willem Schurink, Ronald van Dam en Jan Stoot ben ik veel dank verschuldigd. Jullie enthousiasme en bereidheid tot onderzoek hebben de humane darm studies en nier transplantatie varkensstudies mogelijk gemaakt. Professor Greve en vele anderen binnen de Maastrichtse heelkunde vakgroep wil ik danken voor hun enthousiaste ontvangst van ons en alle overige onderzoekers op de OK's en voor de steun gedurende mijn korte klinische periode. Jullie enthousiasme voor het vak werkt aanstekelijk.

De pulmo's Harry, Ramon, Jos, Astrid, Juanita. Een goede buur is beter dan een verre vriend. Dank jullie voor de vele momenten van samenwerking, hulp en plezier. 
Voor een zeer vruchtbare samenwerking ben ik dank verschuldigd aan de afdeling van de moleculaire genetica binnen CARIM. Menno, Marion en Inge dank voor jullie expertise en de bijdrage aan een fraai staaltje wetenschap.

Dear professor Jensenius and Steffen Thiel. Thank you for many fantastic moments in Århus, a wonderful collaboration and introducing a young researcher in the wonderful world of innate regulatory proteins. The trip to Beijing was a memorable experience.

Beste Ann, je antwoord was gelukkig direct positief, toen ik je vroeg het Engels taalgebruik van het totale document kritisch te belichten. Hiervoor ben ik je zeer dankbaar.

$\mathrm{Na}$ het afronden van de laatste proeven in 2008 volgde de overstap naar regio-II, het AMC in Amsterdam; om te starten met mijn specialisatie tot chirurg. Hoewel ik deze overgang tevoren al vele malen in mijn hoofd had doorlopen, viel met de aankomst in Hoofddorp toch alles anders. Wat een geweldige plek ligt daar verscholen in de Haarlemmermeer. Alle mede assistenten van het eerste uur en de huidige club wil ik net als de chirurgische maatschap van het Spaarne Ziekenhuis danken voor een fantastische sfeer. Jullie bereidheid om een onderzoeker alle welhaast majestueuze aspecten van het vak te laten zien en leren is geweldig.

Vrienden, het is eindelijk af! We gaan weer fietsen, eten, roeien, zeilen en elkaar gewoon zien. Dank voor jullie geduld, steun en de nodige ontspanning. Vanavond, op 12 november, begint de inhaalslag.

Lieve Treesje en Ria. Dank jullie voor al de steun, zorg en liefde gedurende alle 32 jaren.

Lieve familie. Dit moment had nooit kunnen plaatsvinden zonder jullie; mijn ouders, mijn zus, zwager, en schoonfamilie. Lieve pap en mam. Is alles wat jullie ons hebben gegeven en wat jullie voor ons hebben betekend te bevatten in enkele regels? Er is de laatste jaren al veel goeds gezegd en er zal zeker nog veel gezegd gaan worden! Dank voor jullie rotsvast vertrouwen. Vertrouwen in het maken van de juiste keuzes. Het besef dat er altijd een liefdevol thuis is waar je op kunt bouwen en waar mensen naar je luisteren als het goed gaat of tegenzit, is geweldig. 


\section{Chapter 7}

Lieve Tina und natürlich Arne. Een geweldig hoogtepunt dit voorjaar zal nog vele mooie momenten doen volgen. We hebben de laatste maanden veel geleerd. ledere minuut heb ik onthouden en geniet er nog dagelijks van. Jullie zijn geweldig.

Lieve Paul en Hilga. Ook jullie werden meegenomen in de perikelen van het promoveren. Veel dank ben ik jullie verschuldigd voor jullie niet aflatende interesse en steun.

Ten slotte, de belangrijkste persoon. Het dankwoord en daarmee alle belangrijke onderdelen van het manuscript worden nu afgesloten. Lieve Mirte, mijn steun en trots. Dank je, mijn lief, voor al het geluk in de dagen die we samen mogen beginnen, voor je liefde, je steun en je onvoorwaardelijk geloof in ons. Ik hou van je. 
Dankwoord 


\section{Chapter 8 \\ Curriculum vitae}




\section{Chapter 8}

Robert Matthijsen werd geboren op 15 mei 1978 in Eindhoven. Hij doorliep zijn middelbare school in Eindhoven aan de christelijke scholengemeenschap, het Augustinianum. Na het behalen van het VWO-eindexamen in 1996 begon hij aan de studie Gezondheidswetenschappen, aan de Universiteit Maastricht. In 1997, na het behalen van zijn propedeuse in de gezondheidswetenschappen, werd hij alsnog ingeloot voor de studie geneeskunde aan dezelfde universiteit. Gedurende zijn studie was hij lid van de Maastrichtse Studenten Roeivereniging en roeide onder andere in 1999 aan de Henley Royal Regatta in Engeland. Tijdens zijn studie werden de eerste wetenschappelijk stappen gezet en was hij enkele jaren werkzaam als student-assistent binnen de vakgroepen fysiologie (dr. F Lenoble) en algemene heelkunde (prof. dr. W.A. Buurman). Na het behalen van het artsendiploma in 2003 werden de wetenschappelijke werkzaamheden voortgezet binnen de gelederen van de algemene heelkunde aan de Universiteit Maastricht, met dit proefschrift als resultaat. Hij startte zijn medische specialisatie tot chirurg in juli 2008 in het Spaarne Ziekenhuis in Hoofddorp (opleider dr. G. Akkersdijk). Het Spaarne Ziekenhuis maakt daarbij deel uit van de regio van het Academisch Medisch Centrum in Amsterdam (opleider prof. dr. O.R.C. Busch). 
Curriculum Vitae 
Chapter 9

Scientific output 


\section{Chapter 9}

Snoeijs MG, Matthijsen RA, Seeldrayers S, Marcus MA, Daemen JWH, PeutzKootstra CJ, Buurman WA, Schurink GWH, van Heurn ELW.

Autologous Transplantation of Ischemically Injured Kidneys in Pigs.

Accepted in - J Surg Res. 2010.

Grootjans J, Lenaerts K, Derikx JPM, Matthijsen RA, de Bruïne AP, van Bijnen AA, van Dam RM, Dejong CHC, Buurman WA.

Prolonged human intestinal ischemia-reperfusion injury results in intestinal barrier integrity loss and inflammation.

Am J Pathol. 2010 May; 176:2283-91.

Derikx JP*, Matthijsen RA*, de Bruïne AP, van Bijnen AA, van Dam RM, Heineman $\mathrm{E}$, Buurman WA, Dejong $\mathrm{CH}$.

A new model to study intestinal ischemia-reperfusion damage in man.

Accepted in - J Surg Res. 2010.

* both authors contributed equally to this work.

Matthijsen RA, Derikx JP, Kuipers D, van Dam RM, Dejong CH, Buurman WA. Enterocyte shedding and epithelial lining repair following ischemia of the human small intestine attenuate inflammation.

PLoS One. 2009 Sep 15;4:e7045.

Matthijsen RA, Derikx JP, Steffensen R, van Dam RM, Dejong CH, Buurman WA. Mannose-binding lectin null alleles are associated with preserved epithelial cell integrity following intestinal ischemia reperfusion in man.

Mol Immunol. 2009 Jul;46:2244-8.

- Evaluated in Faculty of 1000 Biology - 2009 -

Matthijsen RA, Buurman WA.

Experimental Data Support a Role of Macrophage Specific Expression of MBL in Atherosclerosis

International Atherosclerosis Society, October 2009 commentary.

Matthijsen RA, de Winther MP, Kuipers D, van der Made I, Weber C, Herias MV, Gijbels MJ, Buurman WA. 
Macrophage-specific expression of mannose-binding lectin controls atherosclerosis in low-density lipoprotein receptor-deficient mice.

Circulation. 2009 Apr 28;119:2188-95.

Derikx JP, Matthijsen RA, de Bruïne AP, van Bijnen AA, Heineman E, van Dam RM, Dejong $\mathrm{CH}$, Buurman WA.

Rapid reversal of human intestinal ischemia-reperfusion induced damage by shedding of injured enterocytes and reepithelialisation.

PLoS One. 2008;3:e3428.

Shagdarsuren E, Bidzhekov K, Djalali-Talab Y, Liehn EA, Hristov M, Matthijsen RA, Buurman WA, Zernecke A, Weber C.

$\mathrm{C} 1$-esterase inhibitor protects against neointima formation after arterial injury in atherosclerosis-prone mice.

Circulation. 2008 Jan 1;117:70-8.

Matthijsen RA, Huugen D, Hoebers NT, de Vries B, Peutz-Kootstra CJ, Aratani Y, Daha MR, Tervaert JW, Buurman WA, Heeringa P.

Myeloperoxidase is critically involved in the induction of organ damage after renal ischemia reperfusion.

Am J Pathol. 2007 Dec;171:1743-52.

- Evaluated in Kidney International (2008) 73, 677-678 -

Le Noble F, Moyon D, Pardanaud L, Yuan L, Djonov V, Matthijsen R, Bréant C, Fleury $\mathrm{V}$, Eichmann A.

Flow regulates arterial-venous differentiation in the chick embryo yolk sac.

Development. 2004 Jan;131:361-75.

De Vries B, Matthijsen RA, van Bijnen AA, Wolfs TG, Buurman WA.

Lysophosphatidic acid prevents renal ischemia-reperfusion injury by inhibition of apoptosis and complement activation.

Am J Pathol. 2003 Jul; 163:47-56. 
De Vries B, Matthijsen RA, Wolfs TG, Van Bijnen AA, Heeringa P, Buurman WA. Inhibition of complement factor $\mathrm{C} 5$ protects against renal ischemia-reperfusion injury: inhibition of late apoptosis and inflammation.

Transplantation. 2003 Feb 15;75:375-82.

Snoeijs MG, Matthijsen RA, Christiaans MH, van Hooff JP, van Heurn ELW, Buurman WA, van Suylen RJ, Peutz-Kootstra CJ.

The renal biopsy in non-herat-beating organ transplantation.

Chapter 11 in: Organ donation and transplantation after cardiac death.

Oxford press 2009.

ISBN 978-0-19-921733-5

Matthijsen RA*, Snoeijs MG*, Kuipers D, Steffensen R, Christiaans MH, van den Berg-Loonen PM, Schurink GWH, van Heurn ELW, Buurman WA.

Influence of the Donor MBL Allotype on Non-Heart-Beating Donor RenalTransplantation Outcome.

Submitted.

* both authors contributed equally to this work.

Loubele STBG, Spek AC, Leenders P, Hamulyák K, Matthijsen RA, Buurman WA, Peutz-Kootstra CJ, Spronk HMH, ten Cate H

The anti-coagulants ASIS or APC do not protect against renal ischemia/reperfusion injury

Submitted 
De uitgave van dit proefschrift werd door de volgende bedrijven financieel ondersteund

\author{
ABN AMRO Bank N.V. \\ Astellas Pharma B.V. \\ BARD \\ Baxter \\ Hycult Biotech \\ Johnson \& Johnson Medical B.V. \\ Martin Nederland / Marned B.V. \\ Molnlycke Health Care \\ Norgine \\ Olympus Nederland B.V. \\ Synthes B.V.
}

Wetenschapscommissie Spaarne Ziekenhuis 